\title{
Energy restriction and ageing in man
}

Citation for published version (APA):

Velthuis te Wierik, E. J. (1995). Energy restriction and ageing in man. [Doctoral Thesis, Maastricht University]. Eburon P\&L. https://doi.org/10.26481/dis.19950622ev

Document status and date:

Published: 01/01/1995

DOI:

10.26481/dis.19950622ev

Document Version:

Publisher's PDF, also known as Version of record

\section{Please check the document version of this publication:}

- A submitted manuscript is the version of the article upon submission and before peer-review. There can be important differences between the submitted version and the official published version of record.

People interested in the research are advised to contact the author for the final version of the publication, or visit the DOI to the publisher's website.

- The final author version and the galley proof are versions of the publication after peer review.

- The final published version features the final layout of the paper including the volume, issue and page numbers.

Link to publication

\footnotetext{
General rights rights.

- You may freely distribute the URL identifying the publication in the public portal. please follow below link for the End User Agreement:

www.umlib.nl/taverne-license

Take down policy

If you believe that this document breaches copyright please contact us at:

repository@maastrichtuniversity.nl

providing details and we will investigate your claim.
}

Copyright and moral rights for the publications made accessible in the public portal are retained by the authors and/or other copyright owners and it is a condition of accessing publications that users recognise and abide by the legal requirements associated with these

- Users may download and print one copy of any publication from the public portal for the purpose of private study or research.

- You may not further distribute the material or use it for any profit-making activity or commercial gain

If the publication is distributed under the terms of Article $25 \mathrm{fa}$ of the Dutch Copyright Act, indicated by the "Taverne" license above, 
Energy restriction and ageing in man 


\section{CIP-GEGEVENS KONINKLIJKE BIBLIOTHEEK, DEN HAAG}

Velthuis-te Wierik, Erica Johanna Maria

Energy restriction and ageing in man / Erica Johanna Maria

Velthuis-te Wierik. - Delft : Eburon P\&L

Proefschrift Rijksuniversiteit Limburg Maastricht. - Met

lit. opg. - Met samenvatting in het Nederlands.

ISBN 90-5651-007-X

NUGI 822

Trefw. : voeding; bejaarden / ouderdom

Omslag : Van Berkel Nederland BV, Ridderkerk

Druk : Grafisch bedrijf Ponsen \& Looijen BV, Wageningen

Distributie: : Eburon P\&L, Postbus 2867, $2601 \mathrm{CW}$ Delft

Het drukken van dit proefschrift werd mede mogelijk gemaakt door financiële steun van de Rijksuniversiteit Limburg, TNO-Voeding en de Stichting Dr. Ir. J.H.J. van de Laar. 


\title{
Energy restriction and ageing in man
}

\author{
PROEFSCHRIFT
}

\author{
ter verkrijging van de graad van doctor \\ aan de Rijksuniversiteit Limburg te Maastricht, \\ op gezag van de Rector Magnificus, Prof. mr. M.J. Cohen, \\ volgens het besluit van het College van Dekanen, \\ in het openbaar te verdedigen \\ op donderdag 22 juni 1995 \\ om 14.00 uur
}

door

Erica Johanna Maria Velthuis-te Wierik 
Promotores:

Prof. dr. ir. W.H.M. Saris

Prof. dr. ir. R.J.J. Hermus

Co-promotores: $\quad$ Dr. H. van den Berg (TNO-Voeding, Zeist)

Dr. K.R. Westerterp

Beoordelingscommissie: Prof. dr. H. Kuipers (voorzitter)

Prof. dr. A. van Es (Landbouwuniversiteit Wageningen)

Dr. G. Hornstra

Prof. dr. D.L. Knook (Rijksuniversiteit Leiden)

Prof. dr. E.F.M. Wouters 


\section{Contents}

1 Energy restriction, the basis for successful ageing in man? Nutrition Research 1994;7:1113-1134.

2 Outline of the thesis

3 Energy restriction, a useful intervention to retard human ageing?

Results of a feasibility study

Eur J Clin Nutr 1994;48:138-148

4 Effects of moderate energy restriction on physical performance and substrate utilization in non-obese men

Int J Sports Med 1994;15:478-484

5 Impact of a moderately energy-restricted diet on energy metabolism and body composition in non-obese men

Int J Obesity (in press)

6 Beneficial effect of a moderately energy-restricted diet on

fibrinolytic factors in non-obese men.

Metabolism (accepted for publication)

7 Short-term moderate energy restriction does not affect indicators of oxidative stress and genotoxicity in humans $J$ Nutr (accepted for publication)

8 Magnitude of experimental manipulation in a long-term study on health effects of spontaneous consumption of reduced fat versus full fat products in healthy non-obese volunteers (Submitted)

9 Consumption of reduced fat products, haemostatic parameters and oral glucose tolerance test

(Submitted)

10 Consumption of reduced fat products: effects on parameters of antioxidative capacity

(Submitted)

11 General discussion

Summary

Samenvatting

Dankwoord

Curriculum vitae

Publications 
. 
Chapter 1

\title{
Energy restriction, the basis for successful ageing in man?
}

\author{
Erica J.M. Velthuis-te Wierik and Henk van den Berg
}

TNO Nutrition and Food Research Institute, Zeist, The Netherlands

Nutrition Research 1994; 7: 1113-1134

\begin{abstract}
Restriction of energy intake (ER) without essential nutrient intake deficiency retards ageing and extends life span in various animal species. Although several potential mechanisms have been put forward, the mechanism behind this phenomenon remains unknown. This review describes the effects of ageing and energy restriction on three physiological systems (energy expenditure, free-radical activity and endocrine regulation) that are involved in the metabolic adaptation to ER and that seem to play an important role in the ageing process. Since ageing is a general biological phenomenon it seems likely that ER has the same beneficial effect on the ageing process in man. This article summarizes the effects of ER and ageing on these three physiological systems in both animals and man and attempts to explore the potential application of ER in man.
\end{abstract}




\section{INTRODUCTION}

The phenomenon that restriction of the intake of energy while maintaining the intake of adequate amounts of essential nutrients can retard ageing and extend life span has been first discovered in the thirties by McCay et al. ${ }^{1}$ Since then similar results have been observed in a great variety of animal species such as rats, mice, fish and flies (for reviews $\sec ^{2,3}$ ). Moreover, energy restriction not only retards ageing but also prevents or delays the onset of many age-related diseases in animals. ${ }^{4}$

The mechanism through which energy restriction modulates the ageing process is unknown and is difficult to assess as determinants of the ageing process itself have not yet been identified. The physiological systems involved in, or affected by, the metabolic adaptation to energy restriction seem to play an important role in the ageing process. Reported effects of ageing and energy restriction on metabolic rate, the neuroendocrine system and oxidative stress, i.e. free-radical production and scavenging capacity, are at least suggestive of common or integrated modes of action.

In this article the effects of energy restriction and ageing on these three physiological systems will be summarized and discussed. It is beyond the scope of this article to review all studies and reports published on the mechanisms and physiological systems involved in the intriguing, but very complex, relationships between metabolic adaptation, energy restriction and ageing. In this article we present the 'state of the art' and discuss experimental studies to explore the potential application of energy restriction in man, stimulated by the ideas of Weindruch and Walford ${ }^{3}$ and their suggestions for a dietary regimen of 'undernutrition without malnutrition'.

\section{THE EFFECTS OF AGEING AND ENERGY RESTRICTION ON ENERGY EXPENDITURE}

The basal metabolic rate (BMR) is defined as the rate of energy expenditure in a subject who is fasting and completely relaxed in a thermoneutral environment. In practice, the resting metabolic rate (RMR), in the postabsorptive state and physically at rest, is usually the best approximation of the BMR that can be achieved. The terms are used interchangeably here.

\section{Ageing and energy expenditure}

Ageing is associated with a decline in RMR. ${ }^{5-8}$ Some studies indicate that this decline is mainly due to the loss of fat-free mass (FFM) with age, ${ }^{9,10}$ but others demonstrated a significant effect of age on RMR which is independent of the luss of fat-free mass 
(FFM). ${ }^{11,12}$ Since these contradictory findings might be a consequence of different levels of physical activity in elderly people, Poehlman et al. ${ }^{12}$ compared RMR in sedentary younger and older men with individuals of similar age who regularly participated in aerobic exercise. Besides an age-related decline in RMR (which was independent of FFM) it was noted that regular physical activity diminished this age-related effect.

Thus, with ageing, BMR is reduced in the elderly and this decline is largely, but probably not totally, due to the age-related fall in fat-free mass. The fall in FFM and BMR with age might be attenuated by regular physical exercise.

\section{Effects of energy restriction on energy expenditure}

\section{Animals}

Sacher ${ }^{13}$ proposed that energy restriction influences the ageing process by reducing the metabolic rate, i.e. by reducing 'the rate of living'. McCarter et al. studied BMR in rats after restricting their energy intake for 6 months, ${ }^{14}$ and during their total life span. ${ }^{15}$ They did not find a difference in metabolic rate per kilogram fat-free mass between male Fischer 344 rats fed ad libitum and rats on a food-restricted regimen (40\% reduction). These findings suggest that energy restriction does not lower the metabolic rate per unit of metabolic mass. This negative answer to the question 'Does food restriction retard ageing by reducing metabolic rate?' has been criticized by Lynn and Wallwork. ${ }^{16}$ In their opinion, the problem with McCarter's calculation is that they related oxygen consumption to fat-free mass rather than to functional metabolic mass. Lynn and Wallwork hypothesize that the flow of electrons to oxygen must be faster through the metabolic mass of the animals fed ad libitum, since the amount of metabolizing tissue in both ad libitum fed and restricted animals was calculated to be approximately equal but oxygen consumption was higher in the ad libitum fed animals.

As contrasted with McCarter's finding, Ballor ${ }^{17,18}$ observed in obese male and female Sprague-Dawley rats a decrease in 23-hour and in resting oxygen uptake after 11 weeks of moderate $(-25 \%)$ and severe $(-50 \%)$ energy restriction. When corrections were made for body weight, moderate restriction had little effect on metabolic rate, whereas more severe deprivation lowered metabolic rate, even when metabolic rate was expressed per $\mathrm{kg}^{0.75}$, one of the methods commonly used to correct for the reduction in metabolic rate that occurs as a consequence of the loss of body mass alone.

As indicated, changes in body composition, i.e. functional metabolic mass rather than FFM, play an important role in the change in BMR. However, since accurate measurements in vivo of functional metabolic mass are not yet available, one can only use FFM as an indicator. A decrease in FFM leads to a decreased BMR. Therefore, loss of FFM during periods of energy restriction should be minimized. From these animal studies it seems that energy restriction lowers metabolic rate due to the loss of FFM. However, more severe 
energy restriction (50\%) in adult rats may lead to a more efficient metabolic rate, i.e. a larger decrease in BMR than can be explained by the loss of FFM, which probably reflects reduced functional activity.

\section{Man}

One of the first experiments into the effects of energy restriction in man has been performed by Keys et al. in the early 1950's. ${ }^{19}$ In their Minnesota Experiment, in which 32 healthy men received $50 \%$ of their habitual intake (semi-starvation), the investigators demonstrated that BMR decreased during semi-starvation. After 24 weeks of semi-starvation mean oxygen consumption had decreased by $38.9 \%$, per square meter of body surface by $31.3 \%$, per $\mathrm{kg}$ of body weight by $19.5 \%$ and by $15.5 \%$ per $\mathrm{kg}$ 'active tissue' (active tissue = body weight - (extracellular fluid + fat + bone mineral $)$ ). At the end of the experiment there was no further change in BMR, indicating that a new equilibrium had been reached.

Most of the more recent experimental studies into the effects of energy restriction on energy metabolism have been performed in obese people. In several studies a very-lowcaloric diet $\left(1,380-4,180 \mathrm{~kJ} /\right.$ day) during a few weeks resulted in a decreased $B M R .{ }^{20-22}$ Except in one study, ${ }^{20}$ this fall in BMR was still significant when expressed per kg body weight or per kg FFM. In longer-term studies (12-48 weeks) in obese subjects an absolute reduction in BMR has been found ${ }^{23-27}$ although in most of these studies these reductions were no longer statistically significant when expressed per $\mathrm{kg}$ body weight or per $\mathrm{kg}$ FFM. ${ }^{23,25-27}$ These experimental studies suggest that in obese subjects energy restriction leads to a decreased BMR and that over a short period this decrease may be due to a decreased metabolic activity of the tissues, but that in the long run the loss of body tissue contributes to the lowered BMR.

In people on a habitually low energy intake the reduction in BMR may be in the order of $10 \%{ }^{28}$ In an epidemiological study into the relationship between RMR and different parameters of body size it has been observed that, per kg FFM, RMR in the obese was higher than in normal-weight subjects, ${ }^{29}$ but after weight loss this RMR seems to be similar to that of women who have never been obese. ${ }^{30}$ These epidemiological results suggest that obese persons may be less efficient in energy utilization. Shetty and Soares ${ }^{31.32}$ observed, in chronically undernourished labourers with a lower daily energy intake than the age-matched control group, that the average BMR was lower in the undernourished labourers in absolute terms, but also per kg body weight per day, per kg FFM per day and per unit body surface area. From this study, Shetty concluded that a decreased body weight, adjustments in physical activity and possibly an increased metabolic efficiency in energy utilization contribute to the maintenance of energy balance. In adolescent girls suffering from anorexia nervosa RMR, either expressed in absolute values or per $\mathrm{kg}$ body weight or per $\mathrm{kg}$ FFM, was found to be significantly lower than in matched controls, which most 
probably is an adaption to semi-starvation. ${ }^{33,34}$ The results of BMR measurements in anorexia nervosa patients are similar to those in Keys' experiment mentioned before.

From several reviews on the effects of a negative energy balance it can be concluded that the BMR per kg body weight is not significantly reduced in moderate undernutrition. Only when the energy deficit is severe, i.e. much body weight has been lost, there is a measurable fall in BMR in absolute terms but also per $\mathrm{kg}$ body weight. This fall in BMR will be greater in lean than in obese subjects. ${ }^{28,35-37}$

In summary, it may be concluded that, although the limits are hard to define, in both animals and man severe energy restriction lowers RMR expressed in absolute terms. From studies performed in man it appears that the effect is greater in lean subjects than in the obese, due to a relatively greater loss of FFM. Loss of FFM should therefore be minimized. Long-term energy restriction, for example in undernourished labourers and in anorexia nervosa patients, decreases the activity of metabolic tissue and probably increases metabolic efficiency, since in these studies RMR expressed per $\mathrm{kg}$ FFM was also reduced. Decreased metabolic activity might be the result of decreased thyroid function or sympathetic nervous activity. The effect of energy restriction on the (neuro)endocrine balance will be discussed elsewhere in this manuscript.

EFFECTS OF AGEING AND ENERGY RESTRICTION ON FREE-RADICAL ACTIVITY: OXIDATIVE STRESS AND DNA DAMAGE

\section{Oxidative stress}

Free-radical reactions have been suggested to be responsible for the progressive accumulation of age-related degenerative changes and to a loss of functional capacity due to oxidative damage. This implies that reactive oxygen species, or free radicals, are produced incidentally and uncontrollably during aerobic metabolism. Once generated, free radicals initiate or promote the deleterious reactions that underlie the ageing process.

The suggestion by Sacher ${ }^{13}$ that energy restriction reduces the metabolic rate, and by doing so, retards the ageing processes has been widely embraced. Indeed, Harman ${ }^{38}$ linked this hypothesis to the 'free-radical theory of ageing'. His view was that by lowering the metabolic rate, the rate of electron transport in the respiratory chain will be lowered, leading to decreased production of free radicals and cell damage and thereby to a decreased ageing rate. The findings of Chipalkatti ${ }^{39}$ that energy restriction in mice reduces the damage in tissues by free radicals support this hypothesis. Cutler ${ }^{41}$ divided mammalian species into three separate categories according to their metabolic potential: averaged over their total life span most mammalian species expend about $220 \mathrm{kcal} / \mathrm{g}$ body weight, cat and non-human primates about $458 \mathrm{kcal} / \mathrm{g}$, and man, capuchins and lemurs about $781 \mathrm{kcal} / \mathrm{g}$. Within these 
three categories the basal metabolic rate is apparently inversely related to species-specific life span, which supports the rate of living theory. According to Cutler ageing is partly due to free-radical-induced changes in the differentiated state of the cell. In his view, the optimal state of differentiation gradually degenerates into a state of 'dysdifferentiation' as a result of genomic damage by long-term exposure to free radicals. A higher rate of metabolism accelerates this process.

Another mechanism by which free radicals can modulate the ageing process has been postulated by Sohal and Allen. ${ }^{41,42}$ They hypothesize that ageing is due to the loss of balance between prooxidants and antioxidants in cells, which is necessary for the maintenance of the differentiated state of cells. Whether ageing is due to increased levels of prooxidants (accumulation of free-radical damage) or to decreased antioxidative capacity remains unknown. Roa et al. ${ }^{43}$ studied the effects of ageing and energy restriction on enzymes involved in free radical detoxification in rats. They observed that the activity and the mRNA levels of superoxide dismutase (SOD), catalase and glutathione peroxidase (GSH-Px) were diminished in older animals and that this decrease was eliminated by energy restriction. This indicates that the beneficial effect of an energy-restricted regimen is related to the maintenance of the free-radical scavenging capacity, which is controlled at the level of gene expression. These and other changes that occur in ageing but are prevented by energy restriction are summarized in Table 1.1. The data suggest that there is indeed a relationship between ageing and the activity of antioxidant enzymes as well as between ageing and lipid peroxidation. Generally speaking, in most studies mentioned, a decrease of the activity of antioxidant enzymes such as SOD, catalase and GSH-Px has been found while lipid oxidation increases. This indicates the involvement of peroxidative deterioration in the ageing process. Energy restriction, however, seems to improve protection against peroxidation in animals, which may result in the life-prolonging effect observed in animals.

As compared to younger people, in older people an increased plasma malondialdehyde content (a marker of overall lipid peroxidation), ${ }^{44-46}$ decreased vitamin E level, $, 4,45$ decreased vitamin $\mathrm{C}_{\text {level }}{ }^{45}$ and decreased ${ }^{44,45}$ or unchanged ${ }^{46}$ GSH-Px activity have been observed in cross-sectional studies. From a longitudinal study ${ }^{47}$ it appeared that those subjects who died during the study had a low SOD inducibility by paraquat (mean 2.4\%) at the beginning of the study as compared to the survivors (mean $21 \%$ ). These findings in human studies support the observations on free-radical damage and ageing in laboratory animals. Unfortunately, no human studies are available into the effects of ageing and energy restriction on antioxidants or oxidative stress. 
Table 1.1. Age-related processes and the effect of energy restriction.

\begin{tabular}{|c|c|c|c|c|}
\hline Enzyme & $\begin{array}{c}\text { change with } \\
\text { age }^{\mathrm{a}}\end{array}$ & $\begin{array}{l}\text { effect of ER } \\
\text { with age }\end{array}$ & species & $\overline{\text { ref }}$ \\
\hline$(\mathrm{Cu}-\mathrm{Zn}) \mathrm{SOD}$ activity & $\downarrow$ & $\mathrm{d}$ & rat & 43 \\
\hline mRNA level & $\downarrow$ & d & rat & 43 \\
\hline mRNA level & $=$ & $\mathrm{n}$ & mouse & 102 \\
\hline (Mn)SOD activity & $=$ & $\mathrm{n}$ & mouse & 102 \\
\hline mRNA level & $\downarrow$ & d & mouse & 102 \\
\hline SOD activity & $=$ & $\mathrm{n}$ & mouse & 103 \\
\hline SOD activity & $\downarrow$ & $\mathrm{n}$ & rat & 104 \\
\hline Catalase activity & $\downarrow$ & d & rat & 43 \\
\hline Catalase activity & $\downarrow$ & $d$ & mouse & 102 \\
\hline Catalase activity & $\downarrow$ & d & rat & 104 \\
\hline Catalase activity & $=$ & e & mouse & 103 \\
\hline mRNA level & $\downarrow$ & $d$ & rat & 43 \\
\hline mRNA level & $\uparrow$ & $\mathrm{n}$ & mouse & 102 \\
\hline GSH-Px activity & $\downarrow$ & $d$ & rat & 43 \\
\hline GSH-Px activity & $\downarrow$ & $n$ & rat & 104 \\
\hline GSH-Px activity & $=$ & $n$ & rat & 105 \\
\hline mRNA level & $\downarrow$ & d & rat & 43 \\
\hline mRNA level & $=$ & $\mathrm{n}$ & mouse & 102 \\
\hline cyt. P450 mRNA level & $\downarrow$ & d & mouse & 102 \\
\hline cyt. P450 destruction by $\mathrm{H} 202$ & $\uparrow$ & $d$ & rat & 106 \\
\hline lipofuscin & $\uparrow$ & d & rat & 43 \\
\hline TBARs & $\uparrow$ & $d$ & rat & 43 \\
\hline MDA-oxydation capacity & $\downarrow$ & $d$ & rat & 107 \\
\hline Lipid peroxidation & $\uparrow$ & $d$ & mouse & 103 \\
\hline Lipid peroxidation & $\uparrow$ & d & rat & 104 \\
\hline peroxidizability of membr. & $\uparrow$ & d & rat & 106 \\
\hline
\end{tabular}

s $\uparrow=$ increase; $\downarrow$ = decrease; $==$ no effect.

b $\mathrm{n}=$ no effect of energy restriction on age effect; $d$ = diminishing age effect by energy restriction;

$\mathrm{c}=$ enhanced age effect by energy restriction

\section{DNA damage}

Energy restriction reduces the incidence of spontaneous tumours and delays their appearance. ${ }^{3.48}$ Besides lower levels of ingested dietary carcinogens, a decreased metabolic activity and increased detoxification of free radicals through ER could decrease the endogenous levels of DNA damage. Indeed, protection of DNA damage by ER has been observed in rat liver ${ }^{49.50}$ and in the rat's mammary gland. ${ }^{.9}$ Moreover, enhancement of both specific activity and fidelity of DNA polymerases has been observed in energy-restricted mice. ${ }^{51}$ 
Damaged DNA is repaired in vivo by exonucleases and the resulting free water-soluble 8 -hydroxydeoxyguanosine $(8 \mathrm{OHdG})$ is excreted in the urine. Loft et al. ${ }^{52}$ observed that $8 \mathrm{OHdG}$ excretion decreased with increasing Body Mass Index. The authors speculated that this may relate to the fact that obese persons have a lower metabolic rate than lean ones. As discussed before, obese people have a equal or even higher metabolic rate per kg FFM than lean ones. The decreased $80 \mathrm{HdG}$ excretion in the obese may therefore also be due to decreased DNA repair.

Energy intake and human cancer incidence has also been the subject of epidemiological studies. In a review by Weindruch ${ }^{53}$ a number of studies are summarized in which a relationship between high energy intake and the development of certain human cancers were reported, since a positive association between Body Mass Index or relative body weight and cancer has been demonstrated in most of these investigations. On the basis of these studies and convincing evidence from studies in rodents he hypothesized that the anticancer actions of ER, which are so evident in rodents, may also apply to man.

\section{EFFECTS OF AGEING AND ENERGY RESTRICTION ON ENDOCRINE REGULATION MECHANISMS}

Normal usage of neurons over a prolonged period of time may result in 'wear and tear'. Ageing is accompanied by changes in hormonal secretion (blood hormone levels), hormonal responsiveness and neural activity. These changes in the neuroendocrine system have been related to specific ageing phenomena such as loss of bone mass, decrease in protein turnover and in decline of reproductive capacity. Generally, ageing is characterized by an apparent decrease in homeostatic capacity. Hormones can accelerate or inhibit the ageing process. Much of the ageing action of hormones comes from long-term studies of rodents subjected to hypophysectomy, thyroidectomy, ovariectomy or orchidectomy. Loss of hormones through surgical removal of these endocrine glands slows ageing in many tissues and must (in)directly affect the rates of physiological ageing and development of age-related diseases. On the other hand, the evidence that hormones can produce anti-ageing effects comes mainly from studies in older rats that demonstrate that hormone elevation (gonadal hormones, growth hormone (GH), somatomedins) can inhibit or reverse certain ageing. changes. $^{54}$

Changes in food intake and ER induce also a profound effect on hormonal and neural activity. The life-prolonging effects of ER have been causally related to ER-induced effects on the neuroendocrine system. ER generally results in decreased neuroendocrine function which might have a conserving effect. ${ }^{55}$ Several excellent reviews have been written on the effects of both ageing and ER on neuroendocrine activity. In this review we will briefly 
summarize the main systems involved and discuss especially the interactive effects of both ageing and ER.

There are several hormonal systems which can be modulated by ageing and/or energy restriction: 1) the sympathetic nervous system, 2) thyroid hormones, 3) anterior pituitary hormones and 4) hormones related to glucose homeostasis. In this chapter the effects of energy restriction on these systems will be described with, for each system, some introductory remarks on the changes with advancing age.

\section{Ageing, energy restriction and the sympathetic nervous system}

Stimulation of the sympathetic nervous system, with concurrent release of noradrenaline and adrenaline, increases the metabolic rate of many tissues and stimulates many organs of the body. In animals, urinary excretion of adrenaline and noradrenaline increases during ageing, ${ }^{56}$ while cardiac catecholamine levels at rest and in response to acute exercise decline with age. ${ }^{57}$ Human population studies indicate an increase in plasma catecholamine levels with advancing age. ${ }^{58.59}$ This age-related increase in catecholamine concentration seems to be the consequence of an increased spill over into the plasma rather than a decreased clearance rate. In response to stress, the average plasma level increases to a greater extent in the elderly than in younger individuals. However, although the average levels of plasma adrenaline and noradrenaline during stress are greater in the elderly than in younger subjects, it is noteworthy that there is a substantial heterogeneity among elderly subjects. The age-related enhancement of catecholamine concentrations suggests that with advancing age a diminished responsiveness to $\beta$-adrenergic modulation seems to occur. ${ }^{58,59}$ The underlying mechanism related to the age-related change in sympathetic nervous activity remains to be explained.

In Table 1.2 the main results of studies into energy restriction and the neuroendocrine system are summarized. Changes in urinary levels of catecholamines can be secondary to altered rates of synthesis, release, turnover and excretion, and to any combination of these. Underfeeding generally results in reductions in both noradrenaline release and clearance rates such that the decrease of the plasma concentration of noradrenaline is minimal. ${ }^{60}$ However, a fall in plasma noradrenaline has been observed in obese human subjects undergoing therapeutic semi-starvation, ${ }^{30,61}$ and diminished plasma noradrenaline levels are

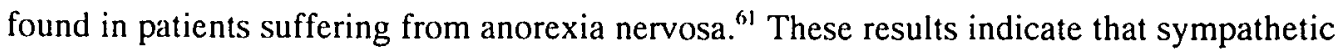
nervous system activity is suppressed by energy restriction.

Thus, with advancing age the sympathetic nervous system seems to be affected but the precise mechanisms are unknown. Energy restriction results in decreased sympathetic function which in turn might be responsible for the observed lowered metabolic rate observed in energy-restricted subjects. 
Ageing, energy restriction and thyroid hormones

The thyroid gland secretes two significant hormones, thyroxine (T4) and 3,5,3'-triiodothyronine (T3). Part of T4 is converted into T3. T3 is about four times as potent as $\mathrm{T} 4$, but is present in the blood in smaller quantities and persists for a shorter time than does T4. Both are very important in stimulating metabolic rate and thus play an important role in energy balance. Thyroid secretion is controlled primarily by thyroidstimulating hormone (TSH) secreted by the anterior pituitary gland. ${ }^{62}$

Thyroid failure is common among the elderly. ${ }^{63}$ The natural history of thyroid failure has been investigated in a four-year longitudinal study. ${ }^{64}$ It has been found that elevated TSH levels with normal T4 levels are common in otherwise healthy elderly subjects and that progression to thyroid failure is common in such subjects. Those with greater elevations of TSH or with low to normal T4 values were more likely to progress to thyroid failure than those with smaller elevations of TSH and those who did not have low to normal T4 levels. The age-related decrease in $\mathrm{T} 4$ concentration might not be due to a decline of the secretory function of the thyroid gland, but to an increase in metabolic clearance of T4. ${ }^{65}$

In order to understand the effects of energy restriction on basal metabolic rate thyroid hormone metabolism has been studied. Short-term animal studies (4-10 weeks) showed that energy restriction decreases T4 and T3 concentration but does not affect TSH level. . $^{6.67}$ Lower T3 and T4 levels, but no effect on TSH, could indicate a decreased responsiveness of the hypothalamic-pituitary axis during underfeeding. Results from long-term animal studies show no effect on T4 and TSH but the effects on T3 reported are conflicting: one study noted a decrease ${ }^{6 / 8}$ whereas another reported no effect on T3. ${ }^{69}$

In man the effect of energy restriction on thyroid hormones has also been studied. Short-term very-low-caloric diets (VLCD) in obese people generally results in decreased T3 levels and unaltered T4 and TSH levels..$^{20,21,69}$ Ten days of total energy deprivation in normal-weight man showed early reductions and later increments of T3 and rT3 levels and a slight and late decrease of T4. Besides these effects, a minute decrease in TSH has been seen. ${ }^{70}$ These studies indicate that $\mathrm{T} 3$ plays an important role in the adaptation to conserve energy stores during energy deprivation. In an epidemiological study Soares and Shetty ${ }^{32}$ noticed that undernourished men had a lower BMR and a lower T3 level but similar T4 levels as normally fed controls.

There are only a few studies that have looked at the effects of both ageing and energy restriction on thyroid hormones. It has been noticed that in old ad libitum fed rats, but not in food-restricted rats, T4 levels were significantly lower than in young rats. Serum levels of $\mathrm{T} 3$ were unaffected by age or diet. ${ }^{71}$ However, in another study energy restriction could not prevent the age-related fall of $\mathrm{T} 4{ }^{6.9}$

In summary, animal and human studies suggest that ageing results in lower T4 levels, possibly due to an increased clearance rate. This effect is probably attenuated by ER. The 
observed lower peripheral conversion of T4 into T3 in both man and animals contributes to a more efficient energy balance by lowering BMR per unit active tissue in the undernourished.

\section{Ageing, energy restriction and pituitary hormones}

Since the neuroendocrine system plays a critical role in body functions such as development, growth, metabolism and immune functions. During early and mature life it may have an equally important role in regulating the decline in body functions during later life. ${ }^{72}$ Meites $^{55}$ observed three ageing events in the rat: 1) the decline in ability of the pituitary to secrete gonadotropic hormones, 2) the progressive increase in pituitary secretion of prolactin (PRL) and 3) the decline in secretion of growth hormone and somatomedin (insulin-like growth factor, IGF), and the resultant decrease in protein synthesis. These ageing phenomena have several features in common. One is that the principal cause for their occurrence lies mainly in hypothalamic dysfunction. There seems to be evidence for a decrease in release of gonadotropin releasing hormone ( $\mathrm{GnRH})$, the peptide that controls secretion of luteinizing hormone ( $\mathrm{LH})$ and follicle-stimulating hormone (FSH). The decrease of $\mathrm{GnRH}$ is probably caused by the decline in noradrenaline activity. Another common feature is that these three ageing events appear during the first third to half of the rat's life span of about three years. ${ }^{55}$ For example, the oestrous cycle in female rats becomes irregular when they are only 7-8 months old, and by 10-15 months of age they cease to cycle and enter into a constant oestrous state without ovulation. In the ageing woman menopause generally occurs between 40 and 50 years of age. ${ }^{73}$ However, caution should be exercised before assuming that results of these animal studies can be extrapolated to man. The changes in pituitary hormones with ageing in man are summarized by Blackman. ${ }^{74}$ In this review increases in both basal serum $\mathrm{LH}$ and $\mathrm{FSH}$, but decreased testosterone levels are mentioned. Furthermore, variable responses of basal levels of PRL, GH and IGF to ageing have been reported.

Underfeeding has been reported to suppress the secretion of hypothalamic, pituitary and target gland hormones. Table 1.2, which summarizes results of several studies, shows that energy restriction leads to decreased serum levels of at least three anterior pituitary hormones (FSH, LH, PRL) in animals. Campbell et al. ${ }^{75}$ injected their acutely starved (no food for 7 days) and chronically starved (no food for 7 days followed by $1 / 4$ of initial average for 2 weeks) rats with LH-releasing hormone (LHRH) and thyrotropin-releasing hormone (TRH). After this injection serum LH and TSH rose significantly in all groups of rats and FSH and PRL rose in the acutely, but not in the chronically, starved rats. These data suggest that the reduction in anterior pituitary hormone levels are due primarily to reduced hypothalamic stimulation rather than to the inability of the pituitary to secrete hormones. 
In animal studies that studied both ageing and energy restriction an increase in serum prolactin with age was observed, but not in the restricted rats. Testosterone and LH levels decreased with age with higher levels in the energy-restricted rats. ${ }^{69.71}$

In 1986, Sapolsky ${ }^{76}$ postulated his hypothesis about the neuro-endocrinological basis of ageing. His hypothesis was based on the notion that the neurons in the hippocampus, which have a high density of glucocorticoid receptors, are involved in the negative feedback regulation of glucocorticoid secretion and that stress-induced increases in plasma glucocorticoid concentration, which inevitably occur during the course of daily life, downregulate these hippocampal glucocorticoid receptors. This may result in periods of hypercortisolism. With advancing age periods of glucocorticoidal excess causes degeneration of hippocampal neurons. Together, these effects form a feed-forward cascade of sustained hyperadrenocorticism. However, studies into ageing and the hypothalamic-pituitary-adrenal axis could not completely confirm Sapolsky's hypothesis. In aged Brown Norway rats an increased adrenocorticotropic hormone (ACTH) response to a conditioned stress stimulus was found but there was no impairment of the negative feedback action of glucocorticoids. However, the data supported the concept of an age-induced change in the balance of central corticoid receptor-mediated effects which consequently affects the set-point of homeostatic control and in turn, may progressively lead to a condition of age-related neuroendocrine disturbances. ${ }^{77}$ On the basis of the 'glucocorticoid cascade hypothesis' it could be predicted that basal plasma corticosterone levels begin to elevate progressively on a given age. This prediction was not corroborated by the results of a longitudinal study of ad libitum fed male Fischer 344 rats. ${ }^{78}$ Although an increase occurred between 9 and 13 and between 15 and 19 months of age, no further increase occurred between 19 and 25 months of age, while there was no increase with age in the food-restricted rats. The delay in recovery of plasma corticosterone levels upon stress was an important piece of evidence in the development of Sapolsky's hypothesis. In the same Fischer 344 rats it was found that the return of plasma corticosterone levels in ad libitum fed rats toward basal levels after a restraint stress is lower in rats 18-19 months old than in those 5-6 months old. However further slowing at 23-24 months, as would be expected on the basis of the 'glucocorticoid cascade hypothesis', was not observed. In addition, both food-restricted rats and ad-libitum fed rats of the same age exhibited similar time courses of recovery of plasma corticosterone levels upon stress. This study shows that the hypothesis that food restriction, at least in part, retards the ageing process by preventing the development of hyperadrenocorticism may be incorrect. Furthermore, the two studies described indicate that the 'glucocorticoid cascade hypothesis' does not describe a major aspect of the ageing process. 


\section{Ageing, energy restriction and hormones related to glucose haemostasis}

Glucose and free fatty acids are the two main substrates for energy production and thus are regarded as the major metabolic fuel. Insulin and glucagon play an important role in the regulation of the fuel system. Insulin secretion is stimulated by elevated blood glucose levels. In skeletal muscle and in adipose tissue, insulin increases glucose transport, glucose oxidation, glycogen and protein synthesis, but inhibits proteolysis and lipoprotein lipase (LPL) activity. In the liver, insulin inhibits gluconeogenesis, and very-low-density lipoprotein secretion. Glucagon, a hormone that is secreted when the blood glucose concentration falls, has several functions which are diametrically opposed to those of insulin. Stimulated glycogenolysis and increased blood glucose concentration are the most important effects of glucagon.

One of the well-known features of ageing in both animal and man is the progressive development of impaired glucose tolerance. The precise mechanism is not known yet, but several reasons have been suggested for this deterioration. Amongst these are skeletal muscle insulin resistance, ${ }^{79,80}$ impaired glucose oxidation in sensitivity to insulin stimulation, ${ }^{81}$ decreased pancreatic insulin response to glucose stimulus, ${ }^{82}$ and decreased response by the liver to the down-regulation by insulin on glucose output. ${ }^{80}$ Results of a recently performed in-vitro study in the whole perfused pancreas and islets of Langerhans of Fischer 344 rats, indicate that glucose-stimulated insulin excretion is not significantly altered with age. However, it appeared that maintenance of insulin secretory capacity by ageing male rats is achieved by enhancement of $\beta$-cell sensitivity to glucose. ${ }^{83}$

Energy restriction influences glucose homeostasis. In rats maintained on a life-long restricted energy intake the progressive early peak of plasma glucose upon oral glucose loading, which occurs in ad libitum fed animals, does not occur. Nor did the energyrestricted animals show an increase in peak value with age, which was found in the ad libitum fed animals. ${ }^{84}$ Low glucose and insulin concentrations have often been observed during periods of energy restriction. ${ }^{59.85 .87}$ The decrease in insulin levels in energy-restricted animals and man indicates that insulin is the primary signal responsible for fuel control during fasting in order to survive periods of energy restriction. ${ }^{87}$ Reduced glucose levels might be another mechanism by which energy restriction can retard ageing since Cerami ${ }^{88}$ advanced the hypothesis that glucose serves as a mediator of ageing. This hypothesis is based on the fact that non-enzymatic reactions occur between glucose and tissue protein, termed 'glycation of protein'. Lower glucose concentration and percentage glycosylation of haemoglobin were found in energy-restricted rats $(60 \% \text { of ad libitum })^{89}$ but not in monkeys fed $70 \%$ of ad libitum. ${ }^{90}$ These results suggest species-specific glucose metabolism and makes extrapolation to man difficult. 
Table 1.2. Effect of energy restriction on the hormone system.

\begin{tabular}{|c|c|c|c|c|c|}
\hline Hormone $^{a}$ & Effect & Subject & Period & Diet & Ref. \\
\hline \multirow[t]{4}{*}{ Adrenaline } & $=$ & non-obese men & 10 days & $400 \mathrm{kcal} / \mathrm{day}$ & 60 \\
\hline & $=$ & non-obese women & 7 days & $15 \mathrm{kcal} / \mathrm{kg} \mathrm{bw} / \mathrm{day}$ & 59 \\
\hline & $=$ & obese women & ca. 3 months & $800 \mathrm{kcal} / \mathrm{day}$ & 30 \\
\hline & $\uparrow$ & non-obese men & 10 days & fasting & 70 \\
\hline \multirow{3}{*}{$\begin{array}{c}\text { Noradrenaline }(\mathrm{pl}) \\
\text { appearance } \\
\text { clearance }\end{array}$} & $=$ & non-obese men & 10 days & $400 \mathrm{kcal} / \mathrm{day}$ & 60 \\
\hline & $\downarrow$ & non-obese men & 10 days & $400 \mathrm{kcal} / \mathrm{day}$ & 60 \\
\hline & $\downarrow$ & non-obese men & 10 days & $400 \mathrm{kcal} /$ day & 60 \\
\hline$(\mathrm{pl})$ & $=$ & non-obese women & 7 days & $15 \mathrm{kcal} / \mathrm{kg}$ bw $/$ day & 59 \\
\hline$(\mathrm{pl})$ & $\downarrow$ & obese women & ca. 3 months & $800 \mathrm{kcal} /$ day & 30 \\
\hline (u) & $=$ & non-obese men & 10 days & fasting & 70 \\
\hline \multirow[t]{7}{*}{ TSH } & $=$ & rats & 28 days & $25 \%$ reduction & 66 \\
\hline & $\downarrow$ & rats & 18 days & $25 \%$ or $50 \%$ reduction & 108 \\
\hline & $\downarrow$ & rats & 7 days & fasting & 75 \\
\hline & $=$ & obese men & 6 weeks & $600 \mathrm{kcal} / \mathrm{day}$ & 96 \\
\hline & $\uparrow$ & obese women & 15 days & $320 \mathrm{kcal} / \mathrm{day}$ & 21 \\
\hline & $=$ & obese adults & 13 weeks & $320 \mathrm{kcal} /$ day & 109 \\
\hline & $=$ & non-obese men & 10 days & fasting & 70 \\
\hline \multirow[t]{9}{*}{$\mathrm{T} 4$} & $\downarrow$ & rats & 18 days & $25 \%$ reduction & 108 \\
\hline & $\downarrow$ & rats & 28 days & $25 \%$ reduction & 66 \\
\hline & $=$ & rats & 6 months & $40 \%$ reduction & 68 \\
\hline & $=$ & non-obese adults & 10 days & $400 \mathrm{kcal} /$ day & 60 \\
\hline & $=$ & obese women & 15 days & $320 \mathrm{kcal} /$ day & 21 \\
\hline & $=$ & obese women & 4 wecks & $730 \mathrm{kcal} /$ day & 21 \\
\hline & $=$ & obese men & 6 weeks & $600 \mathrm{kcal} /$ day & 96 \\
\hline & $=$ & obese adults & 13 wecks & $320 \mathrm{kcal} /$ day & 109 \\
\hline & $\downarrow$ & non-obcse men & 10 days & fasting & 70 \\
\hline \multirow[t]{9}{*}{$\mathrm{T} 3$} & $\downarrow$ & rats & 18 days & $25 \%$ or $50 \%$ reduction & 108 \\
\hline & $\downarrow$ & rats & 28 days & $25 \%$ reduction & 66 \\
\hline & $\downarrow$ & rats & 6 months & $40 \%$ reduction & 68 \\
\hline & $\downarrow$ & non-obese adults & 10 days & $400 \mathrm{kcal} / \mathrm{day}$ & 60 \\
\hline & $\downarrow$ & obese women & 15 days & $320 \mathrm{kcal} /$ day & 21 \\
\hline & $\downarrow$ & obese women & 4 weeks & $730 /$ kcalday & 20 \\
\hline & $\downarrow$ & obese men & 6 weeks & $600 \mathrm{kcal} /$ day & 96 \\
\hline & $\downarrow$ & obese adults & 13 weeks & $320 \mathrm{kcal} / \mathrm{day}$ & 109 \\
\hline & $\downarrow$ & non-obese men & 10 days & fasting & 70 \\
\hline
\end{tabular}


Table 1.2 continued

\begin{tabular}{|c|c|c|c|c|c|}
\hline Hormone & Effect & Subject & Period & Diet & Ref. \\
\hline \multirow[t]{5}{*}{ rT3 } & $\uparrow$ & non-obese adults & 10 days & $400 \mathrm{kcal} / \mathrm{day}$ & 60 \\
\hline & $\uparrow$ & obese women & 4 weeks & $730 \mathrm{kcal} /$ day & 20 \\
\hline & $=$ & obese men & 6 weeks & $600 \mathrm{kcal} /$ day & 96 \\
\hline & $\uparrow$ & obese adults & 13 weeks & $320 \mathrm{kcal} /$ day & 109 \\
\hline & $\uparrow$ & non-obese men & 10 days & fasting & 70 \\
\hline \multirow[t]{5}{*}{ Growth Hormone } & $\downarrow$ & rats & 18 days & $25 \%$ or $50 \%$ reduction & 108 \\
\hline & $\downarrow$ & rats & 10 weeks & $50 \%$ reduction & 67 \\
\hline & $\downarrow$ & rats & 7 days & fasting & 75 \\
\hline & $\uparrow$ & non-obese men & 7 days & fasting & 87 \\
\hline & $\uparrow$ & non-obese men & 10 days & fasting & 70 \\
\hline IGF-1 & $=$ & rats & 28 months & $40 \%$ reduction & 110 \\
\hline \multirow[t]{2}{*}{ IGF-1 mRNA } & $\uparrow$ & rats & 28 months & $40 \%$ reduction & 110 \\
\hline & $=$ & mice & 30 months & $52 \%$ reduction & 111 \\
\hline IGF-binding protein & $=$ & rats & 28 months & $40 \%$ reduction & 110 \\
\hline FSH & $\downarrow$ & rats & 7 days & fasting & 75 \\
\hline LH & $\downarrow$ & rats & 7 days & fasting & 75 \\
\hline \multirow[t]{4}{*}{ Prolactine } & $\downarrow$ & rats & $10,20,24$ months & $30 \%$ reduction & 112 \\
\hline & $\downarrow$ & female rats & 12 months & 6 hours/day & 113 \\
\hline & $=$ & male rats & 12 months & 6 hours/day & 113 \\
\hline & $\downarrow$ & rats & 7 days & fasting & 75 \\
\hline Prolactine mRNA & $\downarrow$ & mice & 18 months & $50 \%$ reduction & 114 \\
\hline Testosterone & $\uparrow$ & rats & $10,20,24$ months & $30 \%$ reduction & 112 \\
\hline Cortisol & $\uparrow$ & non-obese men & 10 days & fasting & 70 \\
\hline \multirow[t]{6}{*}{ Insulin } & $\downarrow$ & rats & $10,20,24$ months & $30 \%$ reduction & 112 \\
\hline & $\downarrow$ & rats & 6 wecks & $40 \%$ reduction & 86 \\
\hline & $\downarrow$ & rats & 70 days & $65 \%$ reduction & 85 \\
\hline & $=$ & monkcys & 36 months & $30 \%$ reduction & 90 \\
\hline & $\downarrow$ & non-obese women & 7 days & $15 \mathrm{kcal} / \mathrm{kg} \mathrm{bw} / \mathrm{day}$ & 59 \\
\hline & $\downarrow$ & non-obese men & 7 days & fasting & 87 \\
\hline Insulin receptor & $\uparrow$ & mice & 30 months & $52 \%$ reduction & 111 \\
\hline
\end{tabular}

${ }^{\mathrm{a}}(\mathrm{pl})=$ analysis in plasma; $(\mathrm{u})=$ analysis in urine 
In conclusion, ageing affects the hormonal system in both animals and man which is manifested in dysfunction of the sympathetic nervous system, decreased T4 concentrations, decreased secretion of gonadotropic hormones, and decreased glucose tolerance. This can be a result of 'wear and tear' with advancing age. Energy restriction also lowers the function of the neuroendocrine system by lowering noradrenaline and $\mathrm{T} 3$ in both animals and man and by lowering FSH, LH, and PRL levels which has only been studied in rats. This confirms the hypothesis that ER may have a conservative effect. Moreover, the finding that ER prevents the decrease in T4, testosterone and $\mathrm{LH}$ provides more evidence for this hypothesis.

\section{IMPLEMENTATION OF AN ENERGY RESTRICTED DIET}

When comparing effects of energy restriction, which have been investigated in both animals and man, no obvious discrepancies have been found. From this point of view ER could have a anti-ageing effect in man as well. However, looking at human studies on energy restriction it is obvious that, except for Keys' semi-starvation study and some short-term starvation studies, most (if not all) studies have been done in obese people. The diets that these obese received were mainly very-low-caloric diets (VLCD's). This is contradictory to the animal studies in which normal-weight animals were restricted to a less stringent low-caloric diet. Thus, to compare the outcomes of animal studies to studies in man it is necessary to perform a study in which normal-weight people receive a moderately energy-restricted diet while maintaining an adequate intake of essential nutrients. To which extent this energy supply should be restricted is open to discussion. However, this restriction should be achieved in such a way that it is acceptable to the subjects and does not lead to deterioration of physical or mental performance capacity or to other health risks when maintained over a longer period of time. Thus, the feasibility of moderate energy restriction needs to be studied. It should also be investigated whether long-term moderate energy restriction leads to a new energy balance at a lower basal metabolic rate. A lower energy metabolism due to energy restriction would support Harman's hypothesis which is based on the metabolic rate and the generation of free radicals.

With regard to the onset of energy restriction Yu et al. ${ }^{91}$ showed that energy restriction started at early adult life was as effective in extending maximum life span of rats than when it was started soon after weaning. This proves that energy restriction does not act by slowing growth and delaying development. Thus, it is not necessary to apply such a regimen to children. The effects of starting at any later age than early adult life still needs to be investigated.

Of the three macronutrients present in food, fats provide the most convenient and 
concentrated source of energy, since 1 gram of fat provides approximately $37 \mathrm{~kJ}$, whereas carbohydrates and proteins provide about 16 and $17 \mathrm{~kJ} / \mathrm{g}$ respectively. In most affluent societies fat usually contributes 35 to $45 \%$ of total energy. Animal and human studies have shown that diet composition, particularly dietary fat intake, can significantly affect the amount of body fat. ${ }^{92-96}$ In accordance with the growing evidence of a positive association between dietary fat and obesity, coronary diseases and cancer, nutrition experts are recommending that intake of fat be reduced to ca. $30 \%$ of total daily energy intake. The possibility of replacing fats in foods through the use of alternative ingredients has generated substantial interest among the food industry and nutrition professionals as well as among the lay public and news media.

The question that arises from our point of view is 'Does fat (and/or carbohydrate) substitution lead to energy restriction?'. In other words, is it possible to reduce one's energy intake through the consumption of fat (and sugar) substitutes? As an approach to study whether fat substitutes decrease energy intake, Lyle et al. ${ }^{97}$ made use of historical dietary records. When fat-free foods were substituted in seven selected food categories (cottage cheese, cream cheese, sour cream, dressings for salads, frozen desserts, process cheese and commercial sweet baked foods), mean energy intake decreased by $460 \mathrm{~kJ} /$ day (ca. $6.2 \%$ of total energy intake). It should be noted here that in this study it was not known whether energy compensation would occur. Unfortunately, the existing published body of research literature, summarized by Mela, ${ }^{96}$ does not directly and clearly answer this question. Most of the studies have been conducted in small patient populations within the confines of a laboratory or clinic or in free living healthy subjects given fixed meals or limited selections and have generally been of short duration. In most experiments in which free living subjects were offered foods covertly reduced in energy content, compensation for most or all the 'lost' energy occurred through increased consumption of these or other foods. With regard to fat substitutes in particular, the picture is less clear, but it would seem that (possibly not complete) energy compensation could be expected, accompanied perhaps by a moderate reduction in proportion of energy derived from fat. ${ }^{98}$ Another number of studies confirm that a compensatory increase of fat reduction is very limited, i.e. that fat reduction has a beneficial effect on energy intake. ${ }^{9 \% 101}$ It is clear that there is a lack of consensus on whether fat substitutes will lead to energy restriction. Studies published on this subject have been carried out in relatively small groups and over a relatively short period of time. Therefore, long-term studies in large groups of consumers might provide more information on the compensatory behaviour in subjects consuming fat and/or sugar substitutes.

Besides the hypotheses on which this paper is based, there certainly are other theories about the routes by which energy restriction may retard ageing. There is still a big challenge in learning how energy restriction retards ageing but more importantly, although it will be hard to introduce it as an intervention, in finding out the relevance for man. 


\section{REFERENCES}

1. McCay CM, Crowel MF, Maynard LA. The effect of retarded growth upon the length of the life span and upon the ultimate body size. J Nutr 1935;10:63-79.

2. Barrows $\mathrm{CH}$, Kokkonen GC. Dictary restriction and life extension, biological mechanisms. In: Moment GB, ed. Nutritional approaches to aging research. CRC Press, Inc., Boca Raton, Florida, 1982.

3. Wcindruch R, Walford RL. The retardation of aging and disease by dietary restriction. Charles $\mathrm{C}$. Thomas Publisher, Springfield Illinois, USA, 1988.

4. Masoro EJ. Assessment of nutritional components in prolongation of life and health by diet. Proc Soc Exp Biol Med 1990;193:31-34.

5. McGandy RB, Barrow CH Jr, Spanias A, Meredithl A, Stone JL, Noris AH. Nutrient intake and energy expenditure in men of different ages. J Gerontol 1966;21:581-587.

6. Boothby WM, Berkson J, Dunn HL. Studies of metabolism of normal individuals: a standard for basal metabolism with a nomogram for clinical application. Am J Physiol 1936;116:468-484.

7. Shock NW, Yiengst MJ. Age changes in basal respiratory measurements and metabolism in males. J Gerontol 1955;10:31-40.

8. Kcys A, Taylor HL, Grande F. Basal metabolism and age of adult man. Metabolism 1973;22:579-587.

9. Nichols JF, Leiter SE, Verity LS, Adams PL. Effect of age and aerobic capacity on resting metabolic rate and the thermic effect of food in healthy men. Nutr Res 1990;10:1161-1170.

10. Webb P. Energy expenditure and fat-free mass in men and women. Am J Clin Nutr 1981;34:18161826.

11. Vaughan L, Zurlo F, Ravussin E. Aging and energy expenditure. Am J Clin Nutr 1991;53:821-825.

12. Poehlman ET, Melby CL, Badylak SF. Relation of age and physical exercise status on metabolic rate in younger and older healthy men. J Gerontol 1991;46:B54-B58.

13. Sacher GA. Life table modifications and life prolongation. In: Finch CE, Hayflick L, eds. Handbook of the biology of aging. New York, van Nostrand Reinold. 1977:582-638.

14. McCarter R, Masoro EJ, Yu BP. Does food restriction retart aging by reducing the metabolic rate? Am J Physiol 1985;248:E488-E490.

15. McCarter RJ, Palmer J. Energy metabolism and aging: a lifelong study of Fischer 344 rats. Am J Physiol 1992;263:E448-E452.

16. Lynn WS, Wallwork JC. Does food restriction retard aging by reducing metabolic rate? J Nutr 1992;122:1917-1918.

17. Ballor DL. Exercise training elevates RMR during moderate but not severe dictary restriction in obese malc rats. J Appl Physiol 1991;70:2303-2310.

18. Ballor DL. Effect of dietary restriction and/or excrcise on 23-h metabolic rate and body composition in femalc rats. J Appl Physiol 1991;71:801-806.

19. Keys A, Brozek J, Henschel A, Mickelsen O, Taylor HL. The biology of human starvation. Minneapolis, The university of Minnesota Press, 1950.

20. Mathieson RA, Walberg JL, Gwazdauskas FC, Hinkle DE, Gregg JM. The effect of varying carbohydrate content of a very-low-caloric dict on resting metabolic rate and thyroid hormones. Metabolism 1986;35:394-398.

21. Cavallo E, Armellini F, Zamboni M, Vicentini R, Milani MP, Bosello O. Resting metabolic rate, body composition and thyroid hormones: short term effects of very low caloric dict. Horm Metab Res 1990;22:632-635.

22. Fricker J, Rozen R, Melchior JC, Apfelbaum M. Encrgy-metabolism adaptation in obese adults on a very-low-calorie diet. Am J Clin Nutr 1991;53:826-830.

23. Wadden TA, Foster GD, Letizia KA, Mullen JL. Long-term effects of dieting on resting metabolic rate in obese patients. JAMA 1990;264:707-711.

24. Burgess NS. Effect of a very-low-caloric diet on body composition and resting metabolic rate in obese men and women. Research 1991;91:430-434.

25. Donnelly JE, Pronk NP, Jacobsen DJ, Pronk SJ, Jakicic JM. Effects of a very-low-caloric dict and physical training regiments on body composition and resting metabolic rate in obesc females. Am J 
Clin Nutr 1991;54:56-61.

26. Foster GD, Wadden TA, Feurer ID, Jennings AS, Stunkard AJ, Crosby LO, Ship J, Mullen JL. Controlled trial of the metabolic effects of a very-low calorie diet: short- and long-term effects. Am J Clin Nutr 1990;51:167-172.

27. Hammer RL, Barrier CA, Roundy WS, Bradford JM, Fisher AG. Calorie-restricted low-fat diet and exercise in obese women. Am J Clin Nutr 1989;49:77-85.

28. Waterlow JC. Metabolic adaptation to low intakes of energy and protein. Ann Rev Nutr 1986;6:495526.

29. Hoffmans M, Pfeifer WA, Gundlach BL, Nijkrake HGM, Oude Ophuis AJM, Hautvast JGAJ. Resting metabolic rate in obese and normal weight women. Int J Obesity 1979;3:111-118.

30. Nelson KM, Wcinsier RL, James LD, Darnell B, Hunter G, Long GL. Effect of weight reduction on resting energy expenditure, subtrate utilization, and the thermic effect of food in moderately obese women. Am J Clin Nutr 1992;55:924-933.

31. Shetty PS. Adaptive changes in basal metabolic ratc and lean body mass in chronic undernutrition. Human Nutr Clin Nutr 1984;38C:443-451.

32. Soares MJ, Shetty PS. Basal metabolic rates and metabolic economy in chronic undernutrition. Eur J Clin Nutr 1991;45:363-373.

33. Vaisman N, Rossi MF, Corey M, Clarke R, Goldberg E, Pencharz PB. Effect of refeeding on the cnergy metabolism of adolescent girls who have anorexia nervosa. Eur J Clin Nutr 1991;45:527-537.

34. Scalfi L, Coltorti A, Borrelli R, Contalda F. Postprandial thermogenesis in leanness and anorexia nervosa. Ann Nutr Metab 1992;36:48-54.

35. Widdowson EM. Responses to deficits in dietary intake. In: Nutritional adaptation in man. Blaxter K, Waterlow JC, eds. London \& Paris, John Libbey, 1984.

36. Garrow JS. Chronic effects of over- and under-nutrition on thermogenesis. Internat J Vit Res 1986;56:201-204.

37. Prentice AM, Goldberg GR, Jebb SA, Black AE, Murgatroyd PR, Diaz EO. Physiological responses to slimming. Proc Nutr Soc 1991;50:441-458.

38. Harman D. Free radical theory of ageing: effect of free radical reaction inhibitors on the mortality rate of male LAF rats. J Gcrontol 1968;23:476-482.

39. Chipalkatti S, De AK, Aiyar AS. Effect of diet restriction on some biochemical parameters related to aging in mice. $J$ Nutr $1983 ; 113: 944-950$.

40. Cutler RG. Antioxidants, aging and longevity. In: Pryor WA ed. Frec radicals in biology, vol 6. Acadamic Press, New York, 1984:371-428.

41. Sohal RS, Allen RG. Relationship between oxygen metabolism, aging and development. Adv. Free Radical Biol Med 1986:2:117-160.

42. Sohal RS, Allen RG. Oxidative stress as a causal factor in differentiation and aging, a unifying hypothesis. Exp Gerontol 1990;25:499-522.

43. Rao G, Xia E, Nadakavukaren MJ, Richardson A. Effect of dietary restriction on the age-dependent changes in the expression of antioxidant enzymes in rat liver. J Nutr 1990;120:602-609.

44. Verical E, Rey C, Calzada C, Haond P, Chapuy PH, Lagarde M. Age-related changes in arachidonic acid peroxidation and gluthatione-peroxidase activity in human platelets. Prostaglandins 1992;43:7585.

45. Reddy KK, Ramachandraiah $T$, Soorya Kumari K, Reddanna $P$, Thyagaraju K. Serum lipid peroxides and antioxidant defense components or rural and urban populations and aging. Age 1993;16:9-14.

46. Rodriguez-Martinez MA, Ruiz-Torres A. Homeostasis between lipid peroxidation and antioxidant enzyme activities in healthy human aging. Mech Aging Development 1992;66:213-222.

47. Niwa $\mathrm{Y}$, Ishimoto $\mathrm{K}$, Kanoh $\mathrm{T}$. Induction of superoxide dismutase in leukocytes by paraquat: correlation with age and possible predictor longivity. Blood 1990;76:835-841.

48. Weindruch R, Albanes D, Kritchevsky D. The rolc of calories and caloric restriction in carcinogenesis. Hematol Oncol Clin North Am 1991;5:79-89.

49. Djuric Z, Lu MH, Lewis SM, Luongo DA, Chen XW, Heilbrun LK, Reading BA, Duffy PH, Hart RW. Oxidative DNA damage levels in rats fed low-fat, high-fat, or caloric restricted diets. Toxicol Appl Pharmacol 1992;115:156-160. 
50. Chung MH, Kasai H, Nishimura S, Yu BP. Protection of DNA damage by dietary restriction. Free Radical Biol Med 1992;12:523-525.

51. Srivasstava V, Tilley R, Miller S, Hart R, Busbee D. Effects of aging and dietary restriction on DNA polymerases: gene expression, enzyme fidelity, and DNA excision repair. Exp Gerontol 1992;27:593613.

52. Loft S, Vistisen K, Ewertz M, Tjönneland A, Overvad K, Poulsen HE. Oxidative DNA damage estimated by 8-hydroxydeoxyguanosine excretion in humans: influence of smoking, gender and body mass index. Carcinogenesis 1992;13:2241-2247.

53. Weindruch R. Effect of caloric restriction on age-associated cancers. Exp Gerontol 1992;27:575-581.

54. Everitt A, Meites J. Minireview: aging and anti-aging effects of hormones. J Gerontol 1989;44:B139B147.

55. Meites J. Neuroendocrine basis of aging. Eur J Cell Biol 1987;44 suppl 20:24-25 abstr 50 .

56. Nakashima $Y$, Esashi T. Age-related changes in sympathetic nervous activity of rats receiving vitamin E-deficient diet. J Nutr Sci Vitaminol 1986;32:569-579.

57. Mazzeo RS, Colburn RW, Horvath SM. Effect of aging and endurance training in tissue catechlamine response to strenuous exercis in Fischer 344 rats. Metabolism 1986;35:602-607.

58. Lakatta EG. Catecholamines and cardiovascular function in aging. In: Sacktor B, ed. Edocrinology and metabolism of clinics of North America, endocrinology and aging. 1987; 16:877-891.

59. Fleg JL, Tzankoff $P$, Lakatta EG. Age related augmentation of plasma catccholemincs during dynamic cxercise in healthy males. J Appl Physiol 1985;59:1033-1039.

60. O'Dea K, Esler M, Leonard P, Stockigt JR, Nestel P. Noradrenaline turnover during under- and overeating in normal weight subjects. Metabolism 1982;31:896-899.

61. Landsberg L, Young JB. The role of the sympathetic nervous system and catecholamines in the regulation of energy metabolism. Am J Clin Nutr 1983;38:1018-1024.

62. Guyton AC. Textbook of medical physiology. WB Saunders Company, Philadelphia, 1986.

63. Sawin CT, Decpak C, Fereidoun A, Mannix JE, Bacharach P. The aging thyroid, increased prevelance of elevated serum thyrotropin levels in the clderly. JAMA 1979;242:247-250.

64. Rosenthal MJ, Hunt WC, Garry PJ, Goodwin JS. Thyroid failure in the clderly, microsomal antibodies as discriminant for therapy. JAMA 1987;258:209-213.

65. Hotta $\mathrm{H}$, Ooka $\mathrm{H}$, Sato A. Changes in basal secretion of thyroxine and 3,3',5-triiodothyronine from the thyroid gland during aging of the rat. Jap J Physiol 1991;41:75-84.

66. Katzeff HL, Selgrad C. Maintenance of thyroid hormone production during cxercise-induced weight loss. Am J Physiol 1991;261:E382-E388.

67. Quigley K, Goya R, Nachreiner R, Meites J. Effects of underfecding and refeeding on GH and thyroid hormone secretion in young, middle-aged and old rats. Exp Gerontol 1990;25:447-457.

68. Herlihy JY, Stacy C, Bertrand HA. Long-term food restriction depresses serum thyroid hormone concentrations in the rat. Mech Aging Development 1990;53:9-16.

69. Katzeff HL, Yang MU, Presta E, Leibel RL, Hirsch J, Van Itallic TB. Caloric restriction and iopanoic efects on thyroid hormone metabolism. Am J Clin Nutr 1990;52:263-266.

70. Palmblad J, Levi L, Burger A, Melander A, Westgren U, von Schenck H, Skude G. Effects of total energy withdrawal (fasting) on the levels of growth hormone, thyrotropin, cortisol, adrenaline, noradrenaline, T4, T3 and rT3 in healthy males. Acta Med Scand 1977;201:15-22.

71. Stokkan KA, Reiter RJ, Vaughan MK, Nonaka KO, Lerchl A. Endocrine and metabolic effects of lifelong food restriction in rats. Acta Endocrinol 1991;125:93-100.

72. Meites J, Goya R, Takahashi S. Why the neuroendocrine system is important in aging processes. Exp Gerontol 1987;22:1-15.

73. Steger RW, Pelusso JJ. Sex hormones in the aging femalc. Endocrinol Metab Clin 1987;16:10271043.

74. Blackman MR. Pituitary hormones and aging. Endocrinol Metab Clin 1987;16:981-993.

75. Campbell GA, Kurcz M, Marshall S, Meites J. Effects of starvation on scrum Icvels of follicle stimulating hormone, luteinizing hormone, thyrotropin, growth hormone and prolactin; response to LH-releasing hormone and thyrotropin relcasing hormonc. Endocrinology 1977;100:580-587.

76. Sapolsky RM, Krey LC, McEwen BS. The neuroendocrinology of stress and aging: the glucocorticoid 
cascade hypothesis. Endocrine Rev 1986;7:284-301.

77. van Eekelen JAM, Rots NY, Sutanto W, de Kloet ER. The effect of aging on stress responsiveness and central corticosteroid receptors in the Brown-Norway rat. Neurobiol Aging 1992;13:159-170.

78. Sabatino F, Masoro EJ, McMahan CA, Kuhn RW. Assessment of the role of the glucocorticoid system in aging process and in the action of food restriction. J Gerontol 1991;46:B171-B179.

79. Ivy JL, Craig BW, Kohrt WM, Holloszy JO. Ageing, exercise and food restriction: effects on skeletal muscle glucose uptake. Mech Aging Development 1991;61:123-133.

80. Anonymous. Insulin resistance in the elderly. Nutr Rev 1991;49:257-258.

81. Gumbiner B, Thorburn AW, Ditzler TM, Bulacan F, Henry RR. Role of impaired intracellular glucose metabolism in the insulin resistance in aging. Metabolism 1992;41:1115-1121.

82. Castro M, Pedrosa D, Osuna JI. Effect of a restricted diet on the in vitro glucose-induced insulin release of aging rats. Experientia 1992;48:996-998.

83. Ruhe RC, Curry DL, Herrmann S, McDonald RB. Age and gender effects on insulin secretion and glucose sensitivity of the endocrine pancreas. Am J Physiol 1992;262:R671-R676.

84. Kalant N, Steward J, Kaplan R. Effect of diet restriction on glucose metabolism and insulin responsiveness in aging rats. Mech Aging Develop 1988;46:89-104.

85. Escriva F, Rodrigeuz C, Cacho J, Alvarez C, Portha B, Pascual-Leone AM. Glucose utilization and insulin action in adult rats submitted to prolonged food restricition. Am J Physiol 1992;263:E1-E7.

86. Chu KU, Ishizuka J, Poston GJ, Townsend CM, Greeley GH, Yu BP, Tompson JC. Change in cndocrine pancreatic function in short-term diet restriction. Nutrition 1991;7:425-429.

87. Cahill GF, Herrera MG, Morgan AP, Soeldner JS, Steinke J, Levy PL, Reichard GA, Kipnis DM. Hormone-fuel interrelationships during fasting. J Clin Inves 1966;45:1751-1769.

88. Cerami A. Hypothesis, glucose as a mediator of aging. J Am Geriat Soc 1985;33:626-634.

89. Masoro EJ, Katz MS, McMahan CA. Evidence for the glycation hypothesis of aging from the foodrestricted rodent model. J Gerontol 1989;44:B20-B22.

90. Cutler RG, Davis BJ, Ingram DK, Roth GS. Plasma concentrations of glucose, insulin and percent glycosylated hemoglobin are unaltered by food restriction in Rhesus and Squirrel monkeys. J Gerontol 1992;47:B9-B12.

91. Yu BP, Masuro EJ, McMahan CA. Nutritional influences on aging of Fischer 344 rats. I. Physical, metabolic and longevity characteristics. J Gerontol 1985;40:657-670.

92. Jen KLC. Effects of diet composition on food intake and carcass composition in rats. Physiol Behav 1988;42:551-556.

93. Oscai LB, Brown MM, Miller WC. Effect of dietary fat on food intake, growth and body composition in rats. Growth 1984;48:415-424.

94. Oscai LB, Miller WC, Arnall DA. Effect of dietary sugar and of dietary fat on food intake and body fat content of rats. Growth 1987;51:64-73.

95. Miller WC. Diet composition, encrgy intake and nutritional status in relation to obesity in men and women. Med Sci Sports Exerc 1990;23:280-284.

96. Tucker LA, Kano MJ. Dictary fat and body fat: a multivariate study of 205 adult females. Am J Clin Nutr 1992;56:616-622.

97. Lyle BJ, McMahon KE, Kreutler PA. Assessing the potential dietary impact of replacing dietary fat with other macronutrients. J Nutr 1992:122:211-216.

98. Mcla DJ. Nutritional implications of fat substitutes. J Am Diet Assoc 1992;92:472-476.

99. Lissner L, Levitsky DA, Strupp BJ, Kalkwarf HJ, Roc DA. Dietary fat and the regulation of energy intake in human subjects. Am J Clin Nutr 1987;46:886-892.

100. Stephen AM, Deneer MJ. The effect of dietary fat reduction on intake of major nutrients and fat solublc vitamins. J Can Dict Ass 1990:51:281-285.

101. Kendall A, Levitsky DA, Strupp BJ, Lissner L. Weight loss on a low-fat diet: consequence of the imprecission of the control of food intake in humans. Am J Clin Nutr 1991;53:1124-1129.

102. Mote PL. Grizzle JM, Walford RL, Spindler SR. Influence of age and caloric restriction on expression of hepatic genes for xenobiotic and oxygen metabolizing enzymes in the mouse. J Gerontol Biol Sci 1991;46:B95-B100.

103. Koizumi A. Weindruch R. Walford RL. Influences of dictary restriction and age on liver enzyme 
activities and lipid peroxidation in mice. J Nutr 1987;117:361-367.

104. Pieri C, Fascala M, Marcheselli F, Moroni F, Recchioni R, Marmocci F, Lupidi G. Food restriction in female Wistar rats: V. lipid peroxidation and antioxidant enzymes in the liver. Arch Gerontol Geriatr 1992;14:93-99.

105. Chen LH, Snyder DL. Effects of age, dietary restriction and germ-free environment on glutathionerelated enzymens in Lobund-Wistar rats. Arch Gerontol Geriatr 1992;14:17-26.

106. Yu BP, Lee DW, Marler CG, Choi JH. Mechanism of food restriction: protection of cellular homeostasis. Proc Soc Exp Biol Med 1990;193:13-15.

107. Yu BP, Kim JW. Characterization of age-related malondialdehyde oxidation: the effect of modulation by food restriction. Mech Aging Development 1989;50:277-287.

108. Rodriguez F, Jolin T. The role of somatostatin and/or dopamine an basal and TRH-stimulated TSH release in food-restricted rats. Acta Endocrinol 1991;125:186-191.

109. Marine N, Hershman JM, Maxwell MH, Dornfeld L.P, Schroth P. Dietary restriction on scrum thyroid hormone levels. Am J Med Sci 1991;301:310-313.

110. Breese $C R$, Ingram RL, Sonntag WE. Influence of age and long term dietary restriction on plasma insulin-like growth factor-1 (IGF-1), IGF-1 gene expression, and IGF-1 binding proteins. J Gerontol 1991;46:B180-B187.

111. Spindler SR, Grizzle JM, Walford RL, Mote PL. Aging and restriction of dictary calories increases insulin receptor $m R N A$, and aging increases glucocorticoid receptor $m R N A$ in the liver of female C3B10RF1 mice. J Gerontol 1991;46:B233-B237.

112. Snyder DL, Towne B. The effect of dietary restriction on serum hormone and blood chemistry changes in aging lobund-wistar rats. In: Snyder DL (ed). Dietary restriction and aging. New York, Alan R. Liss, Inc., 1989:135-146.

113. Atterwil CK, Brown CG, Conybeare G, Holland CW, Jones CA. Relation between dopaminergic control of pituitary lactotroph function and decelcration of agc-related changes in serum prolactin of diet-restricted rats. Fd Chem Tox 1989;27:97-103.

114. Koizumi A, Tsukada M, Masuda H, Kamiyama S, Walford RL. Specific inhibition of pituitary prolactin production by energy restriction in $\mathrm{C} 3 \mathrm{H} / \mathrm{SHN}$ female mice. Mech Aging Development 1992;64:21-35. 


\section{Outline of the thesis}

The studies described in this thesis proceed from the phenomenon, described first by McCay et al., ${ }^{1}$ that restriction of the energy intake, while maintaining the intake of adequate amounts of essential nutrients, can retard ageing and extend life span in rodents. Moreover, diseases associated with ageing are retarded in their onset by energy restriction (ER). Initially, ER was started soon after weaning, but appeared also to be effective when introduced to adult animals. ${ }^{2}$ Without question, ER is an important tool of the experimental gerontologist for studying the ageing process. However, little is known regarding its applicability as an intervention with respect to human ageing. Weindruch and Walford ${ }^{3}$ state that they feel that this dietary regimen would be effective in humans, but they also discuss potential dangers and disadvantages. Stimulated by the ideas of Weindruch and Walford and their suggestions for a dietary regimen of 'undernutrition without malnutrition' the potential application of energy restriction in man has been studied.

In the first chapter the literature describing the effects of ER on three physiological processes related to ageing, i.e. adaptation of energy metabolism, free radical reactions and antioxidative capacity, and modulation of the endocrine system, have been summarized. From this review the following conclusions were drawn:

- In both animals and man severe energy restriction lowers the resting metabolic rate (RMR), expressed in absolute terms. Long-term energy restriction, for example in undernourished labourers and anorexia nervosa patients, decreases the activity of metabolic tissue and probably increases metabolic efficiency, since in these studies RMR expressed per $\mathrm{kg}$ fat-free mass was found to be reduced.

- In animals, a decrease in the activity of free radical scavenging enzymes with increasing age has been found. ER, however, seems to maintain and/or improve protection against free radical damage in these animals, which may play a role in the life-prolonging effect. Unfortunately, data on the effects of ageing and ER on damage due to free radicals or free radical scavenging capacity in man are absent.

- Ageing affects the hormonal system in both animals and man which is manifested in dysfunction of the sympathetic nervous system, decreased T4 concentrations, decreased secretion of gonadotropic hormones, and decreased glucose tolerance. This can be a result of 'wear and tear' with advancing age. ER prevents the decrease in 
T4, testosterone and $\mathrm{LH}$ which provides evidence for the hypothesis that ER maintains the functional integrity of the neuroendocrine system.

Although there certainly are quantitative differences in metabolism between animals and man, the effects of ER, with regard to the three physiological processes mentioned in Chapter 1, described in both animals and man did not seem to differ between these species. Based on this knowledge one can argue that ER might have an anti-ageing effect in man as well. Therefore, there is a challenge in learning how ER retards ageing and in finding out the relevance for man. However, the life-long animal studies are hard, if not impossible, to mimic in interventions with humans. Therefore, this project was started with a 10 -week intervention study in order to investigate the applicability as well as potential health benefits or risks of a moderately energy restricted diet, aimed at $20 \%$ ER. The results of this study, performed in 24 healthy non-obese middle-aged men, are described in the next five chapters. In Chapter 3 the effects on 'general health' parameters such as lipid profile, blood pressure as well as physical and mental performance are presented. The effects on physical performance are further elaborated in Chapter 4. Chapter 5 describes to which extent energy metabolism and body composition are affected by the imposed level of energy restriction. The effects on fibrinolytic factors are reported in Chapter 6.

Since the beneficial effects of ER on the ageing process might proceed by lowering the production rate of free radicals (probably secondary to a lower metabolic rate) and/or by the maintenance of (or enhancing) effective scavenging capacity of free radicals the effects on the primary antioxidant defence system (antioxidant enzymes as well as antioxidant vitamins), oxidative damage and on markers of genotoxicity were also investigated in order to compare the effects of short-term ER in man with the effects observed in animals (Chapter 7).

This first study was performed under strictly dietary controlled conditions and does not provide information about the feasibility to reduce the energy intake under 'free living' conditions. Therefore, a second study was executed under 'free living conditions' in which the potential of reduced-fat products to reduce the energy intake was investigated. This study was part of a multi-centre study, the MSFAT-study (i.e. Multicentre Study on FAT reduction), on the health effects of consumption of reduced fat products. The control and reduced-fat products were provided through a realistic shop in order to mimic a 'free living' situation.

The design of this 6 month parallel comparison trial has been described extensively in Chapter 8. In the MSFAT-study the same parameters as in the first study were 
measured. The effects on fibrinolysis and glucose tolerance are presented in Chapter 9. Since both energy restriction as well as dietary fat intake might affect the antioxidative capacity, again, parameters that reflect the antioxidant/prooxidant balance were measured, the results of which are reported in Chapter 10.

To summarize, the studies described in this thesis are performed in order to answer the following questions:

- What is the potential of implementation of an ER-diet tenable for the longer term?

- what level of ER will be appropriate for the long term?

- how can an ER-diet, acceptable for the long term, be achieved in man?

- Does ER result in health benefits and/or health risks?

- Does short-term ER affect the antioxidant/prooxidant balance, a potential underlying mechanism of the beneficial effects of ER, in man?

Finally, in Chapter 11 the results presented in these thesis are discussed in view of these questions.

\section{REFERENCES}

1. McCay CM, Crowel MF, Maynard LA. The effect of retarded growth upon the length of life span and upon the ultimate body size. J Nutr 1935;10:63-79.

2. Yu BP, Masoro EJ, McMahan CA. Nutritional influences on aging of Fischer 344 rats. I. Physical, metabolic and longevity characteristics. J Gerontol 1985;40:657-670.

3. Weindruch R, Walford RL. The retardation of aging and disease by dictary restriction. Charles $\mathrm{C}$. Thomas Publisher, Springfield Illinois, USA, 1988. 


\title{
Energy restriction, a useful intervention to retard human ageing? Results of a feasibility study
}

\author{
Erica J.M. Velthuis-te Wierik ${ }^{1}$, Henk van den Berg ${ }^{1}$, Gertjan Schaafsma ${ }^{1}$, \\ Henk F.J. Hendriks ${ }^{2}$ and Adriaan Brouwer ${ }^{2}$ \\ ${ }^{1}$ TNO Nutrition and Food Research Institute, Zeist, The Netherlands \\ ${ }^{2}$ TNO Institute of Agcing and Vascular Research, Leiden, The Netherlands
}

European Journal of Clinical Nutrition 1994; 48: 138-148

\begin{abstract}
Energy restriction (ER) retards the ageing process in animal models. It is possible that ER has a similar effect in humans. As a first approach to look after the potential application of ER in man the feasibility of a moderately energy-restricted diet was studied. 24 middle-aged non-obese men, selected from men responding to advertisements in regional newspapers, participated in the study. After a run-in period subjects were divided into two groups, a control group $(n=8)$ and an ER group $(n=16)$. Groups were matched on age and body mass index. The effects of 10 weeks of moderate ER ( $80 \%$ of habitual energy intake) on body composition, general health (blood pressure, lipid profile, routine clinical chemistry and haematology), physical and mental performance, and feelings of hunger, satiety and state of mind were measured. Subjects in the ER group lost about $7.4 \pm 2.6 \mathrm{~kg}$ weight $(\mathrm{P}<0.001)$. This weight loss concerned mainly loss of fat mass. Diastolic and systolic blood pressure decreased significantly within the ER group $(\mathrm{P}<0.05$ and $\mathrm{P}<0.01$ respectively). The increase in HDL-cholesterol level was significantly related to weight loss $(P<0.05)$. These results show beneficial effects of 10 weeks of moderate ER on blood pressure and lipid profile without adverse effects on physical and mental performance and feelings of hunger, satiety and mood.
\end{abstract}




\section{INTRODUCTION}

McCay et al. ${ }^{1}$ were in 1935 the first to find that the restriction of energy intake, with adequate administration of essential nutrients, can retard ageing and extend life span in rats. Since then, this finding has been confirmed and extended in a great variety of animal species such as rats, flies, mice and fish (for reviews $s^{2.3}$ ). Moreover, it appeared that energy restriction (ER) not only extends life span but also prevents or delays the onset of many age-related diseases. ${ }^{3}$

Since ageing is a general biological phenomenon it is likely that energy restriction has similar effects in man. Most human studies on energy restriction deal with involuntary situations of energy restriction and malnutrition of essential nutrients (e.g. war), with fasting or with very low caloric diets in obese men or women. ${ }^{3-5}$ From these studies one cannot conclude whether moderate energy restriction is beneficial for non-obese human beings. An important aspect of extrapolating results of animal studies to the human situation is the uncertainty about the acceptability of long-term voluntary energy restriction by humans, as well as the uncertainty about undesirable side effects.

It is hard, if not impossible, to simulate life-long animal studies on energy restriction in human studies. However, as a first approach at least two aspects can be studied in man: 1) acceptability and feasibility; feelings of hunger and satiety, effects on general health, physical and mental performance and 2) comparison of the results of short-term ER in man with short- and long-term animal studies.

It is difficult to assess the level of energy restriction in man. In their semistarvation study, Keys et al. ${ }^{6}$ showed that 50\% ER led to decreased performance which is not acceptable for the long term. According to Apfelbaum, ${ }^{7}$ it is likely that adult men can adapt over time at a reduced body weight to about $7,537 \mathrm{~kJ}(1,800 \mathrm{kcal}) /$ day, without continuous weight loss. Ross ${ }^{8}$ observed in his animal studies that severe energy restriction at older age leads to a decreased life expectancy. However, the lifespan of older rats could be extended by a less severe regime of energy restriction. Thus, the age-dependend safe level of energy restriction in man can only be surmised.

Because of the anti-ageing effects of energy restriction and because of the lack of knowledge about the effects of moderate energy restriction we performed an experiment in which 24 non-obese healthy middle-aged men volunteered to use a moderately energyrestricted diet $(80 \%$ of habitual intake). As a first step to explore the applicability and feasibility of moderate ER in humans, we assessed the effects on general health, physical and mental performance, feelings of hunger, satiety, and state of mind. 


\section{SUBJECTS AND METHODS}

\section{$\underline{\text { Subjects }}$}

Twenty-four apparently healthy middle-aged men (mean $42.9 \mathrm{yr}$; range $35-50 \mathrm{yr}$ ) selected from men responding to advertisements in regional newspapers, participated in this study. Subjects who had a normal body mass index (BMI) (mean 24.6; range 20.6-27.2), did not take medications, did not smoke, and drank less than four alcoholic drinks per day were included in the study. Each subject was medically screened by a physician. Routine clinical chemistry, ECG, blood pressure and lipid profile had to be within normal ranges. Subjects who reported to have an extremely high or low energy intake $(<9,300$ and $>13,200 \mathrm{~kJ} /$ day $)$ were excluded from the study. The study protocol was approved by the Institute's Medical Ethical Commitee and the participants signed an informed consent form. After completing the study the subjects received a suitable reimbursement.

\section{Study design}

Before the experiment started the participants' habitual energy intake was estimated by means of a 7-day dietary record method. Each participant was visited at home by a qualified dietitian, who presented and explained this method. The subjects were instructed to record all foods and drinks consumed and to continue their habitual lifestyle and consumption pattern. During these 7 record days the dietitian contacted them once by telephone to check whether there were any questions. After the 7-day period subjects were visited again by the dietitian to scrutinize the records so that questions as to quantity or vague descriptions could be resolved. Subjects were asked to weigh themselves every morning in underwear before breakfast and to record their weight to check for weight maintenance.

During the first two weeks of the experiment (run-in period) all subjects received a weight-maintaining test diet based upon the outcome of the 7-day dietary records. Since energy intake varied among individuals the subjects were divided into six 'energy groups' with different levels of energy intake, ranging from 9,304 to 13,147 $\mathrm{kJ}$ (stepwise increase by ca. $770 \mathrm{~kJ}$ ). When subjects lost weight during this run-in period they were reassigned to a higher energy group.

After these two weeks the subjects were divided by lot into two groups: a control group (8 subjects) and an energy-restricted group (ER group; 16 subjects). These groups were matched on age and BMI. During the next 10 weeks the 8 control subjects were kept on their weight-maintaining diet, while the other 16 subjects received a test diet that contained $80 \%$ of the energy of their habitual (weight-maintaining) diet, and micronutrient levels approaching Recommended Dietary Allowances (RDAs). The 20\% energy restriction was achieved by substituting low-fat margarine for margarine, light soft drink for soft drink, artificial sweetener for sugar, low-fat coffee cream for coffee cream, salad dressing for 
mayonnaise, and skimmed yoghurt for whole yoghurt. In this way the intake of fat and carbohydrates was reduced while the intake of protein was maintained. This implied that the relative contribution of carbohydrates and fat to energy intake slightly reduced while that of protein increased. An example of a weight-maintaining test diet and an energyrestricted test diet is presented in Table 3.1.

The total experiment lasted 12 weeks. During the experiment the subjects visited the institute every evening to have dinner and to receive their food for the next 24 hours. The subjects were not allowed to eat or drink anything but the food they received (except water).

Measurements of weight, feelings of hunger and satiety and mood were recorded every week before dinner. Mental performance was measured every other week before dinner. Body composition, blood pressure and physical performance were measured at the end of the run-in period and at the end of the experiment. At the end of the run-in period and at the end of the experiment blood samples were taken for routine clinical chemistry, lipid profile and haematology analysis. The study design is schematically presented in Figure 3.1.

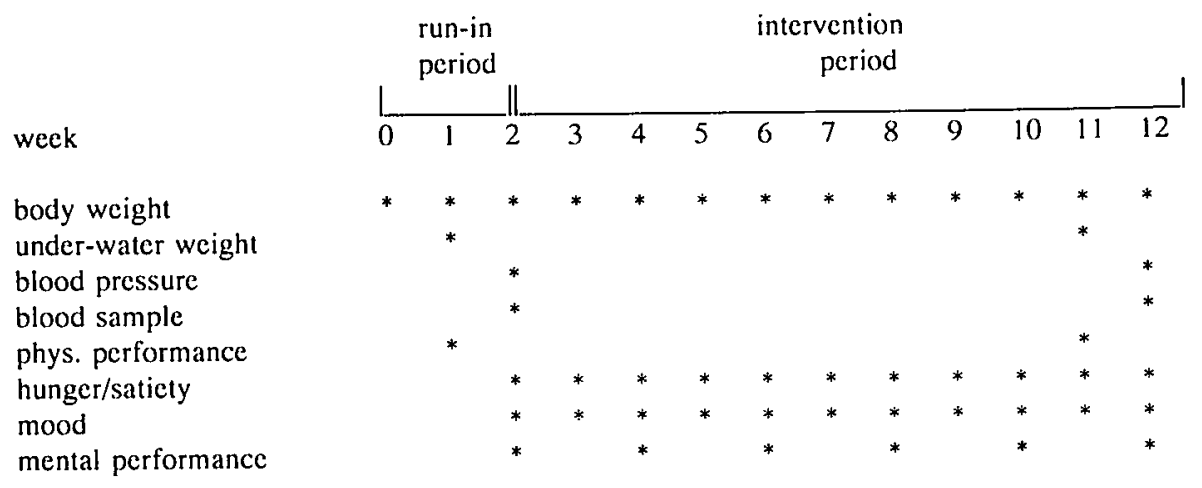

Figure 3.1. Study design

\section{Materials and Methods}

Body composition. The subjects were weighed in underwear every week (Berkel, Ridderkerk, The Netherlands) before dinner. Body composition was computed from measurements of body density using the hydrostatic weighing technique of Brozek et al." Underwater weight was determined with a balance (Berkel, Ridderkerk, The Netherlands) and residual lung volumes were determined by helium dilution and a spirometer (Volutest, Mijnhardt, Bunnik, The Netherlands).

Blood pressure. Blood pressure was measured in supine position by means of a oscillometric method using a digital blood pressure monitor (Omron, Tokyo, Japan) after the subject had laid down for 15 minutes. 
Table 3.1. Example of a weight-maintaining test diet and an energy restricted test diet. ${ }^{a}$

\begin{tabular}{|c|c|c|}
\hline & Weight-maintaining & Energy Restricted \\
\hline Breakfast & $\begin{array}{l}1 \text { slice of brown bread } \\
5 \mathrm{~g} \text { margarine } \\
20 \mathrm{~g} \text { checse, full-cream }\end{array}$ & $\begin{array}{l}1 \text { slice of brown bread } \\
5 \mathrm{~g} \text { low-fat margarine } \\
20 \mathrm{~g} \text { cheese, full-cream }\end{array}$ \\
\hline Lunch & $\begin{array}{l}3 \text { slices of brown bread } \\
15 \mathrm{~g} \text { margarine } \\
2 \text { slices of lunchcon meat }(30 \mathrm{~g}) \\
1 \text { slice of saveloy }(15 \mathrm{~g}) \\
\text { orangc or applc }\end{array}$ & $\begin{array}{l}3 \text { slices of brown bread } \\
15 \mathrm{~g} \text { low-fat margarine } \\
2 \text { slices of luncheon meat }(30 \mathrm{~g}) \\
1 \text { slice of saveloy }(15 \mathrm{~g}) \\
\text { orange or apple }\end{array}$ \\
\hline Snacks & $\begin{array}{l}1 \text { slice of Dutch honey cake } \\
20 \mathrm{~g} \text { cake } \\
250 \mathrm{ml} \text { soft drink } \\
200 \mathrm{ml} \text { orange juice } \\
2 \text { cups of tea } \\
3 \text { cups of coffee } \\
30 \mathrm{~g} \text { sugar } \\
27 \mathrm{~g} \text { coffee cream } \\
1 / 2 \text { liter low-fat milk }\end{array}$ & $\begin{array}{l}\text { 1 slice of Dutch honey cake } \\
20 \mathrm{~g} \text { cake } \\
250 \mathrm{ml} \text { soft drink, 'light' } \\
200 \mathrm{ml} \text { orange juice } \\
2 \text { cups of tca } \\
3 \text { cups of coffec } \\
30 \mathrm{~g} \text { artificial sweetener } \\
22.5 \mathrm{~g} \text { low fat coffee cream } \\
1 / 2 \text { liter low-fat milk }\end{array}$ \\
\hline Dinner & $\begin{array}{l}100 \mathrm{~g} \text { minced meat } \\
100 \mathrm{~g} \text { paprika sauce } \\
125 \mathrm{~g} \text { beans } \\
125 \mathrm{~g} \text { potatoes } \\
75 \mathrm{~g} \text { uncooked vegetables } \\
15 \mathrm{~g} \text { mayonnaise } \\
150 \mathrm{~g} \text { whole yoghurt with fruit }\end{array}$ & $\begin{array}{l}100 \mathrm{~g} \text { minced meat } \\
100 \mathrm{~g} \text { paprika sauce } \\
125 \mathrm{~g} \text { bcans } \\
125 \mathrm{~g} \text { potatocs } \\
75 \mathrm{~g} \text { uncooked vegetables } \\
15 \mathrm{~g} \text { salad dressing, } 25 \% \text { oil } \\
150 \mathrm{~g} \text { skimmed yoghurt with fruit }\end{array}$ \\
\hline $\begin{array}{l}\text { Total encrgy } \\
\text { Fat } \\
\text { Carbohydrates } \\
\text { Proteins }\end{array}$ & $\begin{array}{l}9,304 \mathrm{~kJ} \\
37 \% \text { of total energy } \\
51 \% \text { of total energy } \\
13 \% \text { of total energy }\end{array}$ & $\begin{array}{l}7,511 \mathrm{~kJ} \\
37 \% \text { of total energy } \\
48 \% \text { of total energy } \\
17 \% \text { of total energy }\end{array}$ \\
\hline
\end{tabular}

Differences between the two groups are indicated in bold.

" Encrgy and macronutrient contents were calculated with the computerized Netherlands food composition table (UCV/NEVO). 
Blood analysis. Blood was drawn from an antecubital vein after an overnight fast. For the analysis of lipid profile (triglycerides, total cholesterol, HDL-cholesterol, LDLcholesterol) commercially available kits were used (Boehringer Mannheim Diagnostica, Amsterdam, The Netherlands; Hitachi 911, Japan). HDL-cholesterol was measured in the supernatant fraction after LDL-cholesterol precipitation. Routine clinical chemistry (urea, creatinine, uric acid, total protein, ALAT, ASAT, GGT, albumin, alkaline phosphatase) was performed with a Hitachi 911, Japan (Boehringer Mannheim Diagnostica, Amsterdam, The Netherlands). Haemoglobin concentration and haematocrit were determined by using a semiautomatic computer-equipped haematology analyser (Sysmex K1000, Japan; DA1000, Japan).

Physical performance. Physical performance was measured by means of an electromagnetically braked bicycle ergometer (HL-600R, Lode BV, Groningen, The Netherlands). The subjects were encouraged to keep on cycling until exhaustion while work load was increased every three minutes according to the supramaximal $12 \mathrm{~min}$ test described by Åstrand and Rodahl. ${ }^{10}$ Maximum oxygen uptake ( $\dot{\mathrm{VO}}_{2}$-max) was measured using an Oxycon-4 (Mijnhardt, Bunnik, The Netherlands) in order to establish aerobic capacity. A blood sample for the determination of lactate was taken five minutes after cessation of the test (Boehringer Mannheim Diagnostica, Amsterdam, The Netherlands).

Hunger and satiety. For estimating the subjective hunger and satiety feelings, every week before dinner, five so-called visual-analogous scales were used. These scales consist of horizontal lines with a length of $15 \mathrm{~cm}$, the left and right ends marked with the terms weak and strong. The subjects were asked to express their feelings at that moment about 1) having appetite for a meal, 2) having appetite for something sweet, 3) having appetite for a snack, 4) satiety and 5) faint with hunger, by making a vertical mark on the scale. The length between the left end of the scale and the vertical mark made by the subject served as the parameter used in the analysis.

State of mind (mood). The mood of the subjects was measured every week before dinner using a shortened Dutch version of the 'Profile of Mood States' questionnaire." This questionnaire consists of 32 items measuring five dimensions: 'Depression', 'Anger', 'Fatigue', 'Vigor' and 'Tension'. For every item in the questionnaire the subjects had to mark to what extent the item was applicable to his feelings (not at all, a little, somewhat, rather, very much).

Mental performance. For the measurement of mental performance a Taskomat test station was used (IZF-TNO, Soesterberg, The Netherlands ${ }^{12}$ ). The subjects had to perform a tracking task and a continuous memory task at the same moment. The task lasted $61 / 2$ minutes. The track was a sawtooth pattern moving upward on the screen. The subjects controlled a little gate by means of a joystick and had to keep the gate centered on the line. The distance between the center of the gate and the track was recorded at $32.6 \mathrm{~s}$. intervals. 
The mean standard deviation of the distances of each run was used in the analysis. During the tracking task the continuous memory task was also performed. Every $2.7 \mathrm{~s}$. a letter appeared above the gate of the tracking task. The subjects were instructed to react by pushing a button as soon as an A, B, C, or D (targets) appeared above the gate. The subjects were told to refrain from reacting when any other letter appeared. During this test run 107 letters appeared including 21 targets. The number of hits (a), correct rejections (d), false alarms (b) and misses (c) were recorded. From these data the accuracy of target detection or 'index of discrimination' was calculated, formulated as $d^{\prime}$ ' $=\ln \left(\left(a^{*} d\right) /\left(b^{*} c\right)\right) .^{13}$ To prevent undefined cases of $\mathrm{d}$ ', data with a value equal to zero were reset to 0.5 . This means that $d^{\prime}=8.90$ when no mistakes were made and $d^{\prime}=8.17$ when one mistake was made. For hits, reaction time was also recorded. Repeated performance on a test leads to an improvement of the score. To avoid bias introduced by a learning effect the subject had a pre-experiment practice during which both the tracking task and the continuous memory task were performed until a plateau value was reached.

\section{$\underline{\text { Statistics }}$}

From most parameters (body weight, blood pressure, physical performance, lipid profile, haematology) data were collected at the beginning and at the end of the experimental period. Changes within groups were tested for significance with the paired Student's t-test, and differences in changes between the two groups were tested using the unpaired Student's t-test.

Since measurements of hunger and satiety, the profile of mood states, and mental performance were done repeatedly during the whole experiment, regression lines of the data for each subject were calculated. Differences in slopes of these regression lines between the two groups were tested with the unpaired Student's t-test.

Because all participants in this study lost weight during the experiment, Pearson's linear correlations were calculated between weight changes (as an indirect measure for the severity of ER) and changes in parameters analysed. These correlations are presented in Table 3.4.

BMDP statistical software was used to detect significantly different changes within and between the two groups, and to calculate correlations between parameters.

\section{RESULTS}

Body composition. Results for body composition, blood pressure and physical performance are presented in Table 3.2a. Both the control and the ER group lost weight. As expected, weight loss in in the ER group was substantial (Figure 3.2). Since weight loss is a 
predictible result of energy restriction, this result shows that the subjects complied with our study. Weight loss and decrease in BMI in both groups appeared to be attributable almost entirely to a loss of body fat.

Blood pressure. Diastolic and systolic blood pressure decreased significantly during the experiment in the ER group. The decrease in blood pressure in the ER group was not significantly greater than the nonsignificant decrease in the control group. Heart rate at rest did not change significantly in either group.

Physical performance. During the maximal physical exercise test the control group reached a longer cycling time and a higher maximal power output after the experiment than before, whereas both parameters decreased within the ER group. Within the groups these changes were not significant (except cycling time in the control group). However, changes between the groups were significantly different. $\mathrm{VO}_{2}$-max decreased in the ER group, but did not change significantly in the control group. $\dot{V}$ - $\max$, maximum pulmonary ventilation, did not change during the experiment. Blood lactate concentration 5 minutes after cessation increased significantly in both groups and was similar in both groups.

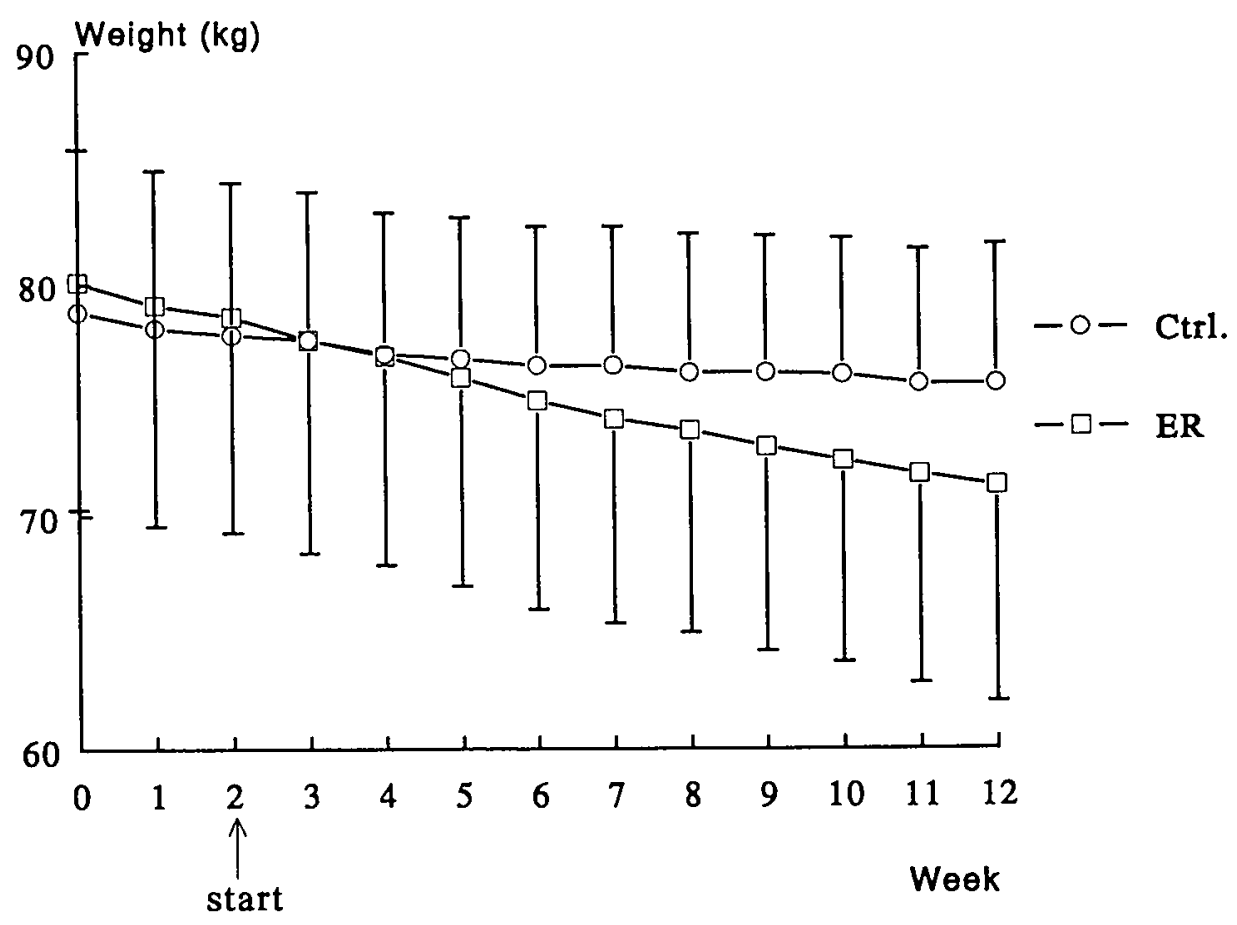

Figure 3.2. Mean body weight of the two groups during the study 
Table 3.2a. Summary of the results for body composition, blood pressure and physical performance."

\begin{tabular}{lllccc}
\hline \multicolumn{2}{c}{ Controls } & & Energy Restricted & P $\Delta$ ctrl \\
before & $\Delta$ controls & before & $\Delta \mathrm{ER}$ & vs $\Delta \mathrm{ER}$ \\
\hline
\end{tabular}

BODY COMPOSITION

$\begin{array}{llllll}\text { BMI }\left(\mathrm{kg} / \mathrm{m}^{2}\right) & 24.6 \pm 2.2 & -0.8 \pm 0.6^{* *} & 24.9 \pm 1.8 & -2.3 \pm 0.8^{* * *} & <0.001 \\ \text { body weight }(\mathrm{kg}) & 77.7 \pm 6.6 & -2.7 \pm 2.1^{* *} & 78.6 \pm 9.3 & -7.4 \pm 2.6^{* * *} & <0.001 \\ \text { fat }(\mathrm{kg}) & 18.8 \pm 6.6 & -2.3 \pm 2.0^{*} & 19.4 \pm 4.9 & -6.8 \pm 1.9^{* * *} & <0.001 \\ \text { fat frec mass }(\mathrm{kg}) & 58.7 \pm 5.6 & -0.3 \pm 0.8 & 60.0 \pm 5.7 & -0.7 \pm 1.4 & \text { NS } \\ \text { fat }(\%) & 23.7 \pm 7.2 & -2.1 \pm 2.0^{*} & 24.4 \pm 5.0 & -6.9 \pm 1.7^{* * *} & <0.001\end{array}$

BLOOD PRESSURE AND HEART RATE

$\begin{array}{lccccc}\text { systolic }(\mathrm{mmHg}) & 121 \pm 9 & -3.4 \pm 5.1 & 124 \pm 10 & -5.9 \pm 6.8^{* *} & \text { NS } \\ \text { diastolic }(\mathrm{mmHg}) & 79 \pm 8 & -1.9 \pm 3.0 & 79 \pm 8 & -4.6 \pm 6.1^{*} & \text { NS } \\ \text { heart rate (beats/min) } & 62 \pm 15 & -2.6 \pm 4.1 & 59 \pm 9 & -1.5 \pm 4.6 & \text { NS }\end{array}$

PHYSICAL PERFORMANCE

\begin{tabular}{|c|c|c|c|c|c|}
\hline$\dot{\mathrm{V}} \mathrm{O}_{2}-\max (1 / \mathrm{min})$ & $3.2 \pm 0.7$ & $0.03 \pm 0.18$ & $3.5 \pm 0.5$ & $-0.18 \pm 0.30^{*}$ & NS \\
\hline$\dot{\mathrm{V}} \mathrm{O}_{2}-\max (\mathrm{ml} / \mathrm{min} / \mathrm{kg})$ & $41.8 \pm 91$ & $1.58 \pm 2.33$ & $44.4 \pm 7.3$ & $1.46 \pm 4.41$ & NS \\
\hline$\dot{\mathrm{V}} \mathrm{O}_{2}-\mathrm{max}(\mathrm{ml} / \mathrm{min} / \mathrm{kg} \mathrm{ffm})$ & $54.3 \pm 7.6$ & $0.6 \pm 2.8$ & $58.6 \pm 7.7$ & $-2.8 \pm 5.2^{*}$ & NS \\
\hline$\dot{V} e-\max (1 / \min )$ & $103 \pm 19$ & $7.1 \pm 12.4$ & $104 \pm 19$ & $-2.7 \pm 14.1$ & NS \\
\hline cycl. time (min) & $13.5 \pm 4.7$ & $1.3 \pm 1.1^{*}$ & $12.7 \pm 2.3$ & $-0.5 \pm 1.6$ & 0.010 \\
\hline $\max$ power $(W)$ & $236 \pm 50$ & $4.3 \pm 5.9$ & $254 \pm 40$ & $-6.3 \pm 13.6$ & 0.049 \\
\hline lactate $(\mathrm{mmol} / \mathrm{l})$ & $10.2 \pm 2.9$ & $2.4 \pm 1.8^{* *}$ & $10.2 \pm 1.5$ & $1.1 \pm 1.4^{* *}$ & 0.073 \\
\hline
\end{tabular}

- mean values and standard deviations of the control group and the energy-restricted group before (after a 2-weck run-in period) and of the change after the experimental period are presented.

${ }^{*} \mathrm{P}<0.05,{ }^{* * \mathrm{P}}<0.01,{ }^{* * *} \mathrm{P}<0.001$ for changes within the group.

Blood analysis. As shown in Table 3.2b, HDL-cholesterol decreased significantly in the control group and showed a slight, nonsignificant tendency to increase in the ER group. The changes between both groups were significantly different. LDL-cholesterol level, HDL/LDL-cholesterol ratio and the HDL/total cholesterol ratio remained unchanged. The decrease in body weight was significantly related to increases in HDL-cholesterol (Figure 3.3). Haemoglobin concentrations decreased significantly and similarly in both groups. No significant changes have been observed on haematocrit. Routine clinical chemistry showed in both groups a decrease in the activity of the liver enzymes ALAT, ASAT, and GGT. Despite the stronger decreases in the ER group, the changes did not differ significantly between the two groups. Serum creatinine levels showed an increase in both groups but no differences between the groups could be observed. Uric acid decreased significantly in the ER group. 
Table 3.2b. Summary of the results of the blood analysis and routine clinical chemistry."

\begin{tabular}{lccccc}
\hline & \multicolumn{2}{c}{ Controls } & \multicolumn{2}{c}{ Energy Restricted } & P $\Delta$ ctrl \\
& before & $\Delta$ controls & before & $\Delta$ ER & vs $\Delta$ ER \\
\hline BLOOD ANALYSIS & & & & & \\
triglycerides & $1.07 \pm 0.35$ & $-0.14 \pm 0.16$ & $1.13 \pm 0.67$ & $-0.22 \pm 0.50$ & NS \\
total cholesterol & $4.88 \pm 1.03$ & $-0.15 \pm 0.33$ & $5.07 \pm 0.93$ & $-0.30 \pm 0.58$ & NS \\
HDL-cholesterol & $1.06 \pm 0.10$ & $-0.07 \pm 0.03^{* * *}$ & $1.14 \pm 0.26$ & $0.02 \pm 0.13$ & 0.028 \\
LDL-cholesterol & $3.51 \pm 1.10$ & $0.04 \pm 0.30$ & $3.54 \pm 1.00$ & $-0.08 \pm 0.51$ & NS \\
HDL/LDL-cholesterol & $0.37 \pm 0.26$ & $-0.04 \pm 0.07$ & $0.36 \pm 0.18$ & $0.00 \pm 0.06$ & NS \\
HDL/total cholesterol & $0.23 \pm 0.08$ & $-0.01 \pm 0.01$ & $0.23 \pm 0.08$ & $0.01 \pm 0.03$ & NS \\
haemoglobin & $9.90 \pm 0.15$ & $-0.38 \pm 0.36^{*}$ & $9.84 \pm 0.42$ & $-0.38 \pm 0.36^{* * *}$ & NS \\
haematocrit & $0.45 \pm 0.01$ & $-0.02 \pm 0.02$ & $0.44 \pm 0.03$ & $-0.01 \pm 0.03$ & NS \\
ROUTINE CHEMICAL CHEMISTRY & & & & \\
urea & $5.44 \pm 0.74$ & $0.14 \pm 0.83$ & $5.33 \pm 0.70$ & $0.38 \pm 1.08$ & NS \\
creatinin & $82.3 \pm 3.4$ & $4.0 \pm 3.4^{*}$ & $82.4 \pm 10.1$ & $3.1 \pm 4.7^{*}$ & NS \\
uric acid & $327 \pm 39$ & $10.3 \pm 36.6$ & $321 \pm 54$ & $-33.9 \pm 28.3^{* * *}$ & 0.004 \\
total protein & $72.9 \pm 2.8$ & $0.15 \pm 3.43$ & $73.2 \pm 3.8$ & $-0.31 \pm 2.60$ & NS \\
ALAT & $16.9 \pm 8.7$ & $-3.9 \pm 2.4^{* *}$ & $20.4 \pm 7.0$ & $-6.9 \pm 8.5^{* *}$ & NS \\
ASAT & $21.6 \pm 5.7$ & $-1.6 \pm 1.3^{* *}$ & $24.4 \pm 4.5$ & $-2.7 \pm 6.2$ & NS \\
GGT & $20.8 \pm 12.5$ & $-3.8 \pm 2.6^{* *}$ & $21.9 \pm 8.5$ & $-9.7 \pm 7.9^{* * *}$ & 0.072 \\
albumin & $51.1 \pm 2.2$ & $-1.1 \pm 2.4$ & $52.3 \pm 2.0$ & $-0.9 \pm 1.6^{*}$ & NS \\
alk. phosphatase & $60.1 \pm 18.6$ & $4.1 \pm 5.1$ & $63.7 \pm 18.8$ & $-8.8 \pm 7.0^{* * *}$ & NS \\
\hline
\end{tabular}

a mean values and standard deviations of the control group and the energy-restricted group before (after a 2-week run-in period) and of the change after the experimental period are presented.

${ }^{*} \mathrm{P}<0.05,{ }^{* *} \mathrm{P}<0.01,{ }^{* * *} \mathrm{P}<0.001$ for changes within the group.

Hunger and satiety. Changes in feelings of hunger and satiety, state of mind and mental performance are shown in Table 3.3. These changes are expressed as the mean slope of the regression line of each parameter for each group during the experiment. Subjects in the ER group showed decreasing scores on 'satiety' (i.e. feelings of satiety seemed to decrease), but no significant differences in any parameter of the hunger and satiety scores between the two groups were observed.

Mood. Slopes of the five states (depression, anger, fatigue, vigor and tension) of the Profile of Mood States were all close to zero and showed no significant differences between the two groups.

Mental performance. Data obtained from the measurements of mental performance (the tracking task and the continuous memory task) did not show any differences between the two groups. 
Table 3.3. Mean slopes and standard deviations of scores on hunger and satiety, profile of mood states, and mental performance, obtained during the experiment."

$\begin{array}{lll}\text { Controls } & \text { ER } & \text { Ctrl vs ER }\end{array}$

HUNGER AND SATIETY

Appetite for a meal

Appetitc for something sweet

$-2.21 \pm 3.14$

$-1.36 \pm 4.25$

NS

$1.16 \pm 2.26$

$1.36 \pm 3.18$

NS

Appetite for a snack

$1.17 \pm 3.64$

$0.95 \pm 3.45$

NS

Saticty

$1.90 \pm 1.98^{*}$

$-0.21 \pm 2.88$

NS

Faint with hunger

$-0.09 \pm 2.19$

$1.88 \pm 3.99$

NS

PROFILE OF MOOD STATES

Depression

Anger

Fatiguc

Vigor

Tension

MENTAL PERFORMANCE

Tracking crror

Reaction time targets

Accuracy target detection, d'

$$
\begin{array}{r}
0.00 \pm 0.04 \\
0.03 \pm 0.15 \\
0.01 \pm 0.09 \\
-0.03 \pm 0.42 \\
-0.04 \pm 0.05
\end{array}
$$

$$
\begin{aligned}
-0.08 & \pm 0.06^{* *} \\
-3.53 & \pm 4.50 \\
0.02 & \pm 0.03
\end{aligned}
$$

$$
\begin{aligned}
& -0.08 \pm 0.22 \\
& -0.06 \pm 0.33 \\
& -0.12 \pm 0.44 \\
& -0.08 \pm 0.54 \\
& -0.07 \pm 0.16
\end{aligned}
$$

NS

NS

NS

NS

NS

"A negative slope means a decrease in that parameter during the experiment; a positive slope mcans an increase in that parameter during the experiment.

${ }^{*} \mathrm{P}<0.05 ;{ }^{* *} \mathrm{P}<0.01$.

\section{DISCUSSION}

In this study we investigated the applicability and feasibility of moderate ER in man and looked after potential benefits and health risks of a moderately energy-restricted diet. We realize that a study like this has several limitations. First of all, the study lasted only 12 weeks, because in our opinion one cannot expect subjects to come to the institute every evening over a longer period of time. However, as no steady state was reached with respect to weight loss, it seems worthwhile to study the effects of moderate ER on general health on a Ionger term. Second, all the food subjects were allowed to eat was provided by the institute. So it was obvious to the subjects what to eat and thus how to eat restrictedly. It remains to be seen whether it is also possible to restrict energy intake under 'free-living' conditions. Since in this study short-term moderate ER did not affect physical and mental performance and feelings of hunger, satiety and mood, it should be feasible to restrict 
energy intake even under 'free living' conditions, although one should keep in mind that the subjects in this study were still losing weight when the study was terminated (Figure 3.2) and it was not clear when they would stabilize on a new, reduced weight. Lastly, the food provided by the institute might, with regard to macronutrient and fatty acid composition and alcohol content, differ somewhat from the subjects' habitual diet. Changes in composition of the diet affect the lipid profile. ${ }^{14.15}$ This might also have occurred during this study despite a run-in period of two weeks. During the whole experiment subjects abstained from alcohol. It is well known that this might lower liver enzymes such as ALAT, ASAT and GGT. However, the decrease in GGT was significantly correlated with the relative decrease in body weight, indicating that energy restriction has a beneficial effect on liver function.

Weindruch and Walford ${ }^{3}$ regard ER as an ethical option for human use, under appropriate conditions. Others are less enthusiastic because of concerns about harmful effects in children, ${ }^{16}$ but animal studies have shown that ER starting at early adulthood was as effective in extending maximum life span of rats as ER started soon after weaning. ${ }^{8,17,18}$ As a first step, we studied therefore the applicability of moderate ER in middle-aged men. A level of $20 \%$ ER was chosen. We regarded this a 'safe' level, well above the $50 \%$ ER reported by Keys et al. ${ }^{6}$ which resulted in undernutrition and slightly above the $7.5 \mathrm{MJ} /$ day level which, according to Apfelbaum, ${ }^{7}$ is a level people can adapt to.

An accurate measurement of habitual food intake was the basis of this study. Both the dietitian and the volunteers were aware of the importance of the dietary record and were motivated to record as accurately as possible. Despite corrections made for weight loss during the 7 dietary record days and during the run-in period, subjects in the control group lost about $2.1 \mathrm{~kg}$ during the 10 -week experimental period. This means that the energy intake recorded was below the energy expenditure. Assuming that 1 gram adipose tissue has an energy content of $29.7 \mathrm{~kJ},{ }^{19}$ a loss of $2100 \mathrm{~g}$ body fat corresponds with a shortage of $62,370 \mathrm{~kJ}$ in 10 weeks, i.e. $891 \mathrm{~kJ} /$ day (ca. $8.5 \%$ of daily intake). We think that, in spite of all precautions taken, with the 7-day dietary record habitual energy intake was underreported, a well known phenomenon in dietary studies. In an evaluation of 14 years of human dietary intervention studies Mertz et al. ${ }^{20}$ reported an underestimation of habitual intake of $18 \%$. One possible explanation is that underreporting is subconscious, motivated by the belief that maintaining a low body weight contributes to a good health and that eating less will have beneficial effects. The same phenomenon might have occurred in our study, to an extent varying from subject to subject. As a consequence, it looks plausible that some subjects have restricted their diet for more than $20 \%$.

In this study energy-restricted men lost about $7.4 \mathrm{~kg}$ weight. About $91 \%$ of this weight loss appeared to ba loss of body fat, measured by under-water weighing. Although results for body composition are dependent on the method used for assessment, ${ }^{21}$ our results 
indicate that almost no fat-free mass was lost as a consequence of moderate ER. Most other studies into ER and body composition have been performed in obese men or women given a very low- caloric diets (VLCD) over a certain period of time. In a review of 21 of such studies lasting from 2 up to 22 weeks, energy intake varied between 1,256 and 7,327 kJ/day resulting a in weight loss between 4.0 and $28.3 \mathrm{~kg}$ (mean $12.1 \mathrm{~kg}$ ) and a in loss of fat-free mass between 1.1 and $7.2 \mathrm{~kg}$ (mean $3.5 \mathrm{~kg}$ ). ${ }^{22}$ This means that ca. $25 \%$ of the reduction in weight induced by VLCD is due to a loss of fat-free mass. Our study indicates that moderate ER is more beneficial, i.e. lean body mass is conserved at the expense of fat mass.

An ER-induced decrease in blood pressure has been found in obese ${ }^{7,23}$ and in chronically undernourished labourers. ${ }^{24}$ Fasting or ER is associated with a drop in plasma norepinephrine levels, diminished excretion of catecholamine metabolites and cardiovascular signs of diminished sympathetic activity. ${ }^{25.26}$ In this study blood pressure decreased significantly in the ER group which is in agreement with the observed suppressed sympathetic activity. However, the decrease in blood pressure in the ER group did not differ significantly from that in the control group. Across all volunteers the decrease in either systolic or diastolic blood pressure did not correlate significantly with decrease in body weight. From this study and the studies mentioned one could conclude that a more pronounced effect on blood pressure only occurs at a diet more restricted than we applied.

The fact that moderate ER did not affect total cholesterol and LDL-cholesterol levels confirms to some extent the findings of Wood et al. ${ }^{27}$ who studied the effects of a one-year prudent weight-reducing diet in men with overweight. Regular dietary recommendations in group sessions extending over one year resulted in a decrease in energy intake by $27 \%$, a decreased (saturated) fat intake and a mean weight loss of $5.1 \mathrm{~kg}$. After this year no significant changes were found in plasma total cholesterol, LDL-cholesterol and HDL-cholesterol levels. As shown in Figure 3.3 and Table 3.4, the increase in HDL-cholesterol in our study correlated significantly with the decrease in body weight. A recently published meta-analysis ${ }^{28}$ led to the conclusion that weight reduction is inversely related to changes in total cholesterol, triglycerides and LDL-cholesterol. A reduced stabilized weight is associated with higher HDL-cholesterol levels, whereas in subjects actively losing weight lower HDL-cholesterol levels are observed. Since 'obesity' and 'dietreducing' were key words used in the literature search for this meta-analysis it is very likely that most of the studies found deal with very low-caloric diets. In contrast with our study, these diets have a macronutrient composition widely diverging from the habitual diet. Besides weight reduction, diet composition plays an important role in plasma lipid profile $e^{1+15}$ and may explain different outcomes on lipid profile in weight reduction studies. 
an extremely important role in physical performance. It therefore cannot be excluded that subjects in the ER group stopped cycling earlier because of their 'belief' that it was impossible to perform better because of their ER.

Scores on feelings of hunger and satiety showed a large standard deviation. Energyrestricted subjects noted a decrease in satiety feelings and an increase in 'faint with hunger', which might be expected. However, the large standard deviation might explain why we failed to find any differences between groups.

Slopes with regard to the Profile of Mood States were all close to zero indicating that the five dimensions recorded only changed slightly during the experiment. Again, a large standard deviation might have precluded significant differences between the two groups.

Table 3.4. Linear correlations of parameter changes with absolute and relative weight changes ( $n=24){ }^{\prime}$

\begin{tabular}{|c|c|c|}
\hline & $\begin{array}{l}\Delta \text { wcight } \\
\text { (absolute) }\end{array}$ & $\begin{array}{l}\Delta \text { weight } \\
\text { (relative) }\end{array}$ \\
\hline$\Delta$ body mass index & $0.933^{*}$ & $0.932^{*}$ \\
\hline$\Delta$ body fat $(\mathrm{kg})$ & $0.929^{*}$ & $0.887^{*}$ \\
\hline$\triangle$ systolic BP & 0.215 & 0.179 \\
\hline$\Delta$ diastolic BP & 0.281 & 0.241 \\
\hline$\Delta \dot{\mathrm{V}} \mathrm{O}_{2}-\max (1 / \mathrm{min})$ & 0.172 & 0.247 \\
\hline$\Delta \dot{\mathrm{V}} \mathrm{O}_{2}-\max (\mathrm{l} / \mathrm{min} / \mathrm{ffm})$ & 0.104 & 0.193 \\
\hline$\Delta$ cycling time & 0.234 & 0.247 \\
\hline$\Delta$ maximal power & 0.235 & 0.230 \\
\hline$\Delta$ lactatc & 0.158 & 0.386 \\
\hline$\triangle$ HDL-cholesterol & $-0.509^{*}$ & $-0.512^{*}$ \\
\hline$\Delta$ LDL-cholesterol & 0.122 & 0.090 \\
\hline$\triangle$ HDL/LDL cholesterol & -0.291 & -0.256 \\
\hline$\Delta$ hacmoglobin & 0.122 & 0.118 \\
\hline$\Delta$ creatinin & 0.061 & -0.006 \\
\hline$\Delta$ uric acid & $0.472 *$ & $0.419^{*}$ \\
\hline$\triangle \mathrm{ALAT}$ & 0.290 & 0.222 \\
\hline$\triangle \mathrm{ASAT}$ & 0.162 & 0.101 \\
\hline$\triangle \mathrm{GGT}$ & 0.394 & $0.405^{*}$ \\
\hline$\Delta$ albumin & 0.148 & 0.164 \\
\hline$\Delta$ alkaline phosphatase & 0.384 & $0.449^{*}$ \\
\hline$\beta_{1}$ saticty & $0.407^{*}$ & 0.395 \\
\hline$\beta$, tracking error & -0.248 & -0.143 \\
\hline$\beta_{1}$ accuracy d' & -0.077 & -0.077 \\
\hline
\end{tabular}

1 Cnly parametes showing significant changes within or between groups are listed.

* $\mathrm{P}<0.05$. 
With regard to mental performance no differences between the control and experimental group were observed on the Taskomat test station, nor did the subjects complain about being less concentrated. In the Minnesota experiment by Keys et al. ${ }^{6}$ in which 23 men were subjected to semi-starvation, subjects complained about inability to concentrate, difficulty in developing thoughts, and declining general alertness and comprehension. However, the measured intellectual performance did not change. It should be noted here that the factor of learning may have been a complication in Keys' study. In our study, to minimize the learning effect, all volunteers were trained on the test station several times before the experiment started.

The results presented here indicate that moderate ER might be a feasible intervention in terms of health risks and satiety. However, long term effects need further investigation.

Another relevant question, not adressed to in this report, is whether ER in man will have similar anti-ageing effects as in animals. Although the mechanism through which ER modulates the ageing process is unknown the (short term) changes in man induced by ER can be compared with short term effects in animals. Some provisional data of ER on the oxidative stress and the neuro-endocrine system will be reported elsewhere and are subject for further investigation.

In conclusion, 10 weeks of moderate ER leads to a significant weight loss which is mainly due to a loss of fat mass. Further, this study showed that 10 weeks of moderate ER have significant beneficial effects on blood pressure and HDL-cholesterol levels without having adverse effects on physical and mental performance, and feelings of hunger, satiety and mood.

In future research we will attempt to obviate most of the difficulties of a controlled study by studying the feasibility of a longer-term moderate energy restriction in subjects in 'free-living' conditions.

\section{ACKNOWLEDGEMENT}

The authors wish to acknowledge Mr. L.C. Boer, TNO Institute for Perception, Soesterberg, The Netherlands, for valuable assistance in performing the mental performance measurements. 


\section{REFERENCES}

1. McCay CM, Crowel MF, Maynard LA. The effect of retarded growth upon the length of the lifespan and upon the ultimate body size. J Nutr 1935;10:63-79.

2. Barrows $\mathrm{CH}$, Kokkonen GC. Dictary restriction and life extension, biological mechanisms. In: Nutritional approaches to aging rescarch, ed. GB Moment. Boca Raton, Florida: CRC Press, Inc. 1982, pp 219-243.

3. Weindruch R, Walford RL. The retardation of aging and disease by dietary restriction. Springfield Illinois, USA: Charles C. Thomas Publisher, 1988.

4. Forbes GB, Brown MR, Welle SR, Underwood LE. Hormonal response of overfeeding. Am J Clin Nutr 1988;49:608-611.

5. Poole DC, Henson LC. Effect of acute caloric restriction on work efficiency. Am J Clin Nutr 1988;47:15-18.

6. Keys A, Brozek J, Henschel A, Michelsen O, Taylor HL. The biology of human starvation, Vols 1 and 2. Minneapolis: University of Minnesota Press, 1950.

7. Apfelbaum M. Adaptation to changes in caloric intake. Prg Food Nutr Sci 1978;2:543-559.

8. Ross MH. Length of life and caloric intake. Am J Clin Nutr 1972;25:834-838.

9. Brozek J, Grande E, Anderson JT, Keys A. Densitometric analysis of body composition: revision of some quantitative assumptions. Ann NY Acad Sci 1963;110:113-140.

10. Åstrand PO, Rodahl K. Textbook of work physiology: physiological bases of exercise. Third ed. Singapore: McGraw-Hill Book Company, 1986.

11. Wald FDM, Mellenbergh GJ. Short version of the Dutch translation of the Profile of Mood States. (De verkorte versie van de Nederlandse vertaling van de Profile of Mood States (POMS)). Ned Tijdschr Psychol 1990;45:86-90.

12. Boer LC. Taskomat, The meaning of test scores. (Taskomat: de betekenis van test scores). Soesterberg: IZF-TNO, The Netherlands, 1992.

13. McNicol D. A primer of signal detection theory. London/Sydney: Allen \& Unwin, 1972.

14. Keys A. Anderson JT, Grande F. Prediction of serum cholesterol responses of man to changes in fats in the diet. Lancet 1957;1:959-966.

15. Berry EM, Eisenberg S, Haratz D, Friedlander Y, Norman Y, Kaufman NA, Stein Y. Effects of diets rich in monounsaturated fatty acids on plasma lipoproteins, the Jerusalem Nutrition Study, high MUFAs vs high PUFAs. Am J Clin Nutr 1991;53:899-907.

16. Widdowson EM. Physiological processes of aging, are there special nutritional requirements for clderly pcople? Do McCay's findings apply to humans? Am J Clin Nutr 1992;55:1246S-1249S.

17. Yu BP, Masoro EJ, McMahan CA. Nutritional influences on aging of Fischer 344 rats. I. Physical, metabolic and longevity characteristics. J Gerontol 1985;40:657-670.

18. Beauchenne RE, Bales CW, Bragg CS, Hawkins ST, Mason RL. Effect of age of initiation of food restriction on growth, body composition, and longevity of rats. J Gcrontol 1986;41:13-19.

19. Garrow JS. Energy balance and obesity in man. Amsterdam: North Holland Publishing Co, 1974.

20. Mertz W, Tsui JC, Judd JT, Reiser S, Hallfrisch J, Morris ER, Stecle PD, Lashley E. What are people rcally eating?. The relation betwcen cnergy intake derived from estimated dict records and intake to maintain body weight. Am J Clin Nutr 1991;54:291-295.

21. McNeill G, Fowler PA, Maughan RJ, McGa BA, Fuller MF, Gvozdanovic D, Gvozdanovic S. Body fat in lean and overweight women estimated by six methods. Br J Nutr 1991;65:95-103.

22. Luke A, Schoeller DA. Basal metabolic rate, fat-free mass, and body cell mass during energy restriction. Metabolism 1992;41:450-456.

23. Melby CL, Sylliaasen S, Rhodes T. Diet-induced weight loss and metabolic changes in obese women with high versus low prior weight loss/regain. Nutr Res 1991;11:971-978.

24. Shetty PS, Kurpad AV. Role of the sympathetic nervous system in adaptation to seasonal energy deficiency. Eur J Clin Nutr 1990;44:47-53.

25. Landsberg $L$, Young $j B$. Dict-induced changes in sympathetic nervous system activity. In Nutritional factors: modulating effects on metabolic processes, cds. RF Becrs, EG Bassett, New York: Raven 
Press, 1981, pp155-174.

26. Landsberg L, Young JB. The role of the sympathetic nervous system and catecholamines in the regulation of energy metabolism. Am J Clin Nutr 1983;38:1018-1024.

27. Wood PD, Stefanick ML, Williams PT, Haskell WL. The effects on plasma lipoproteins of a prudent weight-reducing diet, with or without exercise, in overweight men and women. $\mathrm{N}$ Engl J Med 1991;325:461-466.

28. Dattilo AM, Kris-Etherton PM. Effects of weight reduction on blood lipids and lipoproteins: a metaanalysis. Am J Clin Nutr 1992;56:320-328.

29. Lennmarken C, Rutberg H, Jorfeldt L, Larsson J. Effect of starvation on work capacity and voluntary skeletal muscle function in man. Clin Nutr 1990;9:231-233.

30. Grande F. Impact of food restriction on physical performance. In Predicting decrements in military performance due to inadequatc nutrition, proccedings of a workshop. Washington DC: National Acadcmy Press, 1986. 


\title{
Effects of moderate energy restriction on physical performance and substrate utilization in non-obese men
}

\author{
Erica J.M. Velthuis-te Wierik, Ludowieka V. Hoogzaad, Henk van den Berg \\ and Gertjan Schaafsma
}

TNO Nutrition and Food Research Institute, Zeist, The Netherlands

International Journal of Sports Medicine 1994; 15: 478-484

\section{ABSTRACT}

Energy restriction (ER) has shown to be an effective 'anti-ageing' factor in rodents, resulting in an increased life span and preventing or delaying the occurrence of many agerelated diseases in rodents. As a part of a feasibility study on the potential application of ER in humans, we studied the effects of moderate ER on physical performance in 24 apparently healthy, non-obese middle-aged men. After two weeks of weight maintenance the ER group $(\mathrm{n}=16)$ received $80 \%$ of their habitual energy intake, while a control group $(n=8)$ still received their weight-maintaining diet for ten weeks. Physical performance (bicycle ergometer) was estimated by a maximal (until exhaustion) and a submaximal (30 min at $60 \%$ of $\dot{\mathrm{O}}_{2}$-max) exercise test. After the experimental period the subjects in the ER group had a significantly shorter cycling time $(\Delta=1.31 \pm 1.14$ vs. $-0.45 \pm 1.56 \mathrm{~min}$, $P=0.01)$, and thus had a lower maximal power output $(\Delta=4.3 \pm 5.9$ vs. $-6.3 \pm 13.6$ Watt, $P<0.05)$ and maximal oxygen uptake $(\Delta=0.03 \pm 0.18$ vs. $-0.18 \pm 0.32 \mathrm{l} / \mathrm{min}, \mathrm{P}=0.05)$ during the maximal exercise test, than the subjects in the control group. None of these changes correlated with weight loss. As in every exercise test, motivation could have played an important role. During the submaximal exercise test no significant changes between the two groups in $\mathrm{HR}, \dot{\mathrm{VO}} \mathrm{O}_{2}, \mathrm{RER}$, and FFA, glucose, lactate and catecholamine levels were observed. It is concluded that 10 weeks of moderate ER lead to a slight but significant decrease in maximal power output, which is not related to weight loss. Moreover, no changes on submaximal physical performance and on substrate metabolism have been observed although significant alterations in body weight $(-7.4 \pm 2.6 \mathrm{~kg})$ occurred. 


\section{INTRODUCTION}

Already in 1934, McCay and Crowell' reported that restriction of the food intake in rats markedly increased longevity. Since then, numerous studies have verified the life-prolonging effect of energy restriction (ER) in various strains of animal species. ${ }^{2-5}$ In addition, ER has been observed to inhibit the development of age-related diseases, such as atherosclerosis, cardiovascular disease and various cancers. ${ }^{6}$ Although the underlying mechanism(s) of the 'anti-ageing' effect has not yet been unravelled, the effect on the antioxidant and free radical scavenging capacity, the neuroendocrine system, as well as on gene expression, have all been causally related. ${ }^{7,8}$

However, during periods of severely restricted food intake the capacity for physical performance might decrease as has been observed in the semistarvation experiment of Keys et al. ${ }^{9}$ Decreased physical performance capacity would be an undesirable effect that might complicate the applicability of moderate ER in man and should hence be prevented. Moreover, dieting is generally practiced in sports, also lean people, which might affect performance.

Only few studies have dealt with energy restriction and physical performance. The subject focused on is either 25 days and 26 weeks of semistarvation (i.e. 50\% ER), ${ }^{9,10}$ chronic undernutrition in children ${ }^{11}$ or $3.5,5$ and 1 day of fasting. ${ }^{12-14}$ To our knowledge, no earlier studies were reported on the effects of moderate ER on physical performance in the nonobese human. Therefore, as a part of the study into the feasibility of moderate energy restriction in man, we studied the effects of a 10-week $20 \%$ ER diet on physical performance parameters. Moreover, to assess metabolic adaptation during moderate energy restriction, substrate utilization during submaximal exercise was studied.

\section{MATERIALS AND METHODS}

\section{$\underline{\text { Subjects }}$}

Twenty-four apparently healthy men, aged 34-51, were selected from respondents to advertisements in regional newspapers to participate in this study which lasted 12 weeks. All subjects were nonsmoking, nonobese men (Body mass index $<27 \mathrm{~kg} / \mathrm{m}^{2}$ ), and showed a normal routine clinical chemistry. Each subject was medically screened for the required test protocol on the basis of a health questionnaire and a medical examination which included blood pressure and electrocardiographic measurements. None of the subjects participated in regular sports or fitness programs for more than $4 \mathrm{hr} / \mathrm{week}$.

The study was reviewed and approved by the Medical Ethical Committee of the TNO Toxicology and Nutrition Institute, and the subjects were provided detailed information 
about the test procedures before giving their written consent to participate.

\section{Experimental design}

Before the experiment started the habitual energy intake of the subjects was estimated by means of a 7-day dietary record. During the first two weeks of the study (run-in period) all subjects received a weight-maintaining test diet that contained the same amount ( $\pm 0.6 \mathrm{MJ} /$ day) of energy as reported in their 7-day dietary record (range: $9.3-13.2 \mathrm{MJ} /$ day).

After this run-in period, the subjects were divided into a control group $(n=8)$ and an energy-restricted group (ER group, $\mathrm{n}=16$ ). These groups were matched for age, height and initial weight (Table 1). The assignment to groups was done randomly. During the next 10 weeks the ER group consumed a restricted test diet, providing $80.0 \pm 5.1 \%$ of the energy of their test diet, while the control group continued their test diet. The $20 \%$ energy reduction was achieved by substituting low-fat and artificially sweetened products for ordinary products. The diets were composed such that the relative contribution of the carbohydrates, fat and protein to total energy intake was $51 \%, 34 \%$ and $15 \%$ and $47 \%, 36 \%$ and $17 \%$ in the control group and the ER group respectively. More details on the experimental protocol and the diets are described elsewhere (Chapter 3).

All food was provided by the Institute. The subjects consumed their dinner at the Institute every evening and then received food for the next 24 hours. The subjects were not allowed to eat or drink anything but the food supplied. Water could be taken ad libitum. Since subjects in the ER group were expected to loose weight, compliance was controlled for as much as possible by weighing the subjects every week, and by a daily questionnaire.

All subjects performed a maximal and a submaximal bicycle ergometer test during the run-in period and at the end of the intervention period, using exactly the same protocol. The submaximal exercise test was performed two weeks after the maximal exercise test. The subjects were not allowed to eat, drink coffee or to engage themselves in physical activity for a period of 2 hours prior to any exercise test in order to standardize the procedure and to avoid gastrointestinal complaints. All subjects were tested during the afternoon in the same order in any exercise test.

\section{Body composition}

Subjects were weighed every week in underwear to the nearest $0.1 \mathrm{~kg}$, before having dinner at the Institute (Berkel, ED-60-T, Ridderkerk, The Netherlands). Body composition was determined from measurements of body density using a hydrostatic weighing technique of Brozek et al. ${ }^{15}$ Underwater weight was determined to the nearest $0.1 \mathrm{~kg}$ by a balance (Berkel, SK, Ridderkerk, The Netherlands) while simultaneously the residual lung volume was determined by helium dilution and a spirometer (Volutest, Mijnhardt, Bunnik, The Netherlands). 


\section{Exercise tests}

The subjects had to perform exercise tests on an electromagnetically braked bicycle ergometer (Lode, model L-77, Groningen, The Netherlands). During exercise, ventilatory and gas exchange parameters were monitored and printed every $30 \mathrm{~s}$ by an open-circuit sampling system (Oxycon-4, Mijnhardt, Bunnik, The Netherlands). $\mathrm{O}_{2}$ and $\mathrm{CO}_{2}$ analysers were calibrated against standardized gas mixtures prior to testing. The subjects breathed through a low-resistance breathing valve (Hans Rudolph \#2700, Kansas City, MO). Heart rate was monitored electrographically throughout the test (Transport Monitor, Laméris Medical Equipment, Groenekan, The Netherlands).

\section{Maximal exercise test}

The method used to obtain maximal oxygen uptake $\left(\mathrm{VO}_{2}\right.$-max) was derived from the supramaximal 12 min test described by Åstrand and Rodahl." After warming up with a 3 min load at 100 Watts, $\dot{\mathrm{VO}}_{2}$-max was predicted according to the heart rate at the end of the second minute, using the nomogram of Åstrand. ${ }^{16}$ This predicted $\mathrm{VO}_{2}$-max was then corrected for age and a matching work load of $80 \%$ was calculated. This was the work load for the next 3 minutes, followed by a $3 \mathrm{~min}$ load at $115 \%$ and a $3 \mathrm{~min}$ load at $120 \%$ $\dot{\mathrm{VO}}_{2}$-max, until exhaustion. The subjects maintained a constant pedalling rate at $60 \mathrm{rpm}$ throughout the test as indicated by a metronome.

Exhaustion was defined as the point in each test at which the pedalling rate could no longer be maintained, despite the subjects being encouraged to continue as long as possible. Criteria for maximal effort were no further increase in oxygen uptake $\left(\mathrm{VO}_{2}\right)$ despite an increase in work load and either 1) blood lactate concentrations greater than $10 \mathrm{mmol} / \mathrm{l}, 2$ ) a respiratory exchange ratio (RER) above 1.10 , or 3 ) a heart rate greater than 220 minus age. ${ }^{16,17}$ The subject's maximal produced power output (Po-max) was defined as the highest work load which could be achieved.

In the maximal exercise test as performed in this study, a contribution of anaerobic energy to total power output is likely. ${ }^{\text {it }}$ The power/oxygen consumption ratio $\left(\mathrm{P}^{2} / \mathrm{VO}_{2}\right)$ can offer an impression of the relative contribution of anaerobic energy to total power output. In this ratio $\mathrm{VO}_{2}$-max is expressed in Watts, by assuming that only glycogen is oxidized and that each liter of $\mathrm{O}_{2}$ is equivalent with $21.2 \mathrm{~kJ}$ of energy. The $\mathrm{P} / \mathrm{VO}_{2}$ ratio will increase at a higher relative contribution from anaerobic sources. ${ }^{18.19}$

\section{Submaximal exercise test}

The submaximal work loads were chosen such that they represented $60 \%$ of the individuals' $\mathrm{VO}_{2}$-max. Before blood sampling for assessment of basal $(t=0)$ catecholamine levels, subjects rested for $15 \mathrm{~min}$ in supine position. The exercise period was $30 \mathrm{~min}$ and the subjects had to maintain a pedalling rate of $60 \mathrm{rpm}$. 
The rate of energy input $(\mathrm{Pi})$, expressed in Watts was calculated from the oxygen uptake $(1 / \mathrm{min})$ using formula 1 :

$$
\mathrm{Pi}=\frac{(4.940 \mathrm{RER}+16.040) * \dot{\mathrm{VO}}_{2}}{60}
$$

where RER equals the respiratory exchange ratio. ${ }^{20} \mathrm{Pi}$ was calculated for the period from 5 to $10 \mathrm{~min}$ and for the period from 25 to $30 \mathrm{~min}$ after the beginning of the test, assuming that after $5 \mathrm{~min}$ of exercise oxygen uptake reaches a 'steady state'. ${ }^{16}$ The resulting values were averaged over the 5 min period.

\section{Blood sampling}

Blood samples were drawn fiom a catheter inserted in an antecubital vein. Blood samples for the analysis of lactate were taken $5 \mathrm{~min}$ after cessation of the maximal exercise test. During the submaximal test blood was drawn $15 \mathrm{~min}$ before the test $(\mathrm{t}=-15)$, at the start of the test after $15 \mathrm{~min}$ of resting in supine position $(t=0)$, after 10,20 and 30 minutes of cycling $(t=10, t=20$ and $t=30)$, and 5 and 15 minutes after the test $(t=35$ and $t=45)$ for the analysis of lactate. At $t=0$ and $t=30$ blood was also drawn for the analysis of glucose, free fatty acids and catecholamine levels.

Lactate, glucose and free fatty acids were analysed using commercially available kits (Boehringer Mannheim Diagnostica, Amsterdam, The Netherlands; Hitachi 911, Japan). The catecholamines norepinephrine, epinephrine and dopamine were determined radioenzymatically as described by Peuter and Johnson. ${ }^{21}$

\section{$\underline{\text { Statistics }}$}

All values in the tables are expressed as mean \pm SD and $\dot{V O}_{2}$ is expressed as STPD value. BMDP statistical software was used to perform Student's t-tests to establish differences between and within groups. Probabilities of difference less than 0.05 were regarded as statistically significant. To establish changes within groups paired t-tests were performed. Comparison of the changes of the two groups were made in unpaired t-tests. Skewed frequency distributions were transformed logarithmically before t-test. Analysis of variance with repeated measurements was used for the lactate data. Because all participants lost weight during the experiment Pearson's linear correlations were calculated between weight loss (as an indirect measure for the severity of ER) and changes in parameters analysed. 


\section{RESULTS}

\section{Body composition}

Mean values of body weight (BW), lean body mass (LBM) and body fat (BF) are presented in Table 4.1. Both BW and BF were significantly reduced in both groups after the experiment and, as expected, these losses were greater in the ER group $(P<0.001)$, whereas LBM remained unaltered. This indicates that the loss of body weight was mainly due to a loss of body fat rather than lean body mass.

Table 4.1. Subject characteristics and results of body composition measurements before $(\bar{x} \pm$ SD), and the absolute changes $(\Delta \pm S D)$ after 10 weeks of moderate energy restriction.

\begin{tabular}{|c|c|c|c|c|c|}
\hline \multicolumn{3}{|c|}{ Controls $(n=8)$} & \multicolumn{2}{|c|}{ Energy Restricted $(n=16)$} & \multirow{2}{*}{$\begin{array}{l}\text { P } \Delta c t r l \\
\text { vs } \Delta E R\end{array}$} \\
\hline & before & $\Delta$ & before & $\Delta$ & \\
\hline Age (yr) & $43 \pm 5$ & & $43 \pm 4$ & & \\
\hline Height $(\mathrm{cm})$ & $179 \pm 9$ & & $179 \pm 8$ & & \\
\hline $\mathrm{BW}(\mathrm{kg})$ & $78.6 \pm 7.3$ & $-2.7 \pm 2.1^{* *}$ & $79.4 \pm 9.8$ & $-7.4 \pm 2.6^{* * *}$ & $<0.001$ \\
\hline LBM (kg) & $59.7 \pm 5.6$ & $-0.3 \pm 0.8$ & $60.0 \pm 5.7$ & $-0.7 \pm 1.4$ & NS \\
\hline $\mathrm{BF}(\mathrm{kg})$ & $18.8 \pm 6.6$ & $-2.3 \pm 2.0^{*}$ & $19.4 \pm 4.9$ & $-6.8 \pm 1.9^{* * *}$ & $<0.001$ \\
\hline $\mathrm{BF}(\%)$ & $23.7 \pm 7.2$ & $-2.1 \pm 2.0^{*}$ & $24.4 \pm 5.0$ & $-6.9 \pm 1.7^{* * *}$ & $<0.001$ \\
\hline
\end{tabular}

For abbreviations see text.

${ }^{*} \mathrm{P}<0.05,{ }^{* *} \mathrm{P}<0.01,{ }^{* * *} \mathrm{P}<0.001$ within group.

\section{Maximal exercise test}

Table 4.2 summarizes average values before the intervention and the change observed after the study for maximal heart rate (HR-max), maximal power output (Po-max), maximal oxygen uptake $\left(\dot{\mathrm{VO}}_{2}\right.$-max), $\dot{\mathrm{VO}}_{2}$-max expressed per unit of LBM, highest respiratory exchange ratio (RER-max), maximal pulmonary ventilation (Vie-max), time until exhaustion (ET) and blood lactate concentration $5 \mathrm{~min}$ after cessation. The power/oxygen consumption ratio $\left(\mathrm{P} / \mathrm{VO}_{2}\right)$ was calculated from $\mathrm{Po}$-max and $\mathrm{VO}_{2}$-max. None of the parameters were different between the two groups at the start of the intervention.

After the intervention period of 10 weeks the ER group reached significantly lower Po-max and a shorter ET than the control group. $\mathrm{VO}_{2}$-max (either expressed in absolute terms or per kg LBM) decreased significantly in the ER group, but these decreases were not significantly different from the changes in the control group. The change in $\mathrm{P} / \mathrm{VO}_{2}$ ratio tended to be higher in the ER group than in the control group. Lactate levels increased significantly in both groups, and this increase tended to be higher in the control group. 
As weight loss might be an indirect measure for the severity of ER, the changes in parameters measured during this maximal exercise test were correlated with changes in body weight. However, no significant correlations were found.

Table 4.2. Physiological parameters of the maximal exercise test before $(\overline{\mathrm{x}} \pm \mathrm{SD})$, and the absolute changes $(\Delta \pm \mathrm{SD})$ after 10 weeks of moderate energy restriction.

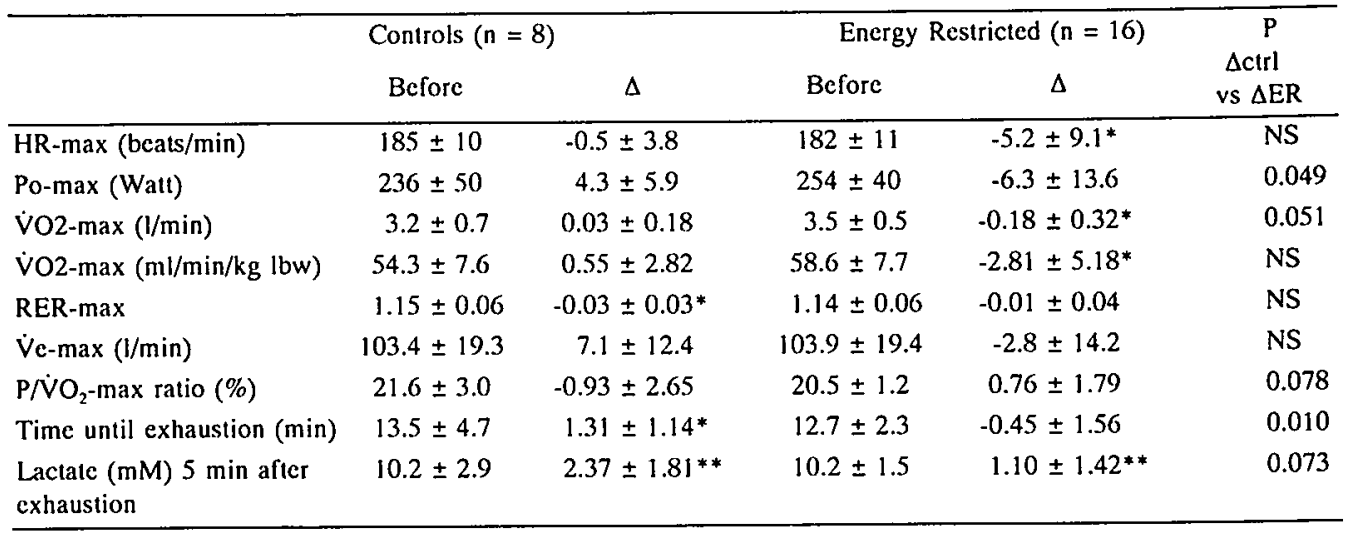

For abbreviations sec text.

${ }^{*} \mathrm{P}<0.05,{ }^{* *} \mathrm{P}<0.01,{ }^{* * *} \mathrm{P}<0.001$ within group.

\section{Submaximal exercise test}

Table 4.3 summarizes the results of the submaximal exercise test. RER between $t=25$ and $t=30$ increased in the ER group, which might be due to a lower starting value. Energy input $(\mathrm{Pi})$, calculated according to formula 1, decreased significantly in the ER group, and this decrease correlated significantly with weight loss. No effects on FFA, glucose, catecholamine and lactate levels (Figure 4.1) were found.

\section{DISCUSSION}

\section{Effects of moderate energy restriction; general findings}

In the present study BW was significantly reduced in both groups but, as expected, weight loss in the ER group was substantial $(-7.4 \pm 2.6 \mathrm{~kg})$. The fact that subjects in the control group lost weight during the experiment is characteristic of the problems that are encountered when feeding a weight-maintaining test diet. Underreporting is very common in human dietary intervention studies and most probably has also occurred in this study. 


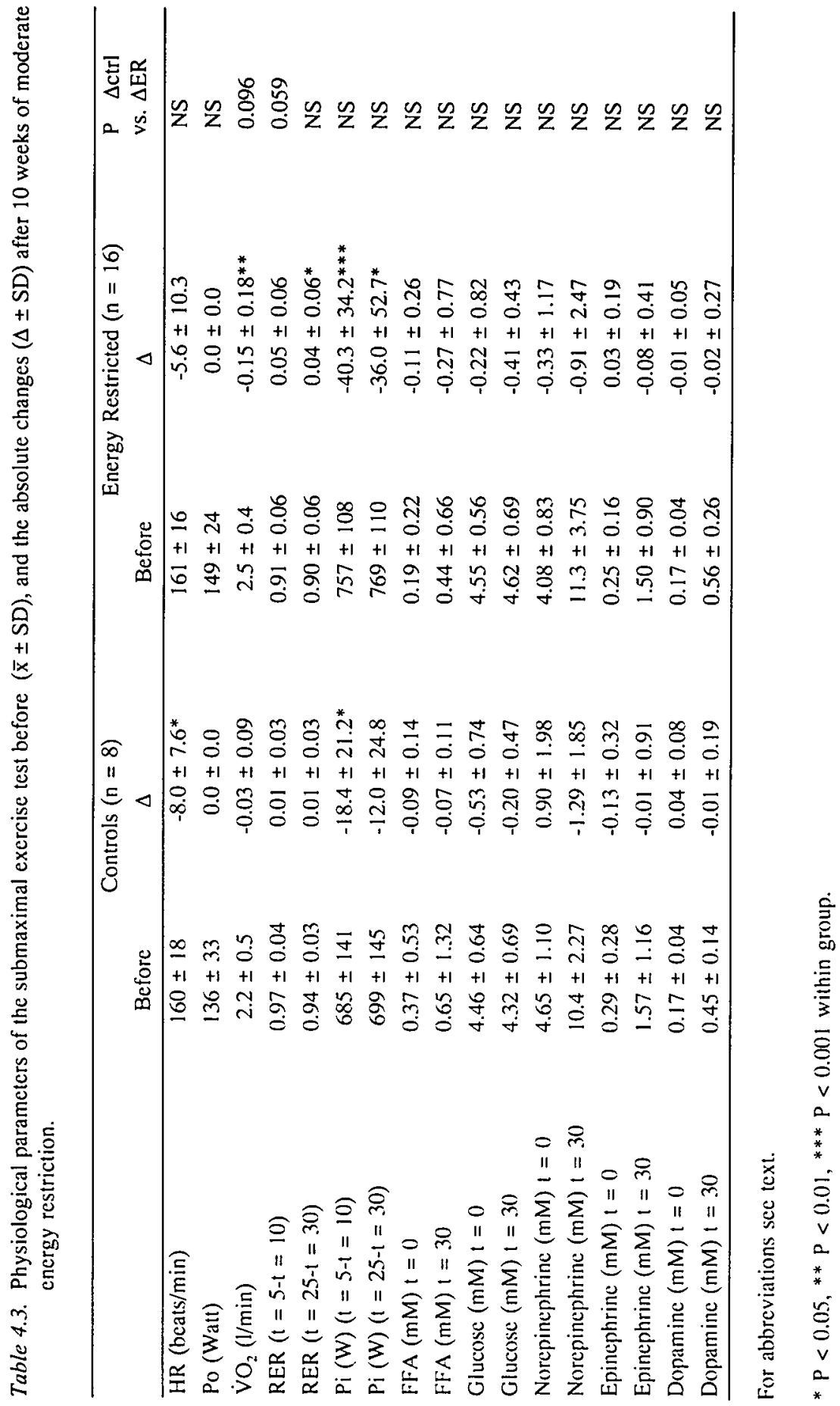




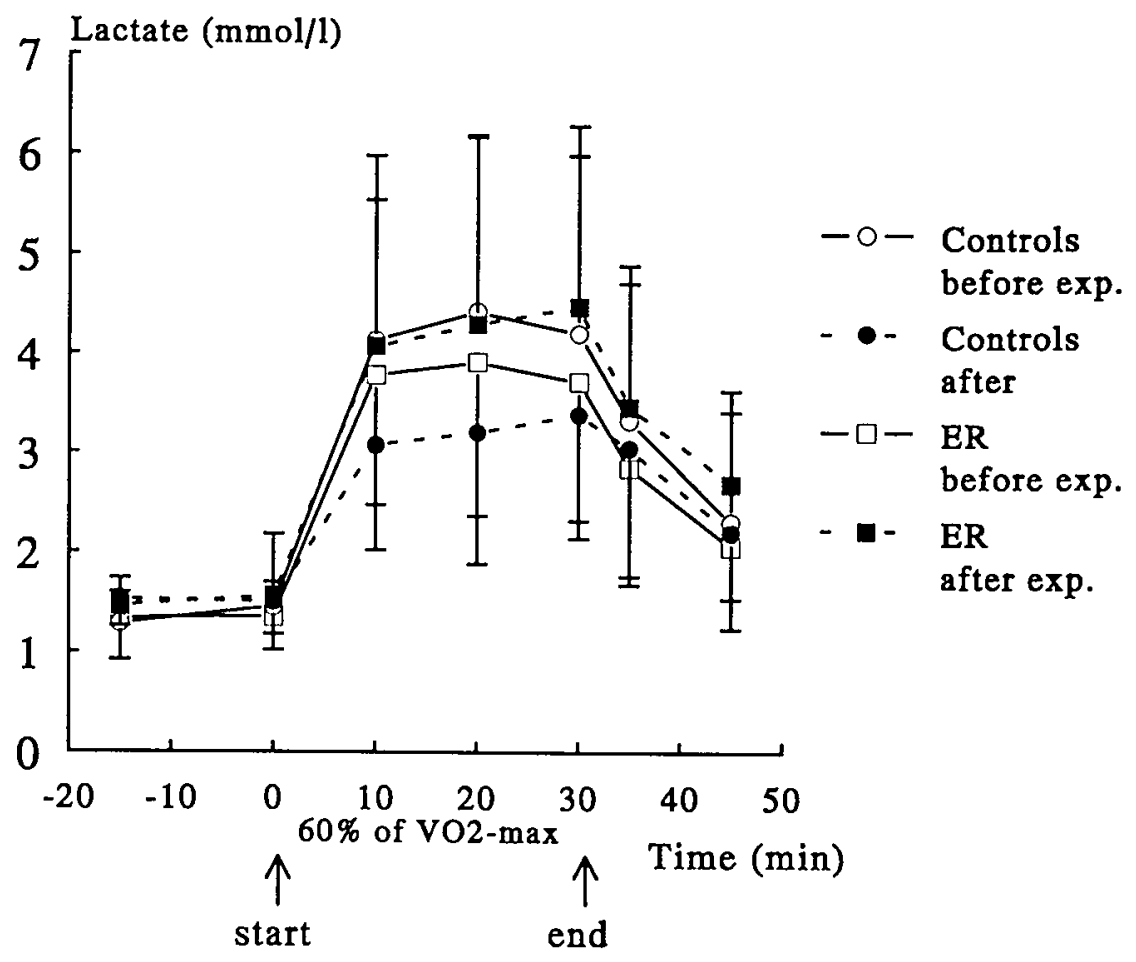

Figure 4.l. Mean lactate concentrations during submaximal excrcisc. Data points are mean \pm SD.

This implies that the ER group might be restricted by more than $20 \%$ because underreporting may have occurred in this group as well. Results of the measurements of BF and LBM by underwater weighing before and after the diet indicate that the decrease in BW was almost entirely due to a significant BF loss rather than to a loss of LBM. It has been observed in studies dealing with very low caloric diets that about $25 \%$ of the weight loss was due to loss of fat-free mass, ${ }^{22}$ moderate energy restriction might preserve this loss of fat-free mass. This conservation of fat-free mass might play a role in the minimizing the decrease in physical performance during moderate energy restriction.

\section{Effect of moderate energy restriction on physical performance}

Physical performance decreases after 26 weeks of semistarvation, ${ }^{9,10}$ whereas impairments after a few days fast are minimal. ${ }^{12.14}$ The major question in the present study was whether or not a regimen of moderate ER affects physiological parameters during maximal and submaximal exercise.

No significant changes in Ve-max were found as a result of the dietary intervention. 
$\dot{\mathrm{VO}}_{2}$-max expressed as an absolute value (i.e. $1 / \mathrm{min}$ ) allows assessment of the effect of dietary manipulation on the capacity of uptake, transport and utilization of $\mathrm{O}_{2}$ to be assessed. ${ }^{23}$ This parameter decreased significantly in the ER group and this fall nearly reached significance when compared to the change in the control group. However, $\dot{V}_{2}$-max expressed per unit LBM decreased in the ER group but this change was not significantly different from the control group. Subjects in the ER group showed a shorter time until exhaustion (ET) after the intervention and therefore had a decreased maximal power, $\mathrm{VO}_{2}$-max and maximal heart rate since these changes were significantly related. The decrease in maximal power output in the ER group is minor, but significantly different from the slight increase in the control group. The individual's ability to sustain progressive incremental exercise of the type we used is highly dependent on the glycogen content of the muscles which, in turn, is dependent on the type of diet before exercise. ${ }^{24}$ When muscle glycogen is markedly reduced by prior exercise, by consumption of a diet rich in fat and protein $^{26}$ or by fasting, ${ }^{13,27}$ aerobic metabolism becomes more dependent on the oxidation of fat. A short-term very-low-caloric diet (VLCD) in obese subjects did not affect physical performance, ${ }^{23}$ or alter muscle glycogen, lactate, pyruvate or energy stores. ${ }^{8}$ Although muscle glycogen concentrations were not measured in this study (i.e. no muscle biopsies were taken), a reduction of the muscle glycogen stores by the $20 \%$ ER diet seems unlikely, as no significant changes in RER-max were noted and no decreased lactate values were found. ${ }^{25}$ Blood lactate concentration is widely accepted as an indicator of anaerobic glycolytic metabolism. ${ }^{24}$ Lactate levels 5 minutes after exhaustion increased significantly and similarly in both groups. The $\mathrm{P} / \mathrm{VO}_{2}$ ratio can offer also an impression of the anaerobic contribution to total power output. This variable was not affected after the intervention period, suggesting no change in anaerobic metabolism. Thus, lower glycogen levels and a lower anaerobic contribution most likely do not account for the decreased cycling time. A maximum performance test of any type is always biased by a motivation or cooperation factor: in order to obtain the best possible score, the individual must be willing to push himself to the limit and to continue work until the last possible second of exhaustion. In all practical work situations the motivation factor is extremely important in physical performance. After the intervention period subjects were encouraged to cycle at least as long as the first time. It is possible that subjects in the ER group did not cycle longer because of their supposed reduced power, as a consequence of their negative energy balance. Alternatively, it is possible that ER reduces more directly the motivation to physical strain.

To assess whether a relationship between weight loss and the physiological indices measured could be demonstrated, linear correlations between weight changes (as an indirect measure of energy restriction) and changes in several parameters were calculated for the whole group $(n=24)$. None of the changes in variables measured during these maximal 
exercise tests correlated significantly with weight change. From this finding we conclude that 10 weeks of moderate ER lead to a slight but significant decrease in maximal power output, which is not related to the amount of weight loss.

\section{Effect of moderate energy restriction on substrate utilization}

Moderate restriction of the energy intake did not affect substrate utilization (Table 4.3). Previous studies on the combined effects of fasting and moderately intense exercise have shown increased reliance on fats and decreased utilization of carbohydrates as inferred from changes in plasma free fatty acid (FFA) concentrations and RER. ${ }^{14,27-30}$ In all these studies fasting resulted in significantly higher FFA values, indicating a greater fat mobilization and utilization. This was also evidenced by RER values near 0.70 during the first $30 \mathrm{~min}$ of exercising on a treadmill at $70 \% \mathrm{VO}_{2}$-max. ${ }^{29}$ Thus, after fasting fatty acids are the most obvious energy substrate. From our data no change in substrate utilization during submaximal exercise was apparent as a result of 10 weeks of moderate energy restriction. However, our study differs in some aspects from the studies mentioned before. First, in contradiction to these fasting studies, in the present study subjects were restricted in their energy uptake for only $20 \%$. Second, since both artificial sweeteners and low fat products were used, the relative contribution of the macronutrients to total energy intake did not change during the experiment. Therefore, the diet might replenish glycogen stores sufficiently, which is also indicated by unaltered lactate levels. So, despite substantial weight loss substrate utilization remains unaltered during submaximal exercise. The increase in RER levels observed in the ER group might be caused by lower starting values. These lower starting values are most likely explained by differences in physical activity. At the time of the submaximal exercise test all subjects used standardized meals with similar macronutrient composition.

When an individual is fasting the body attempts to preserve the limited carbohydrate stores. One method to accomplish this is by reducing sympathetic nervous system (SNS) activity. Reductions in norepinephrine turnover have been reported to occur with fasting in an attempt to reduce individuals' resting metabolic rate, thereby sparing fuel utilization. ${ }^{31}$ Another function of catecholamines is the regulation of muscle glycogenolysis. Epinephrine binds to $\beta$-adrenergic receptors on the skeletal membrane, initiating a cascade of events leading to glycogen breakdown which ultimately increases lactate production. Decreased epinephrine, norepinephrine and lactate levels during exercise were found after glycogen depletion. ${ }^{32}$ The fact that there were no differences between both groups in plasma catecholamine and lactate levels during submaximal exercise indicates that moderate energy restriction did not change SNS activity despite substantial weight loss.

Power input (i.e. energy expenditure) as calculated from the formula by Garby and Astrup $^{20}$ decreased significantly in the ER group although power output did not change. 
Since there are no decreased RER values the decrease in power input must be attributed to the decreased $\mathrm{O}_{2}$ consumption $\left(\mathrm{VO}_{2}\right)$. Decreased oxygen consumption during rest and exercise has also been observed in obese women on a very-low-caloric-diet. ${ }^{33}$ The explanation might be that the subjects showed a decreased metabolic rate (Chapter 5). The decrease in power input at $t=5$ up to $t=10$ correlates significantly with the decrease in body weight $(\mathrm{r}=0.454 ; \mathrm{P}<0.05)$.

To summarize, it is concluded that 10 weeks of moderate energy restriction decreased maximal power output in non-obese middle-aged men. However, this decrease was not related to a decreased body weight. Despite a substantial weight loss, no effect on plasma FFA, glucose, catecholamine and lactate levels was observed, indicating that substrate utilization remained unchanged. Further, during submaximal exercise moderate energy restriction led to lower power input (energy expenditure) while power output did not change, indicating a decreased resting metabolic rate.

The duration and degree of ER and the intensity and duration of the exercise period seem to be important factors determining changes in physiological performance parameters. This study lasted only 12 weeks, since we expected that this was the maximal period for subjects to visit the institute every evening. However, since no steady state was reached with respect to weight loss, it cannot be inferred from this study whether significant alterations in physical performance and metabolic adaptation will occur beyond 10 weeks. Therefore, it seems worthwhile to study the effects of moderate ER on a longer term. Thus, the long-term effect of ER diets as well as the minimum energy intake necessary to prevent physiological changes deserve further investigation.

\section{ACKNOWLEDGEMENT}

The authors would like to thank Dr. A.P. Hollander, Free University of Amsterdam, Dept. of Exercise Physiology and Biophysics, for his critical review of this manuscript.

\section{REFERENCES}

1. McCay CM, Crowell MF. Prolonging the life span. Sci Monthly 1934;39:405-414.

2. Chipalkatti S, de Ajit K, Aiyar AS. Effect of dict restriction on some biochemical parameters related to aging in mice. J Nutr 1983;113:944-950.

3. Comfort A. Effect of delayed and reduced growth on the longevity of a fish in captivity. Gerontologica 1963;8:150-155.

4. Ingle E, Wood TR, Banta AM. A study of longevity, growth, reproduction and heart rate in Daphnia longispina as influenced by limitations in quantity of food. J Exp Zool 1937;76:325-352.

5. Velthuis-te Wierik EJM, van den Berg H, Schaafsma G, Hendriks HFJ, Brouwer A. Encrgy restriction, a useful intervention to retard human aging? Results of a feasibility study. Eur J Clin Nutr 
1994;48:138-148.

6. Kannel WB. Nutrition and the occurrence and prevention of cardiovascular disease in the eldery. Nutr Rev 1988;46:68-78.

7. Velthuis-te Wierik EJM, van den Berg H. Energy restriction, the basis for successful aging in man? Nutr Res 1994;7:1113-1134.

8. Russell DM, Walker PM, Leiter LA, Sima AAF, Tanner WK, Mickle DAG, Whitwell J, Marliss EB, Jeejeebhoy $\mathrm{KN}$. Metabolic and structural changes in skeletal muscle during hypocaloric dieting. Am J Clin Nutr 1984;39:503-513.

9. Keys A, Brozek J, Henschel A, Michelsen O, Taylor HL. The biology of human starvation, Vols 1 and 2. Minneapolis:University of Minnesota Press, 1950.

10. Grande F. Impact of food restriction on physical performance. In: Predicting decrements of military performance duc to inadequate nutrition, proceedings of a workshop. Committee on Military Nutrition Research, National Acadamy Press, Washington DC, 1986.

11. Spurr BG, Barac-Nicto M, Reina JC. Growth, maturation, body composition and maximal aerobic power of nutritionally normal and marginally malnourished school-aged Colombian children. In: Shephard RJ, Pařizková J (eds). Human Growth, Physical Fitness and Nutrition. Med Sport Sci. Basel, Karger, 1991;31:41-60.

12. Knapik JJ, Jones BH, Meredith CN, Evans WJ. Influence of a 3.5 day fast on physical performance. Eur J Appl Physiol 1987;56:428-432.

13. Lennmarken C, Rutberg H, Jorfeldt L, Larsson J. Effect of starvation on work capacity and voluntary skeletal muscle function in man. Clin Nutr 1990;9:231-233.

14. Loy SF, Conlec RK, Winder WW, Nelson AG, Arnall DA, Fisher AG. Effects of 24-hour fast on cycling endurance time at two different intensities. J Appl Physiol 1986;61:654-659.

15. Brozek J, Grande E, Anderson JT, Keys A. Densitomctric analysis of body composition: revision of some quantitative assumptions. Ann NY Acad Sci 1963;110:113-140.

16. Åstrand PO, Rodahl K. Textbook of workphysiology: physiological bases of exercise. Third ed. Singapore, McGraw-Hill Book Company, 1986.

17. Stachenfeld NS, Eskenazi M, Gleim GW, Coplan NL, Nicholas JA. Predictive accuracy of criteria used to assess maximal oxygen consumption. Am Heart J 1992;123:922-925.

18. van Ingen Schenau GJ, de Groot G. Differences in oxygen consumption and external power between malc and female speed skaters during supramaximal cycling. Eur J Appl Physiol 1983;51:337-345.

19. van Ingen Schenau GJ, de Groot G, Hollander AP. Some technical, physiological and anthropometrical aspects of specd skating. Eur J Appl Physiol 1983;50:343-354.

20. Garby L, Astrup A. The relationship between the respiratory quotient and the energy equivalent of oxygen during simultaneous glucose and lipid oxydation and lipogenesis. Acta Physiol Scand 1987:129:443-444.

21. Peuter JD, Johnson GA. Simultancous single isotope radiocnzymatic assay of plasma norepinephrine, epinephrinc and dopamine. Life Sci 1977;21:625-636.

22. Luke A, Schocller DA. Basal metabolic rate, fat frec mass, and body cell mass during energy restriction. Metabolism 1992;41:450-456.

23. Poole DC, Henson LC. Effect of acute caloric restriction on work efficiency. Am J Clin Nutr 1988;47:15-18.

24. Jacobs I. Lactate, muscle glycogen and exercise performance in man. Acta Physiol Scand 1981 ;Suppl. 495: $1-35$.

25. Heigenhauser GJF, Sutton JR, Jones NL. Effect of glycogen depletion on the ventilatory response to exercise. J Appl Physiol 1983;54:470-474.

26. Jansson E. Diet and muscle metabolism in man. Acta Physiol Scand Suppl. 1980;487:1-24.

27. Knapik JJ, Meredith CN, Jones BH, Suek L, Young VR, Evans WJ. Influence of fasting on carbohydrate and fat metabolism during rest and exercise. J Appl Fysiol 1988;64:1923-1929.

28. Björkman O, Eriksson LS. Splanchnic glucose metabolism during leg excrcise in 60-hour-fasted human subjects. Am J Physiol 1983;245:E443-E448.

29. Dohm GL. Becker RT, Isracl RG, Tapscott EB. Metabolic responses to exercise after fasting. J Appl Physiol 1986;61:1363-1368. 
30. Minuk HL, Hanna AK, Marliss EB, Vranic M, Zinman B. Metabolic response to moderate exercise in obese man during prolonged fasting. Am J Physiol 1980;238:E322-E329.

31. Young CB, Landsberg L. Supression of sympathetic nervous system during fasting. Science, Washington DC 196:1473-1475, 1977.

32. Podoling DA, Munger PA, Mazzeo RS. Plasma catecholamine and lactate response during graded exercise with varied glycogen conditions. J Appl Physiol 1991;71:1427-1433.

33. Apfelbaum $M$, Brigant $L$, Joliff $M$. Effects of severe diet restriction on the oxygen consumption of obese women during exercise. Int J Obesity 1977;1:387-393. 


\title{
Impact of a moderately energy-restricted diet on energy metabolism and body composition in non-obese men
}

\author{
Erica J.M. Velthuis-te Wierik ${ }^{1}$, Klaas R. Westerterp ${ }^{2}$ and Henk van den Berg ${ }^{1}$ \\ 1 TNO Nutrition and Food Research Institute, Zeist, The Netherlands \\ ${ }^{2}$ University of Limburg, Maastricht, The Netherlands
}

International Journal of Obesity, accepted for publication

\section{ABSTRACT}

Since little information is available on the capacity of the non-obese to adapt to a moderate decrease in energy intake, the effect of a 10-week moderately energy-restricted diet (ER) on energy expenditure and body composition was studied in a controlled intervention study. After a weight-maintaining run-in period of 2 weeks, the ER group received a diet that contained $9.2 \mathrm{MJ} /$ day on average, i.e. $80 \%$ of the energy of their habitual diet (estimated by means of a 7-day dietary record) for the next ten weeks while the control group received the weight-maintaining diet. 24 healthy non-obese, middle-aged men participated. They continued daily life habits and came to the Institute every evening to have dinner and to receive food for the next 24 hours. Subjects were matched for age and body mass index and randomly assigned to a control group $(n=8)$ or an ER group $(n=16)$. Average daily metabolic rate (ADMR, i.e. total energy expenditure), measured with doubly labeled water in 8 subjects of the ER group, appeared to be $82.5 \%$ of reported energy intake resulting in an actual level of energy restriction in these eight subjects of $33 \%$ on average (range $18-42 \%$ ), rather than $20 \%$. Subjects in the ER group lost $7.4 \pm 1.7 \mathrm{~kg} ; 83 \%$ of this weight loss was fat mass, $17 \%$ was fat-free mass. Subjects in the control group lost some weight too $(2.1 \pm 1.5 \mathrm{~kg})$. Resting metabolic rate (RMR) (MJ/day) decreased in the ER group $(\mathrm{P}<0.001)$. In this group the thyroid hormone triiodothyronine $(\mathrm{T} 3)$ decreased $(\mathrm{P}<0.001)$, while reverse $\mathrm{T} 3$ ( $\mathrm{rT} 3$ ) increased $(\mathrm{P}<0.05)$. ADMR decreased significantly. It has been concluded that under conditions of a controlled moderately energy restricted diet in daily life a significant weight loss can be induced, similar to that observed after a balanced dietary deficit, providing $5 \mathrm{MJ} /$ day. In addition, moderate energy restriction induces a decrease in fat-free mass and a fall in RMR. 


\section{INTRODUCTION}

Many investigations have been done to document the adaptations of energy expenditure in response to very-low calorie diets (VLCD's), providing approximately $2.1 \mathrm{MJ} /$ day, in obese subjects. ${ }^{1-3}$ There is general agreement that these diets can induce: a rapid weight loss, suppression of the resting metabolic rate (RMR) and a reduction of the thyroid hormone triiodothyronine (T3). ${ }^{4}$ However, the adaptation to decreased energy intake might be different in subjects who are in a more normal weight range. Dieting has become a way of life for many people. Many slightly overweight people as well as people who perceive themselves as overweight are trying to lose some weight. Several studies have reported about the effects of low-fat diets on energy intake compensation. ${ }^{5.7}$ Reports on the capacity of energy expenditure to adapt to a moderate decrease in energy intake in normal-weight, healthy individuals are scarce, especially those performed under controlled conditions. The effects of a moderate energy deficit $(3,350 \mathrm{~kJ} /$ day $)$ for 3 weeks in normal weight students ${ }^{8}$ as well as the results of 12 weeks counseling ${ }^{9}$ have been reported. Since these studies are either short-term or not performed under dietary-controlled conditions we studied the effect of a 10-week controlled moderately energy-restricted (aimed at $80 \%$ of habitual) diet on energy expenditure and body composition in healthy non-obese men.

\section{MATERIALS AND METHODS}

\section{Subjects}

Twenty-four apparently healthy men, aged $43 \pm 5 \mathrm{yr}$ (range $35-50 \mathrm{yr}$ ) with a mean BMI of $24.6 \pm 1.8 \mathrm{~kg} / \mathrm{m}^{2}$ (range $20.6-27.2 \mathrm{~kg} / \mathrm{m}^{2}$ ) participated in this study. Ail subjects had a stable weight during the past year, normal routine clinical chemistry and were non-smoking. They had normal dietary habits (no vegetarian, macrobiotics etc.) and no extreme level of reported energy intake (9.3-13.2 MJ/day). Each subject was medically screened on the basis of a health questionnaire and a medical examination. Informed consent was obtained from each subject and the research protocol was approved by the Institute's external Medical Ethical Committee.

\section{Experimental design}

A detailed description of the study has been published elsewhere (Chapter 3). ${ }^{10}$ Habitual energy intake was estimated by means of a 7-day dietary record before the study started. The total experiment lasted 12 weeks. Subjects were randomly assigned to two groups: a control group (8 subjects) and an energy-restricted group (ER group; 16 subjects). These groups were matched on age and BMI. During the first two weeks of the study (run-in 
period) all subjects received a weight-maintaining test diet based upon the outcome of the dietary record. Since energy intake differs among individuals, subjects were divided into 6 'energy groups' with a stepwise increase of approximately $770 \mathrm{~kJ} /$ day, ranging from 9,304 to $13,147 \mathrm{~kJ} /$ day. When subjects lost more than $1 \mathrm{~kg} /$ week during this run-in period they were reclassified into a higher energy group.

After these two weeks the 8 control subjects were kept on their weight-maintaining diet for the next ten weeks, while the other 16 subjects received a diet that contained $80 \%$ of the energy of their habitual (weight-maintaining) diet, and micronutrient levels of at least $100 \%$ their recommended dietary allowances (RDAs). Energy restriction was achieved by substituting low-fat and artificially sweetened products for ordinary products (i.e. substituting low-fat margarine for margarine, light soft drink for soft drink, artificial sweetener for sugar, low-fat coffee cream for coffee cream, salad dressing for mayonnaise, and skimmed yoghurt for whole yoghurt). The relative contribution of carbohydrates, fat and protein to total energy intake was $51 \%, 34 \%, 15 \%$ respectively for the control group and $47 \%, 36 \%, 17 \%$ respectively for the ER group. All foods and drinks to be consumed during these twelve weeks were supplied by the Institute. Subjects came to the Institute every evening to have dinner (cycle of 3 menus) and to receive the food for the next 24 hours. The subjects were not allowed to eat or drink anything else (except water) but the diet supplied by the Insitute. The subjects continued daily life habits during the study, and were asked to maintain physical activity at a constant level. In studies like this, compliance is difficult to measure. However, subjects in the ER group were expected to loose weight. Therefore, compliance was stimulated as much as possible by weighing all subjects regularly and by using a daily questionnaire, which included items like 'have you eaten all the food that you received?', 'have you eaten anything besides the food that you received?'.

The subjects were weighed every week. Body composition, urinary creatinine excretion and the thyroid hormones 3,5,3'-triiodothyronine (T3), reverse T3 (rT3), thyroxine (T4) and thyrotropin releasing hormone (TSH) were determined at the end of the run-period and at the end of the experiment. Resting metabolic rate (RMR) was measured twice before and twice at the end of the experimental period. The mean of the two measurements was used as a variable in the analysis. Average daily metabolic rate (ADMR) was measured in eight subjects, randomly chosen from the ER group, over two weeks, during the run-in period and during the last two weeks of the study.

\section{Methods}

Body composition. The subjects were weighed to the nearest $0.1 \mathrm{~kg}$ every week on a balance (ED-60-T; Berkel, Ridderkerk, The Netherlands) before dinner, while wearing underwear. Body composition was estimated from the three-compartment model of Siri" which combines body density with total body water. This technique has been shown to 
improve the precision of body fat estimates over that obtained from either densitometry or total body water alone." Body density was measured using the hydrostatic weighing technique of Brozek et al. ${ }^{12}$ Underwater weight was determined to the nearest $0.1 \mathrm{~kg}$ by a balance (SK; Berkel, Ridderkerk, The Netherlands) while the residual lung volume was determined simultaneously by helium dilution and a spirometer (Volutest, Mijnhardt, Bunnik, The Netherlands). Total body water was determined by deuterium dilution. Subjects drank a weighed dose of labeled water $\left(0.1 \mathrm{~g}^{2} \mathrm{H}_{2} \mathrm{O}\right.$ per kg estimated body water (from ageand sex-specific formula' ${ }^{13}$ ), resulting in an excess enrichment of $100 \mathrm{ppm}$ ) after emptying the bladder at 22:00. This was the baseline urine sample. Another urine sample was collected the next morning from the second voiding. This $10 \mathrm{~h}$ sampling time is a preferable protocol for determining total body water as compared with $4 \mathrm{~h}$ and $6 \mathrm{~h}$ equilibration times. ${ }^{14}$ Total body water was calculated as the deuterium dilution space divided by 1.04 , correcting for exchange of the deuterium label with nonaqueous hydrogen of body solids. ${ }^{15}$ The values of body density and body water (as a percentage of body mass) were used to calculate body fat in the following equation:"

\%body fat $=(2.118 /$ density $)-(0.78 \times$ \%body water $)-1.354$

Creatinine. To measure creatinine excretion subjects collected urine over $24 \mathrm{~h}$ at the end of the run-in period and at the end of the experiment. Creatinine was analysed using a commercially available kit (enzymatic PAP; Boehringer, Mannheim, Germany) and a Hitachi-911 autoanalyser.

Thyroid hormones. Serum T4 and T3 levels were analysed using a commercial radioimmunoassay (EURO/DPC, Llanberis, United Kingdom) according to the kit protocol. Serum rT3 was analysed using a commercial radioimmunoassay (Techland, Liège, Belgium). TSH was analysed using an immunoradiometric assay (IRMA) (Behring, Marburg, Germany).

Resting metabolic rate. RMR was measured in the morning after the subjects had stayed overnight in the metabolic ward of the Institute. $\mathrm{O}_{2}$ consumption (paramagnetic analyser, Beryl 102; Cosma, Igny, France) and $\mathrm{CO}_{2}$ production (AR-400 infrared gas analyser; Anarad, Santa Barbara, CA, USA) was measured under thermoneutral temperature conditions in the fasting state on four occasions, twice during the run-in period and twice at the end of the experiment. $\mathrm{O}_{2}$ and $\mathrm{CO}_{2}$ analysers were calibrated against standardized gas mixtures every morning. While lying for 30 minutes in supine position, the subjects were breathing through a low-resistance breathing valve (\#2700; Hans Ruldolph, Kansas City, MO, USA). Weir's ${ }^{16}$ formula was used for calculating RMR.

Average daily metabolic rate (ADMR). ADMR was measured in eight subjects from the ER group using doubly labeled water. These subjects were given a weighed dose of a 
mixture of ${ }^{2} \mathrm{H}_{2} \mathrm{O}$ and $\mathrm{H}_{2}{ }^{18} \mathrm{O}$ after collecting a background urine sample. The dose was calculated to create an excess of $150 \mathrm{ppm}{ }^{2} \mathrm{H}$ and $300 \mathrm{ppm}{ }^{18} \mathrm{O}$. Further urine samples were collected on days 1,8 and 15 after dosing from the second voiding in the morning. Isotope abundances in the urine samples were measured with an isotope-ratio mass spectrometer (Aqua Sira; VG Isogas Ltd, Middlewich, Cheshire, United Kingdom) and $\mathrm{CO}_{2}$ production was calculated as previously described. ${ }^{17}$ The analytical precision was $0.2 \mathrm{ppm}$ for ${ }^{2} \mathrm{H}$ and $0.4 \mathrm{ppm}$ for ${ }^{18} \mathrm{O}$.

The Physical activity level (PAL) was calculated as the ratio ADMR/RMR.

\section{$\underline{\text { Statistics }}$}

BMDP statistical software, version: 1990 vax/vms (Los Angeles, CA, USA) was used to detect changes within as well as between the groups, and to calculate correlations between parameters. Changes within the groups were tested for significance with the paired Student's $\mathrm{t}$-test. Differences in changes between the two groups were tested using the unpaired Student's t-test. Relationships between two variables were calculated by Pearson's linear correlation. Analysis of covariance using FFM as the covariate was used to adjust for differences in body composition when comparing RMR values.

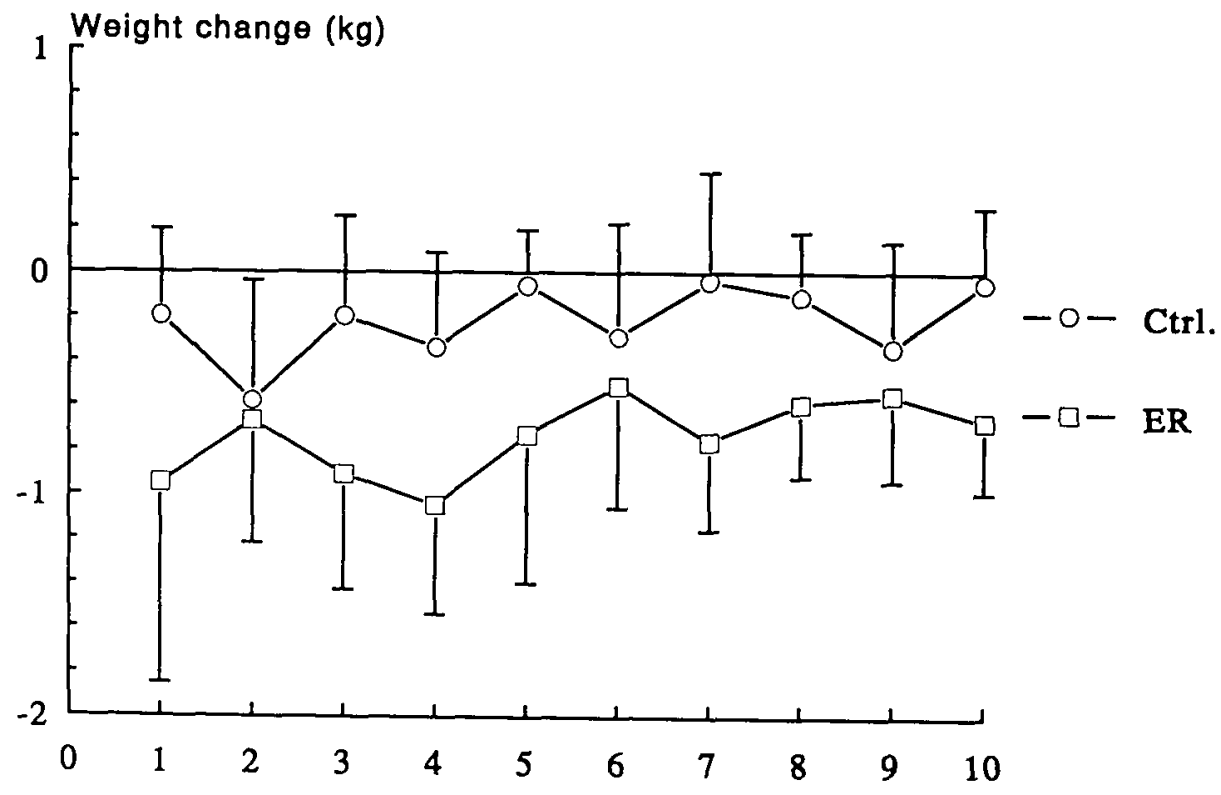

Week

Figure 5.l. Rate of weight loss during the study. Data are presented as $\bar{x} \pm$ SD. 


\section{RESULTS}

Table 5.1 presents the results on body composition and energy metabolism. Since total body water measurements were not completed in two subjects, the results of body fat (FM) and fat-free mass (FFM) in the ER group represent 14 subjects. As expected, weight loss in the ER group was substantial $(7.4 \pm 1.7 \mathrm{~kg})$. Subjects in the control group lost some weight too $(2.1 \pm 1.5 \mathrm{~kg}$ ) (Figure 5.1). About $83 \%$ of the weight loss in the ER group appeared to be loss of fat mass, and the remaining $17 \%$ of the weight loss was attributed to loss of FFM. The ER group lost significantly more fat and FFM than the control group. Urinary creatinine excretion had not changed after the experimental period.

Table 5.1. Summary of the results of cnergy intake, energy expenditure and body composition. Mean values and standard deviations of the control group and the energy restricted group before (after a two-week run-in period) and of the change after the experimental period are presented.

\begin{tabular}{|c|c|c|c|c|c|}
\hline & \multicolumn{2}{|c|}{ Controls $(n=8)$} & \multicolumn{2}{|c|}{ Energy Restricted $(n=16)$} & \multirow{2}{*}{$\begin{array}{c}\text { P } \Delta c t r l \\
\text { vs } \Delta E R\end{array}$} \\
\hline & before & $\Delta$ & before & $\Delta$ & \\
\hline \multicolumn{6}{|l|}{ BODY COMPOSITION } \\
\hline BMI $\left(\mathrm{kg} / \mathrm{m}^{2}\right)$ & $24.6 \pm 2.2$ & $-0.8 \pm 0.6^{* *}$ & $24.9 \pm 1.8$ & $-2.3 \pm 0.8^{* * *}$ & $<0.001$ \\
\hline Weight (kg) & $77.7 \pm 6.6$ & $-2.1 \pm 1.5^{* *}$ & $78.6 \pm 9.3$ & $-7.4 \pm 1.7^{* * *}$ & $<0.001$ \\
\hline $\mathrm{FM}(\mathrm{kg})$ & $18.3 \pm 6.2$ & $-1.8 \pm 1.8^{*}$ & $18.1 \pm 5.2^{1}$ & $-6.1 \pm 1.7^{* * * 1}$ & $<0.001$ \\
\hline FFM (kg) & $59.5 \pm 5.2$ & $-0.2 \pm 1.0$ & $60.5 \pm 6.7^{1}$ & $-1.1 \pm 1.0^{* * * 1}$ & 0.027 \\
\hline \multicolumn{6}{|l|}{ URINARY EXCRETION } \\
\hline Creatininc (mmol/24h) & $12.4 \pm 2.6$ & $-0.3 \pm 2.5$ & $12.7 \pm 2.1$ & $-0.4 \pm 1.9$ & NS \\
\hline \multicolumn{6}{|c|}{ ENERGY METABOLISM } \\
\hline Intakc (MJ/day) & $11.13 \pm 1.51$ & $0.69 \pm 0.80^{*}$ & $11.43 \pm 1.24$ & $-2.23 \pm 0.6^{* * *}$ & $<0.001$ \\
\hline $\mathrm{RMR}(\mathrm{MJ} /$ day) & $7.40 \pm 0.75$ & $-0.60 \pm 0.40^{* *}$ & $8.02 \pm 1.26$ & $-1.07 \pm 0.63^{* * *}$ & 0.060 \\
\hline \multicolumn{6}{|l|}{ THYROID HORMONES } \\
\hline $\mathrm{T} 4(\mathrm{nmol} / \mathrm{L})$ & $101.9 \pm 17.2$ & $-6.0 \pm 11.5$ & $98.7 \pm 14.0$ & $-3.2 \pm 6.9$ & NS \\
\hline $\mathrm{T} 3(\mathrm{nmol} / \mathrm{L})$ & $1.88 \pm 0.20$ & $-0.18 \pm 0.18^{*}$ & $1.79 \pm 0.22$ & $-0.23 \pm 0.19^{* * *}$ & NS \\
\hline rT3 (ng/dL) & $25.1 \pm 6.0$ & $-0.75 \pm 4.53$ & $25.6 \pm 8.2$ & $2.44 \pm 4.35^{*}$ & NS \\
\hline $\mathrm{TSH}(\mathrm{mIU} / \mathrm{L})$ & $1.63 \pm 0.72$ & $0.14 \pm 0.23$ & $1.59 \pm 0.64$ & $-0.14 \pm 0.45$ & NS \\
\hline
\end{tabular}

${ }^{1} \mathrm{n}=11$.

${ }^{* * *} \mathrm{P}<0.001,{ }^{* *} \mathrm{P}<0.01,{ }^{*} \mathrm{P}<0.05$ within group. 
Energy restriction led to significantly decreased RMR (MJ/day) values in both groups. This decrease in RMR tended to be stronger in the ER group. RMR correlated to $\mathrm{kg}$ FFM both before $(r=0.613 ; P=0.001)$ and after the study $(r=0.657 ; P<0.001)$. However, as tested with analysis of covariance, after the period of energy restriction the intercept of the regression line had decreased $(P<0.001)$ (Figure 5.2). No effects of energy restriction on T4 and TSH were observed. T3 concentration decreased significantly in both groups. The differences in changes between the two groups were not significant. rT3 levels increased in the ER group. The increase in $\mathrm{TT} 3$ levels correlated with the decrease in RMR $(\mathrm{r}=-0.431, \mathrm{P}=0.036)$.

As shown in Table 5.2, ADMR, as measured in 8 subjects, was higher than energy intake during the run-in period which was based on the 7-day dietary record, indicating some degree of underreporting. During the experimental period ADMR decreased significantly. PAL tended to decrease. Table 5.3 presents the rate constants and dilution spaces for ${ }^{18} \mathrm{O}$ and ${ }^{2} \mathrm{H}$.

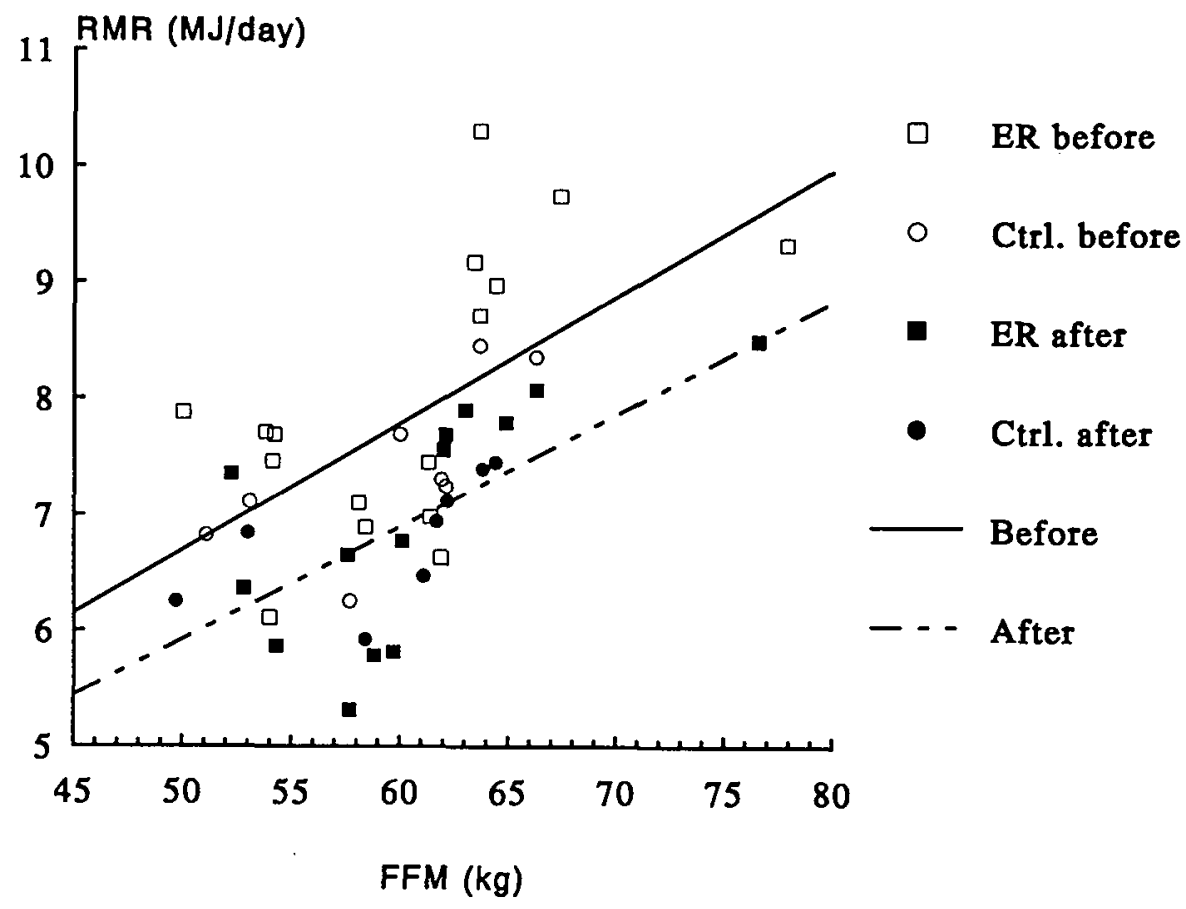

Figure 5.2. FFM versus RMR before and after the intervention period.

Before: $y=1.24+0.109 x ; r=0.613 ; P=0.01$.

After: $y=1.07+0.079 x ; r=0.657 ; P<0.001$. 
Table 5.2. Summary of energy intake, energy expenditure and body composition in a part of the ER group $(n=8)$. Mean values and standard deviations of part of the energy-restricted group before (after a two-week run-in period) and the change after the experimental period are presented.

\begin{tabular}{lccc}
\hline & \multicolumn{2}{c}{ Energy Restricted } & P-Value \\
& Before & $\Delta$ ER & $\Delta$ ER \\
\hline BODY COMPOSITION & & & \\
Weight & $77.8 \pm 5.5$ & $-6.8 \pm 1.8$ & $<0.001$ \\
FM (kg) & $16.7 \pm 4.3$ & $-5.8 \pm 1.9$ & 0.001 \\
FFM (kg) & $59.1 \pm 4.2$ & $-1.0 \pm 1.2$ & 0.025 \\
& & & \\
ENERGY METABOLISM & & & $<0.001$ \\
Intake (MJ/day) & $11.8 \pm 1.4$ & $-2.3 \pm 0.9$ & $<0.001$ \\
ADMR (MJ/day) & $14.3 \pm 2.3$ & $-2.87 \pm 1.14$ & 0.011 \\
RMR (MJ/day) & $7.90 \pm 1.44$ & $-0.97 \pm 0.80$ & 0.066 \\
PAL (ADMR/RMR) & $1.85 \pm 0.37$ & $-0.10 \pm 0.13$ & \\
\hline
\end{tabular}

\section{DISCUSSION}

The basis for restricting one's energy intake is knowledge of his/her habitual intake. The availability of the doubly labeled water technique permits the measurement of ADMR over one to two weeks. Since estimation of ADMR by the doubly labeled water method is expensive, it was performed in eight subjects from the ER group only. Habitual energy intake was estimated by means of a 7-day dietary record by all subjects. To gain some insight into the difference between reported intake and energy expenditure, these two methods were compared. Reported energy intake appeared to be $82.5 \%$ of the ADMR. Underreporting is a common phenomenon in recording dietary intake, ${ }^{18}$ and seemed to have occurred also in our study, despite the fact that the subjects were aware of the importance of the dietary record. Therefore some subjects might be restricted in their energy intake by more than $20 \%$. In these eight subjects the average level of energy restriction was $33 \%$ (range 18-42\%). This result might be a reflection of the whole ER group. Since the control group lost some weight as well, underreporting might also have played a role in this group.

The main goal of this study was to evaluate the adaptation to a moderate restriction in energy intake in non-obese subjects. Many studies on the effects of an energy-restricted diet are performed in obese subjects receiving very low caloric diets, or in anorexia nervosa patients. 
Table 5.3. Rate constants (per day) and dilution spaces of ${ }^{18} \mathrm{O}$ and ${ }^{2} \mathrm{H}(\mathrm{mol})$ before and at the end of the intervention period.

\begin{tabular}{|c|c|c|c|c|c|c|c|c|}
\hline \multirow[t]{2}{*}{$\begin{array}{l}\text { Subject } \\
\text { nr. }\end{array}$} & \multicolumn{4}{|c|}{$\begin{array}{l}\text { Before } 10 \text { weeks of moderate } \\
\text { energy restriction }\end{array}$} & \multicolumn{4}{|c|}{$\begin{array}{l}\text { At the end of } 10 \text { weeks of moderate } \\
\text { energy restriction }\end{array}$} \\
\hline & $\mathrm{kO}$ & kH & nO & $\mathrm{nH}$ & $\mathrm{kO}$ & $\mathrm{kH}$ & nO & $\mathrm{nH}$ \\
\hline 1 & 0.11171 & 0.07857 & 2554.3 & 2627.4 & 0.12582 & 0.09808 & 2439.7 & 2552.0 \\
\hline 2 & 0.10670 & 0.07948 & 2627.8 & 2731.8 & 0.10957 & 0.08361 & 2527.1 & 2608.0 \\
\hline 3 & 0.10180 & 0.07690 & 2550.1 & 2652.2 & 0.09671 & 0.07378 & 2481.4 & 2606.3 \\
\hline 4 & 0.11005 & 0.08116 & 2218.2 & 2299.6 & 0.10543 & 0.08371 & 2143.8 & 2224.1 \\
\hline 5 & 0.10282 & 0.07885 & 2222.2 & 2287.8 & 0.09671 & 0.07581 & 2151.7 & 2242.3 \\
\hline 6 & 0.09018 & 0.06750 & 2615.3 & 2709.4 & 0.09406 & 0.07567 & 2449.9 & 2534.8 \\
\hline 7 & 0.09866 & 0.07333 & 2345.4 & 2424.6 & 0.10246 & 0.07939 & 2304.9 & 2370.8 \\
\hline 8 & 0.12160 & 0.09524 & 2378.2 & 2462.3 & 0.10429 & 0.08486 & 2308.7 & 2415.3 \\
\hline
\end{tabular}

$\mathrm{kO}=$ rate constant for ${ }^{18} \mathrm{O} ; \mathrm{kH}=$ rate constant for ${ }^{2} \mathrm{H} ; \mathrm{nO}=$ dilution space for ${ }^{18} \mathrm{O} ; \mathrm{nH}=$ dilution space for ${ }^{2} \mathrm{H}$.

However, data on the effects of moderate ER in non-obese man have, to our knowledge, only been reported by two groups: Heyman et al. ${ }^{8}$ provided normal-weight subjects with a diet with a gross energy deficit of $3.37 \mathrm{MJ} /$ day for 21 days, i.e. approximately $20 \%$ ER. Subjects lost about $2.0 \mathrm{~kg}$ body weight. The authors noted that energy balance is regulated by changes in body energy stores (63\%) and energy expenditure (37\%). However, these data reflect the results of only the short-term effects of moderate ER. Garby et al. ${ }^{9}$ asked normalweight subjects to reduce their energy intake by $25 \%$ over a period of 12 weeks. No changes were observed in $24 \mathrm{~h}$ energy expenditure and pattern of physical activity. Mean change in body weight was $-2.9 \pm 3.0 \mathrm{~kg}$. When the recorded food intake was assumed to be correct, this weight loss was far below that calculated and indicates non-compliance with the diet. Since little information is available about the effects of longer-term moderate energy restriction under controlled dietary conditions our study was performed, especially to investigate the adaptation of energy metabolism to a reduced energy intake.

One of the questions was whether the subjects would regain a new stable weight after a period of moderate energy restriction. In the classical semi-starvation study by Keys et al., ${ }^{19}$ in which the subjects received a 50\% energy-restricted diet for 24 weeks, the rate of weight loss did not decrease during the first 16 weeks but was close to zero at the end of the study. Since this $50 \%$ reduction in energy intake appeared to introduce several negative health effects (symptoms of lethargy, apathy and listlessness), a level of $20 \%$ energy restriction for 10 weeks was chosen. However, since underreporting of food intake has taken place the actual level of energy restriction was about 33\%. As shown in Figurc 5.1, subjects were still losing weight at the end of the experimental period and there was no tendency to stabilization. Whether or when these subjects would reach a new stable 
weight (steady state), and what this new weight would be, is uncertain. The control group, submitted to a mild level of energy restriction due to underreporting, did show weight stabilization as rate of weight loss was close to zero at the end of the study (Figure 5.1). Linear regression revealed a significant relationship between week and weight change $(r=0.602, P=0.032)$ in the control group.

To assess when the ER group would reach a steady state a computer simulation model can be used..$^{20}$ This model simulates changes in FM and FFM using energy intake (EI) and physical activity as input variables. EI can be set at a chosen value or calculated from dietary intake with a data base on the net energy of foods. Physical activity can be set at a chosen multiple of basal metabolic rate (BMR) or calculated from the activity budget with a data base on the energy cost of activities in multiples of BMR. BMR is calculated from FFM and FM and, if necessary, FFM is calculated from body weight, height, sex and age, using emperical equations. The model uses existing knowledge on the adaptation of energy expenditure (EE) to a disbalance between $\mathrm{EI}$ and $\mathrm{EE}$, and to resulting changes in FM and FFM. Mobilisation and storage of energy as FM and FFM is a function of the relative size of the deficit (EI/EE) and of the body composition. The model was validated with three recent studies measuring $\mathrm{EE}$ at a fixed EI during an interval with energy restriction, overfeeding and exercise training, respectively. Discrepancies between observed and simulated changes in energy stores were within the measurement precision of EI, EE, and body composition. Introduction of our data in this computer simulation model revealed that, on the long term, this $33 \%$ level is too high to adapt to. Even when a level of $20 \%$ energy restriction was induced, then, according to this simulation model, the subjects would still be in negative energy balance $(-940 \mathrm{~kJ} /$ day) after a period of one year. Body weight would be approximately $59 \mathrm{~kg}$, and subjects would have about $5.6 \%$ body fat.

$25 \% \mathrm{FFM} / 75 \% \mathrm{FM}$-loss is considered as a 'rule of thumb' in weight-loss studies. ${ }^{4}$ In the study presented $17 \%$ of weight loss was attributed to loss of FFM which might be a favourable effect of moderate ER. FFM has also been calculated from urinary creatinine excretion. ${ }^{21}$ Urinary creatinine excretion before the experimental period correlated moderately with FFM $(r=0.445 ; \mathrm{P}=0.029)$. Despite some loss of FFM in the ER group, no significant change in creatinine excretion could be detected. This may be due to the small size of the group, and to the fact that only one 24-hour urine was collected. Creatinine excretion is affected by the amount of meat in the diet. In this study food intake was completely controlled since all food, including meat, was supplied by the Institute, and was kept constant during the entire study.

From the measurements performed in all subjects it is clear that the subjects reacted to the moderate energy deficit by lowering resting energy metabolism $(-13 \%)$ and by losing $7.4 \pm 1.7 \mathrm{~kg}$ body weight in ten weeks, which means that mean rate of weight loss was approximately $0.74 \mathrm{~kg} /$ week. Weight losses, induced by balanced deficit diets (BDD) 
providing $5 \mathrm{MJ} / \mathrm{day}$, of $0.72 \mathrm{~kg} /$ week and $0.70 \mathrm{~kg} /$ week after a period of 10 weeks have been observed $d^{22,23}$ which is not lower than that observed in our study. Since energy expenditure in obese women has been reported to be about $11 \mathrm{MJ} / \mathrm{day},{ }^{24,25}$ these BDD's induce approximately $50 \%$ ER. It is not very likely that the 33\% ER (providing ca. 9.2 $\mathrm{MJ} /$ day), is as effective in loosing weight as $50 \%$ ER induced by BDD's (providing ca. $5 \mathrm{MJ} /$ day). This can only be explained by supposing that the participants in these BDDstudies did not adhere completely to their prescribed diets, and most probably decreased their level of ER to approximately $30 \%$.

FFM correlated significantly with RMR (MJ/day) both before $(\mathrm{P}=0.01)$ and after $(P<0.001)$ the experimental period. However, after the experimental period the intercept of the regression line had decreased significantly (Figure 5.2). This might indicate an enhanced metabolic efficiency after a period of energy restriction, related to the changes in thyroid function (i.e. decreased T3 and increased rT3 levels), a phenomenon also seen after VLCD. ${ }^{26}$ However, the fall in RMR (MJ/day) of $13.3 \%$ was less than that reported after VLCD ${ }^{4}$ but is comparable to that observed after BDD. ${ }^{27}$

From the difference between ADMR measured before and energy intake during the intervention period in those 8 subjects who consumed the doubly labeled water, the total energy deficit in the energy-restricted period was calculated to be $333.7 \mathrm{MJ}$. As shown in Table 5.2, these 8 subjects lost $6.8 \mathrm{~kg}$ body weight (5.8 kg fat mass; $1.0 \mathrm{~kg}$ FFM) on average. The energy values for the two body constituents, fat mass and FFM, are 37.7 and $3.68 \mathrm{MJ} / \mathrm{kg}$ respectively. ${ }^{28}$ Thus, the energy content of the body decreased by $5.8 * 37.7+1.0 * 3.68=222.4 \mathrm{MJ}$ in 10 weeks of energy restriction. This indicates that approximately $111.3 \mathrm{MJ}(333.7$ - 222.4) was saved by decreasing energy expenditure (ADMR). We may therefore conclude that the decrease in body energy stores compensated for $67 \%$ and the decrease in ADMR for $33 \%$ of the energy deficit on average. The decrease in ADMR was partly due to decreased activity, partly to a decreased RMR, and partly to a decreased diet-induced thermogenesis (DIT) assumed to be $10 \%$ of energy intake. These findings are consistent with those observed by Heyman et al. ${ }^{8}$ The decrease in energy expended on physical activity might be the consequence of either reduced physical activity, or decreased expenditure on work due to reduced body weight, or both. The reduction in RMR may be due to a loss of metabolizing tissue, or to a change in the rate of metabolism of the remaining tissue, or to a combination of both factors.

To summarize, this study shows that, under controlled dietary conditions, a moderately energy restricted diet (33\%), can lead to an average rate of weight loss of $0.74 \mathrm{~kg} /$ week in non-obese men. In addition, moderate energy restriction induces a loss of FFM, as well as a decreased RMR which is associated with decreased T3 concentrations. These results are comparable to those of studies providing a balanced dietary deficit (5 MJ/day) in obese. 


\section{REFERENCES}

1. Burgess NS. Effect of a very-low-calorie diet on body composition and resting metabolic rate in obese men and women. Research 1991;91:430-434.

2. Cavallo E, Armellini F, Zamboni M, Vicentini R, Milani MP, Bosello O. Resting metabolic rate, body composition and thyroid hormones: short term effects of very low calorie diet. Horm Metab Res 1990;22:632-635.

3. Fricker J, Rozen R, Melchoir JC, Apfelbaum M. Energy-metabolism adaptation in obese adults on a very-low-calorie diet. Am J Clin Nutr 1991;53:826-830.

4. Prentice AW, Goldberg GR, Jebb, SA, Black AE, Murgatroyd PR, Diaz EO. Physiological responses to slimming. Proc Nutr Soc 1991;50:441-458.

5. Hulshof $T$, de Graaf C, Weststrate JA. Fat and non-absorbable fat (SPE) in croissants have similar effects on satiety and subsequent short term food intake. Int J Obesity 1993;17:64.

6. Kendall A, Levitsky DA, Strupp BJ, Lissner L. Weight loss on a low-fat diet: consequence of the imprecision of the control of food intake in humans. Am J Clin Nutr 1991;53:1124-1129.

7. Lissner L, Levitsky DA, Strupp BJ, Kalkwarf HJ, Roe DA. Dietary fat and the regulation of energy intake in human subjects. Am J Clin Nutr 1987;46:886-892.

8. Heyman MB, Young VR, Fuss P, Tsay R, Joseph L, Roberts SB. Underfeeding and body weight regulation in normal-weight young men. Am J Physiol 1992;32:R250-R257.

9. Garby L, Kurzer MS, Lammert O, Nielsen E. Effect of 12 weeks' light-moderate underfeeding on 24-hour energy expenditure in normal male and female subjects. Eur J Clin Nutr 1988:42:295-300.

10. Velthuis-te Wierik EJM, van den Berg H, Schaafsma G, Hendriks HFJ, Brouwer A. Energy restriction, a useful intervention to retard human aging? Results of a feasibility study. Eur $\mathrm{J}$ Clin Nutr 1994;48:138-148.

11. Siri WE. Body composition from fluid spaces and density: analysis and methods. In: Techniques for measuring body composition, eds J. Brozek \& A. Henschel, Washington DC: Natl Acad Sci, Natl Dairy Council, 1961, p223-244..

12. Brozek J, Grande E, Anderson JT, Keys A. Densitometric analysis of body composition: revision of some quantitative assumptions. Ann NY Acad Sci 1963;110:113-140.

13. Deurenberg $P$, Weststrate JA, Seidell JC. Body mass index as a measure of body fatness: age- and sex-specific prediction formulas. Br J Nutr 1991;65:105-114.

14. van Marken Lichtenbelt WD, Westerterp KR, Wouters L. Deuterium dilution as a method for determining total body water: effect of test protocol and sampling time. $\mathrm{Br}$ J Nutr 1994;72:491-497.

15. Schoeller DA, van Santen E, Peterson DW, Dietz W, Jaspan J, Klein PD. Total body water measurement in humans with ${ }^{18} \mathrm{O}$ and ${ }^{2} \mathrm{H}$ labeled water. Am J Clin Nutr 1980;33:2686-2693.

16. Weir JB. New methods for calculating metabolic rate with special reference to protein metabolism. J Physiol 1949;109:1-9.

17. Westerterp KR, Wouters L, van Marken Lichtenbelt WD. The Maastricht protocol for the measurement of body composition and energy expenditure with labeled water. Obesity Res 1995;3 suppl 1:49-57.

18. Mertz W, Tsui JC, Judd JT, Reiser S, Hallfrisch J, Morris ER, Steele PD, Lasley E. What are peoplc really eating? The relation between energy intake derived from estimated diet records and intake determined to maintain body weight. Am J Clin Nutr 1991;54:291-295.

19. Keys A, Brozek J, Henschel A, Mickelsen O, Taylor HL. The biology of human starvation. Minneapolis: The University of Minnesota Press, 1950.

20. Westerterp KR, Donkers JHHLM, Fredrix EWHM, Boekhoudt P. Energy intake, physical activity and body weight: a simulation model. Br J Nutr, 1995;73:337-347.

21. Forbes GB, Bruining GJ. Urinary creatinine excretion and lean body mass. Am J Clin Nutr 1976;29:1359-1366.

22. Foster GD, Wadden TA, Feurer ID, Jennings AS, Stunkard AJ, Crosby LO, Ship J, Mulien JL. Controlled trial of the metabolic effects of a very-low-calorie diet: short- and long-term cffects. Am $\mathrm{J}$ Clin Nutr 1990;51:167-172.

23. Wadden TA, Foster GD, Letizia KA, Mullen JL. Long-term effects of dieting on resting metabolic 
rate in obese outpatients. JAMA 1990;264:707-711.

24. Meijer GAL, Westerterp KR, van Hulsel AMP, ten Hoor F. Physical activity and energy expenditure in lean and obese adult human subjects. Eur J Appl Physiol 1992;65:525-528.

25. Prentice AM, Black AE, Coward WA, Davies HL, Goldberg GR, Murgatroyd PR, Ashford J, Sawyer M, Whitehead RG. High levels of energy expenditure in obese women. $\mathrm{Br}$ Med J 1986;292:983-987.

26. Apfelbaum M. Metabolic effects of low and very low calorie diets. Int J Obesity 1993;17 (suppl 1):S13-S16.

27. Wadden TA, van Italie TB, Blackburn GL. Responsible and irresponsible use of very-low-calorie diets in the treatment of obesity. JAMA 1990;263:83-85.

28. Garrow JS. Energy balance in obesity and man. Amsterdam, London: North-Holland Publishing Company, 1974. 


\title{
Beneficial effect of a moderately energy-restricted diet on fibrinolytic factors in non-obese men
}

\author{
Erica J.M. Velthuis-te Wierik ${ }^{1}$, Piet Meijer ${ }^{2}$, Cornelis Kluft $^{2}$ and \\ Henk van den Berg ${ }^{1}$
}

${ }^{1}$ TNO Nutrition and Food Research Institute, Zeist, The Netherlands

${ }^{2}$ TNO Prevention and Health, Gaubius Institute, Leiden, The Netherlands

Metabolism, accepted for publication

\section{ABSTRACT}

Impaired fibrinolytic activity has been reported in the elderly and is thought to play a role in the aetiology of cardiovascular disease, one of the leading causes of death in most western countries. Since restriction of energy intake has been demonstrated to act beneficially on the ageing process in a variety of species, we studied the effect of a 10-week moderately energy-restricted regimen (80\% of habitual) on PAI activity, PAI-1 antigen, tPA activity and TPA antigen in non-obese middle-aged men. Moreover, the relationship between these fibrinolytic markers and glucose tolerance was investigated. Weight loss in the energy restricted group (ER group; $n=16$ ) was considerable $(-7.4 \pm 1.7 \mathrm{~kg} ; \mathrm{P}<0.001)$. Subjects in the control group $(\mathrm{n}=8)$ lost some weight too $(-2.1 \pm 1.5 \mathrm{~kg} ; \quad \mathrm{P}<0.01)$. Fasting glucose levels decreased in the ER group $(-0.31 \pm 0.48 \mathrm{mM} ; \mathrm{P}<0.05)$ which was correlated with the extent of weight loss $(\mathrm{P}<0.01)$. Baseline insulin levels at 2 hours after an oral glucose load correlated with baseline PAI activity $(\mathrm{P}<0.001)$ and PAI- 1 antigen levels $(\mathrm{P}<0.001)$. PAI activity decreased in the ER group $(-2.94 \pm 2.90 \mathrm{IU} / \mathrm{ml} ; \mathrm{P}<0.001)$ in particular in subjects with a high baseline PAI activity $(>9 \mathrm{IU} / \mathrm{ml})$. Furthermore, ER lead to decreased PAI-1 antigen concentration $(\mathrm{P}<0.05)$, a nonsignificant increase in tPA activity as well as a decrease in IPA antigen concentration $(P<0.001)$. All these changes were more clear in those subjects with a high baseline PAI activity. These results suggest that 10 weeks of moderate energy restriction has a profibrinolytic effect in non-obese middle-aged men, at least in subjects with higher baseline PAI activity $(>9 \mathrm{IU} / \mathrm{ml})$. Moreover, in line with the suggestion that a high PAI activity goes together with insulin resistance, a relationship between the insulin concentration after a glucose load and PAI activity was found. 


\section{INTRODUCTION}

Restriction of the energy intake (ER), with adequate intake of essential nutrients, is up to now the only dietary regimen known to have a beneficial effect on the ageing process in rodents, ER prolongs life span and delays or prevents the onset of several age-related diseases. ${ }^{1}$ The mechanism behind this process is still largely unknown and many efforts are now being directed at unravelling the causal relationship between energy metabolism and the ageing process. Since ER has been demonstrated to be effective in a variety of species these beneficial effects might also hold for human beings on an appropriate energy-restricted regimen. Obviously, it is difficult to assess the potential effect of ER in human beings in an experimental design. However, as a first approach, the feasibility and potential health risks/benefits of a moderately energy-restricted diet can be assessed. Another approach could be to study the effects of ER on physiological systems associated with the ageing process.

Cardiovascular disease is one of the leading causes of death in most western countries and has been related to the ageing process. Impaired fibrinolytic activity has been reported in the elderly ${ }^{2}$ and is thought to play a role in the pathogenesis/aetiology of cardiovascular disease. The activity of the fibrinolytic system depends on competing processes in a dynamic equilibrium involving circulating activators of plasminogen, primarily tissue-type plasminogen activator (tPA), and circulating inhibitors of these activators, primarily plasminogen activator inhibitor type 1 (PAI-1). Since energy restriction has a beneficial effect on the ageing process it may also have an effect on haemostatic function. Therefore, as part of a study into potential benefits and/or risks of a 10-week moderately energy-restricted regimen in non-obese middle-aged man, activities and concentrations of indicators of the fibrinolytic system (PAI activity, PAI-1 antigen, tPA activity, and TPA antigen) were analysed. In addition, since it has been suggested that PAI-1 contributes to the increased cardiovascular risk together with insulin resistance, ${ }^{3}$ the relationship between fibrinolytic markers and glucose tolerance was investigated.

\section{SUBJECTS AND METHODS}

\section{Subjects}

Twenty-four apparently healthy men aged $43 \pm 5 \mathrm{yr}$ (range $35-50 \mathrm{yr}$ ) with a mean body mass index (BMI) of $24.6 \pm 1.8 \mathrm{~kg} / \mathrm{m}^{2}$ (range $20.6-27.2 \mathrm{~kg} / \mathrm{m}^{2}$ ), participated in this study. All subjects had a stable weight during the past year, normal routine clinical chemistry and were non-smoking. They had normal dietary habits and no cxtreme level 
of energy intake (9.3-13.2 MJ/day; i.e. $97-214 \mathrm{~kJ} / \mathrm{kg} /$ day). Each subject was medically screened on the basis of a health questionnaire and a medical examination. Informed consent was obtained from each subject and the research protocol was approved by the Institute's external Medical Ethical Committee.

\section{Experimental design}

A detailed description of the study has been published elsewhere (Chapter 3 ).$^{4}$ In short, the habitual energy intake was estimated by means of a 7-day dietary record before the study started. The total experiment lasted 12 weeks. Subjects were randomly assigned to one of two groups: a control group (8 subjects) and an energy-restricted group (ER group; 16 subjects). These groups were matched on age and BMI. During the first two weeks of the study (run-in period) all subjects received a weight-maintaining test diet based upon the outcome of the dietary record. Since energy intake differs among individuals, subjects were divided into 6 'energy groups' with a stepwise increase of ca. $770 \mathrm{~kJ} /$ day, ranging from 9,304 to $13,147 \mathrm{~kJ} /$ day. When subjects lost more than $1 \mathrm{~kg} /$ week during this run-in period they were reclassified into a higher energy group.

After these two weeks the 8 control subjects were kept on their weight-maintaining diet for the next 10 weeks, while the other 16 subjects received a diet that contained $80 \%$ of the energy of their habitual (weight-maintaining) diet, and micronutrient levels of at least their recommended dietary allowances (RDAs). Energy restriction was achieved by substituting low-fat and artificially sweetened products for ordinary products. This implied that the relative contribution of carbohydrates, fat and protein to total energy intake was $51 \%, 34 \%$ and $15 \%$ respectively for the control group and $47 \%$, $36 \%$ and $17 \%$ respectively for the ER group. All foods and drinks to be consumed during these 12 weeks were supplied by the Institute. The subjects were not allowed to eat or drink (except water) anything but the diet supplied.

At the end of the run-in period and at the end of the experiment blood samples were drawn after an overnight fast for the analysis of indicators of the fibrinolytic system, as well as for fasting $(t=0)$ glucose and insulin concentrations. Thereafter, an oral glucose tolerance test (OGTT) was performed according to the WHO protocol: ${ }^{5}$ 2 hours after an oral glucose load (75 $\mathrm{g}$ in $250 \mathrm{ml}$ water, which had to be drunk within 15 minutes) another blood sample $(t=120)$ was drawn for the analysis of glucose and insulin concentrations.

\section{Methods}

Plasma glucose concentrations were analysed with a commercially available kit (Boehringer Mannheim Diagnostica; Hitachi 911, Japan). Plasma insulin concentrations were analysed with a commercial radioassay (Pharmacia, Roosendaal, The Netherlands) 
according to the kit protocol.

For the analysis of fibrinolytic factors blood was taken into ice-chilled tubes from the intermedian cubital vein by a venoject system. After centrifugation for $10 \mathrm{~min}$ at $1700 \mathrm{xg}$ and $4^{\circ} \mathrm{C}$ the plasma was collected, snap frozen and stored at $-80^{\circ} \mathrm{C}$ until analysis.

To measure PAI activity, PAI-1 antigen and tPA antigen blood was collected in CTAD buffer $(0.11 \mathrm{M}$ citrate, $15 \mathrm{nM}$ theophylline, $3.7 \mathrm{mM}$ adenosine and $0.198 \mathrm{mM}$ dipyridamole; Becton Dickinson, Meylon, France). For measuring IPA activity blood was collected in Stabilyte tubes (Biopool, Umeå, Sweden). PAI activity was measured by a titration method with two-chain tPA according to the method of Verheijen et al. ${ }^{6}$ Results are expressed relative to pooled plasma: $100 \%$ activity corresponds to neutralization of $7.6 \mathrm{IU} / \mathrm{ml}$ of tPA. PAI- 1 antigen was measured by means of an enzyme linked immunosorbent assay (ELISA) (Coalize@ PAI-1/Innotest PAI-1, Chromogenix $A B$, Möndal, Sweden ${ }^{7}$ ). tPA activity was measured with a bioimmunoassay for t-PA (Coatest ${ }^{\circledR}$ BIA t-PA, Chromogenix ${ }^{8}$ ). tPA antigen was measured with the Imulyse t-PA ${ }^{\mathrm{TM}}$ method (Biopool).

\section{$\underline{\text { Statistics }}$}

BMDP statistical software was used to detect changes within and between the groups, and to calculate correlations between parameters. Changes within the groups were tested for significance with the paired Student's t-test. Differences in changes between the two groups were tested with the unpaired Student's t-test. Relationships between two variables were calculated with Pearson's linear correlation coefficient. Since the control group lost some weight too, correlations were calculated for the entire subject population $(n=24)$.

\section{RESULTS}

Baseline subject characteristics (age, body weight, BMI and OGTT) as well as the change $(\Delta)$ after the experimental period are presented in Table 6.1. Both groups lost weight. However, as could be expected, subjects in the ER group lost significantly more weight, resulting in a drop in BMI. Fasting glucose levels $(t=0)$ significantly decreased in the ER group, with no significant difference between the ER group and the control group. This decrease in the fasting glucose level correlated with the extent of weight loss $(\mathrm{r}=0.531, \mathrm{P}=0.008)$, and with the change in BMI $(\mathrm{r}=0.576, \mathrm{P}=0.003)$. With regard to the parameters of the OGTT, no other significant changes were observed. 
Table 6.1. Baseline (start) physiological characteristics of the participants and the change ( $\Delta$ ) after 10 weeks of moderate energy restriction.

\begin{tabular}{|c|c|c|c|c|c|}
\hline & \multicolumn{2}{|c|}{ Control group } & \multicolumn{2}{|c|}{ Energy Restricted } & \multirow{2}{*}{$\begin{array}{c}P \\
\Delta c t r l \\
\text { vs } \Delta E R\end{array}$} \\
\hline & Start & $\Delta$ & Start & $\Delta$ & \\
\hline Age (yr) & $43 \pm 5$ & & $43 \pm 4$ & & \\
\hline Body weight (kg) & $77.7 \pm 6.6$ & $-2.1 \pm 1.5^{* *}$ & $78.6 \pm 9.3$ & $-7.4 \pm 1.7^{* * *}$ & $<0.001$ \\
\hline Body Mass Index $\left(\mathrm{kg} / \mathrm{m}^{2}\right)$ & $24.6 \pm 2.2$ & $-0.8 \pm 0.6$ & $24.9 \pm 1.8$ & $-2.3 \pm 0.8^{* * *}$ & $<0.001$ \\
\hline Glucose $t=0(m M)$ & $4.95 \pm 0.44$ & $0.02 \pm 0.30$ & $4.87 \pm 0.40$ & $-0.31 \pm 0.48^{*}$ & NS \\
\hline Glucose $t=120(\mathrm{mM})$ & $4.44 \pm 0.92$ & $-0.08 \pm 0.67$ & $4.44 \pm 1.04$ & $0.02 \pm 1.38$ & NS \\
\hline Insulin $\mathrm{t}=0(\mathrm{mU} / \mathrm{l})$ & $8.25 \pm 2.82$ & $-0.96 \pm 2.38$ & $7.37 \pm 2.75$ & $-1.38 \pm 3.00$ & NS \\
\hline Insulin $\mathrm{t}=120(\mathrm{mU} / \mathrm{l})$ & $30.5 \pm 19.9$ & $-1.5 \pm 6.4$ & $24.9 \pm 21.5$ & $-1.0 \pm 22.7$ & NS \\
\hline
\end{tabular}

${ }^{*}=\mathrm{P}<0.05 ;^{* *}=\mathrm{P}<0.01 ;^{* * *}=\mathrm{P}<0.001$.

Table 6.2. Baseline (start) levels of fibrinolytic factors and the change $(\Delta)$ after 10 weeks of moderate energy restriction."

\begin{tabular}{|c|c|c|c|c|c|}
\hline & \multicolumn{2}{|c|}{ Control group } & \multicolumn{2}{|c|}{ Energy Restricted } & \multirow{2}{*}{$\begin{array}{c}\text { P } \\
\Delta \text { ctrl } \\
\text { vs } \Delta \mathrm{ER}\end{array}$} \\
\hline & Start & $\Delta$ & Start & $\Delta$ & \\
\hline PAI activity (IU/mI) & $9.3 \pm 3.2$ & $0.7 \pm 3.6$ & $10.3 \pm 4.4$ & $-2.9 \pm 2.9^{* * *}$ & 0.018 \\
\hline (subgroup 1) & $7.4 \pm 1.8$ & $-0.7 \pm 0.5$ & $7.0 \pm 1.5$ & $-0.5 \pm 0.6^{*}$ & NS \\
\hline (subgroup 2) & $12.3 \pm 2.6$ & $3.0 \pm 5.7$ & $13.6 \pm 3.8$ & $-5.4 \pm 2.1^{* * *}$ & 0.007 \\
\hline PAI-1 antigen (ng/ml) & $57.1 \pm 40.0$ & $-4.6 \pm 40.2$ & $60.8 \pm 41.3$ & $-30.1 \pm 38.8^{*}$ & NS \\
\hline (subgroup 1) & $45.9 \pm 44.5$ & $-15.3 \pm 28.0$ & $39.1 \pm 16.1$ & $-18.5 \pm 17.3^{*}$ & NS \\
\hline (subgroup 2) & $75.6 \pm 82.4$ & $13.3 \pm 57.8$ & $82.4 \pm 48.4$ & $-41.7 \pm 51.5$ & NS \\
\hline tPA activity $(\mathrm{mIU} / \mathrm{ml})$ & $291 \pm 116$ & $-91 \pm 91^{*}$ & $341 \pm 247$ & $50 \pm 165$ & NS \\
\hline (subgroup 1) & $352 \pm 89$ & $-100 \pm 78$ & $490 \pm 268$ & $-8 \pm 217$ & NS \\
\hline (subgroup 2) & $189 \pm 80$ & $-76 \pm 127$ & $192 \pm 90$ & $108 \pm 61^{* *}$ & 0.012 \\
\hline tPA antigen $(\mathrm{ng} / \mathrm{ml})$ & $4.9 \pm 2.8$ & $-1.1 \pm 0.8$ & $6.3 \pm 3.5$ & $-3.1 \pm 2.1^{* * *}$ & 0.005 \\
\hline (subgroup 1) & $3.3 \pm 1.8$ & $-1.1 \pm 1.1$ & $4.4 \pm 3.3$ & $-2.0 \pm 2.4$ & NS \\
\hline (subgroup 2) & $7.6 \pm 1.7$ & $-1.2 \pm 0.3$ & $8.3 \pm 2.5$ & $-4.3 \pm 0.8^{* * *}$ & $<0.001$ \\
\hline
\end{tabular}

a subgroup 1: baseline PAI activity $\leq 9 \mathrm{IU} / \mathrm{ml}$, control group $\mathrm{n}=5$, ER group $\mathrm{n}=9$; subgroup 2: baseline PAl activity $>9 \mathrm{IU} / \mathrm{ml}$, control group $n=3$, ER group $n=7$.

${ }^{*}=\mathrm{P}<0.05 ;{ }^{* *}=\mathrm{P}<0.01 ;{ }^{* *}=\mathrm{P}<0.001$. 
The results on fibrinolytic parameters are presented in Table 6.2. At baseline, these parameters did not differ significantly between groups. Energy restriction resulted in significantly lower PAI activity. Further inspection of the data (Figure 6.1) showed that the decrease of PAI activity in the ER group was modest in subjects $(n=9)$ with baseline PAI activity levels $\leq 9 \mathrm{IU} / \mathrm{ml}$ (subgroup 1), but was most marked in subjects $(\mathrm{n}=7$ ) with a baseline PAI activity higher than $9 \mathrm{IU} / \mathrm{ml}$ (subgroup 2). PAI-1 antigen level decreased significantly in the ER group. In this group, the high-PAI subgroup (subgroup 2) showed the strongest decrease in PAI-1 antigen level but this decrease was not significant $(P=0.08)$. tPA activity decreased significantly in the control group but not in the ER group. However, when baseline PAI activity level was taken into account TPA activity increased significantly in subgroup 2. tPA antigen decreased significantly in both the control and the ER group, although the effect was more outspoken in the ER group, especially in subgroup 2.

A similar subgroup analysis was also performed for the control group although the subgroups are relatively small $(n=3 ; n=5)$ for statistical analysis.

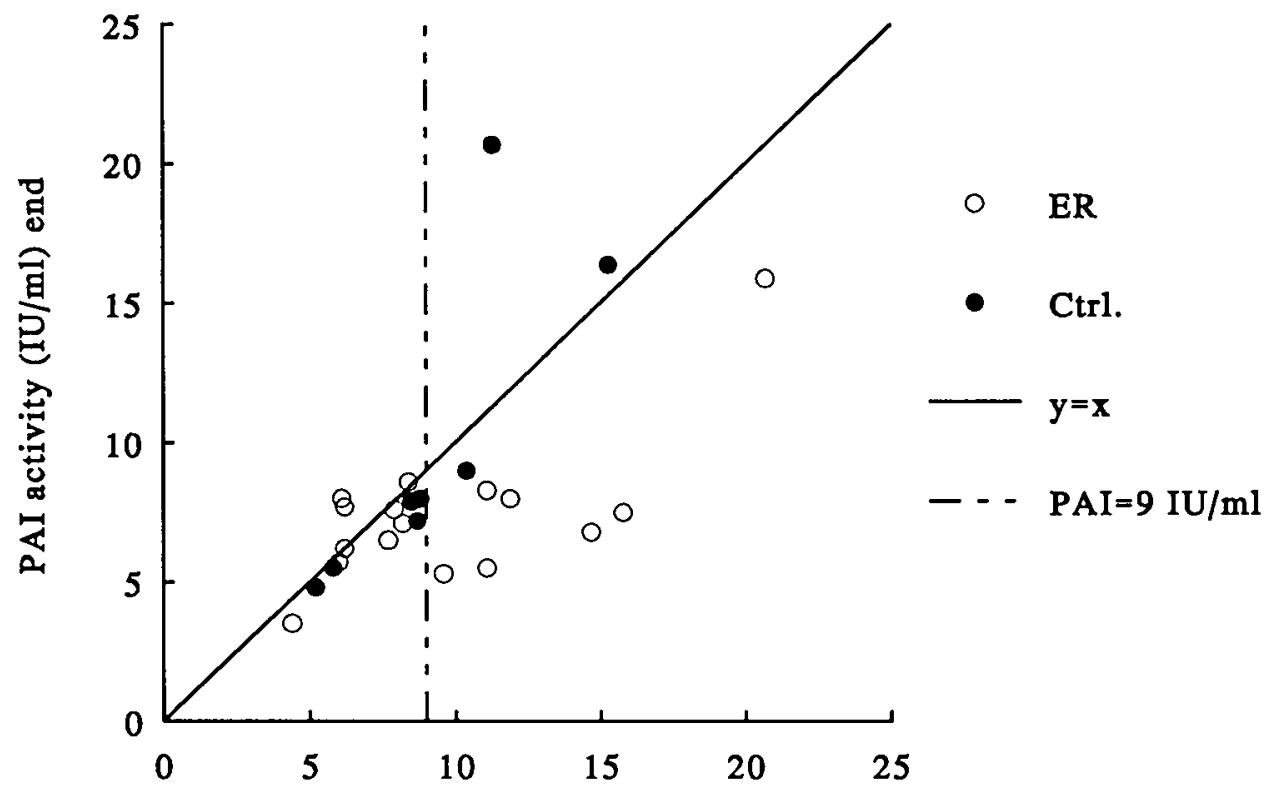

PAI activity (IU/ml) baseline

Figure 6.1. Relationship between PAI activity at baseline and at the end of the intervention period.

$-y=x ;-\cdots-.-P A I=9 \mathrm{IU} / \mathrm{ml}$. 
Correlation coefficients were calculated between baseline values as well as between changes in the parameters analysed. Baseline PAI activity was found to be inversely correlated to tPA activity $(r=-0.683, P<0.001)$, and significantly related to PAI-1 antigen concentration $(r=0.675, P<0.001)$ as well as to tPA antigen concentration $(r=0.640, P<0.001)$. Baseline insulin level at $t=120$ was significantly related to baseline PAI activity and antigen levels. Baseline BMI was not correlated with baseline PAI activity, but the decrease in BMI correlated slightly but significantly with the decrease in PAI activity (Table 6.3).

Table 6.3. Correlations ( $\mathrm{r}$ ) between baseline fibrinolytic factors and some physiolocal parameters (BMI and OGTT), as well as between changes in these parameters $(n=24)$.

\begin{tabular}{lcccc}
\hline & PAI activity & PAI-1 antigen & t-PA activity & t-PA antigen \\
\hline BMI & 0.295 & 0.349 & -0.151 & 0.264 \\
Glucose $\mathrm{t}=0$ & 0.330 & 0.305 & -0.296 & 0.339 \\
Insulin $\mathrm{t}=0$ & $0.291^{*}$ & 0.226 & 0.053 & 0.394 \\
Glucose $\mathrm{t}=120$ & $0.504^{*}$ & $0.594^{* *}$ & -0.245 & 0.360 \\
Insulin $\mathrm{t}=120$ & $0.711^{* * *}$ & $0.752^{* * *}$ & $-0.538^{* *}$ & $0.619^{* * *}$ \\
& & & & \\
& $\Delta$ PAI activity & $\Delta$ PAI antigen & $\Delta$ t-PA activity & $\Delta$ t-PA antigen \\
\hline$\Delta$ BMI & $0.414^{*}$ & 0.360 & -0.330 & $0.442^{*}$ \\
$\Delta$ Glucose $\mathrm{t}=0$ & $0.126^{*}$ & 0.180 & -0.244 & 0.006 \\
$\Delta$ Insulin $\mathrm{t}=0$ & $-0.008^{*}$ & -0.082 & $0.440 *$ & 0.311 \\
$\Delta$ Glucose $\mathrm{t}=120$ & 0.052 & 0.253 & 0.044 & 0.045 \\
$\Delta$ Insulin $\mathrm{t}=120$ & 0.073 & 0.303 & -0.084 & 0.016 \\
\hline
\end{tabular}

${ }^{*}=\mathrm{P}<0.05 ;{ }^{* *}=\mathrm{P}<0.01 ;{ }^{* * *}=\mathrm{P}<0.001$.

\section{DISCUSSION}

The aim of this study was to look after potential health risks or benefits of the application of a moderately energy-restricted diet with special regard to fibrinolytic factors. High PAI activity, leading to decreased fibrinolytic activity, can predict coronary thrombosis. ${ }^{9}$ There is general agreement on lower fibrinolytic activity in obesity: in observational studies an inverse relationship between obesity and fibrinolytic activity, ${ }^{10,11}$ as well as a positive correlation between BMI and PAI activity ${ }^{12,13}$ has been found. From a case-control study it appeared that obese subjects had lower fibrinolytic activity associated with elevated PAI-1 concentrations which, in turn, correlated with increased concentrations of insulin. ${ }^{14}$ The small range in BMI in our study probably explains why 
we did not find an association between BMI and fibrinolytic factors, as compared to the large range $\left(16-39 \mathrm{~kg} / \mathrm{m}^{2}\right)$ in the studies mentioned.

Intervention studies into the effects of ER and/or weight loss on the fibrinolytic system have especially been reported for obese but hardly for lean subjects, and were focused either on very-low-caloric-diets (VLCD) or on surgical treatment. In obese subjects $\left(\mathrm{BMI}>30 \mathrm{~kg} / \mathrm{m}^{2}\right.$ ), VLCD for 3 months $^{15}$ or 6 months ${ }^{16}$ has been reported to lower factor VII, ${ }^{15,16}$ PAI activity, ${ }^{15}$ PAI-1 antigen ${ }^{16}$ as well as IPA antigen ${ }^{16}$ which is associated with marked weight loss. Surgical treatment resulted in a mean decrease in body weight of $64 \mathrm{~kg}$ at 12 months and was accompanied by significant reductions in factor VII, fibrinogen concentration and PAI activity. ${ }^{17}$ From these intervention studies it can be concluded that fibrinolytic activity increases after severe weight loss in the obese. However, dieting also occurs among lean subjects. Ogston ${ }^{10}$ noted that a diet of $590 \mathrm{~kJ} /$ day for 3 days increased fibrinolytic activity in non-obese subjects. To our knowledge, no studies have reported on the effects of moderate energy restriction in non-obese subjects. Therefore, this is the first longer-term study into the effects of moderate energy restriction on fibrinolytic factors showing that even moderate energy restriction has beneficial effects on fibrinolytic factors, at least in subjects with higher $\mathrm{PAI}$ activity ( $>9 \mathrm{IU} / \mathrm{ml}$ ). Although this decrease could be ascribed to a 'regression to the mean', it is noteworthy that PAl activity did not decrease in the control group (Figure 6.1).

In the present study the effect of ER on lipid profile was also measured, the results of which are presented elsewhere ${ }^{4}$. Briefly, no significant of ER on fasting triglyceride, total cholesterol, LDL-cholesterol and HDL-cholesterol concentrations were observed using students t-test. However, the decrease in body weight was significantly related with an increase in HDL-cholesterol. PAI-1 antigen has been associated with several cardiovascular risk factors including hypertension, hypertriglyceridemia, glucose intolerance and type II diabetes mellitus. ${ }^{18}$ In this study PAI-activity correlated significantly with fasting triglyceride, total cholesterol and LDL-cholesterol concentrations $(r=0.743, P<0.001 ; r=0.506, P=0.012$ and $r=0.514, P=0.010$ respectively in 24 subjects). In addition, in our study subjects with a PAI activity $>9 \mathrm{IU} / \mathrm{ml}(\mathrm{n}=10)$ did not differ in BMI or in systolic or diastolic blood pressure but had significantly higher baseline glucose levels at $\mathrm{t}=0(\mathrm{P}=0.015)$ and triglycerides concentration $(P=0.038)$ and tended to have higher insuline levels at $t=120$ $(P=0.059)$. This association suggests a link between PAI-1 antigen and insulin resistance (i.e. 'resistance to the glucose-stimulating effects of insulin in key organs such as muscle tissue, liver and fat, leading to higher glucose concentrations, albeit within the normal ranges' ${ }^{19}$ ). This link has been studied by Potter van Loon et al. ${ }^{3}$ by means of a sequential hyperinsulinemic euglycemic clamp study in obese subjects. They found that 
PAI-1 antigen correlated significantly with peripheral insulin resistance. In our study significant correlations between baseline fasting PAI activity/antigen and glucose as well as insulin levels at two hours after a glucose load were observed. This finding suggest a similar relationship between insulin sensitivity and PAI activity, even in lean subjects. After 10 weeks of moderate energy restriction the correlation between PAI activity and insulin at $t=120$ was less obvious but still significant $(r=0.565, P=0.006)$, probably due to smaller ranges.

The mediator between insulin and PAI is not clear yet. ${ }^{20,21}$ In vitro, the secretion of PAI-1 by cultured hepatocytes in promoted by insulin.?

In conclusion, this study shows that moderate energy restriction in non-obese men with PAI activity levels higher than $9 \mathrm{IU} / \mathrm{ml}$ has beneficial effects on fibrinolytic factors. In addition, before the intervention period, PAI activity was significantly correlated with insulin and glucose levels at two hours after a glucose load, in agreement with the suggestion that higher PAI activity encounters insulin resistance. Since moderate energy restriction has a beneficial effect on the ageing process, and impaired fibrinolytic activity is associated with ageing, energy restriction might at least in part delay the ageing process by increasing fibrinolytic activity.

Since this study presents the results of a 10 -week energy-restricted diet we can only speculate on the longer-term effects. However, it is very difficult to conduct controlled feeding studies for periods longer than 12 weeks. In this study we aimed at $20 \% \mathrm{ER}$, but due to underreporting of habitual energy intake, as indicated by weight loss in the control group, the imposed energy restriction was probably higher than $20 \%$. Since subjects were still losing weight at the end of the intervention period with no sign of a tendency to stabilize, we feel that the imposed level of energy restriction might be too high and not feasible as a long-term intervention. Therefore, in future studies, we will focus on longer- term feasibility of a more moderate ER regimen and under freeliving conditions. However, the results of this study clearly show that moderate ER is also relevant in lean subjects and has a health-potentiating effect.

Since this study presents only fibrinolytic factors, and not true fibrinolytic activity, it would also be worthwhile to study the effect of a period of moderate energy restriction on true fibrinolytic activity. However, from the results of this study, i.e. a decreased PAI activity and in increased tPA activity in the high-PAI subgroup, an increased true fibrinolytic activity might be expected. Since this study shows that moderate energy restriction acts profibrinolytically in healthy non-obese men, it would also be valuable to study whether these results are representative for other populations, including those with higher risks for cardiovascular disease. 


\section{ACKNOWLEDGEMENT}

The authors wish to thank R.M. van den Burg for his skilful assistence.

\section{REFERENCES}

1. Weindruch R, Walford RL. The retardation of aging and disease by dietary restriction. Springfield, Illinois USA, Charles C. Thomas Publisher, 1988.

2. Abbate R, Prisco D, Rostagno C, Boddi M, Gensini GF. Age-related changes in the hemostatic system. Int J Clin Lab Res 1993;23:1-3.

3. Potter van Loon BJ, Kluft C, Radder JK, Blankenstein MA, Meinders AE. The cardiovascular risk factor plasminogen activator inhibitor type 1 is related to insulin resistance. Metabolism 1993;42:945-949.

4. Velthuis-te Wierik EJM, van den Berg H, Schaafsma G, Hendriks HFJ, Brouwer A. Energy restriction, a useful intervention to retard human aging? Results of a feasibility study. Eur $J$ Clin Nutr 1994;48:138-148.

5. WHO Study Group: Diabetes Mellitus. World Health Organisation Technical Report Series 727. Geneva, World Health Organisation, 1985.

6. Verheijen JH, Chang GTG, Kluft C. Evidence for the occurrence of a fast-acting inhibitor for tissue-type plasminogen activator in human plasma. Thromb Haemostas 1984;51:392-395.

7. Meijer P, Pollet DE, Wauters J, Kluft C. Specificity of antigen assays of plasminogen activator inhibitor in plasma: Innotest PAI-1 immunoassay evaluated. Clin Chem 1994;40:110-115.

8. Meijer $\mathrm{P}$, Boon R, Jic AFH, Rosén S, Kluft $\mathrm{C}$. Bioimmunoassay for tissuc-type plasminogen activator ( $t-P A)$ in human plasma: elevation of blood sampling and handling procedures and comparison with other t-PA activity methods. Fibrinolysis 1992;6(suppl 3):97-99.

9. Prisco D, Chiaranti E, Boddi M, Rostagno C, Colella A, Gensini GF. Predictive valuc for thrombic disease of plasminogen activator inhibitor-1 plasma levels. Int $\mathrm{J}$ Clin Lab Res 1993;23:78-82.

10. Ogston D, McAndrew GM. Fibrinolysis in obesity. Lancet 1964;ii:1205-1207.

11. Meade TW, Chakrabarti R, Haines AP, North WR, Stirling Y. Characteristics affecting fibrinolytic activity and plasma fibrinogen concentrations. BMJ 1979;1:153-156.

12. Heinrich J, Nguyĉn T, Kokott R, Epping PH, Schulte H, Assman G. Interrelationships betwecn coronary risk factors and the fibrinolytic system. Fibrinolysis 1990;4:37.

13. Vague P, Juhan-Vague I, Aillaud F, Badier C, Viard R, Alessi MC, Collen D. Correlation between blood fibrinolytic activity, plasminogen activator inhibitor level, plasma insulin level, and relative body weight in normal and obese subjects. Metabolism 1986;35:250-253.

14. McGill JB, Schneider DJ, Arfken CL, Lucore CL, Sobel BE. Factors responsible for impaired fibrinolysis in obese subjects and NIDDM paticnts. Diabctes 1994;43:104-109.

15. Palareti G, Legnani C, Poggi M, Parenti M, Babini AC, Biagi R, Baraldi L, Luchi A, Capclli M, Coccheri S. Prolonged very low calorie diet in obese subjects reduces factor VII and PAI but not fibrinogen levels. Fibrinolysis 1994;8:16-21.

16. Folsom AR, Qamhieh HT, Wing RR, Jeffery RW, Stinson VL, Kuller LH, Wu HK. Impact of weight loss on plasminogen activator inhibitor (PAI-1), Factor VII, and other hemostatic factors in moderately overweight adults. Arterioscl Thromb 1993;13:162-169.

17. Primrose JN, Davies JA, Prentice CRM, Hughes R, Johnston D. Reduction in factor VII, fibrinogen and plasminogen activator inhibitor-1 activity after surgical treatment of morbid obesity. Tromb Hacmost 1992;68:396-399.

18. Alessi MC, Juhan-Vague I, Kooistra T, Declerck PJ, Collen D. Insulin stimulates the synthesis of plaminogen activation inhibitor 1 by the human hepatocellular cell line Hep G22. Thromb Hacmost 1988;60:491-494. 
19. Smith U. Carbohydrates, fat and insulin. Am J Clin Nutr 1994;59(suppl):686S-689S.

20. Kluft $C$. Constitutive synthesis of tissue-type plasminogen activator (t-PA) and plasminogen activator inhibitor type 1 (PAI-1): conditions and therapeutic targets. Fibrinolysis 1994;suppl 2:117.

21. Kluft C, Potter van Loon BJ, de Maat MPM. Insulin resistance and changes in haemostatic variables. Fibrinolysis 1992;6,suppl 3:11-16. 


\title{
Short-term moderate energy restriction does not affect indicators of oxidative stress and genotoxicity in humans
}

\author{
Erica J.M. Velthuis-te Wierik ${ }^{1,}$ Rick E.W. van Leeuwen², \\ Henk F.J. Hendriks' ${ }^{1}$, Hans Verhagen ${ }^{1}$, Steffen Loft ${ }^{3}$, Henrik E. Poulsen ${ }^{3}$ and \\ Henk van den Berg ${ }^{1}$
}

1 TNO Nutrition and Food Rescarch Institute, Zeist, The Netherlands

2 TNO Prevention and Health Institute, Leiden, The Netherlands

3 University of Copenhagen, Copenhagen, Denmark.

The Journal of Nutrition, accepted for publication

\section{ABSTRACT}

Restriction of energy intake (ER), without malnutrition of essential nutrients, has repeatedly been demonstrated to increase longevity in rodents. Several hypotheses have been put forward to explain this phenomenon. In the 'antioxidant theory of ageing' the unbalance between the generation of free radicals and free radical scavenging has been suggested to be a main causal agent in the ageing process. From this point of view the anti-ageing effect induced by ER in animals might be due to the lower rate of free-radical production and related damage induced by a lower metabolic rate. The anti-ageing effects of ER might also occur in humans. This study explored the short-term effects (10 weeks) of a moderately energy-restricted diet ( $80 \%$ of habitual) in 24 non-obese middle-aged men (16 ER subjects, 8 controls) on resting metabolic rate (RMR) and indicators of the primary antioxidant defence system, oxidative stress and genotoxicity. RMR decreased significantly in both groups, even when adjustments were made for the change in body composition. No significant effects were observed for the indicators of oxidative stress or for indicators of genotoxicity. Erythrocyte catalase activity decreased significantly and similarly in both groups. The activities of glutathione peroxidase and superoxide dismutase did not change. Blood vitamin $\mathrm{C}$ concentrations increased $(+13.4 \pm 14.0 \mu \mathrm{mol} / \mathrm{L} ; \mathrm{P}<0.01)$ in the ER group. Changes in blood vitamin $\mathrm{C}$ correlated with the increases in urinary 8 -hydroxy-deoxyguanosine $(8 \mathrm{OHdG})$ excretion in all subjects $(\mathrm{n}=21 ; \mathrm{r}=0.478 ; \mathrm{P}=0.021)$. The change in urinary $80 \mathrm{OHG}$ excretion also 
correlated with the change in RMR ( $n=21 ; r=0.516 ; P=0.017)$ when values were expressed per kg fat-free mass. No differences between groups were found for changes in plasma vitamin $E$, vitamin $A$ or $\beta$-carotene concentrations. We conclude that 10 weeks of moderate ER did not affect indicators of antioxidative capacity, oxidative stress and genotoxicity of humans. Since subjects were not in energy balance at the end of the study, no conclusions can be made with respect to long-term effects.

\section{INTRODUCTION}

Energy restriction (ER), without malnutrition of essential nutrients, has repeatedly been demonstrated to effectively and reproducibly increase longevity in rodents. Although ER retards many of the physiological changes associated with ageing, the mechanism(s) responsible for the anti-ageing effects of ER are not well understood, which is also true for the basic causes of the ageing process itself. Among the many theories of ageing, the possibility that free radicals, generated by oxygen metabolism, are involved as main causal agents is receiving particular attention. Harman' formulated his 'free radical theory of living' as early as 1954 , when he postulated that ageing might be attributed at least in part to accumulative damage caused by radical generation associated with cellular metabolic activity. According to this theory, free-radical damage can by reduced by lowering metabolic rate. This theory has been supported by studies from $\mathrm{Cutler}^{2}$ who showed an inverse relationship between species-specific life span and metabolic rate.

Therefore, one of the causes underlying the anti-ageing effect induced by ER might be a lower rate of free-radical production and related damage, induced by a lower metabolic rate.

In addition to the effect on metabolic rate, the beneficial effects of ER on the ageing process have been explained by a positive effect of ER on maintaining, or even increasing, the anti-oxidative defence system with age. ${ }^{3}$ Free radicals are effectively scavenged by both radical-scavenging enzymes such as superoxide dismutase (SOD), catalase and glutathione peroxidase (GSH-Px), as well as by antioxidants such as vitamins $E$ and $C$ and $\beta$-carotene.

Thus, the beneficial effects of ER on the ageing process may proceed through both effects, i.e. by lowering the production rate and by effective scavenging of free radicals, both resulting in lowering of oxidative stress. An intriguing question remains whether ER might also be beneficial in humans. Since ageing is a pleiotropic process, the anti-ageing effects of ER might also occur in human beings. However, it is very difficult, if not impossible, to test this hypothesis in life-long controlled human experiments. The aim of this study was to investigate the effects of a 10-week 
moderately energy-restricted diet in non-obese middle-aged men on indicators of the primary antioxidant defence system (antioxidant enzymes as well as antioxidant vitamins), oxidative stress and of genotoxicity. The duration of the study was 12 weeks because, in our opinion, volunteers would not be willing to participate for a longer period of time under these controlled conditions. It was hypothesized that ER might increase anti-oxidative capacity or reduce oxidative damage, in parallel with a decrease in resting metabolic rate.

\section{MATERIALS AND METHODS}

\section{Subjects:}

Twenty-four apparently healthy men, aged $43 \pm 5$ (range 35-50 years) with a mean body mass index (BMI) of $24.6 \pm 1.8 \mathrm{~kg} / \mathrm{m}^{2}$ (range $20.6-27.2 \mathrm{~kg} / \mathrm{m}^{2}$ ) participated in this study. All subjects had a stable weight during the past year, had a normal routine clinical chemistry profile and were non-smokers. They had normal dietary patterns and no extreme level of energy intake (9,300-13,200 kJ/day). Some physiological characteristics (body weight, BMI, resting metabolic rate) of the subjects are presented in Table 7.1. Each subject was medically screened through a health questionnaire and a medical examination. Informed consent was obtained from each subject and the research protocol was approved by the Institute's external Medical Ethical Committee.

\section{Experimental design:}

A detailed description of the experimental design has been published elsewhere (Chapter 3). ${ }^{4}$ Briefly, the total experiment lasted 12 weeks. Subjects were assigned to two groups: a control group $(n=8)$ and an energy-restricted group (ER group; $n=16$ ). Groups were matched on the basis of age and BMI. Habitual food intake was assessed by means of a 7-day dietary record. As calculated with the computerized Netherlands Food Composition Table (UCV/NEVO), habitual intake of saturated fatty acids (SFA), monounsaturated fatty acids (MUFA) and polyunsaturated fatty acids (PUFA), respectively was $17.3 \pm 2.9 \%, 16.0 \pm 2.0 \%$ and $6.6 \pm 1.1 \%$ of total energy intake in the control group and $15.8 \pm 2.2 \%, 15.4 \pm 2.9 \%$ and $6.4 \pm 1.3 \%$ of total energy intake in the ER group. The groups did not differ significantly for any of these fatty acid intakes.

During the first two weeks of the study (run-in period) all subjects received a weight-maintaining test diet based upon the outcome of their dietary record. Since energy intake differs among individuals, subjects were divided into 6 'energy groups' with a stepwise increase of ca. $770 \mathrm{~kJ}$ (i.e. 9,$304 ; 10,073 ; 10,841 ; 11,610 ; 12,378$ and $13,147 \mathrm{~kJ} /$ day respectively). When subjects lost more than $1 \mathrm{~kg} /$ week during this run-in 
period they were reclassified into a higher energy group.

After these two weeks the 8 control subjects were kept on their weight-maintaining diet for the next ten weeks, while the other 16 subjects received a test diet that contained $80 \%$ of the energy of their habitual (weight-maintaining) diet, with micronutrient levels of at least their Recommended Dietary Allowance (RDA). The $20 \%$ energy restriction was achieved by substituting low-fat and artificially sweetened products for ordinary products, such that the relative contribution of carbohydrates, fat and protein to total energy intake remained approximately the same. During the experimental period intake of SFA, MUFA and PUFA was calculated to be $13.6 \pm 0.3 \%, 13.2 \pm 0.5 \%$ and $11.1 \pm 0.4 \%$ of total energy intake in the control group and $14.2 \pm 0.1 \%, 13.8 \pm 0.2 \%$ and $8.1 \pm 0.1 \%$ respectively in the ER group, indicating that PUFA intake was lower in the ER group. Diets with the highest and lowest energy content were analysed for antioxidant micronutrients. Analyses of these extremes revealed that vitamin $\mathrm{E}$ intake was between 7.8 and $18.6 \mathrm{mg}$ per day for the control group and between 9.3 and 10.1 mg per day for the ER group; vitamin C intake was between 97.4 and $136.1 \mathrm{mg}$ per day for the control group and between 117.4 and $135.2 \mathrm{mg}$ per day for the ER group; $\beta$-carotene intake was between 1.9 and $2.1 \mathrm{mg}$ per day for the control group and between 1.9 and $2.0 \mathrm{mg}$ per day for the ER group; selenium intake was between 39 and $52 \mu \mathrm{g}$ per day for the control group and between 28 and $51 \mu \mathrm{g}$ per day for the ER group.

All foods and drinks to be consumed during the 12-week study were supplied by the Institute. The subjects were not allowed to eat or drink (except water) anything but the food supplied.

Resting metabolic rate (RMR) was measured twice before and twice at the end of the experimental period. The mean of the duplicate measurements was used as a variable in the analysis. At the end of the run-in period and at the end of the experimental period body composition was measured and blood was drawn from fasting subjects for the analysis of variables related to oxidative stress (plasma malondialdehyde (MDA), oxidazibility of LDL (LDL-ox), and 8-hydroxydeoxyguanosine (8-OHdG) in both lymphocytes and urine), as well as for the indicators of anti-oxidative capacity (erythrocyte catalase, glutathione peroxidase (GSH-Px) and superoxide dismutase (SOD) activities as well as plasma vitamins $C, E$ and $A$, and $\beta$-carotene concentrations).

\section{Methods:}

Resting metabolic rate. RMR was measured in the morning after the subjects had stayed overnight in the metabolic ward of the Institute. $\mathrm{O}_{2}$ consumption (paramagnetic analyser, Beryl 102; Cosma, Igny, France) and $\mathrm{CO}_{2}$ production (AR-400 infrared gas analyser; Anarad, Santa Barbara, CA, USA) were measured under thermoneutral temperature 
conditions in fasting subjects on four occasions, twice during the run-in period and twice near the end of the experiment. $\mathrm{O}_{2}$ and $\mathrm{CO}_{2}$ analysers were calibrated against standardized gas mixtures every morning. While lying for $30 \mathrm{~min}$ in supine position, the subjects were breathing through a low-resistance breathing valve (\#2700; Hans Ruldolph, Kansas City, MO, USA). Weir's ${ }^{5}$ formula was used for calculating RMR.

Body composition. The subjects were weighed to the nearest $0.1 \mathrm{~kg}$ every week on a balance (ED-60-T; Berkel, Ridderkerk, The Netherlands) before dinner, while wearing underwear. Body composition, i.e. fat mass and fat-free mass (FFM), was estimated from the three-compartment model of Siri ${ }^{6}$ which combines body density with total body water. Body density was measured using the hydrostatic weighing technique of Brozek et al. ${ }^{7}$ Underwater weight was determined to the nearest $0.1 \mathrm{~kg}$ with a balance (SK; Berkel, Ridderkerk, Netherlands) while the residual lung volume was determined simultaneously by helium dilution and a spirometer (Volutest; Mijnhardt, Bunnik, The Netherlands). Total body water was determined by deuterium dilution.

Plasma malondialdehyde (MDA). For the analysis of MDA blood was collected in EDTA-containing tubes. Plasma was stored under helium at $-80^{\circ} \mathrm{C}$ until analysis. MDA was analysed fluorometrically (Perkin-Elmer spectrophotometer 204-A, Gouda, The Netherlands) after formation of an adduct with thiobarbituric acid (TBA) as reported by Hendriks and Assman. ${ }^{8}$

Low-density lipoprotein resistance of ex-vivo copper-mediated oxidation (LDL-ox) was analysed according to the method of Princen et al. ${ }^{9}$ The lag-time (min) was used as a measure of LDL-ox.

8-Hydroxydeoxyguanosine ( $8 \mathrm{OHdG}$ ) in lymphocytes. Lymphocytes were isolated using Ficoll. From these lymphocytes DNA was isolated. The number of $80 \mathrm{HdG}$ adducts was measured by HPLC with electrochemical detection, essentially according Richter et al.," ${ }^{10}$ and was expressed mol $80 \mathrm{Hdg}$ per $10^{5}$ mol deoxyguanosine. Analysis of lymphocyte $8 \mathrm{OhdG}$ was completed in 19 subjects at the start of the intervention (ER group $n=13$; control group $n=6$ ), and in 22 subjects at the end of the intervention (ER group $\mathrm{n}=15$, control group $\mathrm{n}=7$ ).

Urinary 8OHdG. 24-hour urine samples were collected at the end of the run-in period and at the end of the experimental period and stored at $-20^{\circ} \mathrm{C}$ until analysis of 8-OHdG by HPLC with electrochemical detection." The second urine collection was not completed in one subject from the ER group.

For the analysis of catalase, GSH-PX and SOD in erythrocytes, heparinized blood was collected. Erythrocytes were washed three times and stored at $-80^{\circ} \mathrm{C}$ until analysis.

Catalase activity (EC 1.11.1.6) was measured by monitoring substrate $\left(\mathrm{H}_{2} \mathrm{O}_{2}\right)$ disappearance spectrophotometrically (LKB, Cambridge, UK) at $240 \mathrm{~nm}$ according to the method of Aebi. ${ }^{12}$ 
GSH-Px activity ((EC 1.11.1.9) was measured according to a 'FLAIR-standardized method' (Belsten and Wright, unpublished). This FLAIR assay is based on Paglia and Valentine's method, ${ }^{13}$ including an enzyme stabilization step and using t-butyl hydroperoxide rather than hydrogen peroxide.

SOD activity (EC 1.15.1.1) was measured spectrophotometrically (LKB, Cambridge, UK) using the RANSOD kit (Randox laboratories, Ireland) according to the kit's protocol.

Total vitamin C. Vitamin C concentration in whole blood was measured by HPLC with fluorometric detection ${ }^{14}$ immediately after blood sampling (between-assay variability: $5 \%$ ).

Vitamin E, vitamin A and $\beta$-carotene. Heparinized blood was collected. Plasma was separated immediately after collection by centrifugation $(10 \mathrm{~min}, 2000 \mathrm{~g})$ and stored at $-80^{\circ} \mathrm{C}$ until analysis. Vitamin $\mathrm{E}$, vitamin $\mathrm{A}$ and $\beta$-carotene were analysed by HPLC as described by van Vliet et al. ${ }^{16}$

Total cholesterol. For the analysis of total cholesterol concentration a commercially available kit was used (Boehringer Mannheim Diagnostica, Amsterdam, The Netherlands).

Hemoglobin $(\mathrm{Hb})$ concentration was determined by using a semi-automatic computer equipped hematology analyser (Sysmex K1000, Japan; DA1000, Japan).

Near the end of the experimental period (after 10 weeks of moderate energy restriction) after al overnight fast, blood was collected by venapuncture into heparinized tubes. Lymphocyte cultures were set up using whole blood and phytohaemaglutinin stimulation for the assessment of a variety of cytogenetic biomarkers by routine methods: 1) sister chromatid exchanges (SCE) ${ }^{16.17}$; 2) chromosomal aberrations ${ }^{16,17}$; 3) micronuclei in binucleated cells (cytokinesis block method ${ }^{18}$ ).

\section{Statistics:}

BMDP statistical software (Los Angeles, CA, USA; version 1990 VAX/VMS) was used to detect changes within and between the groups, and to calculate correlations between variables. Changes within the groups were tested for significance with the paired Student's t-test. Differences in changes between the two groups were tested with the unpaired Student's t-test. Relationship between two variables was calculated with Pearson linear correlations. $\mathrm{P}$-values were considered statistically significant at $\mathrm{P}<0.05$. 


\section{RESULTS}

Table 7.1 presents the physiological characteristics, including body weight and RMR before and after the intervention as well as the change $(\Delta)$ that had occurred at the end of the intervention. As expected, there was a considerable weight loss in the ER group, which was significantly greater than the relatively small weight loss in the control group. At the end of the intervention period subjects were still losing weight, and there was no tendency to stabilize. As a consequence of the weight loss, BMI decreased significantly in the ER group. RMR significantly decreased in both groups. RMR tended $(p=0.06)$ to decrease more in the ER group than in the control group. Even after adjusting for body composition, RMR still significantly decreased in both groups, suggesting an increase in metabolic efficiency in subjects in negative energy balance.

The effects of a moderately energy-restricted diet on indicators of oxidative stress and anti-oxidative capacity are summarized in Table 7.2. No effects could be demonstrated for any of the indicators of oxidative stress (MDA, LDL-ox and 8OHdG) measured. $80 \mathrm{HdG}$ was measured in both lymphocytes and urine. Lymphocyte $80 \mathrm{HdG}$ is considered to reflect the balance between damage and repair at the time of sampling, while urinary $80 \mathrm{HdG}$ is interpretated as the rate of oxidative DNA modification. Neither indicator of oxidative DNA modification was affected significantly by ER. However, the change in $8 \mathrm{OHdG}$ excretion, i.e. the change in the rate of rate of oxidative DNA modification, correlated positively with the change in RMR $(\mathrm{r}=0.516, \mathrm{P}=0.017$, $\mathrm{n}=21$ ) when both indicators were expressed per $\mathrm{kg}$ fat-free mass (FFM). Of the freeradical-scavenging enzymes measured, catalase significantly decreased in both groups, with no difference between groups. The activities of the two other free radical scavenging enzymes, GSH-Px and SOD, did not change. Of the antioxidant vitamins analysed, vitamin $\mathrm{C}$ concentrations increased significantly in the ER group, but not in the control group. The change in whole blood vitamin $\mathrm{C}$ concentration correlated with the change in $80 \mathrm{OHG}$ excretion when all subjects were included in the analysis $(r=0.478, P=0.021)$ (Figure 7.1). Plasma vitamin $E$ concentration decreased in the ER group. However, when expressed relative to plasma total cholesterol concentration this decrease was not significant. No changes were observed in plasma vitamin A concentrations. Beta-carotene concentration increased significantly in the ER group, but this increase was not significantly different from the nonsignificant increase in the control group.

No differences between the two groups were observed for any of the indicators of genotoxicity measured after 10 weeks of moderate energy restriction only (Table 7.3). 


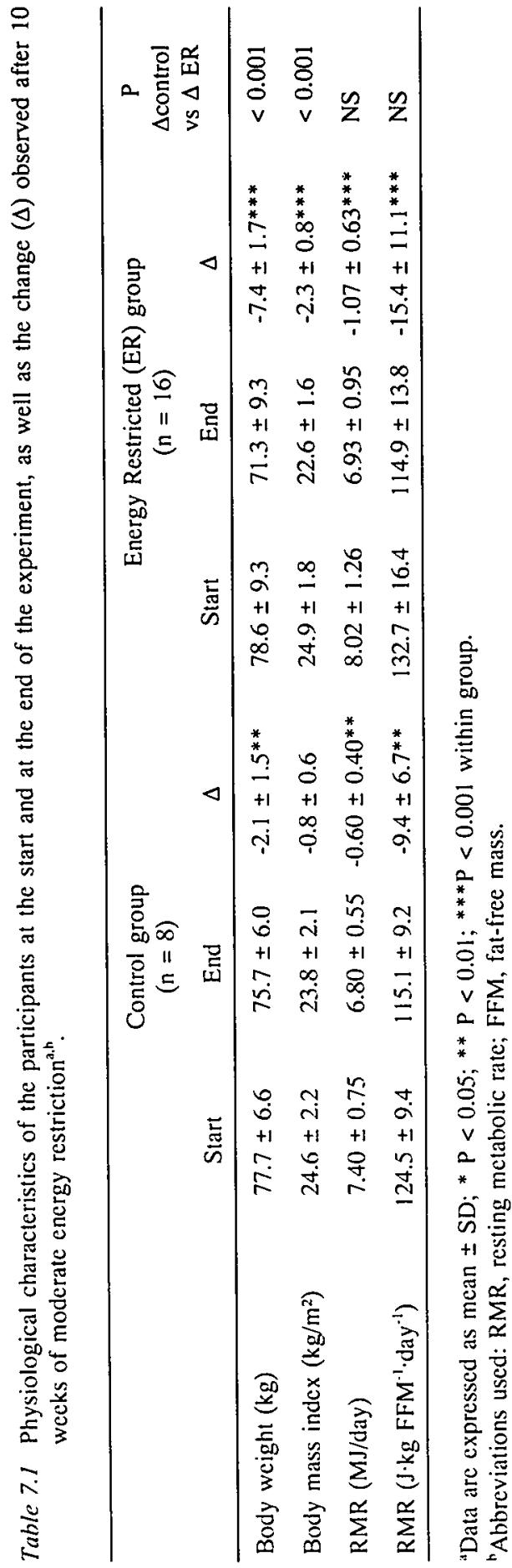




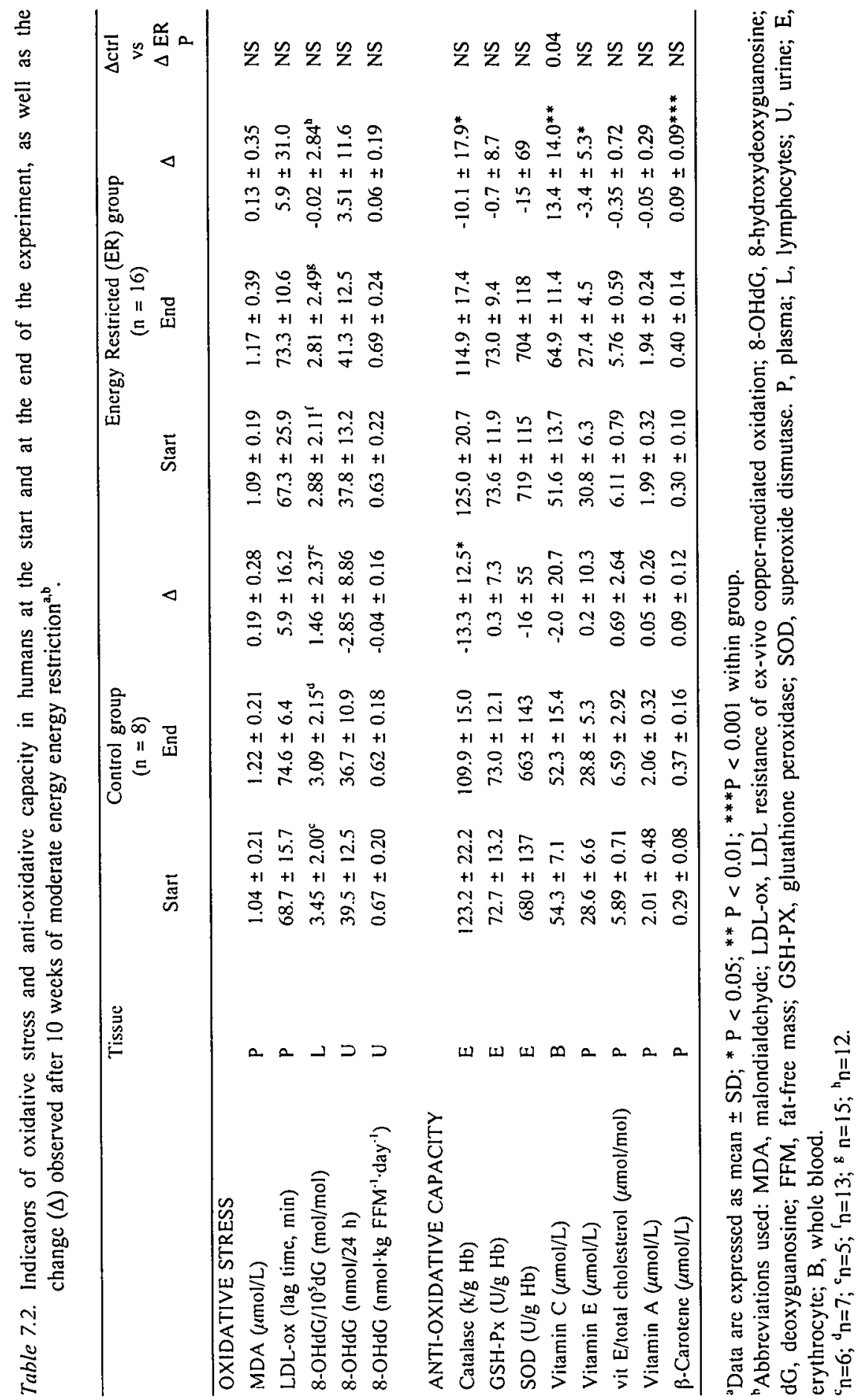


Table 7.3. Indicators of genotoxicity after 10 weeks of moderate energy restriction in humans. ${ }^{2}$

\begin{tabular}{|c|c|c|}
\hline & $\begin{array}{l}\text { Control group } \\
(n=8)\end{array}$ & $\begin{array}{c}\text { Energy restricted } \\
(n=16)\end{array}$ \\
\hline Sister chromatid exchanges ${ }^{\mathrm{b}}$ & $4.2 \pm 0.3$ & $4.3 \pm 0.2$ \\
\hline 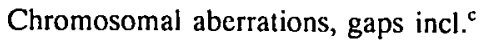 & $0.7 \pm 0.5$ & $0.7 \pm 0.7$ \\
\hline Chromosomal aberrations, gaps excl. ${ }^{\mathrm{c}}$ & $0.3 \pm 0.5$ & $0.3 \pm 0.6$ \\
\hline Micronuclei/1000 binucleates ${ }^{d}$ & $10.0 \pm 3.7$ & $10.4 \pm 4.5$ \\
\hline
\end{tabular}

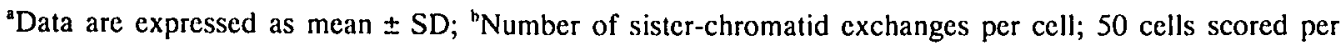
individual from 2 slides; 'Number of chromosomal aberrations per 100 cells; 100 cells scored per individual from 4 slides; ${ }^{\mathrm{N}}$ Number of micronucleated cells per 1000 binucleated cells; 2000 binucleated cells scored per individual from 2 slides.

\section{DISCUSSION}

One of the hypothesis that has been put forward to explain the ageing process is that ageing is related to a disregulation in the balance between prooxidants and antioxidants leading to oxidative stress. The large body of literature on animal studies indicates that 1) the levels of anti-oxidant defence are positively correlated with species life span, 2) the rate of production of free radicals correlates inversely with species life span, 3) anti-oxidant defence declines with increasing age, 4) the rate of production of free radicals increases with age and that, as a result, 5) oxidative damage increases with age. ${ }^{19}$ However, results are not always comparable because of differences in study protocol and type of experiment (matrix, type of marker, species, sex, age groups etc.). Nevertheless, results obtained in lifelong studies in animals strongly suggest that the maintenance of an appropriate antioxidant/prooxidant balance does have an important role in maintaining health in ageing..$^{21}$ One of the best known age-related signs of lipid peroxidation in both animals and humans is an accumulation of the lipoidal fluorescent called lipofuscin or age pigment. Lipofuscin is formed in non-dividing cells, such as neurons and skeletal and cardiac muscle cells, from the auto-oxidation of lipids, which involves free-radical chain reactions. ${ }^{21}$ An age-related increase in another lipid peroxidation product, MDA, has also been observed in human subjects aged between 10 and 80 years, $^{22}$ and when comparing young people (21-43 years) with elderly $\left(>65\right.$ years). ${ }^{23}$ In addition, lower platelet vitamin E levels ${ }^{23}$ and lower platelet GSH-Px activities ${ }^{23}$ were found in the elderly humans. Niwa et al ${ }^{24}$ reported that the inducibility of lymphocyte SOD in healthy subjects decreases with age. Moreover, low inducibility at 67-73 years appeared to be predictive of malignancy or fatal cardiovascular events for the next 5 years. Recently, Orr and Sohal ${ }^{25}$ reported that simultaneous overexpression of SOD and catalase in Drosophila melanogaster resulted in a one-third extention of 
lifespan and a longer mortality rate doubling time, which supports the free radical hypothesis of ageing.

Thus, in both animals and humans an age-related increase in lipid peroxidation is apparent. Two years ER in rodents seems to prevent this age-related increase in lipid peroxide levels and decrease in anti-oxidant defence in rodents. ${ }^{26} \mathrm{ER}$ might therefore have a similar beneficial effect in humans.

The aim of our intervention was to study the short-term effects of moderate energy restriction on indicators of oxidative stress and antioxidative capacity as well as on resting metabolic rate in humans. Since, to our knowledge, no previous studies have addressed this question, this appears to be the first attempt to study the relevance of findings from animal studies to human beings. An interesting long-term experimeny involving ER in humans is Biosphere 2. The diet of the eight subjects in this ecosystem is low in energy $(7,500 \mathrm{~kJ} /$ day $)$ and fat (10\% of energy intake). Body weight and clinical chemistry data have been published ${ }^{27}$ but not data concerning prooxidant/antioxidant balance.

Our results are hard to compare with data obtained from animals since data on the effects of short-term ER in animals are scarce and unequivocal: $\mathrm{Yu}^{3}$ found that the anti-lipid peroxidative action of ER (40\% of ad libitum), initiated at 6 weeks of age, was discernable after six months of ER as indicated by suppressed MDA formation, while Rao et al..$^{28}$ did not demonstrate an effect of ER (60\% of ad libitum), also initiated at 6 weeks of age, on MDA formation after four months. Although these studies are classified as short-term, the duration of ER is approximately $1 / 4$ of the life span of the rodent, which might compare roughly to 15 to 20 years in humans. Another difficulty in comparing our data with data from animal studies is the age of the subjects used. Althoug ER initiated in adult rodents extends longevity, ${ }^{29}$ it remains to be established whether ER imposed in full-grown animals acts through similar physiological mechanisms as when imposed soon after weaning.

Considerably more data are available concerning the effects of long term (24 months) ER in animal models. $\mathrm{Yu}^{3}$ noted that MDA generation in freely fed rats increased with age. The anti-lipid peroxidative action of $60 \%$ ER was demonstrated by suppressed MDA formation. Rao et al. ${ }^{28}$ observed that the $40 \%$ ER-induced retardation of the age-dependent increase in MDA levels was apparent at 12 months of age. With respect to ex-vivo LDL oxidizibility, to our knowledge, no studies have reported the effects of ER on LDL-oxidizibility. Oxidative DNA damage as measured by $80 \mathrm{OdG}$ was attenuated by $40 \%$ ER in livers of 24 -month old rats. ${ }^{29}$ The prodects of DNA damage (including non-oxidative DNA damage) accumulate with age in mice $e^{30}$ and may therefore contribute to the ageing process. We therefore hypothesized that the beneficial 
effects of ER might be reflected in fewer cytogenetic biomarkers for genotoxicity. Although, cytogenetic biomarkers were not measured at the start of the study there is no reason to assume that they differed between the groups at the start of the intervention. Pieri et al. ${ }^{31}$ studied antioxidant enzymes activities in erythrocytes from young (6 months), old (24 months) and energy restricted (fed every other day) old rats and found an age-associated decrease in activities of catalase and GSH-Px, which was prevented by ER. Most of the data concerning ER and ageing are generated by lifelong animal studies. Therefore, it was uncertain whether we could expect a beneficial effect of ER on the indicators presented in this paper. In addition, a complicating factor in comparing human to animal data is that most of the evidence in animal studies is based upon findings obtained from unaccessible organ tissues, especially liver. Studies in humans are limited with respect to the substrates for analysis since only blood and urine samples are readily available.

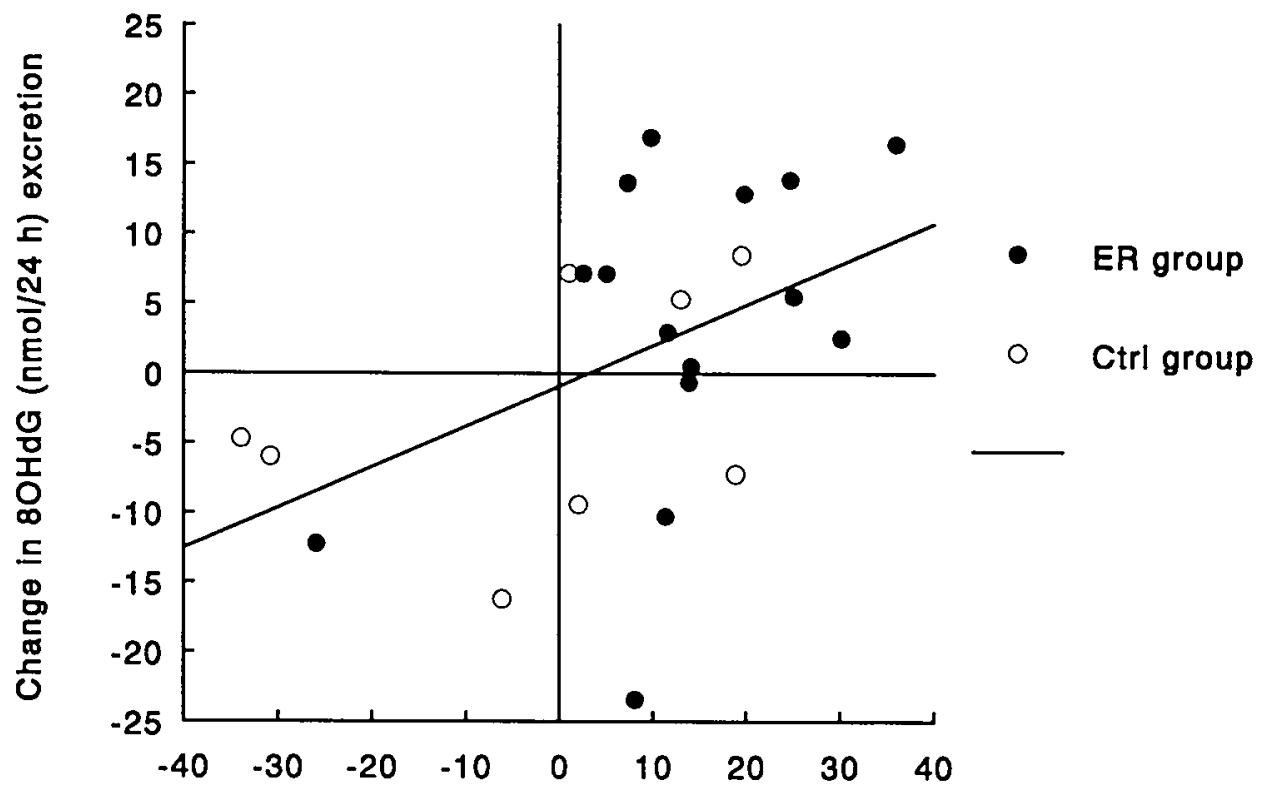

Change in vitamin $C$ conc. $(\mu \mathrm{mol} / \mathrm{L})$

Figure 7.1. Relationship between the change in the rate of oxidative DNA damage (8OHdG excretion) and the change in whole blood vitamin $C$ concentration after 10 wecks of consuming a weight maintaining dict or a moderately energy restricted dict. 
Ten days of ER $(5,000 \mathrm{~kJ} /$ day $)$ in one human subject has been shown to decrease urinary $80 \mathrm{HdG}$ excretion. ${ }^{32}$ In our study we found no support for our hypothesis, i.e. no reduction in measures of lipid peroxidation, anti-oxidative capacity, DNA modification or genotoxicity were observed after moderate ER for ten weeks. No effects were observed on plasma anti-oxidant vitamins, except for vitamin $\mathrm{C}$ concentrations which increased in the ER group. As vitamin $\mathrm{C}$ intake did not differ between groups (see 'experimental design' section), differences in intake cannot explain the increase in whole blood vitamin $\mathrm{C}$ concentrations.

Surprisingly, there was a positive correlation between the change in the rate of oxidative DNA damage, $80 \mathrm{HdG}$ excretion, and the change in whole blood vitamin $\mathrm{C}$ concentrations when all subjects were considered. Since vitamin $C$ is a free radical scavenger, we expected a negative correlation, i.e. an increase in vitamin $C$ level should reduce the rate of oxidative DNA damage. The explanation, presumably, is related to an interplay between vitamin $\mathrm{C}$ and other antioxidants. An additional factor could be a changed distribution between intra- and extracellular vitamin $C$. Whether there is a relationship between oxidative DNA damage and vitamin $C$ concentration in the habitual, or in the vitamin $C$ supplemented state, and whether this correlation is physiologically relevant, is presently unknown.

In the ER group the PUFA/SFA ratio (P/S ratio) appeared to be higher in the food supplied ( $0.82 \pm 0.04$ in the control group; $0.57 \pm 0.03$ in the ER group) than in the subjects' habitual diet $(0.39 \pm 0.09$ in the control group; $0.42 \pm 0.10$ in the ER group). The increase in $\mathrm{P} / \mathrm{S}$ ratio ( $0.43 \pm 0.12$ in the control group; $0.15 \pm 0.10$ in the ER group) could have strengthened a potential effect since this increase was most apparent in the control group. However, since no effects could be demonstrated the change in dietary fatty acid profile was of no apparent importance.

Since free radicals are thought to be derived from $\mathrm{O}_{2}$ during oxidative metabolism, lower metabolic rate may partly explain the beneficial effects of ER. Although the rate of oxidative DNA damage as evaluated by a paired t-test did not change after moderate energy restriction, we observed that the change in RMR per $\mathrm{kg}$ fat-free mass (FFM) correlated with the change in $80 \mathrm{HdG}$ excretion per kg FFM. Detailed analysis of this finding will be published elsewhere. ${ }^{33}$ The subjects did not reach a new energy balance because they were still losing weight at the end of the experimental period. It is not certain whether RMR would still be lower after a new weight equilibrium had been reached. It has been reported that obese subjects have a higher $\mathrm{RMR} / \mathrm{kg} \mathrm{FFM}^{34}$ whereas girls suffering from anorexia nervosa have a lower RMR/kg FFM ${ }^{35}$ than normal-weight subjects. Despite the fact that we studied lean instead of obese or anorectic subjects and moderate energy restriction in stead of semi-starvation, on the basis of these reports it 
could be expected that RMR/kg FFM would remain lower in the ER subjects studied in this experiment. Several explanations for not finding any changes in the indicators measured can be suggested: 1) since humans have a low metabolic rate they may suffer relatively less from damage due to free radicals, therefore, they might benefit less from ER than species with a high metabolic rate; 2) the small ranges of the variables measured may be the cause of not finding any correlations between variables, 3) the period studied might have been too short. However, under controlled conditions like in this study, 10 weeks is the longest period one can expect a subject to participate in; 4) antioxidative capacity might be rather stable in the age category used in this study and 5) as already mentioned, another reason for not finding changes in the indicators of oxidative stress and antioxidative capacity might be the tissue used. Finding no effects on a peripheral level does not exclude changes on a cellular level.

The imposed level of ER (20\% of reported intake) was probably too high to be acceptable for the long term because the subjects kept losing weight and showed no tendency to stabilize. In this study we aimed at $20 \%$ ER, but the real imposed ER may have been higher because of underreporting of habitual intake (as indicated by weight loss in the control group). A milder level of energy restriction would probably be more feasible but whether this level of ER beneficially afects the ageing process in humans remains to be studied.

To summarize, in this study ER did not affect indicators of antioxidative capacity, oxidative stress or genotoxicity in humans. A correlation between the change in $\mathrm{RMR} / \mathrm{kg}$ FFM and the change in urinary $80 \mathrm{HdG} / \mathrm{kg}$ FFM was found. However, since subjects were not stabilized at a new energy balance no conclusions can be drawn with respect to the long-term effect. Not finding an effect on the variables measured in this study does not necessarily mean that ER does not affect oxidative stress and/or the ageing process in humans. More studies, utilizing better markers for oxidative stress than presently available, are needed before a definitive conclusion can be drawn.

\section{ACKNOWLEDGEMENT}

We would like to thank W.R. Leeman, N. de Vogel, and G.C.D.M. Bruijntjes-Rogier for excellent technical assistance. 


\section{REFERENCES}

1. Harman D. Free radical theory of agcing: History. In: Emerit I, Chance B. eds. Free Radicals and Aging. Basel, Birkhäuser Verlag, Switzerland, 1992, pp 1-10.

2. Cutler RG. Antioxidants, aging and longevity. In: Pryor WA ed. Free radicals in biology, vol 6 . Acadamic Press, New York, 1984:371-428.

3. Yu BP. Antioxidant action of dictary restriction in the aging process. $J$ Nutr Sci Vitaminol 1993;39:S75-S83.

4. Velthuis-te Wierik EJM, van den Berg H, Schaafsma G, Hendriks HFJ, Brouwer A. Energy restriction, a useful intervention to retard human ageing? Results of a feasibility study. Eur $\mathrm{J}$ Clin Nutr 1994;48:138-148.

5. Weir JB. New methods for calculating metabolic rate with special reference to protein metabolism. J Physiol 1949;109:1-9.

6. Siri WE. Body composition from fluid spaces and density: analysis and methods. In: Brozek J. \& Henschel A. eds. Techniques for measuring body composition. Washington DC, Natl Acad Sci, Natl Dairy Council 1961, pp. 223-244.

7. Brozek J, Grande E, Anderson JT,Keys A. Densitometric analysis of body composition: revision of some quantitative assumptions. Ann NY Acad Sci 1963;110:113-140.

8. Hendriks T, Assman RFTA. On the fluorimetric assay of circulating lipoperoxides. Clin Chim Acta 1988; 174:263-270.

9. Princen HMG, van Poppel G, Vogelczang C, Buytenhek R, Kok FJ. Supplementation with vitamin $\mathrm{E}$ but not $\beta$-carotene in vivo protects low density lipoprotein from lipid peroxidation in vitro. Effect of cigarette smoking. Artherioscl Thromb 1992;12:554-562.

10. Richter C, Park JW, Ames BN Normal oxidative damage to mitochondrial and nuclear DNA is extensive. Proc Natl Acad Sci USA 1988;85:6465-6467.

11. Loft S, Vistisen K, Ewertz M, Tjønneland A, Overvad K, Poulsen HE. Oxidative DNA damage estimated by 8 -hydroxydeoxyguanosine cxcretion in humans: influence of smoking, gender and body mass index. Carcinogenesis 1992;13:2241-2247.

12. Aebi H. Catalase in vitro. In: Packer L. ed. Methods in enzymology. Orlando, Academic Press Inc. 1984;105:121-126.

13. Paglia DE, Valentinc WN. Studics on the quantitative and qualitative characterization of crythrocyte glutathione peroxidase. J Lab Clin Med 1967;70:158-169.

14. Speck AJ, Schrijver J, Schreurs WHP. Fluorimetric determination of total vitamin C in whole blood by high-performance liquid chromatography with precolumn derivatization. J Chromatogr 1984;305:53-60.

15. van Vliet $T$, van Schaik F, van Schoonhoven J, Schrijver J. Determination of several retinoids, carotenoids and $\mathrm{E}$ vitamers by high-performance liquid chromatography. J Chromatogr 1991;553:179-186.

16. World Health Organization. Environmental Health Criteria 46. Guidelines for the study of genetic effects in human populations. Geneva, World Health Organization, 1985.

17. Carrano AV, Natarajan AT. International commision for protection against environmental mutagens and carcinogens. ICPEMC Publication no. 14. Considerations for population monitoring using cytogenetic techniques. Mut Res 1988;204:379-406.

18. Fenech $\mathrm{M}$. The cytokinesis-block micronucleus technique: a detailed description of the method and its application to genotoxicity studies in human populations. Mut Res 1993;285:35-44.

19. Warner HR. Overvicw, mechanisms of antioxidant action of life span. Toxicol Industrial Health 1993;9:151-161.

20. Barja de Quiroga G, Lopez-Torres M, Pcrez-Campo R. Relationship between antioxidants, lipid peroxidation and aging. In: Emerit I, Chance B. cds. Free Radicals and Aging. Basel, Birkhäuser Verlag, Switzcrland, 1992:109-123.

21. Sohal RS, Brunk UT. Lipofuscin as an indicator of oxidative stress and aging. Adv Exp Med Biol 1989;266:17-29.

22. Rodriguez-Martinez MA, Ruiz-Torres A. Homeostasis between lipid peroxidation and antioxidant 
enzyme activities in healthy human aging. Mech Aging Dev 1992;66:213-222.

23. Vericel E, Rey C, Calzada C, Haond P, Chapuy PH, Lagarde M. Age-related changes in arachidonic acid peroxidation and glutathione-peroxidase activity in human platelets. Prostaglandins 1992;43:75-85.

24. Niwa $\mathrm{Y}$, Ishimoto $\mathrm{K}$, Kanoh $\mathrm{T}$. Induction of superoxide dismutase in leukocytes by paraquat: correlation with age and possible predictor of longivity. Blood 1990;76:835-841.

25. Orr WC, Sohal RS. Extension of life-span by overexpression of superoxide dismutase and catalase in Drosophila melangaster. Science 1994;263:1128-1130.

26. Velthuis-te Wierik EJM, van den Berg H. Energy restriction, the basis for successful aging in man? Nutr Res 1994;14:1113-1134.

27. Walford RL, Harris SB, Gunion MW. The calorically restricted low-fat nutrient-dense diet in Bioshere 2 significantly lowers blood glucose, total leucocyte count, cholesterol, and blood pressure in humans. Proc Natl Acad Sci USA 1992;89:11533-11537.

28. Rao G, Xia E, Nadakavukaren MJ, Richardson A. Effect of dietary restriction on the age-dependent changes in the expression fo antioxidant enzymes in rat liver. J Nutr 1990;120:602-609.

29. Chung MH, Kasai H, Nishimura S, Yu BP. Protection of DNA damage by dietary restriction. Free Radical Biol Med 1992;12:523-525.

30. Holmes GE, Bernstein C, Bernstein H. Oxidative and other DNA damages as the basis of aging: a review. Mut Res 1992;275:305-315.

31. Pieri C, Falasca M, Moroni F, Recchioni R, Marchesellu F, loppolo C, Marmocchoni F. Antioxidant enzymes is erythrocytes from old and diet restricted rats. Boll Soc Ital Biol Sper 1990;10:909-914.

32. Simic MG, Bergtold DS. Dictary modulation of DNA damage in human. Mut Res 1991;250:17-24.

33. Loft S, Velthuis-te Wierik EJM, van den Berg H, Poulsen HE. Energy restriction and oxidative DNA-damage in humans. Cancer Epidemiol Biomarkers Prevention (accepted for publication).

34. Hoffmans M, Pfeifer WA, Gundlach BL, Nijkrake HGM, Oude Ophuis AJM, Hautvast JGAJ. Resting metabolic rate in obese and normal weight women. Int J Obesity 1979;3:111-118.

35. Vaisman N, Rossi MF, Corey M, Clarke R, Goldberg E, Pencharz PB. Effect of refeeding on the energy metabolism of adolescent girls who have anorexia nervosa. Eur J Clin Nutr 1991;45:527537. 


\title{
Magnitude of experimental manipulation in a long-term study on health effects of spontaneous consumption of reduced fat versus full fat products in healthy non-obese volunteers
}

\author{
Karin H. van het Hof ${ }^{1}$, Jan A. Weststrate ${ }^{1}$, Henk van den Berg' ${ }^{2}$, \\ Erica J.M. Velthuis-te Wierik ${ }^{2}$, Cees de Graaf ${ }^{3}$, Nicolle J.H. Zimmermanns ${ }^{3}$, \\ Klaas R. Westerterp ${ }^{4}$, Margriet S. Westerterp-Plantenga ${ }^{4}$ and \\ Wilhelmine P.H.G. Verboeket-van de Venne ${ }^{4}$ \\ 1 Unilever Research Laboratorium, Vlaardingen, The Netherlands \\ 2 TNO Nutrition and Food Research Institute, Zeist, The Netherlands \\ ${ }^{3}$ Wageningen Agricultural University, Wageningen, The Netherlands \\ +University of Limburg, Maastricht, The Netherlands
}

\section{Submitted for publication}

\begin{abstract}
The aim of this paper is to present the background, study design and outcome of the magnitude of experimental manipulation of a long-term multicentre study on health effects of reduced fat products. The design of this study is a randomized semi-controlled parallel comparison trial of six months, preceded by a one-month adaptation period, in which healthy non-obese male and female volunteers, 19-55 yr, participated. The study was performed by three research centres and one coordinating centre. 241 volunteers were recruited from the general population. 220 completed the study, 117 of the reduced fat group and 103 of the control group. The subjects consumed either reduced fat or full-fat products, clearly labelled as such, in a free-living situation, obtained from a realistic supermarket at the research centre. The magnitude of the experimental manipulation was that the reduced fat group consumed on average $46 \%$ less fat from the experimental products than the control group. Consumption of the experimental products remained stable throughout the study period in the control group and increased significantly in the reduced fat group. It has been concluded that the setup of this study was feasible for such a long-term semi-controlled trial, that the adherence to the experimental products was excellent throughout the study, and that the magnitude of experimental manipulation appeared to be what we had planned.
\end{abstract}




\section{INTRODUCTION}

An excessive consumption of total fat and saturated fat increases the risk of coronary heart diseases, obesity, some types of cancer, and possibly gall bladder disease. ${ }^{1}$ Therefore, many countries have advised individuals to reduce their total fat intake to between 30 to 35 percent of total daily energy intake and saturated fat intake at or below $10 \%$ of total energy intake. $^{2,3}$ Results of recent food consumption surveys in Europe and North America have shown however that average fat intake still exceeds these recommendations. ${ }^{4-6}$ Besides, the prevalence of overweight and obesity has remained stable or has even increased in several western countries over the past decades. ${ }^{7.9}$ These data indicate that dietary recommendations have not been successfully implemented by the consumer, in spite of the growth in consumer awareness of health and nutritional issues over the last decades and the increase in availability of reduced fat products, at least in North America and the northwestern part of Europe. ${ }^{10}$

One of the reasons for these findings seems to be that many people underestimate their actual fat intake. ${ }^{11}$ Other reasons might be that reduced fat products are less palatable ${ }^{12}$ or that intake compensation for the decreased fat and energy intake occurs after consumption of reduced fat products. A number of studies have investigated the effectiveness of reduced fat products to decrease total energy and fat intake using different study designs. ${ }^{13-27}$ In all of the performed studies, irrespective of their design and duration, macronutrient specific compensation was negligible. If reduced fat products were offered, fat consumption did not specifically increase during the ad libitum food consumption periods and total daily fat intake decreased in comparison with the consumption of high-fat products. No consensus exists however about the effect of reduced fat products on total daily energy intake although most studies found a decrease in total energy intake. ${ }^{13-15,18,19,21-26}$

However, these studies have invariably included not very large numbers of subjects (minimum: $\mathrm{n}=5^{19}$ to maximum: $\mathrm{n}=47^{26}$ ), studied partly under laboratory conditions and over a period of time usually no longer than 11 weeks (e.g. ${ }^{22}$ ). Besides, the impact of knowledge about the nature of the experimental manipulation has not always been taken into account in the previous studies. To obtain results with a high ecological validity, this aspect should be taken into account because in everyday life consumers buy products that are overtly marketed as reduced fat alternatives of traditional products. Eating behaviour may be differently affected when information about the fat content of a consumed product is present. ${ }^{28}$ Therefore, we have executed a multicentre six-months study in which a large group of volunteers had free access to both reduced fat commercially available products in the laboratory as well as to products obtained from regular shops. We here report the magnitude of the experimental manipulation we achieved in this study under realistic, semicontrolled circumstances. 


\section{SUBJECTS AND METHODS}

\section{$\underline{\text { Subjects }}$}

The protocol of the study was approved by the Research Ethics Committees of each participating research centre. Subjects gave their written informed consent prior to participation. Volunteers who completed the study received a financial reward.

Volunteers were recruited amongst inhabitants of the areas where each research centre is located. Each research centre recruited and selected their own volunteers. Eligible adult volunteers (19-55 yr), were healthy as assessed by a medical investigation (serum cholesterol level $\leq 8 \mathrm{mmol} / \mathrm{L}$ ) and not obese (QI 21-28 kg/m $\mathrm{m}^{2}$ at age 19-35 $\mathrm{yr}$ and QI 24-30 $\mathrm{kg} / \mathrm{m}^{2}$ at age $36-55 \mathrm{yr}$ ). They did not use a medically prescribed or slimming diet and had been weight-stable for at least one month prior to the start of the study. Exclusion criteria were intensive exercise ( $>7 \mathrm{hrs} /$ week), excessive alcohol intake ( $>21$ vs 28 units/week for females vs males) and for females: pregnancy or lactation. These criteria were chosen because we wanted to study the health effects of consumption of reduced fat products in a population of healthy normal- to slightly over-weight people in a stable physical condition, having no or moderate exercise habits and not drinking too heavily. We chose different ranges of eligible Quetelet Indexes for the age groups under and over 36 years because it has been shown that the average Quetelet Index of populations increases with age. ${ }^{4}$ Blood and urine samples were taken for analysis of clinical parameters to evaluate the state of health of the volunteers. These parameters were also assessed at the end of the study. Fasting body weight was assessed of the subjects in underwear and after voiding. Body height was measured and sociodemographic characteristics and eating behaviour characteristics were assessed by questionnaires. Eating behaviour characteristics were assessed with a Dutch translation ${ }^{29}$ of the Three Factor Eating. ${ }^{30}$

Half of the volunteers of each research centre had to be younger than $36 \mathrm{yr}$ and the other half had to be $36 \mathrm{yr}$ or older. This criterium was applied to obtain a comparable age distribution among the different research centres.

241 volunteers were selected; 59 males and 61 females were assigned to the control group and 60 males and 61 females to the reduced fat group.

\section{Study design}

The study was a multicentre parallel comparison trial of six months. 241 non-obese volunteers received either reduced fat products (reduced fat group) or full-fat products (control group) and the products were clearly labelled as such. Two months before the start of the study, a one month adaptation period was executed to optimize the experimental procedures.

Four research centres participated in this MSFAT study (Multicentre $\underline{\text { Study on FAT }}$ 
reduction). Three centres, the Agricultural University of Wageningen, the University of Limburg in Maastricht and TNO Nutrition and Food Research Institute in Zeist, each selected 80 or 81 volunteers. The fourth research centre, Unilever Research Laboratorium in Vlaardingen, was responsible for coordination of the study and for carrying out some of the measurements.

In each test facility, volunteers were randomized over the two study groups, ensuring an equal distribution over the groups of both sexes, eating behaviour characteristics (restrained or unrestrained eater) and type of household (single, two-person or family household), as far as possible. Both groups were matched for mean age and Quetelet Index.

\section{Power of the study}

Power calculations indicated that, taking into account a dropout rate of $20 \%, 120$ volunteers per treatment group in this design would provide sufficient power to detect a significant difference between the reduced fat and control group in e.g. change in fat intake of $3.4 \mathrm{en} \%$. The target of the design was to obtain a reduction in fat intake in the reduced fat group of 40 to $30-35$ en\% compared to the control group.

Hypothetical calculations showed that this aim would be achieved if the reduced fat products would provide 50\% less fat compared to the full-fat products and if in the control group about $70 \%$ of the total fat intake would be derived from the experimental products.

\section{Experimental foods}

Based on manufacturer's food composition data and results of sensory tests, a selection was made of the pairs of products of fat-reduced and control products which agreed most in nutrient composition except for fat, had the best sensory similarity and were evaluated as acceptable for regular consumption during six months. Appendix I shows the pairs of products which were included in the study as experimental products and their macronutrient composition. The experimental products were identical to commercially available foods and labelled as branded products. Only the cakes and cookies were not commercially available, but manufactured specifically for the experiment.

The macronutrient and vitamin $\mathrm{E}$ content, as well as the fatty acid composition of the products were analyzed at the end of the study in one of the research centres. Macronutrient content and fatty acid composition were analyzed in duplicate products or in a homogenized mixture of duplicate products. Fat content was assessed by direct extraction after freeze drying, carbohydrate content was assessed by spectophotometry after extraction with perchloric acid and Antron coloring, protein content was assessed by Kjeldahl destruction and fatty acid composition was determined by gaschromotography. Vitamin $\mathrm{E}$ was analyzed by straight phase HPLC in duplicate in a selection of experimental products which were expected to contain a high amount of vitamin $E$, based on food composition data. ${ }^{31}$ The 
pizza Picante and Bellisima appeared to be the only pair of products which were classified wrongly, due to a mistake in the food composition data. These products were available throughout the study because the analyses were executed at the end of the study. The pairs of reduced fat and control products differed mainly in fat content as shown in Appendix I. The average difference in fat content was $52 \%$.

\section{Availability of experimental foods}

A small supermarket, resembling a regular small supermarket as much as possible, was installed at each research centre. The supermarkets were open during 6 to $7 \mathrm{hrs}$ per week, divided over three occasions and in principle subjects came once a week. If a volunteer could not consume the experimental products during a holiday and if this lasted longer than one week, the experimental period was extended for this particular volunteer by the duration of the holiday. This extension was maximally one month.

Volunteers were free to take as many products as they wanted. They were also allowed to buy foods in regular shops. In fact this was essential since a number of products (e.g. bread, cereals, fruit, vegetables, meat, beverages) were not available.

Consumption of the experimental products was registered by a computer programme. The products taken from the supermarket were registered with a barcode reader and during the next visit volunteers reported how much was left in stock at home and how much had not been consumed but thrown away. Volunteers' consumption of the experimental products could be calculated with this information, so that the subjects did not have to register their consumption every day.

Volunteers in the control group had to consume at least $35 \mathrm{~g}$ fat/day from the experimental products. The aim was to maintain a $50 \%$ difference in fat intake from the experimental products between the treatment groups. Therefore, in the reduced fat group, volunteers had to consume at least so many reduced fat products that the hypothetical difference in fat content between these consumed reduced fat products and the full-fat counterparts exceeded $17.5 \mathrm{~g}$ fat/day. For practical reasons, the minimum amount volunteers had to consume was independent of their energy requirements. Volunteers who failed to meet this criterium, i.e. were actually not taking part in the experiment, were told so by the investigator. If a volunteer did not respond and consumed less than the minimum amount during four consecutive weeks, participation was stopped, unless good reasons were given. This instruction may have interfered slightly with the free-living concept of the study. However, it was considered essential to have some form of control over the intake of the experimental products in order to successfully complete the study.

\section{Measurement of total food intake}

Total food intake was assessed before the adaptation period, after 2-4 weeks, 3 months and 
at the end of the main study period. Volunteers recorded their food intake during two weekdays and one weekend day, estimating quantities in household measures. ${ }^{32}$ Each particular volunteer stuck to the same days of the week and weekend during each of the four measurement periods. Macronutrient and vitamin $\mathrm{E}$ intake were calculated using the Dutch food composition table ${ }^{31}$ and data of our own analyses of the experimental products.

At the time of the baseline measurement of food consumption, before the start of the adaptation period, volunteers were still unaware of which treatment they would receive to avoid a possible effect of this knowledge on their habitual food intake before the start of the study.

\section{$\underline{\text { Statistical analyses }}$}

Significance of differences in descriptive characteristics and fat consumption from the experimental products between the treatment groups, within subgroups of volunteers, was assessed by Student's t-test for continuous variables and by Fisher Exact test for numerical variables. Significance of differences within treatment groups, between subgroups of volunteers, was assessed by Student's t-test for the subgroups divided according to gender and age, and Tukey's studentized range test was used to detect pairwise differences between the subgroups of research centres. The interaction between treatment group and research centre was assessed by analysis of variance to investigate a difference in treatment effect on the fat consumption from experimental products between the research centres. Significance of differences between different time points in fat consumption from experimental products, within one treatment group and subgroup, was assessed with Tukey's studentized range test.

SAS computer software was used for all statistical calculations. ${ }^{33}$ All comparisons were made at the two-sided 0.05 significance level.

\section{Data monitoring}

Standardized information material and selection procedures were used during recruitment of the volunteers. Procedures for general measurements, e.g. haematological and urine investigations, discussions of food consumption diaries with the volunteers, were described in standard operating procedures. Besides, the responsible investigators of each research centre attended a training session on the procedures of food consumption diaries to minimize observer bias. Blood chemistry investigations and processing of the food consumption data were performed centrally.

The coordinating research centre visited the test facilities regularly to make sure that differences in study procedures were minimized. Besides, regular meetings between all investigators were organized to discuss how the study proceeded. 


\section{RESULTS}

\section{Volunteers}

A total of 117 volunteers of the reduced fat group and 103 volunteers in the control group completed the study according to the protocol. In the control group, four volunteers withdrew immediately after randomization because they preferred the reduced fat group and one volunteer because she disliked the taste of the control products. Three volunteers withdrew because of pregnancy, nine because of changed personal circumstances (e.g. medical reasons, removal, illness of partner) and four volunteers were asked to quit participation because of non-compliance. These 21 volunteers who dropped out of the study, did no differ in mean descriptive characteristics and food consumption pattern from the volunteers who completed the study, as shown in Table 8.1.

Table 8.1. Mean \pm SD baseline values of descriptive characteristics, socio-demograghic characteristics and food consumption of volunters who dropped out before the the end of the study and volunteers who completed the study.

\begin{tabular}{|c|c|c|c|}
\hline & & $\begin{array}{l}\text { Dropped out the study } \\
(\mathrm{n}=21)\end{array}$ & $\begin{array}{l}\text { Completed the study } \\
(n=220)\end{array}$ \\
\hline \multirow[t]{2}{*}{ Treatment group } & Red.fat (n) & 4 & 117 \\
\hline & $\mathrm{Ctrl}(\mathrm{n})$ & 17 & 103 \\
\hline \multirow[t]{2}{*}{ Gender } & Malc (n) & 9 & 111 \\
\hline & Female $(n)$ & 12 & 109 \\
\hline \multicolumn{2}{|l|}{$\operatorname{Age}(y r)$} & $33.3 \pm 9$ & $35.8 \pm 11$ \\
\hline \multicolumn{2}{|l|}{ Body weight (kg) } & $75.3 \pm 8.8$ & $75.8 \pm 10.3$ \\
\hline \multicolumn{2}{|l|}{ Body height (m) } & $1.75 \pm 0.07$ & $1.74 \pm 0.10$ \\
\hline \multicolumn{2}{|c|}{ Quetelet Index $\left(\mathrm{kg} / \mathrm{m}^{2}\right)$} & $24.6 \pm 1.6$ & $24.9 \pm 2.1$ \\
\hline \multicolumn{2}{|c|}{ Restrained Eaters (\%) } & 4.8 & 10.9 \\
\hline \multirow[t]{3}{*}{ Type of Household } & 1 -person $(\%)$ & 9.5 & 10.9 \\
\hline & 2-person (\%) & 28.6 & 21.4 \\
\hline & other $(\%)$ & 61.9 & 67.7 \\
\hline \multirow[t]{2}{*}{ Education } & $<12$ yr $(\%)$ & 47.6 & 50.9 \\
\hline & $>12$ yr $(\%)$ & 52.4 & 49.1 \\
\hline \multicolumn{2}{|c|}{ Energy intake (MJ/day) } & $11.4 \pm 3.0^{*}$ & $10.3 \pm 3.0$ \\
\hline \multicolumn{2}{|l|}{ Fat intake $(\mathrm{cn} \%)$} & $35.9 \pm 6.8^{*}$ & $35.1 \pm 5.9$ \\
\hline \multicolumn{2}{|c|}{ Protein intake (MJ/day) } & $15.2 \pm 2.6^{*}$ & $15.2 \pm 2.8$ \\
\hline \multicolumn{2}{|c|}{ Carbohydrate intake (en\%) } & $45.5 \pm 6.8^{*}$ & $45.8 \pm 6.6$ \\
\hline \multicolumn{2}{|l|}{ Alcohol intake $(\mathrm{en} \%)$} & $3.4 \pm 3.9^{*}$ & $3.7 \pm 4.5$ \\
\hline
\end{tabular}

* $n=20$ because one voluntecr dropped out before the baseline measurement of food consumption.

Note: no significant differences were found between the group of drop outs and volunteers who completed the study. 
影

4

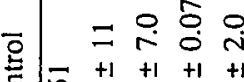

त)

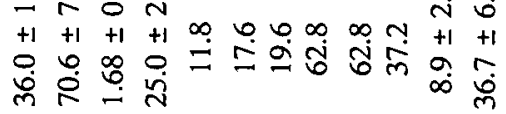

岂

西

믐

을

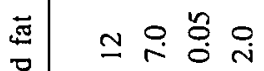

宅

禺

s.

惫

选递

는

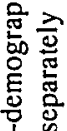

递

政

氖

选

$\infty$

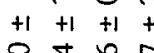

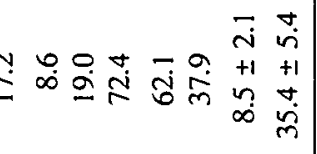

$\dddot{\mathscr{a}}$

宓

咅

岕

인

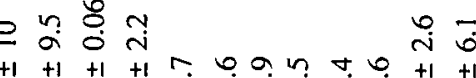

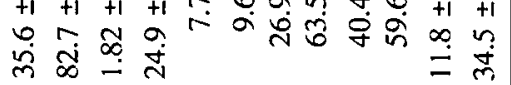

0 幽宓先

$=m$ 


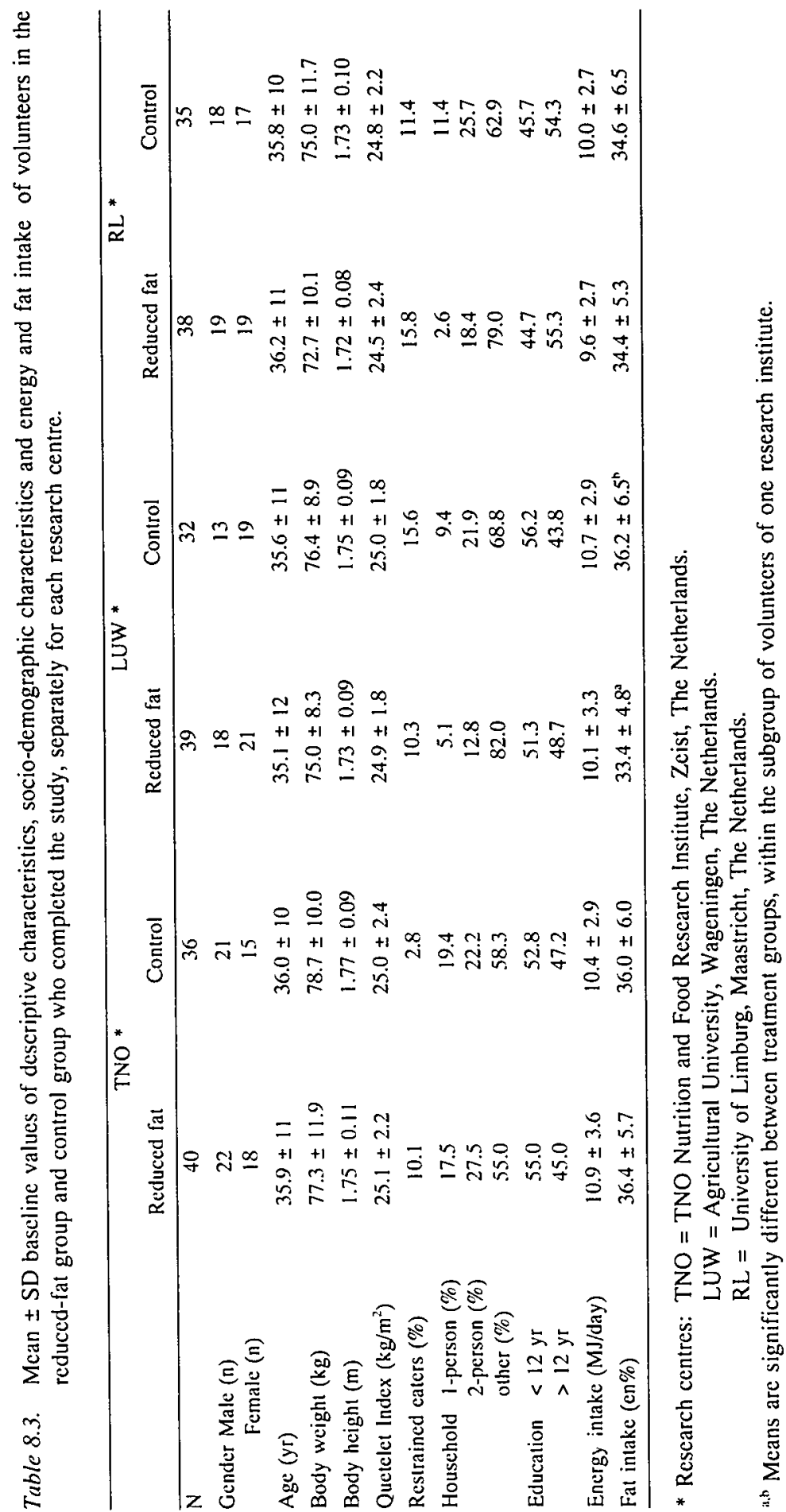




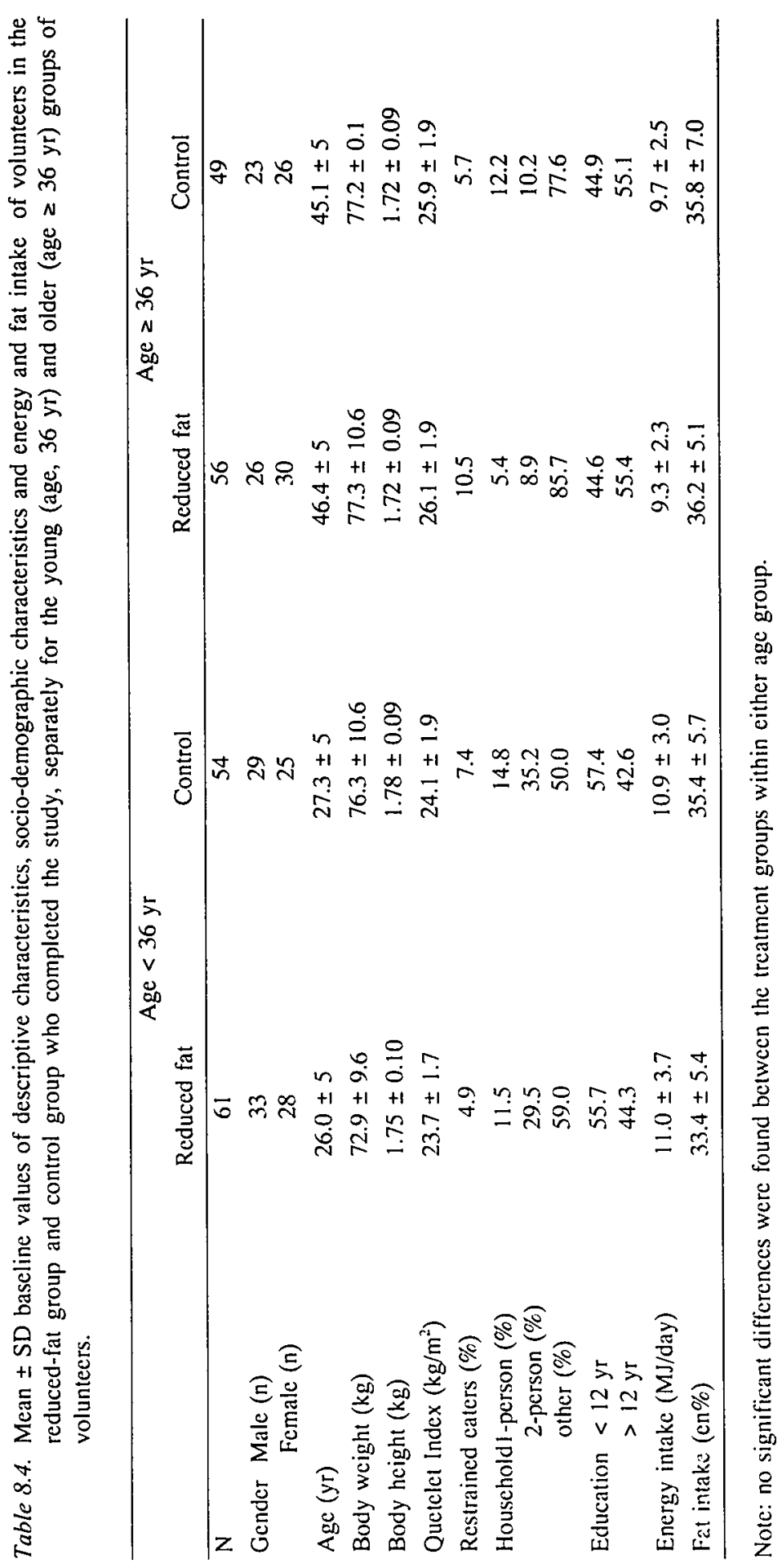




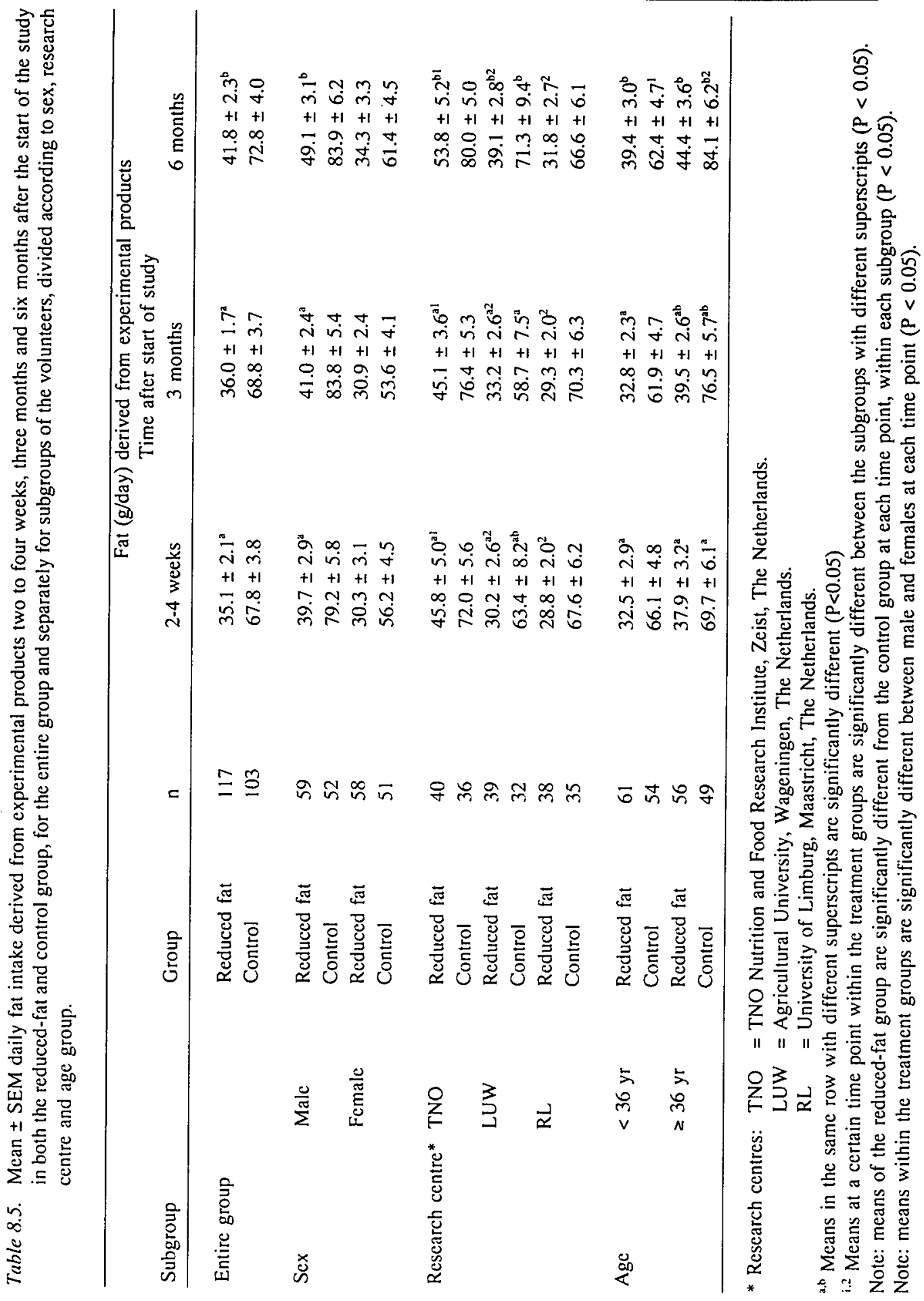


Tables 8.2-8.4 show the descriptive and sociodemographic characteristics and the average energy and fat intake before the start of the study of the volunteers who completed the study as per protocol. No significant differences were found in baseline characteristics between the treatment groups within any of the subgroups, except for the differences in fat intake between the reduced fat and control group in the subgroup of volunteers participating in the Agricultural University of Wageningen (respectively 33.4 en\% and 36.2 en\%; $P=0.04)$. All values of the clinical parameters, as assessed before as well as after the study, were within the normal ranges. This indicates that healthy subjects were selected and that they were still in good health after completion of the study.

The study was extended for 38 volunteers by two to four weeks because these volunteers had been on holiday or had been ill for one or more weeks during the experimental period.

\section{Obtained magnitude of experimental manipulation}

Table 8.5 shows the consumption of experimental products, expressed as the daily amount of fat intake from the experimental products, calculated from the data of the food consumption diaries. The remainder of the fat intake came from non-experimental products, bought in regular shops.

Volunteers in the reduced fat group consumed significantly less fat from the reduced fat products than the amount of fat volunteers in the control group consumed from the fullfat products. In both treatment groups, at each time point, males were found to consume significantly more experimental products than females. At each time point, volunteers in the reduced fat group who participated in the TNO Nutrition and Food Research Institute consumed significantly more from the experimental products than the volunteers in the reduced fat group of the other two research centres. No effect was found however from the type of research centre on the outcome of the difference between the treatment groups in fat intake derived from the experimental products. Significant differences between the age groups were found only in the control group, six months after the start of the study. Volunteers in the older age group ( $\geq 36 \mathrm{yr}$ ) consumed significantly more from the experimental products than the younger volunteers.

The amount of fat intake from the experimental products in the entire control group remained stable throughout the study period and increased significantly in the reduced fat group between three and six months after the start of the study. This significant increase was not present in all subgroups of volunteers of the reduced fat group and in some of the subgroups, a significant increase in fat intake from the experimental products was found in the control group. 
The magnitude of the experimental manipulation, i.e. the average difference in fat consumption from the experimental products between the entire reduced fat and control group, calculated over the whole study period, was $46 \%$.

\section{DISCUSSION}

In this six-months, semi-controlled study, we achieved an experimental manipulation of an average reduction of $46 \%$ of fat intake from the experimental products in the reduced fat group compared to the control group. The consumption of experimental products did not decrease during the time course of the experiment. These findings indicate that compliance to the treatment was good and that the magnitude of the experimental manipulation we had planned, i.e. 50\% reduction in fat intake from the experimental products in the reduced fat group, has been achieved. The volunteers consumed on average $\pm 70 \mathrm{~g}$ fat/day from the full-fat products. This would be $70 \%$ of their total daily fat intake, if total fat intake in this group has remained the same as before the start of the study $( \pm 100 \mathrm{~g}$ fat/day). Also this contribution of the experimental products to the total diet was the size we had aimed at.

The difference we found between males and females in consumption of the experimental products could be expected because of the difference in average energy requirements between males and females. We also found a difference in consumption between the young and old age groups. This difference was however not expected because the older volunteers were found to consume less energy at baseline than the younger volunteers. Although it was only found at the end of the study and only in the control group, this points to a difference in compliance to the experimental products between the age groups. The older volunteers may have felt more affected to the experiment or it may have been more easy for them to introduce the experimental products in their diet.

A multicentre approach was chosen because of the broader range of parameters which could be investigated with the different expertises and the geographical spread over the country. One of the disadvantages of a multicentre approach is the possibility that betweenlaboratory variation occurs in experimental procedures. Despite the strict standardization, we did find a difference in consumption of experimental products between the research centres. This difference can not be explained by a difference in average total energy requirements between the subgroups of volunteers, because we did not find a difference in baseline daily energy intake between the different research centres. The difference may therefore be due to a difference in interaction between the investigators and the volunteers. No interaction was found between the type of research centre and the treatment effect on the fat intake from experimental products and thus the magnitude of the experimental manipulation was not different between the research centres. The treatment effect on total 
daily fat intake may therefore not be affected by the type of research centre.

Average daily energy intake at baseline was comparable to what has been found during the Dutch food consumption survey ${ }^{6}$ in males and females of similar age groups (22-50 yr). Average percentage of energy derived from fat in our volunteers was however somewhat lower than the $37 \mathrm{en} \%$ found in the Dutch food consumption survey. During the baseline measurement the weather was unusually hot in The Netherlands. This may have affected the dietary intake during those days. Our target was that the control group would consume about 40 en\% of fat and that the reduced fat group would reduce their fat intake to on average $30-35 \mathrm{en} \%$. As our population was used to consume less fat than $40 \mathrm{en} \%$ of fat, an increase in fat intake may be found in the control group instead of a stable fat consumption, due to an increase in consumption of full-fat products. On the other hand, only a small reduction in fat intake can be expected in the reduced fat group. This will however not affect our conclusions about a possible positive effect of reduced fat products on energy and fat intake. Previous studies using a parallel design have also drawn conclusions about differences in treatment effects while both treatment groups showed a change in the investigated parameters. ${ }^{34,35}$

In conclusion, the compliance to the experimental products in this six-months semicontrolled trial did not decrease during the time course of the experiment and the magnitude of the experimental manipulation we aimed at was achieved. We therefore believe we have completed the long-term, realistic trial necessary to answer the question whether consumption of reduced fat products is an effective tool to decrease total fat intake and to improve human health.

\section{ACKNOWLEDGEMENT}

We kindly acknowledge the expert help of Ms. J. Drijvers, Mr. G.P. Dubbelman, Ms. W.M.C. Dubelaar, Ms. A. Engelgeer-Bekius, Ms. T. Hermans, Ms. J. de Vries, Ms. N. Wijckmans and the other members of the technical and dietary staff of the research centres and Unilever Research Laboratorium for their help in conducting the study and we thank the Unilever companies for provision of the reduced fat and full fat products. We also thank the volunteers for their participation in the trial. 


\section{REFERENCES}

1. US Department of Health and Human Services. The Surgcon Gerneral's Report on Nutrition and Health. DHHS (PHS): Publication No 88-50210, 1988.

2. World Health Organization. Diet, nutrition, and the prevention of chronic diseases. Report of a WHO study group. Geneva: Technical Report Serics 797, 1990.

3. Department of Health. Dietary reference values for food energy and nutrients for the United Kingdom. Report on health and social subjects 41 . Report of the pancl on dictary reference values of the committec on medical aspects of food policy. London, HMSO, 1991.

4. Gregory J, Foster K, Tylor H, Wiseman M. The dictary and nutritional survey of British adults. Office of population censuses and surveys. London, HMSO, 1990.

5. Stephen AR, Wald NJ. Trends in individual consumption of dietary fat in the United States, 19201984. Am J Clin Nutr 1990;52:457-469.

6. Anonymous. Zo cet Nederland, 1992. Resultaten van de Voedsel-consumptiepeiling 1992. Den Haag, Voorlichtingsburcau voor de Vocding, 1993 (ISBN 9051770278 ).

7. Blokstra A, Kromhout D. Trends in obesity in young adults in the Netherlands from 1974 to 1986. Int J Obes 1991;15:513-521.

8. Kuczmarski RJ, Flegal KM, Campbell SM, Johnson CL. Increasing prevalence of overweight among US adults. The National Health and Nutrition Examination Surveys, 1960 to 1991. JAMA 1994;272:205-211.

9. Laurier D, Guiget M, Pong Chan N, Wells JA, Valleron AJ. Prevalence of obesity: a comparative survey in France, the United Kingdom and the United States. Int J Obesity 1992;16:565-572.

10. The Gallup Organization. Gallup survey of public opinion regarding diet and health, conducted for International Food Information Coucil and American Dictetic Association. Princeton NJ, 1990.

11. Brug J, van Assema P, Kok G, Lenderink T, Glanz K. Self rated dictary fat intake: Association with objective assessment of fat, psychosocial factors, and intention to change. JNE 1994;26:218-223.

12. Mela $D$. The perception and acceptance of dictary fat: What, Who, Why? Nutr Bull Br Nutr Found 1992;17:74-86.

13. Louis-Sylvestere J, Tournier A, Chapelot D, Chabert M. Effect of a fat-reduced dish in a meal on 24-h energy and macronutrient intakc. Appetitc 1994;22:165-172.

14. de Graaf C, Hulshof T, Weststrate JA, Jas P. Short-term effects of different amounts of protein, fats, and carbohydrates on saticty. Am J Clin Nutr 1992;55:33-38.

15. Hill AJ, Leathwood PD, Blundell JE. Some evidence for short-term caloric compensation in normal weight human subjects: the effects of high- and low-energy meals on hunger, food preference and food intake. Hum Nutr Appl Nutr 1987;41 A:244-257.

16. Hulshof $T$, de Graaf $C$, Weststrate JA. The effects of preloads varying in physical state and fat content on satiety and energy intake. Appetite 1993;21:273-286.

17. Foltin RW, Rolls BJ, Moran TH, Kelly TH, McNelis AL, Fischman MW. Caloric, but not macronutrient, compensation by humans for required-eating occasions with meals and snack varying in fat and carbohydrate. Am J Clin Nutr 1992;55:331-342.

18. Caputo FA, Mattes RD. Human dictary responses to covert manipulations of energy, fat, and carbohydrate in a midday meal. Am J Clin Nutr 1992;56:36-43.

19. Mattes RD, Pierce CB, Friedman MI. Daily caloric intake of normal-weight adults: response to changes in dictary energy density of a luncheon meal. Am J Clin Nutr 1988;48:214-219.

20. Duncan KH, Bacon JA, Weinsier RL. The effects of high and low energy density diets on satiety, encrgy intake, and eating time of obese and nonobese subjects. Am J Clin Nutr 1983;37:763-767.

21. Foltin RW, Fischman MW, Moran TH, Rolls BJ, Kelly TH. Caloric compensation for lunches varying in fat and carbohydrate content by humans in a residential laboratory. Am J Clin Nutr 1990;52:969980.

22. Kendall A, Levitsky DA, Strupp BJ, Lissner L. Weight loss on a low-fat diet: consequence of the imprecision of the control of food intake in humans. Am J Clin Nutr 1991;53:1124-1129.

23. Lissner L, Levitsky DA, Strupp BJ, Kalkwarf HJ, Roe DA. Dictary fat and the regulation of energy intake in human subjects. Am J Clin Nutr 1987;46:886-892. 
24. Tremblay A, Plourde G, Despres, JP, Bouchard C. Impact of dietary fat content and fat oxidation on energy intake in humans. Am J Clin Nutr 1989;49:799-805.

25. Thomas CD, Peters JC, Reed GW, Abumrad NN, Sun M, Hill JO. Nutrient balance and energy expenditure during ad libitum feeding of high-fat and high-carbohydrate diets in humans. Am J Clin Nutr 1992;55:934-942.

26. Shah M, McGovern P, French S, Baxter J. Comparison of a low-fat, ad libitum complex-carbohydrate diet with a low-energy diet in moderately obese women. Am J Clin Nutr 1994;59:980-984.

27. Stephen AM, Deneer MJ. The effect of dietary fat reduction on intake of major nutrients and fat soluble vitamins. J Can Diet Assoc 1990;51:281-285.

28. Caputo FA, Mattes RD.Human dietary responses to perceived manipulation of fat content in a midday meal. Int J Obesity 1993;17:237-240.

29. Westerterp-Plantenga MS, Wouters L, ten Hoor F. Restrained eating, obesity and cumulative food intake curves during four-course meals. Appetite 1991;16:149-158.

30. Stunkard AJ, Messinck S. The three factor eating questionnaire to measure dietary restraint, disinhibition and hunger. J Psychosom Res 1985;29:71-83.

31. Anonymous. NEVO Tabel, Nederlands vocdingsstoffenbestand 1993. Den Haag, Voorlichtingsbureau voor de Voeding, 1993.

32. Anonymous. Maten, gewichten en codenummers 1992. Zeist, Netherlands, TNO-Nutrition, 1992, Report No V 92.003.

33. SAS Institute. SAS/STAT guide for personal computers. USA, Carry NC, 1987, 6th ed.

34. Mensink RP, Katan MB. Effect of a diet enriched with monounsaturated or polyunsaturated fatty acids on levels of low-density and high-density lipoprotein cholesterol in healthy women and men. N Engl J Med 1989;321:436-441.

35. Valsta LM, Jauhiainen M, Aro A, Katan MB, Mutanen M. Effects of a monounsaturated rapeseed oil and a polyunsaturated sunflower oil diet on lipoprotein levels in humans. Arterioscl Thromb 1992;12:50-57. 


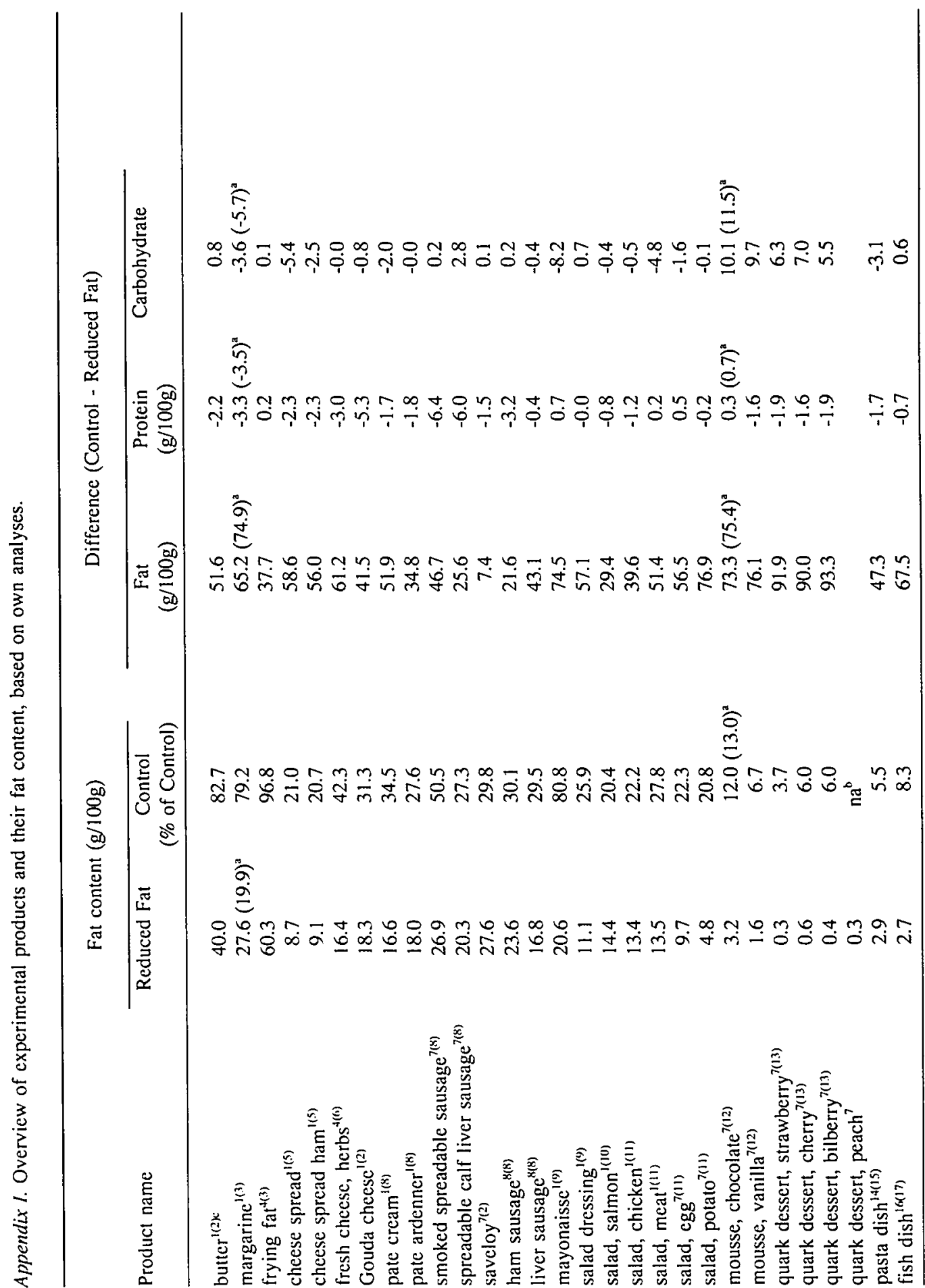




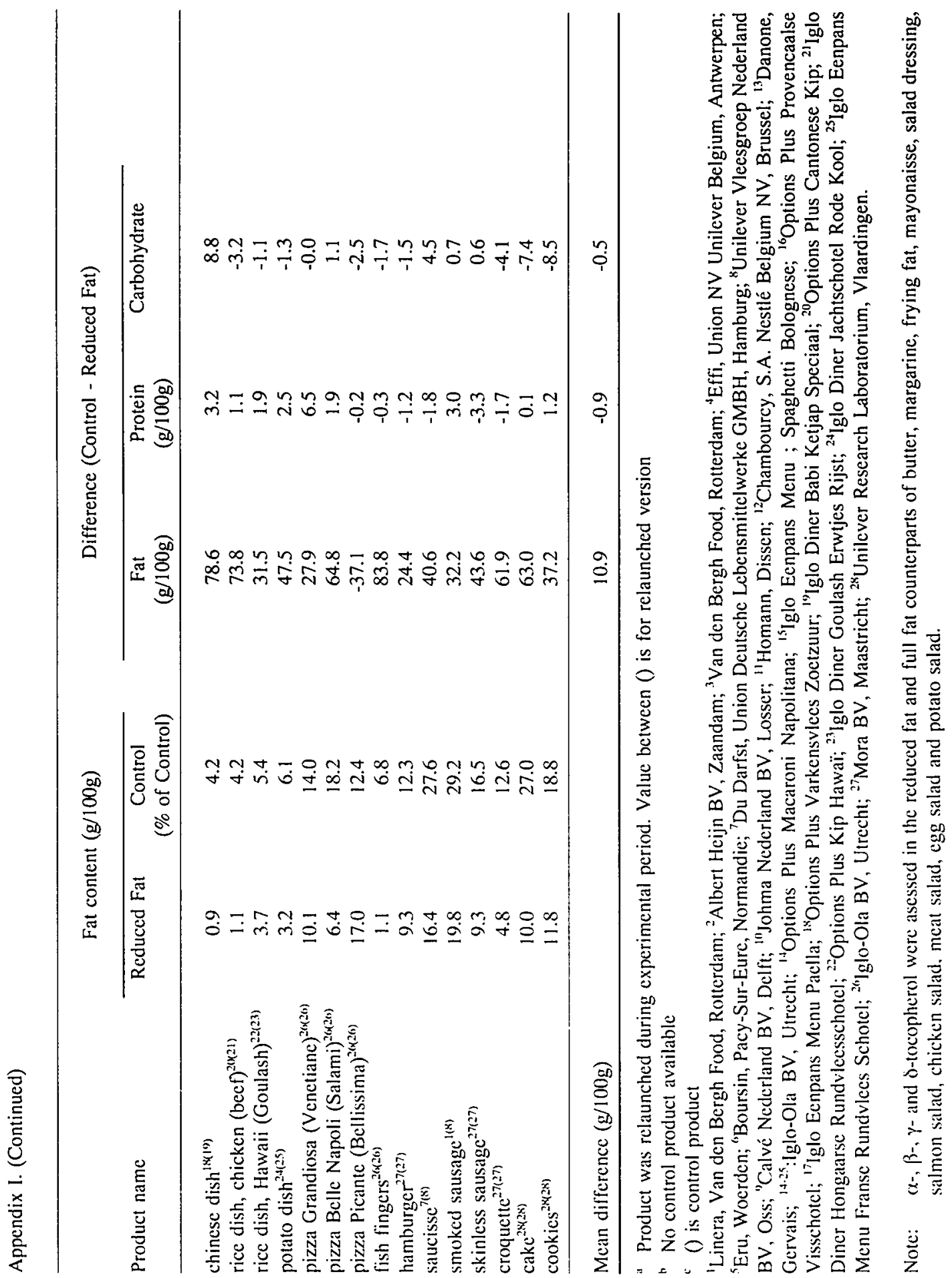




\title{
Consumption of reduced-fat products, haemostatic parameters and oral glucose tolerance test
}

\author{
Erica J.M. Velthuis-te Wierik ${ }^{1}$, Cornelis Kluft ${ }^{2}$, Henk van den Berg ${ }^{1}$ \\ and Jan A. Weststrate ${ }^{3}$ \\ ' TNO Nutrition and Food Research Institute, Zeist, The Netherlands \\ 2 TNO Prevention and Health, Gaubius Institute, Leiden, The Netherlands \\ ${ }^{3}$ Unilever Research Laboratorium, Vlaardingen, The Netherlands
}

Submitted for publication

\section{ABSTRACT}

A high fat intake has been associated with the high prevalence of coronary heart disease (CHD) in most western countries. Consumption of reduced fat products might reduce the fat intake and beneficially affect markers of CHD risk. Therefore, the effects of 6 months realistic consumption of reduced fat products on energy and fat intake, concentrations of Factor VII, PAI-1 antigen and fibrinogen as well as tPA activity was investigated. In addition, an oral glucose tolerance test was performed to study the effects on insulin sensitivity, in relation to haemostatic factors. Participants $(n=76)$ were healthy, non-obese men and women. The reduced fat group $(n=40)$ showed a significantly lower energy intake as well as a lower percentage energy derived from fat than the control group $(n=36)$, who received the full fat equivalents. However, this did not result in differences in the haemostatic parameters measured, or in altered insulin sensitivity. It has been concluded that consumption of reduced fat products does not decrease, nor increase, the CHD risk through improvement of the risk markers Factor VII, fibrinogen, PAI-1 antigen, tPA activity and insulin sensitivity in healthy non-obese subjects. 


\section{INTRODUCTION}

A high fat consumption, especially when rich in saturated fat, has, besides smoking, been targeted as an important enemy of good health. The high prevalence of coronary heart disease (CHD) in most western countries has been associated with a high fat intake, i.e. it is often higher than the recommended $30-35 \%$ of total energy intake. In recent prospective epidemiological studies, various haemostatic risk indicators for $\mathrm{CHD}$ have been identified. In the Northwick Park Heart Study both elevations of fibrinogen and of Factor VIIc were risk indicators. ${ }^{1}$ Fibrinogen has been been established now as a prominent risk indicator in several other prospective studies. ${ }^{2-9}$ Factor VIIc obtained less support in prospective studies: Another prospective study could not confirm the findings in the The Nortwick Park Heart Study. ${ }^{5}$ In several cross-sectional studies, however, postmyocardial infarction patients had significantly elevated levels of Factor VII compared to controls. ${ }^{10-12}$ Also, recently the blood fibrinolytic activity, ${ }^{13,14}$ determined mainly by tissue-type plasminogen activator (t-PA) and its inhibitor (PAI-1), has been recognized as risk indicators. ${ }^{15}$ Specific studies showed a prospective value of elevated PAI-activity, ${ }^{16}$ reduced t-PA activity ${ }^{17,18}$ and elevated t-PA antigen. ${ }^{9,19-22}$ Studies of Juhan Vague $^{23}$ indicated that elevation of PAI-1 and reduction of blood fibrinolytic activity are related to insulin resistance. Potter van Loon et al. ${ }^{24}$ atribute this abnormality to a close relation to insulin resistance.

The growing public concern about the adverse effects of a high fat intake has led to an increased availability of 'reduced-fat' products. Consumption of reduced-fat products might be a convenient way to reduce the fat intake and might consequently reduce the CHD risk.

The present study was performed in order to investigate whether a realistic consumption of reduced-fat products can alter dietary fat intake as well as markers of cardiovascular risk, including fibrinolytic factors and insulin sensitivity.

In this paper we present the effects of 6-month consumption of reduced-fat products on energy and fat intake, PAI-1 antigen, tPA activity, fibrinogen and Factor VII concentration in 76 healthy non-obese subjects. Moreover, an oral glucose tolerance test was performed to assess the effects of reduced fat products on insulin sensitivity, in relation to haemostatic factors. The reduced-fat products were provided through a realistic shop in order to mimic a 'free living' situation. 


\section{SUBJECTS AND METHODS}

\section{Subjects}

Eighty apparently healthy subjects ( 40 men, 40 women) started as a participant in the study. They were selected from responders to advertisements in regional newspapers. Subjects were aged between 20 and 55 yr. Those aged between 20 and $35 \mathrm{yr}$ had a body mass index (BMI) between 20 and $28 \mathrm{~kg} / \mathrm{m}^{2}$, and those aged between 35 and $55 \mathrm{yr}$ had a BMI between 24 and $30 \mathrm{~kg} / \mathrm{m}^{2}$. All subjects were medically screened by a physician. Routine clinical chemistry, blood pressure and lipid profile had to be within normal ranges. Exclusion criteria were: following a medically prescribed diet or slimming diet; being pregnant or wishing to become pregnant during the experiment; weight loss or gain $>2 \mathrm{~kg} /$ month 1 month before prestudy examination; and sporting activities of more than $7 \mathrm{hrs} /$ week. Subjects were randomly assigned to either the reduced-fat group or the control group which received the full-fat equivalents. The groups were stratified according to gender, age, BMI, eating behaviour characteristics and type of household. Four females from the control group withdrew from the study because one disliked the taste of the products, one got pregnant, and two because of changed personal circumstances, so that 36 subjects in the control group and 40 in the reduced-fat group finished the study. The study protocol was approved by the Institute's Medical Ethical Committee and the participants signed an informed consent form.

\section{Study design}

The study was part of a multicentre study, the MSFAT-study, on the long-term health effects of realistic consumption of reduced-fat products in healthy non-obese volunteers. The design was a randomized 6 month parallel comparison trial which has been described extensively elsewhere (Chapter 8). ${ }^{25}$ In short, four Dutch research centres participated in the study. One centre was responsible for coordination of the study, the other three centres selected each about 80 volunteers. A realistic shop was installed in these three centres. Two months before the start of the study, an one month adaptation period was executed to optimize the experimental procedures and to get the volunteers used to these procedures. Volunteers were free to take as many of the reduced fat products or their full fat equivalents (e.g. spreads, dressings, frozen meals, cheeses, meat products, non-dairy creams, biscuits, snacks etc.) as they wanted. They were also free to buy non-experimental products such as bread and vegetables in regular shops. In the three centres food intake was assessed before the adaptation period, after 2 weeks, 3 months and at the end of the study by 3 -day food consumption diaries, estimating quantities in household measures. Body weight was assessed before, after two months, four months and at the end of the study. Next to the general measurements research 
centre-specific measurements were performed. In the subjects participating at our Institute fibrinolytic factors were measured and an oral glucose tolerance test was performed before and at the end of the study.

\section{Compliance}

Consumption of the experimental products was monitored using a computer programme. Products taken from the research shop were registered by means of a barcode reader. During the next visit, volunteers reported how much was left in stock at home and how much was not consumed but thrown away. It appeared from the data of the food consumption diaries that in the reduced-fat group on average $37 \mathrm{~g}$ /day of fat intake was derived from the experimental products, for the control group this was $70 \mathrm{~g} /$ day. The mean daily fat intake from the experimental products remained stable during the study period. The remainder of their fat intake came from non-experimental products bought in regular shops.

\section{Procedures}

Body weight: The subjects were weighed in underwear after an overnight fast four times during the study (ED-60-T; Berkel, Ridderkerk, The Netherlands). From body weight and height body mass index $\left(\mathrm{BMI} ; \mathrm{kg} / \mathrm{m}^{2}\right)$ was calculated.

Before and at the end of the study blood samples were drawn after an overnight fast for the analysis of indicators of the haemostatic system. For the analysis of haemostatic factors blood was taken into ice-chilled tubes from the intermedian cubital vein by a venoject system. After centrifugation for $10 \mathrm{~min}$ at $1700 \mathrm{~g}$ and $4^{\circ} \mathrm{C}$ the plasma was collected, snap frozen and stored at $-80^{\circ} \mathrm{C}$ until analysis.

PAI-1 antigen: To measure PAI-1 antigen blood was collected in CTAD buffer $(0.11 \mathrm{M}$ citrate, $15 \mathrm{nM}$ theophylline, $3.7 \mathrm{mM}$ adenosine and $0.198 \mathrm{mM}$ dipyridamole; Becton Dickinson, Meylon, France). PAI-1 antigen was measured by means of an enzyme linked immunosorbent assay (ELISA) (Coalize $\mathbb{B}$ PAI-1/Innotest PAI-1, Chromogenix $\mathrm{AB}$, Möndal, Sweden). ${ }^{26}$

tPA activity: For measuring tPA activity blood was collected in Stabilyte tubes (Biopool, Umeå, Sweden). tPA activity was measured with a bio-immunoassay for t-PA (Coatest $\left({ }^{\circ}\right.$ BIA t-PA, Chromogenix ${ }^{27}$ ). tPA antigen was measured with the Imulyse $t-P^{\mathrm{TM}}$ method (Biopool).

Fibrinogen: Fibrinogen was measured with a clotting rate method. ${ }^{28}$

Factor VII: Factor VII was measured with a chromogenic method (Chromogenix AB).

At the end of the run-in period and at the end of the experiment blood samples were also drawn for the measurement of fasting glucose and insulin concentrations. Thereafter, an oral glucose tolerance test (OGTT) was performed: subjects drank $75 \mathrm{~g}$ 
glucose in $250 \mathrm{ml}$ water within 15 minutes. Then, at 4 moments after the glucose load (30, 6090 and $120 \mathrm{~min}$ ) another blood sample was drawn for the analysis of glucose and insulin concentrations. Fasting $(t=0)$ glucose and insulin concentrations, as well as the area under the curves (AUC), calculated by the trapezoidal rule and using $t=0$ as the baseline value, were used as parameters in the analysis.

Plasma glucose concentrations were analysed with a commercially available kit (Boehringer Mannheim Diagnostica; Hitachi 911, Japan).

Plasma insulin concentrations were analysed with a commercial radioassay (Pharmacia) according to the kit protocol.

\section{$\underline{\text { Statistics }}$}

BMDP statistical software was used for all statistical analyses.

Food intake \& body weight:

The changes in energy and fat intake (as compared to baseline values), as well as changes in body weight and body mass index, that occurred during the intervention period were analysed with analysis of variance (ANOVA). This type of analysis is appropriate in detecting differences between groups, time effects and interactions. Students t-test was used to detect differences between groups at a certain moment in the study.

\section{Haemostatic parameters \& OGTT:}

Since these parımeters showed a non-normal group distribution the nonparametric Mann-Whitney $U$ test for paired or unpaired data, as appropriate, was used.

Baseline correlations:

Pearsons correlations analysis was used to detect significant relationships between the parameters analysed.

Some gender differences were apparent at baseline: energy intake was higher in man than in women $(\mathrm{P}<0.001)$; PAI-1 antigen levels were higher in man than in women $(\mathrm{P}=0.045)$ and $\mathrm{PA}$ activity and fibrinogen concentration were higher in women than in men $(P=0.018$ and $P<0.001$ respectively). However, no difference in intervention effects between men and women were observed. Therefore, data of the group as a whole are presentt $d$.

All values in the tables are expressed as mean \pm SD. Probabilities of difference less than 0.05 were regarded as statistically significant. 


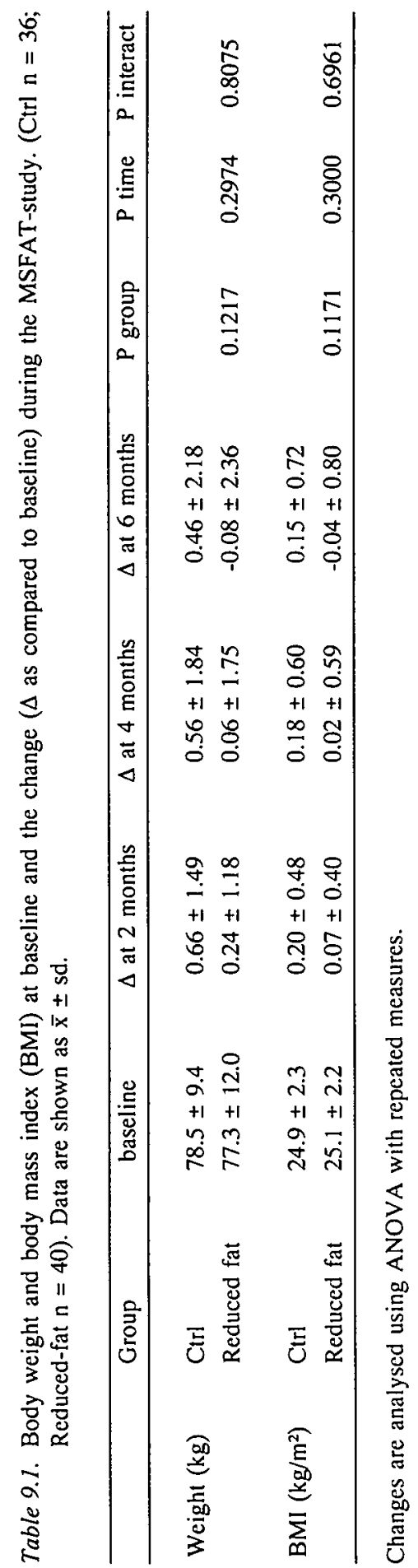




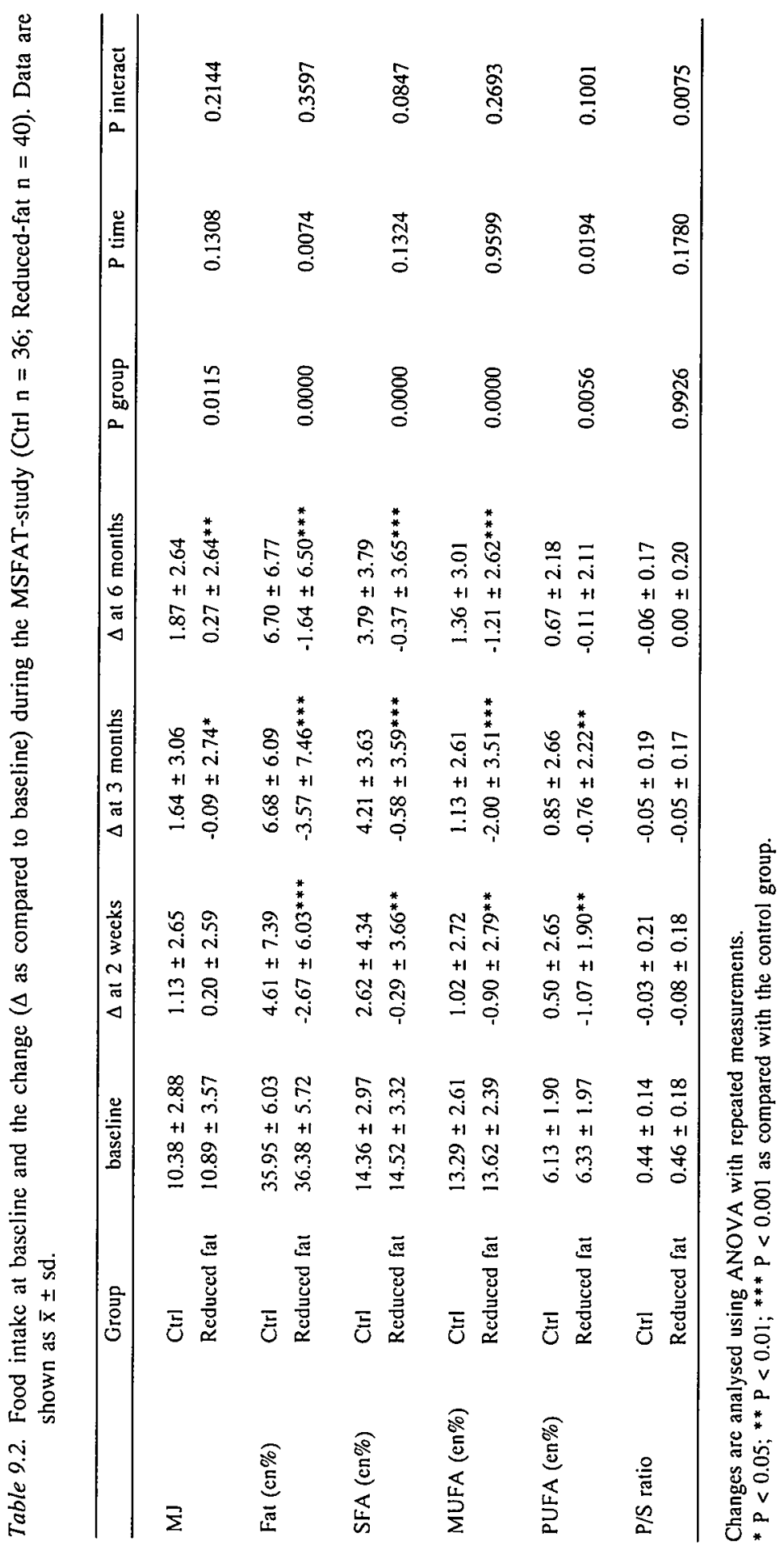




\section{RESULTS}

The results on body weight and BMI for the 76 subjects participating at our Institute are summarized in Table 9.1. Although body weight and BMI seemed to increase slightly in the control group repeated measures ANOVA did not reveal any significant time or diet effects in body weight or BMI.

Data on baseline energy and fat intake as well as the change during the intervention period, as assessed by means of 3-day dietary records, are summarized in Table 9.2. Repeated measures ANOVA revealed a significantly stronger increase in energy intake in the control group as compared to the reduced-fat group. Energy percentage derived from dietary fat was significantly reduced in the reduced-fat group as compared to the control group. Repeated measures ANOVA also showed significant effects on fatty acid intake: percentage energy derived from saturated fatty acid (SFA), mono-unsaturated fatty acids (MUFA) as well as polyunsaturated fatty acids (PUFA) intake was significantly reduced in the reduced-fat group as compared to the control group. However, the change in PUFA intake in the reduced-fat group was no longer different from that in the control group at the end (after 6 months) of the study. Although a significant interaction was found in the ratio PUFA/SFA intake (PS-ratio), no difference in average changes between the groups was observed.

There appeared to be a large variation in the haemostatic parameters. No significant effects on these parameters, PAI-1 antigen, tPA activity, Fibrinogen and Factor VII, were observed (Table 9.3). Results from the oral glucose tolerance test are presented in Table 9.4. No differences in fasting glucose and insulin levels as well as in the area under the curves of glucose and insulin were observed (see also Figure 9.1).

At baseline, PAI-1 antigen was inversely related with tPA activity $(x=-0.599$; $\mathrm{P}<0.001)$, and positively with fasting glucose concentration $(r=0.384 ; P<0.001)$ (Figure 9.2a). Closer examination of this relationship revealed that two outliers appeared in this plot. However, correlation analysis without these outliers showed an even stronger relationship between PAI-1 antigen and fasting glucose concentration $(r=0.483 ; \quad P<0.001)$. PAI-1 antigen also correlated with the AUC of insulin $(r=0.323 ; \quad P=0.005)$. tPA activity inversely correlated with baseline glucose concentrations $(r=-0.267 ; P=0.019)$ (Figure 9.2b). Fibrinogen concentration correlated with the AUC of glucose $(r=0.236 ; P=0.040)$ (Figure 9.2c). Factor VII concentration was significantly related with fasting insulin levels $(r=0.321 ; P=0.005)$ (Figure 9.2d), with the AUC of insulin $(r=0.245 ; P=0.037)$, and nearly significantly related with the AUC of glucose $(r=0.218 ; P=0.058)$. The AUC of glucose correlated with that of insulin $(\mathrm{r}=0.477 ; \mathrm{P}<0.001)$. 

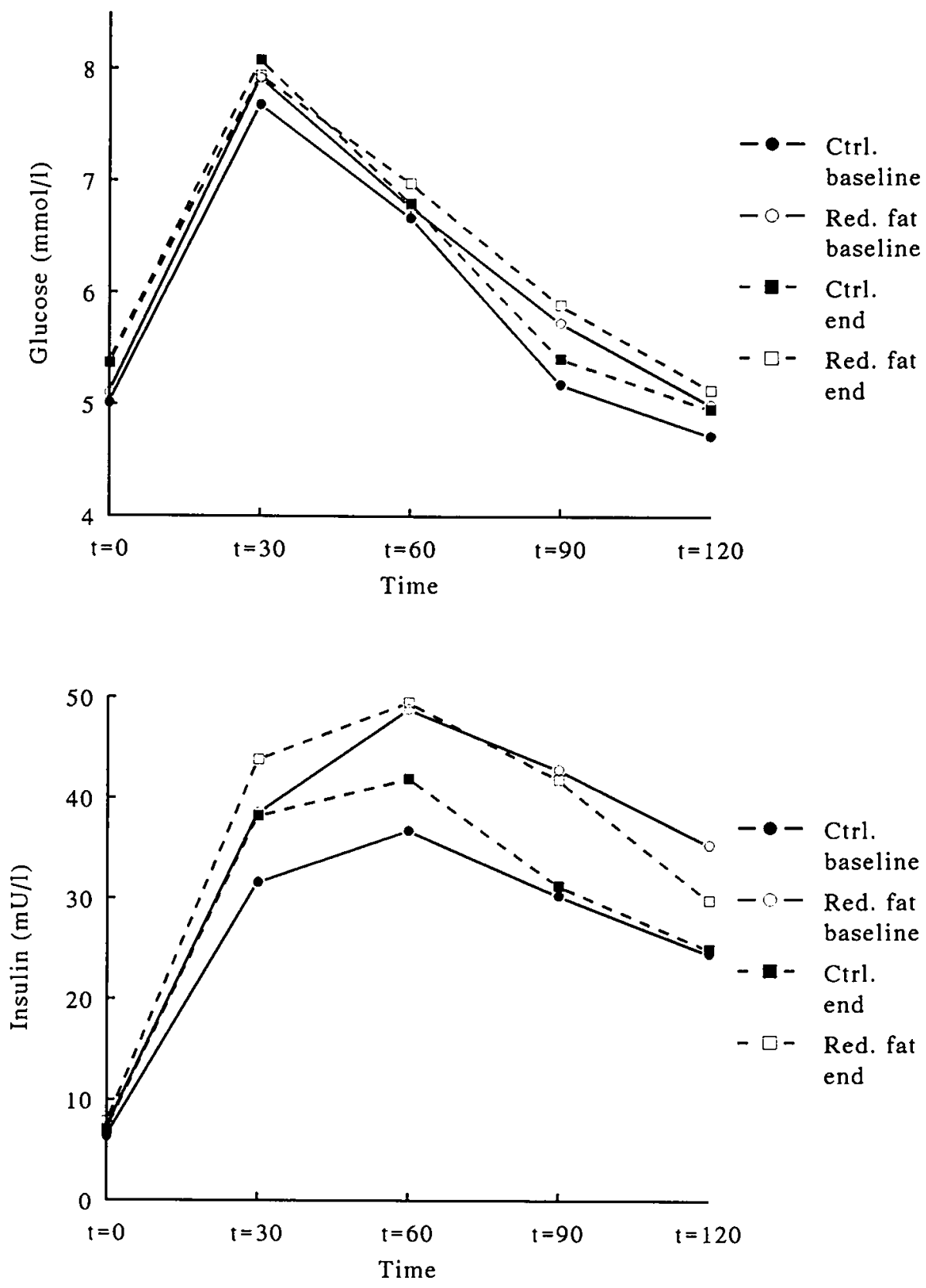

Figure 9.1. Glucose (top) and insulin (bottom) concentrations during the oral glucose tolerance test (OGTT) at bascline and at the end of 6 months consumption of reduced fat products. 
Table 9.3. Fibrinolytic factors at baseline and the change $(\Delta)$ after six months of consumption of either reduced fat products or their full fat equivalents (control). Data are shown as $\bar{x} \pm \mathrm{sd}$.

\begin{tabular}{lccccc}
\hline & \multicolumn{2}{c}{ Control group } & \multicolumn{2}{c}{ Reduced fat group } & $\begin{array}{c}\text { P } \\
\text { baseline }\end{array}$ \\
& $\Delta$ & baseline & $\Delta$ & $\begin{array}{c}\Delta \text { Ctrl vs. } \\
\Delta \text { Red.fat }\end{array}$ \\
& & & & & \\
\hline & & & & & \\
PAl-1 antigen $(\mathrm{ng} / \mathrm{ml})$ & $58.1 \pm 42.2$ & $8.1 \pm 39.7$ & $62.0 \pm 59.9$ & $-1.9 \pm 37.8$ & NS \\
tPA activity $(\mathrm{mIU} / \mathrm{ml})$ & $289 \pm 145$ & $1 \pm 169$ & $272 \pm 140$ & $57 \pm 192$ & NS \\
Fibrinogen $(\mathrm{g} / \mathrm{l})$ & $2.90 \pm 0.50$ & $0.16 \pm 0.52$ & $2.83 \pm 0.63$ & $0.20 \pm 0.51$ & NS \\
Factor VII $(\%)$ & $99 \pm 29$ & $2 \pm 14$ & $115 \pm 21$ & $-3 \pm 16$ & NS \\
\hline
\end{tabular}

Table 9.4. Results from the oral glucose tolerance test at baseline and the change $(\Delta)$ after six months of consumption of either reduced fat products or their full fat equivalents (control). Data are shown as $\bar{x} \pm$ sd.

\begin{tabular}{lccccc}
\hline & \multicolumn{2}{c}{ Control group } & \multicolumn{2}{c}{ Reduced-fat group } & $\begin{array}{c}\text { P } \\
\Delta \text { Ctrl vs. } \\
\end{array}$ \\
& baseline & $\Delta$ & baseline & $\Delta$ & $\Delta$ Red.fat \\
\hline Glucose (mM) $t=0$ & $5.02 \pm 0.44$ & $0.35 \pm 0.31$ & $5.10 \pm 0.53$ & $0.27 \pm 0.33$ & NS \\
Insulin (mM) $t=0$ & $6.34 \pm 1.83$ & $0.62 \pm 1.95$ & $7.19 \pm 1.69$ & $0.49 \pm 2.27$ & NS \\
AUC Glucose & $133 \pm 140$ & $-15 \pm 118$ & $152 \pm 131$ & $-14 \pm 123$ & NS \\
AUC Insulin & $2689 \pm 1444$ & $300 \pm 1143$ & $3490 \pm 2505$ & $167 \pm 1700$ & NS \\
\hline
\end{tabular}

Furthermore, BMI was significantly related with PAI-1 antigen $(r=0.496 ; \mathrm{P}<0.001)$, tPA activity $(r=-0.459 ; \quad P<0.001)$, fasting glucose concentration $(r=0.415$; $P<0.001)$, the AUC of glucose $(r=0.326 ; P=0.004)$ and the AUC of insulin $(\mathrm{r}=0.281 ; \mathrm{P}=0.016)$. Partial correlation analysis after removing the linear effect between BMI and AUC of insulin revealed that the correlation between BMI and PAI-1 antigen, tPA activity as well as fasting glucose level were still significant $(r=0.458$, $\mathrm{P}<0.001 ; \mathrm{r}=-0.408, \mathrm{P}<0.001 ; \mathrm{r}=0.390, \mathrm{P}<0.001$ respectively).

The age of the subjects correlated with baseline PAI-1 antigen concentration $(r=0.353 ; P=0.002)$, with fasting glucose concentration $(r=0.360 ; P=0.001)$ and with the AUC of insulin $(r=0.247 ; P=0.035)$. After removing linear effects between age and AUC of insulin, the relationships between age and PAI-1 antigen as well as fasting glucose concentration were still significant $(r=0.280, P=0.014 ; r=0.328$, $\mathrm{P}=0.005$ respectively). 


\section{DISCUSSION}

The aim of the present study was to investigate whether realistic consumption of reduced-fat products beneficially affects indicators of the haemostatic system. Moreover, the effects on glucose tolerance and its relationship with indicators of the haemostatic system has been studied. Previously, we reported that restriction of the energy intake, while keeping relative contributions of the macronutrients constant, beneficially affects fibrinolytic parameters in non-obese men, especially in those with a high PAI activity. These effects were related to the decrease in $\mathrm{BMI} .{ }^{29}$ However, it is hard to differentiate whether these effects on fibrinolytic factors are the consequence of the reduction in the total amount of dietary fat or to the weight loss. It has been reported that a moderate reduction in dietary fat did not influence blood coagulation and fibrinolysis. ${ }^{30}$ However, diet might be involved in the haemostatic system since results from intervention studies, reported by Marckmann, showed that a 2-week low-fat/high-fibre diet lowered Factor VII caogulant activity and raised plasma fibrinolytic activity. ${ }^{31}$ In addition, consumption of a low-fat/high-fibre diet (26\% of energy derived from fat, $58 \%$ of energy derived from carbohydrates; P/S-ratio $=0.77$ ) for 8 months elevates tPA activity as well as the systemic fibrinolytic activity of the euglobulin fraction of plasma. Both effects were already apparent after 60 days. ${ }^{32}$ These studies suggest that macronutrient composition plays a role in fibrinolytic activity. However, Marckmann's intervention studies were performed under dietary controlled conditions, using a diet which seems not to be realistic under 'free living' conditions.

The present study showed that consumption of reduced fat products under realistic conditions resulted in a significantly lower energy intake as well as in a lower contribution of fat to energy intake when compared to consumption of their full-fat equivalents. However, in the present study no effect of diet on selected fibrinolytic parameters could be detected in healthy non-obese subjects. This result does not exclude that indicators of haemostatic system are not affected by consumption of reduced fat products in subjects with higher risk for CHD either. The observed beneficial effects in Marckmann's long-term study cannot be explained by weight reduction, since body weight at the end of the study did not differ from initial values, after a drop of $1.4 \mathrm{~kg}$ on average midway in the study..$^{33}$ Therefore, it seems that, if macronutrient composition plays a role in the haemostatic system, a more complex and relatively large dietary change, as implemented by Marckmann, has to be realised in order to affect haemostasis. 

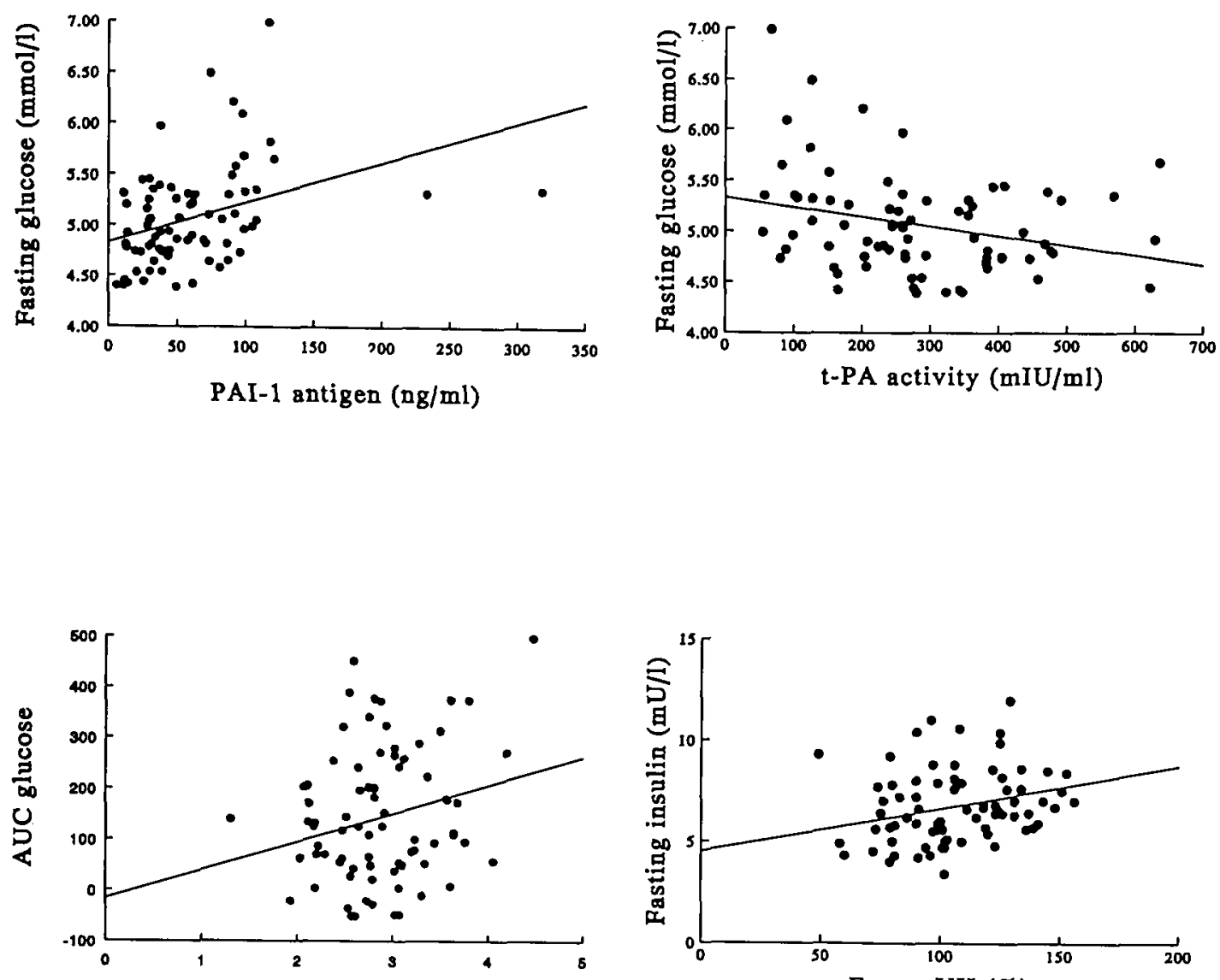

Fibrinogen ( $/ \mathrm{g} / \mathrm{l})$

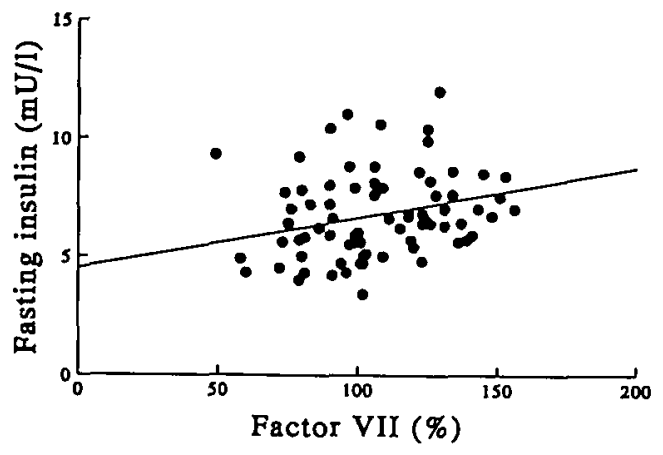

Figure 9.2. Baseline relationships between haemostatic factors and parameters of the oral glucose tolerance test.

a) (upper left): PAI-1 antigen versus fasting glucose concentration $(r=0.384 ; P<0.001$ ).

b) (upper right): $t-P A$ activity versus fasting glucose concentration $(r=-0.267 ; P=0.019)$.

c) (lower left): Fibrinogen concentration versus AUC of glucose $(r=0.236 ; P=0.040)$.

d) (lower right): Factor VIl versus fasting insulin concentration $(r=0.321 ; P=0.005)$. 
Apart from total fat consumption the composition of dietary fatty acids might also affect the haemostatic system. However, reports on this relationship are conflicting as both an increase in PAI activity has been reported after 4 months of fish consumption, ${ }^{34}$ as well as a decrease in PAI activity after fish oil supplementation. ${ }^{35}$ Also, no effect on haemostatic factors after n-3 PUFA supplementation has been reported. ${ }^{36}$ Recently, it has been reported that the effect of n-3 fatty acids on platelet and vascular function is modulated by the content of saturated fatty acids in the diet. ${ }^{37}$ In the present study percentage energy derived from total PUFA's was ca. 1.5 en\% lower in the reduced-fat group when compared to the control group, which was statistically significant. No effect of this relatively small change in PUFA intake on haemostatic parameters was observed. In addition, no significant relationship could be demonstrated between fatty acid intake (PUFA, SFA, PUFA/SFA ratio) and the haemostatic parameters measured. Unfortunately, our data do not allow further distinguishment between the various PUFA's.

In agreement with previous reports we found a significant correlation between BMI and several parameters of haemostasis and OGTT. Others have reported a significant positive relationship between PAI-1 antigen concentration and fasting insulin levels in subjects with a wide range of $\mathrm{BMI},{ }^{38}$ and in a group including diabetic and obese subjects. ${ }^{39}$ We did not observe such a relationship in the present study. However, a significant relationship between the AUC of insulin and PAI-1 antigen concentration was observed, confirming a relationship between fibrinolysis and insulin sensitivity in healthy, non-obese subjects. The relationship between BMI and PAI-1 antigen concentration and tPA activity was still significant after correction for the AUC of insulin, suggesting an independent relationship between BMI and fibrinolysis.

Since both the age of the subjects as well as the BMI was positively related to PAI-1 antigen concentration and AUC of insulin, it could be suggested that older subjects with a higher BMI could benefit more from consumption of reduced fat products than the younger and leaner subjects. However, after dividing the reduced-fat group in two age categories, no differences in changes in haemostatic parameters after 6 months was observed. Nor was there any statistically significant difference between different BMI subgroups, or between combinations of age and BMI subgroups.

In conclusion, realistic consumption of reduced-fat products leads to a significantly lower energy intake and as well as to lower percentage of energy derived from dietary fat as compared to consumption of full-fat equivalents. However, this did not result in a change in the CHD risk markers PAI-1 antigen, tPA activity, fibrinogen concentration, Factor VII concentration and insulin sensitivity. However, since this study is performed in healthy non-obese subjects it does not exclude that consumption of reduced fat products does not affect haemostatic parameters in subjects with a higher risk for CHD. 


\section{ACKNOWLEDGEMENT}

The authors would like to thank Ms. A. Engelgeer-Bekius for her skilful research assistance.

\section{REFERENCES}

1. Meade TW, Mellows S, Brozovic M, Miller GJ, Chakrabarti RR, North WRS, Haines AP, Stirling $Y$, Imeson JD, Thompson SG. Haemostatic function and ischaemic heart disease: principal results of the Northwick Park Heart Study. Lancet 1986;ii:533-537.

2. Wilhelmsen L, Svärdsudd K, Korsan-Bengtsen K, Larsson B, Welin L, Tibblin G. Fibrinogen as a risk factor for stroke and myocardial infarction. N Engl J Med 1984;311:501-505.

3. Kannel WB, Wolf PA, Castelli WP, D'Anostino RBD. Fibrinogen and risk of cardiovascular disease: The Framingham study. JAMA 1987;258:1183-1186.

4. Stone MC, Thorp JM. Plasma fibrinogen - a major risk factor. J R Coll Gen Pract 1985;12:565569.

5. Heinrich J, Balleisen L, Schulte J, Assman G, van de Loo J. Fibrinogen and factor VII in the prediction of coronary risk. Results from the PROCAM Study in healthy men. Arterioscler Thromb 1994;14:54-59.

6. Lee AJ, Smith WCS, Lowe GDO, Tunstall-Pedoe H. Plasma fibrinogen and coronary risk factors: the Scottish Heart Health Study. J Clin Epidem 1990;43:913-919.

7. Baker LA, Easthan RM, Elwood PC, Etherington M, O'Brian JR, Swcetham PM. Hacmostatic factors associated with ischemic heart discase in men aged 45 to 64 years. The Speedwell Study. Br Heart J 1982;47:490-494.

8. Yarnell JWG, Baker IA, Sweetman PM, Bainton D, O'Brien JR, Whitehead PJ, Elwood PC. Fibrinogen, viscosity, and white blood cell count are major risk factors for ischemic heart discase. The Cacrphilly and Speedwell Collaborative Heart Disease Studies. Circulation 1991;83:836-844.

9. Haverkate F. Thrombosis and disabilities. In: Baya C. ed. Adv Med Biol, Amsterdam, Oxford, Washington, Tokyo, Ios Press, 1984, pp 81-103.

10. Broadhurst $P$, Kelleher $C$, Hughes L, Imeson JD, Raftery EB. Fibrinogen, factor VII clotting activity and coronary artery disease severity. Athcrosclerosis 1990;85:169-173.

11. Carvalho de sousa J, Azevedo J, Soria C. Factor VII hyperactivation in acute myocardial thrombosis. A relation to the coagulation activation. Thromb Res 1988;51:165-173.

12. Hoffman CJ, Miller RH, Lawson WE, Hultin MB. Elevation of factor VIl activity and mass in young adults at risk for ischemic heart diseasc. J Am Coll Cardiol 1989;941-946.

13. Meade TW, Ruddock V, Stirling Y, Chakrabarti R, Miller GJ. Fibrinolytic activity, clotting factors, and long-term incidence of ischaemic disease in the Northwick Park Heart Study. Lancet 1993;342:1076-1079.

14. Meade TW, Howarth DJ, Cooper J, MacCalllum PK, Stirling Y. Fibrinolytic activity and arterial discase. Lancet 1993;343:1442.

15. Kluft C. Constitutive synthesis of tissue-type plasminogen activator (t-PA) and plasminogen activator inhibitor type 1 (PAI-1): conditions and therapeutic targets. Fibrinolysis 1994;8 suppl 2:1-7.

16. Hamsten A, De Faire U, Walldius G, Dahlen G, Szamosi A, Landon C, Blombäck M, Wiman B. Plasminogen activator inhibitor in plasma: risk factor of recurrent myocardial infarction. Lancet 1987;2:3-9.

17. Gram J, Jespersen J. A selective depression of tissuc plasminogen activator (t-PA) activity in euglobulin charactcrizcs a risk group among young survivors of acute myocardial infarction. Thromb Haemostas 1987;57:137-139. 
18. Munkvad S, Gram J, Jespersen J. A depression of active plasminogen activator in plasma characterizes patients with unstable angina pectoris who develop myocardial infarction. Eur Heart J 1990;11:525-528.

19. Janson $\mathrm{H}$, Nilsson TK, Olofsson BO. Tissue plasminogen activator and other risk factors as predictors of cardiovascular events in patients with severe angina pectoris. Eur Heart $\mathrm{J}$ 1991;12:157-161.

20. Janson JH, Olofsson BO, Nilsson TK. Predictive value of tissue plasminogen activator mass concentration on long-term mortality in patients with coronary artery disease. A 7-year follow-up. Circulation 1993;88:2030-2034.

21. Ridker PM, Vaughan DE, Stampfer MJ, Manson JE, Hennekens CH. Endogenous tissue-type plasminogen activator and risk myocardial infarction. Lancet 1993;342:1165-1168.

22. Ridker PM, Hennekens CH, Stampfer MJ, Manson JE, Vaughan DE. Prospective study of cndogenous tissue plasminogen activator and risk of stroke. Lancet 1994;343:940-942.

23. Juhan-Vague I, Alessi MC, Vague P. Increased plasma plasminogen activator inhibitor 1 levels. A possible link between insulin resistance and atherothrombosis. Diabetologia 1991;34:457-462.

24. Potter van Loon BJ, Kluft C, Radder JK, Blankenstein MA, Meinders AE. The cardiovascular risk factor plasminogen activator inhibitor type 1 is related to insulin resistance. Metabolism 1993;42:945-949.

25. van het Hof $\mathrm{KH}$, Weststrate JA, van den Berg $\mathrm{H}$, Velthuis-te Wierik EJM, de Graaf C, Zimmermanns $N$, Westerterp KR, Westerterp-Plantenga $M$, Verboeket-van de Venne WPHG. MSFAT-study: long-term health effects of realistic consumption of low-fat products in healthy non-obese volunteers. Study design and preliminary results. Submitted.

26. Mcijer P, Pollet DE, Wauters J, Kluft C. Specificity of antigen assays of plasminogen activator inhibitor in plasma: Innotest PAI-1 immunoassay evaluated. Clin Chem 1994;40:110-115.

27. Meijer P, Boon R, Jie AFH, Rosén S, Kluft C. Bioimmunoassay for tissue-type plasminogen activator (t-PA) in human plasma: elevation of blood sampling and handling procedures and comparison with other t-PA activity methods. Fibrinolysis 1992;6(suppl 3):97-99.

28. Von Clauss A. Gerinnungsphysiologische Schnellmethode zur Bestimmung des Fibrinogens. Acta Hacmatol 1957;17:237-246.

29. Velthuis-te Wierik EJM, Meijer P, Kluft C, van den Berg H. Beneficial effect of a moderately energ-restricted diet on fibrinolytic factors in non-obese men. Metabolism, accepted for publication.

30. Marckmann P, Sandström B, Jespersen J. Fasting blood coagulation and fibrinolysis of young adults unchanged by reduction in dietary fat content. Arterioscler Thromb 1992;12:201-205.

31. Marckmann P, Sandström B, Jespersen J. Low-fat, high fiber diet favorably affects several independent risk markers of ischemic heart disease: observations of blood lipids. Am J Clin Nutr 1994;59:935-939.

32. Marckmann P, Sandström B, Jespersen J. Favorable long-term effect of low-fat/high-fiber diet on human blood coagulation and fibrinolysis. Arteriosclerol Thromb 1993;13:505-511.

33. Sandström B, Marckmann P, Bindslev N. An eight-month controlled study of a low-fat high-fibre dict: effects on blood lipids and blood pressure in healthy young subjects. Eur $\mathrm{J}$ Clin Nutr 1992;46:95-109.

34. Emeis JJ, van Houwelingen $\mathrm{AC}$, van den Hoogen $\mathrm{CM}$, Hornstra G. A moderate fish intake increases plasminogen activator inhibitor type-1 in human volunteers. Blood 1989;74:233-237.

35. Mehta J, Lawson D, Saldecn T. Reduction in plasminogen activator inhibitor-1 (PAI-1) with omega-3 polyunsaturated fatty acid (PUFA) intake. Am Heart J 1988;116:1201-1206.

36. Prisco D, Paniccia R, Filippini M, Francalanci I, Bandinelli B, Comeglio C, Abbate R, Serneri GGN. No changes in PAI-1 levels after four-month n-3 PUFA ethyl ester supplementation in healthy subjects. Thromb Res 1994;76:237-244.

37. Nordoy A, Hatcher L, Goodnight S, Fitzgerald GA, Conner WE. Effects of dietary fat content, saturated fatty acids, and fish oil on cicosanoid production and hemostatic parameters in normal men. J Lab Clin Med 1994;123:914-920.

38. Vague P, Juhan-Vague I, Aillaud MF, Badier C, Viard R, Alessi MC, Collen D. Correlation 
between blood fibrinolytic activity, plasminogen activator inhibitor level, and relative body weight in normal and obese subjects. Metabolism 1986;35:250-253.

39. McGill JB, Schneider DJ, Arfken CL, Lucore CL, Sobel BE. Factors responsible for impaired fibrinolysis in obese subjects in NIDDM patients. Diabetes 1994;43:104-109. 


\section{Consumption of reduced-fat products: effects on parameters of antioxidative capacity}

Erica J.M. Velthuis-te Wierik ${ }^{1}$, Henk van den Berg', Jan A. Weststrate, Karin H. van het Hof $^{2}$ and Cees de Graaf ${ }^{3}$

TNO Nutrition and Food Research Institute, Zeist, The Netherlands
${ }^{2}$ Unilever Research Laboratorium, Vlaardingen, The Netherlands
${ }^{3}$ Wageningen Agricultural University, Wageningen, The Netherlands

Submitted for publication

\section{ABSTRACT}

It is widely held that energy restriction (ER) retards the ageing process. The beneficial effects of ER has repeatedly been demonstrated in laboratory rodents, but ER might also be effective in humans since ageing seems to be a universal phenomenon in all living organisms. Reduced oxidative stress, induced by the maintenance or improvement of the antioxidant/prooxidant balance, has been mentioned as a potential mechanism through which ER might affect the ageing process in rodents. Oxidative stress can also be affected by the total dietary fat intake as well as fatty acid composition. In this paper we present the effects of 6-month consumption of reduced-fat products on body weight, energy and fat intake, concentration of the plasma lipidperoxidation product malondialdehyde (MDA), erythrocyte free radical scavenging enzymes activities (glutathione peroxidase activity, GSH-Px; superoxide dismutase, SOD; and catalase) as well as plasma fat-soluble antioxidative vitamin concentrations ( $\beta$-carotene, lycopene and $\alpha$-tocopherol). The reduced-fat products were provided through a realistic shop in order to mimic a 'free living' situation. Healthy, normal weight (BMI: range $20-30 \mathrm{~kg} / \mathrm{m}^{2}$ ) subjects $(n=76)$, aged between $20-55 \mathrm{yr}$, participated in this study. During the intervention period, consumption of reduced fat products resulted in significantly lower energy intake, in a lower percentage of energy derived from saturated fatty acids, monounsaturated fatty acids and polyunsaturated fatty acids as well as in lower vitamin $\mathrm{E}$ intake, when compared to the control group. Body weight, the ratio polyunsaturated fatty acids/saturated fatty acids, plasma MDA and vitamin concentrations ( $\beta$-carotene, lycopene and $\alpha$-tocopherol), and erythrocyte free radical scavenging enzyme activities (SOD, GSH-Px and catalase) were not affected by the 
intervention. It is concluded that neither the difference in energy intake, nor the change in dietary fat composition seems to affect the integrity of the antioxidant scavenging capacity, assessed by measuring plasma MDA and antioxidative vitamins (lycopene, $\beta$-carotene and $\alpha$-tocopherol) and erythrocyte free radical scavenging enzymes (SOD, GSH-Px and catalase).

\section{INTRODUCTION}

It is widely held that energy restriction (ER) retards the ageing process. ${ }^{1}$ This 'life-extension effect' has repeatedly been demonstrated in various rat and mouse strains. ${ }^{1}$ The beneficial effects of ER has been extensively studied and evaluated in laboratory rodents, but ER might in principle also be effective in humans since ageing seems to be a universal phenomenon in all living organisms. A potential mechanism through which ER might affect the ageing process in rodents is the maintenance or improvement of the antioxidant/prooxidant balance, leading to reduced oxidative stress. ${ }^{2-4}$

It is difficult, if not impossible, to mimic the life-long animal studies in human volunteers, and to extrapolate the results of ER observed in animals to man. However, one of the strategies to evaluate whether similar effects of ER could be achieved in humans is to test whether a certain physiological system, related to the ageing process in an animal model, is also affected by ER in humans. For example, one could test whether the effects of ER on maintenance or improving the antioxidant/prooxidant balance, i.e. reduction of oxidative damage, as observed in ageing rodents, could also be demonstrated in humans.

Apart from conceptual and/or mechanistic considerations implementation of an ER-diet, tenable for longer periods and under 'free living conditions', seems to be a prerequisite before studying potential health- and age-retardation effects in humans.

Since dietary fat provides the most concentrated source of energy, decreasing the amount of dietary fat intake may be an option to reduce the energy intake. Dietary fat intake is higher than recommended in most western countries and is associated with the prevalence of cardiovascular diseases, obesity and cancer. The growing public concern about the adverse effects of a high fat intake has led to an increased availability of 'reduced-fat' products. Consumption of reduced-fat products might be a convenient way to reduce the energy intake.

Besides the potential of reduced energy intake changes in dietary fat intake, qualitative and quantitative, might also affect oxidative stress, i.e. the antioxidant/prooxidant ratio. Polyunsaturated fatty acids (PUFA's) contain two or more double bonds within their structure which makes them more susceptible to oxidative 
damage by free radical attack. A secondary effect of reduced fat intake might be a reduced intake and/or absorption of fat-soluble antioxidative vitamins. In this regard, the total antioxidative capacity in the cell, determined by antioxidative vitamins and free radical scavenging enzymes, should be considered.

The present study was performed in order to investigate the potential of reduced-fat products to reduce the energy intake. The reduced-fat products were provided through a realistic shop in order to mimic a 'free living' situation. Also, it was investigated whether consumption of reduced-fat products alters dietary fat intake or fatty acid composition. Since both energy restriction as well as dietary fat intake might affect the antioxidative capacity, parameters that could affect the antioxidant/prooxidant balance were measured.

In this paper we present the effects of 6-month consumption of reduced-fat products on body weight, energy and fat intake, concentration of plasma lipid peroxidation product malondialdehyde (MDA), erythrocyte free radical scavenging enzymes activities (glutathione peroxidase activity, GSH-Px; superoxide dismutase, SOD; and catalase) as well as plasma fat-soluble antioxidative vitamin concentrations ( $\beta$-carotene, lycopene and $\alpha$-tocopherol). Furthermore, correlations between (changes in) fat intake and (changes in) parameters of the antioxidant/prooxidant balance, as well as between these various parameters were calculated.

\section{SUBJECTS AND METHODS}

\section{$\underline{\text { Subjects }}$}

Eighty apparently healthy subjects ( 40 men, 40 women) started as a participant in the study. They were selected from responders to advertisements in regional newspapers. Subjects were aged between 20 and $55 \mathrm{yr}$. Those aged between 20 and $35 \mathrm{yr}$ had a body mass index (BMI) between 20 and $28 \mathrm{~kg} / \mathrm{m}^{2}$, and those aged between 35 and $55 \mathrm{yr}$ had a BMI between 24 and $30 \mathrm{~kg} / \mathrm{m}^{2}$. All subjects were medically screened by a physician. Routine clinical chemistry, blood pressure and lipid profile had to be within normal ranges. Exclusion criteria were: following a medically prescribed diet or slimming diet; being pregnant or wishing to become pregnant during the experiment; weight loss or gain $>2 \mathrm{~kg} /$ month 1 month before prestudy examination; and sporting activities of more than $7 \mathrm{hrs} /$ week. Subjects were randomly assigned to either the reduced-fat group or the control group which received the full-fat equivalents. The groups were stratified according to sex, age, BMI, eating behaviour characteristics and type of household. Four females from the control group withdrew from the study because one disliked the taste of the products, one got pregnant, and two because of changed personal circumstances, 
so that 36 subjects in the control group and 40 in the reduced-fat group finished the study.

The study protocol was approved by the Institute's Medical Ethical Committee and the participants signed an informed consent form.

\section{Study design}

The study was part of a multicentre study, the MSFAT-study, on the long-term health effects of realistic consumption of reduced-fat products in healthy non-obese volunteers. The design was a randomized 6 month parallel comparison trial which has been described extensively elsewhere (Chapter 8). ${ }^{5}$ In short, four Dutch research centres participated in the study. One centre was responsible for coordination of the study, the other three centres selected each about 80 volunteers. A realistic shop was installed in these three centres. Two months before the start of the study, a one month adaptation period was executed to optimize the experimental procedures and to get the volunteers used to these procedures. Volunteers were free to take as many of the reduced fat products or their full fat equivalents (e.g. spreads, dressings, frozen meals, cheeses, meat products, non-dairy creams, biscuits, snacks etc.) as they wanted. They were also free to buy non-experimental products such as bread and vegetables in regular shops. In the three centres food intake was assessed before the adaptation period, after 2 weeks, 3 months and at the end of the study by 3 -day food consumption diaries, estimating quantities in household measures. Fasting blood levels were taken before, after two months, four months and at the end of the study. On the same days body weight was assessed. Before and at the end of the study body composition was measured. Next to these general measurements research centre-specific measurements were performed. In the subjects participating at our Institute biomarkers of oxidative stress, malondialdehyde (MDA), free radical scavenging enzymes (GSH-Px, SOD and catalase) and plasma antioxidative vitamin concentrations ( $\beta$-carotene, lycopene, $\alpha$-tocopherol) were measured.

\section{Compliance}

Consumption of the experimental products was monitored using a computer programme. Products taken from the research shop were registered by means of a barcode reader. During the next visit, volunteers reported how much was left in stock at home and how much was not consumed but thrown away. It appeared from the data of the food consumption diaries that in the reduced-fat group on average $37 \mathrm{~g} /$ day of fat intake was derived from the experimental products, for the control group this was $70 \mathrm{~g} /$ day. The mean daily fat intake from the experimental products remained stable during the study period. The remainder of their fat intake came from non-experimental products bought in regular shops. 


\section{Procedures}

Body weight: The subjects were weighed in underwear after an overnight fast four times during the study (ED-60-T; Berkel, Ridderkerk, The Netherlands). For the measurement of body composition, total body water (assuming to be $73 \%$ of subjects' fat-free mass) was determined by deuterium dilution. Subjects drank a weighed dose of labelled water after emptying the bladder at 22:00. This was the baseline urine sample. Another sample was collected the next morning from the second voiding. Deuterium was measured in the urine samples with an isotope ratio mass spectrometer (VG-Isogas Aqua Sira). ${ }^{6}$

Blood was drawn from an antecubital vein after an overnight fast for the following measurements. All analyses were performed in the same period at the end of the study.

Plasma malondialdehyde (MDA): For the analysis of MDA blood samples were put in liquid nitrogen immediately after collection and stored at $-80^{\circ} \mathrm{C}$ until analysis. MDA content was measured after pre-column derivatisation with thiobarbituric acid (TBA) using HPLC and a fluorescence detector as described by Young and Trimble. ${ }^{7}$

For the analysis of catalase, GSH-PX and SOD in erythrocytes heparinized blood was collected. Erythrocytes were washed three times and stored under helium at $-80^{\circ} \mathrm{C}$ until analyzed. Catalase activity was measured by monitoring substrate $\left(\mathrm{H}_{2} \mathrm{O}_{2}\right)$ disappearance spectrophotometrically (LKB, Cambridge, UK) at $240 \mathrm{~nm}$ according to the method of Aebi." The activity of GSH-PX was measured according to a "FLAIRstandardized method." This FLAIR assay is based on the method of Paglia and Valentine's, ${ }^{10}$ including an enzyme stabilization step and using t-butyl hydroperoxide rather than hydrogen peroxide. SOD-activity was measured spectrophotometrically (LKB, Cambridge, UK) using the RANSOD kit (Randox laboratories, Ireland) according to the kit's protocol.

Plasma samples for analysis of concentrations of $\beta$-carotene, lycopene and $\alpha$-tocopherol were stored under argon at $-70^{\circ} \mathrm{C}$ until analysis. After extraction, $\beta$ carotene and lycopene were separated by HPLC on Nucleosil $5-\mathrm{N}\left(\mathrm{CH}_{3}\right)_{2}$ column (Machery \& Nagel, Duren, Germany) with $\mathrm{n}$-heptane as the mobile phase. The chromatographic system for $\alpha$-tocopherol consisted of a Nucleosil $5 \mathrm{CN}$ column and a mobile phase of $\mathrm{n}$-heptane/dichloromethane/isopropanol $(90: 10: 0.2, \mathrm{v} / \mathrm{v})$ for $5 \mathrm{~min}$ followed by $\mathrm{n}$-heptane/dichloromethane/isopropanol $(90: 10: 2, \mathrm{v} / \mathrm{v})$ for $20 \mathrm{~min}$ at a flow rate of $1 \mathrm{ml} / \mathrm{min}$.

\section{$\underline{\text { Statistics }}$}

Intervention effects

The changes (as compared to baseline values) that occurred during the intervention period were analysed with analysis of variance (ANOVA) with repeated measures using BMDP statistical software. This type of analysis is appropriate in detecting differences 
between groups, time effects and interactions. Students t-test was used to detect differences between groups at a certain moment in the study.

\section{Correlations $(n=76)$}

To assess relationship between food intake and the parameters analysed at baseline Pearson's linear correlation coefficient was calculated. Since most variables appeared to be quite variable during the intervention period, the mean of the three samples taken during the intervention period was also used as a variable in Pearson's linear correlation analysis. Relationships between changes ( $\Delta$ at six months as compared to baseline) in variables were also calculated with Pearson's linear correlation coefficient.

As no differences were observed in ANOVA-analysis using gender as a grouping factor, data from male and female subjects are pooled. P-values were considered statistically significant at $P<0.05$. Results are expressed as means \pm standard deviation (sd).

\section{RESULTS}

\section{Intervention effects}

The results on body weight, BMI and body composition for the 76 subjects participating at our institute are summarized in Table 10.1. Although body weight and BMI seemed to increase slightly in the control group repeated measures ANOVA did not reveal any significant time or diet effects in body weight or BMI. In addition, no significant effects on body composition were found.

Food intake as assessed by means of 3-day dietary records is summarized in Table 10.2. Repeated measures ANOVA revealed a significantly stronger increase in energy intake in the control group as compared to the reduced-fat group. Energy percentage derived from dietary fat was significantly reduced in the reduced-fat group as compared to the control group. Repeated measures ANOVA also showed significant effects on fatty acid intake: percentage energy derived from saturated fatty acid (SFA), mono-unsaturated fatty acids (MUFA) as well as polyunsaturated fatty acids (PUFA) intake was significantly reduced in the reduced-fat group as compared to the control group. However, the change in PUFA intake in the reduced-fat group was no longer different from that in the control group at the end (after 6 months) of the study. Although a significant interaction was found in the ratio PUFA/SFA intake, no difference in average changes between the groups was observed. Vitamin $E$ intake, both expressed in absolute terms as well as per gram PUFA, decreased significantly in the reduced-fat group. 


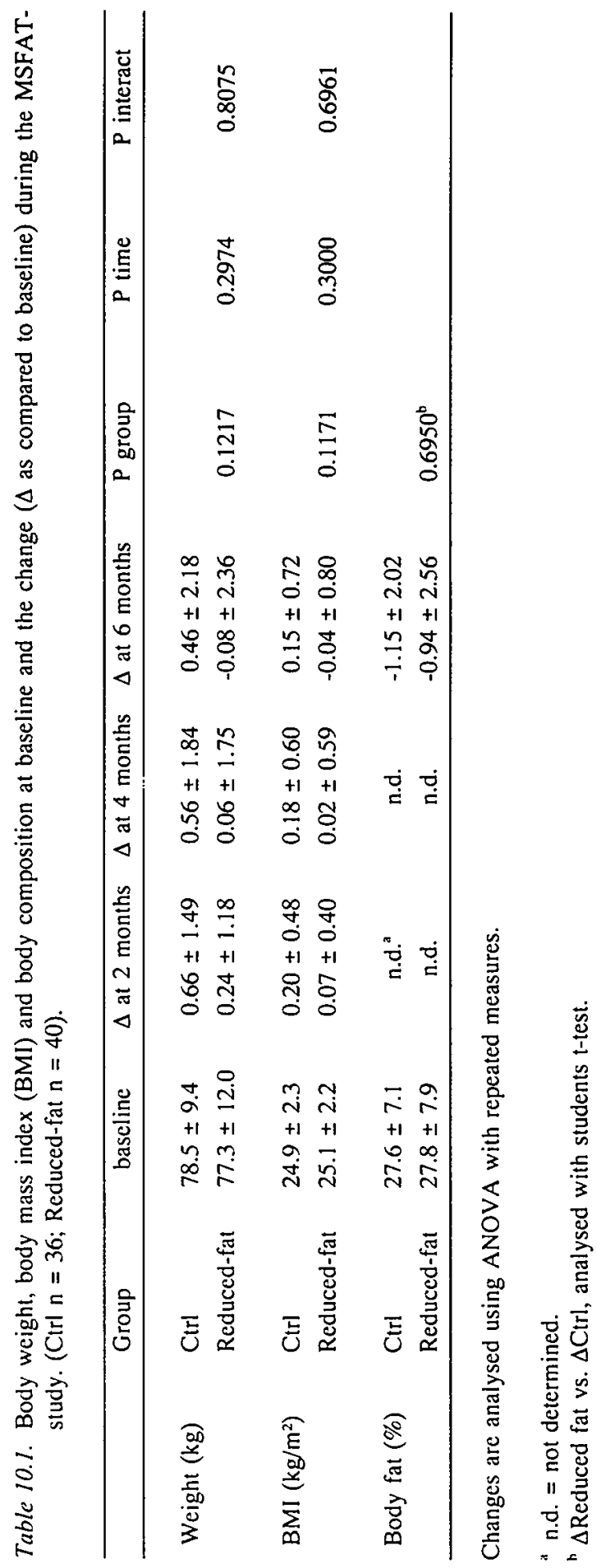




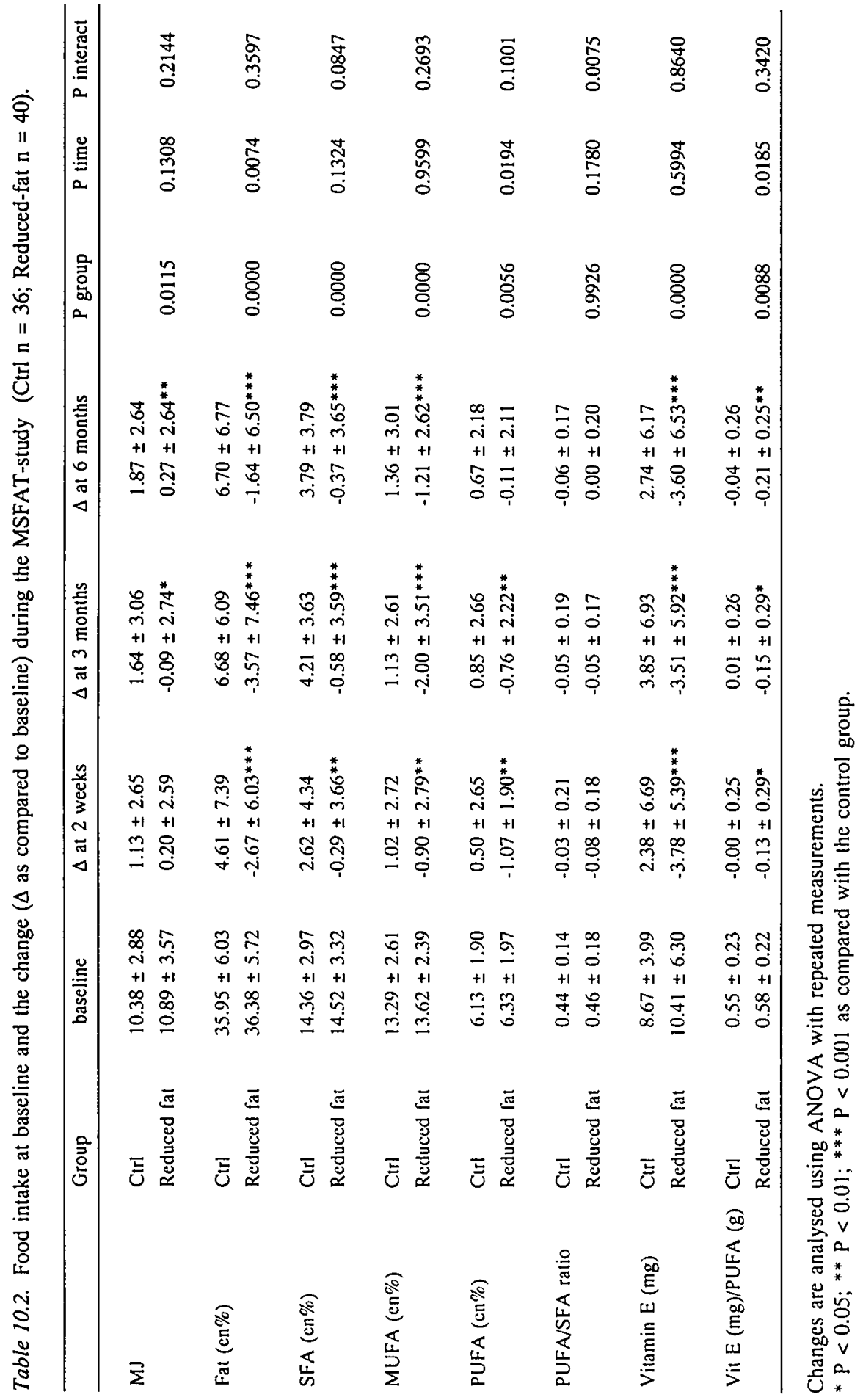




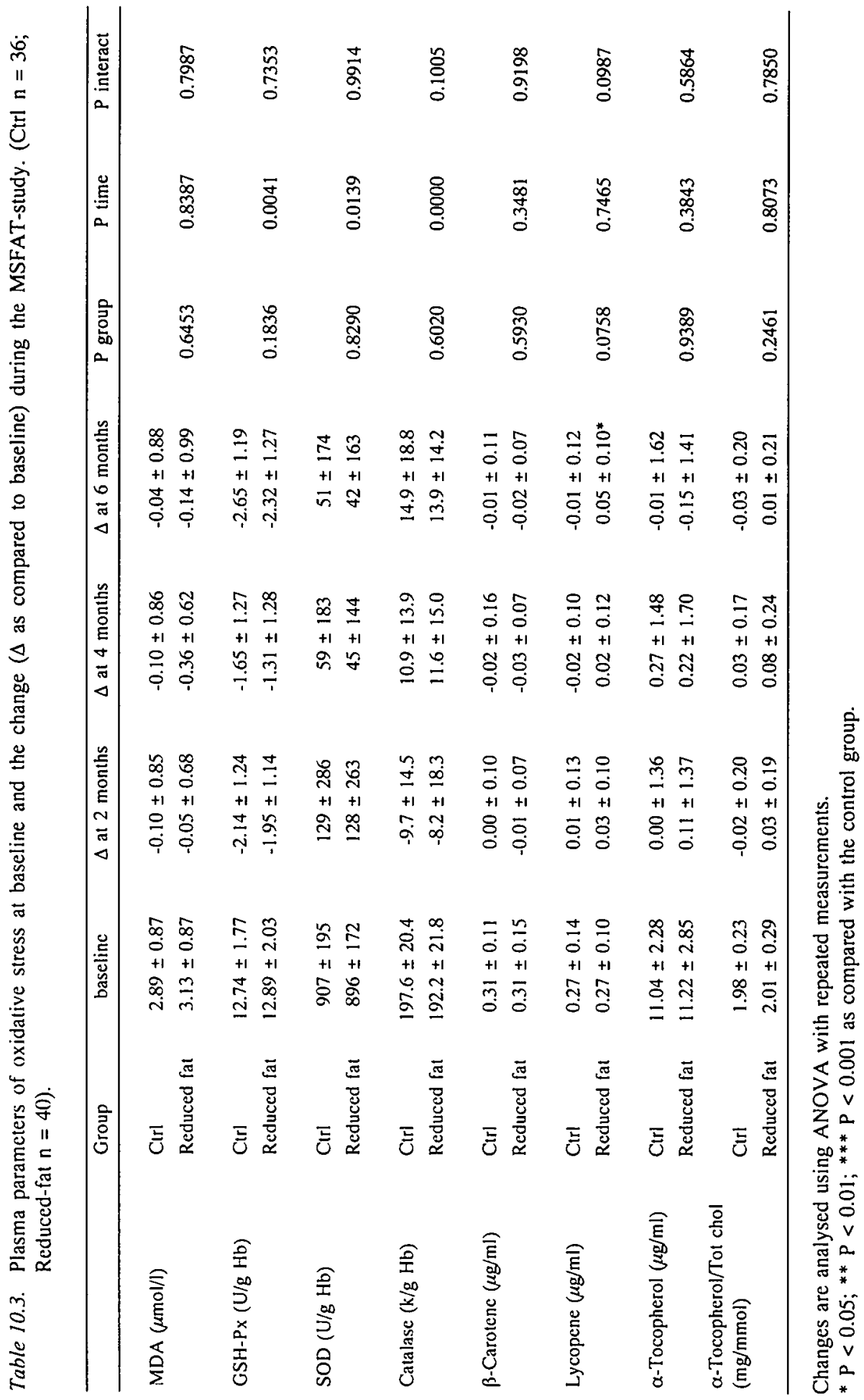


Table 10.3 presents the results on lipid peroxidation measured as plasma MDA concentration, the free radical scavenging enzymes GSH-Px, SOD and catalase and the antioxidative enzymes $\beta$-carotene, lycopene and $\alpha$-tocopherol. None of these parameters changed differently between groups. Both groups showed a decrease in GSH-Px activity and an increase in SOD activity during the intervention period. Catalase activity showed a more variable pattern, i.e. a decrease at two months and an increase at four and six months in both groups.

\section{Correlations}

At baseline, a relationship between erythrocyte GSH-Px activity and SFA intake $(r=0.273 ; P=0.017)$, as well as an inverse relationship between GSH-Px and catalase activity $(r=-0.388 ; P<0.001)$ was found. Plasma MDA concentration correlated with plasma $\alpha$-tocopherol concentration $(r=0.413 ; \quad P<0.001)$. Plasma lycopene and $\beta$-carotene concentrations were related $(r=0.295 ; P=0.010)$. Age was inversely related to energy intake $(r=-0.258 ; P=0.024)$, and positively related with plasma $\beta$-carotene concentrations $(r=0.295 ; P=0.010)$ as well as with plasma $\alpha$-tocopherol concentrations $(r=0.422 ; \mathrm{P}<0.001)$. However when plasma $\alpha$-tocopherol was expressed as per $\mathrm{mmol}$ cholesterol, this association was no longer significant. Age did not correlate with the activity of the free radical scavenging enzymes GSH-Px, SOD and catalase.

Considering the mean values calculated for the intervention period, GSH-Px activity again correlated negatively with catalase activity $(\mathrm{r}=-0.462 ; \mathrm{P}<0.001)$. Contrary to the baseline correlation analysis, a negative correlation between GSH-Px activity and SOD activity was observed $(r=-0.446 ; P<0.001)$. SOD activity, in turn, correlated with MUFA intake $(r=0.406 ; P<0.001)$ and negatively with the age of the subjects $(r=-0.251 ; P=0.035)$. Age did not correlate significantly with the activity of the other two free radical scavenging enzymes, GSH-Px and catalase. Furthermore, age was inversely related with energy intake $(r=-0.330 ; P=0.004)$, as well as with plasma lycopene concentration $(\mathrm{r}=-0.342 ; P=0.003)$. Plasma $\alpha$-tocopherol concentration correlated with the age of the subjects $(r=0.432 ; P<0.001)$. Again, when $\alpha$-tocopherol was expressed as per mmol cholesterol this association was no longer significant. Plasma MDA concentration correlated with plasma $\alpha$-tocopherol $(r=0.268 ; P=0.022)$. No correlation between vitamin $\mathrm{E}$ intake and plasma $\alpha$-tocopherol concentration was found.

There was a significant relationship between the change in MUFA intake and the change in catalase activity $(r=-0.317 ; P=0.007)$. Changes in plasma $\beta$-carotene concentrations were related with changes in lycopene $(r=0.406 ; P<0.001)$ as well as with changes in $\alpha$-tocopherol concentrations $(r=0.256 ; P=0.030)$. No other significant correlations between changes have been observed 


\section{DISCUSSION}

\section{Intervention effects}

Since it has been suggested that energy restriction might retard the ageing process in humans, we reported before about the feasibility of an imposed moderately energy restricted diet in non-obese men. "In the present study we investigated the potential of reduced-fat products to reduce the energy intake. The influence of reduced-fat products on energy-balance has been studied in many short and long-term studies which have been summarized by Bellisle and Perez. ${ }^{12}$ The authors concluded that the longest experiments on reduced-fat feeding suggest that some compensatory increase in intake progressively develops, but does not completely reverse the modest weight loss that occurred during the first few weeks on the reduced-fat diet. However, the studies summarized were performed under strictly controlled conditions. The present study was designed to mimic a 'free living' situation by installing a realistic shop where subjects can go on errands weekly, and are free to buy additional food products elsewhere. The results of this study showed that consumption of reduced-fat products under 'free living conditions' leads to a significantly lower energy intake as compared to consumption of their full-fat equivalents. These results are in agreement with previous suggestions that macronutrient composition plays a role in energy intake. ${ }^{13}$

Reduced energy intake might retard the ageing process through maintenance or improvement of the prooxidant/antioxidant balance. ${ }^{14,15}$ However, the difference in energy intake between the reduced-fat group and the control group achieved in this study, however, did not result in an effect on plasma MDA concentration, plasma antioxidative vitamins and erythrocyte free radical scavenging enzymes during the intervention period.

Activities of these enzymes changed similarly in both groups. The fluctuations observed are not easily to explain. Time of storage, or storage conditions, seem to be an unlikely cause as in this case one would expect that blood samples drawn at the end of the study show higher activity than those drawn at the start of the study. However, none of the enzyme activities measured in this study showed a linear trend to increase during the study. In addition, since all samples of one subject were analysed in the same run, variation in analytical procedures does also not explain the changes observed either.

Besides restriction of the energy intake, the quantity and composition of dietary fat intake might also affect fat-soluble antioxidative vitamin intake and/or antioxidative capacity and lipid peroxidation status. Fats in foods serve as a carrier for fat-soluble vitamins. Reduced-fat foods might therefore adversely affect the availability of fat-soluble vitamins and subsequently antioxidative capacity, since both vitamin $E$ and 
carotenoids act as an antioxidant. Most of the reports on reduced fat products and plasma vitamin concentrations refer to the effects of a non-caloric sucrose polyester (SPE), not allowed to be used as a fat-substitute in The Netherlands yet. Consumption of SPE decreases plasma vitamin $A$ and $E$ concentrations after 10 days in healthy subjects receiving normal diets in which SPE was introduced by addition or substitution ${ }^{16}$ as well as after 16 weeks in obese subjects receiving hypocaloric diets, containing $25 \%$ of calories of fat plus SPE. ${ }^{17}$ Results from our study show that 6 months realistic consumption of reduced fat products did not affect plasma lycopene and $\beta$-carotene concentrations. It has been reported that dietary intake of lycopene ${ }^{18}$ and $\beta$-carotene $e^{19}$ reflect their serum concentrations. Although we had no data on lycopene and $\beta$-carotene intake, it might therefore be speculated that intake of these carotenoids did not change during the study. Remarkably, plasma concentration of $\alpha$-tocopherol did not change either, despite a decrease in vitamin $E$ intake. Vitamin $E$ intake, as well as the vitamin $E$ per gram PUFA intake, decreased significantly in the reduced-fat group. The intake of $0.37 \pm 0.16 \mathrm{mg}$ vitamin $\mathrm{E}$ per $\mathrm{g}$ PUFA in this group at the end of the study became even lower than the recommended intake of $0.4 \mathrm{mg} / \mathrm{g}$, needed to maintain tissue concentrations. ${ }^{20}$ This finding might suggest that 'usage' of plasma $\alpha$-tocopherol is decreased in the reduced-fat group. However, this aspect might need further attention.

\section{Correlations $(n=76)$}

Reports on the relationship between dietary fatty acid intake and free-radical scavenging enzymes are scarce, especially those performed in humans. It has been observed that a diet rich in oleic acid (18:1n-9; MUFA) lead to lower hepatic catalase activity in mice. ${ }^{21}$ In our study fatty acid intake did not correlate with catalase activity, neither at baseline, nor during the intervention period. However, MUFA intake increased in the control group and decreased in the reduced-fat group. Pooling the two groups, a significant inverse relationship between the change in MUFA intake and the change in erythrocyte catalase activity after 26 weeks was observed $(r=-0.317, P=0.007)$, which is in agreement with the observation in mice. In mice, no effects of dietary fatty acids composition on hepatic GSH-Px activity and MDA levels was found, ${ }^{21}$ whereas oral supplementation of $20 \mathrm{ml}$ fish oil (PUFA) for 10 weeks in humans led to increased GSH-Px activity. ${ }^{22}$ In our study no correlation between GSH-Px activity and percentage energy derived from PUFA was observed, whereas no relationship between plasma MDA concentration and dietary fatty acid composition was found. The changes accomplished in our study are most probably not that extreme to alter the enzymes activities measured. 
In this study a negative correlation between catalase and GSH-Px has been found. This inverse relationship has been observed in various species. ${ }^{23}$ Since both enzymes detoxify $\mathrm{H}_{2} \mathrm{O}_{2}$ this might suggest that a compensatory relationship may exist. A correlation between SOD and catalase might be expected since catalase is thought to account for a notable part of the elimination of $\mathrm{H}_{2} \mathrm{O}_{2}$, which is partly generated by SOD. Others also failed to show a correlation between catalase and SOD activity ${ }^{23,24}$ but the reason remains unclear.

A positive correlation between MDA and plasma $\alpha$-tocopherol has been found in the present study. A possible explanation is that a high PUFA intake, which is attended with high vitamin $E$ intake, leads to a high plasma $\alpha$-tocopherol concentration as well as to a high MDA concentration. However, correlation analysis did not support this hypothesis.

Many reports on animal studies suggest a decline in free radical scavenging capacity with advancing age. This is in line with the 'Free radical theory of ageing', formulated by Harman, ${ }^{25}$ which postli.:.:ss that ageing is caused by free radical reactions. Sohal and Allan $^{26}$ further elaborated on this theory and postulated that ageing is due to a dysbalance between prooxidants and antioxidants within cells. In line with Sohal and Allan's hypothesis, a negative correlation between age and SOD activity as well as between age and lycopene was found in this study, considering mean values of the intervention period.

$\mathrm{Cutler}^{27}$ presented evidence supporting Harman's 'rate of living theory' by showing that the species-specific basal metabolic rate is inversely related to life span. To assess whether such a relationship is also present in the subjects participating in this study, basal metabolic rate (BMR) was calculated from their fat mass and fat-free mass according to the formula: BMR (MJ/day) $=0.102 * \mathrm{FFM}(\mathrm{kg})+0.024 * \mathrm{FM}(\mathrm{kg})+0.85 .^{28}$ Correlation analysis between calculated BMR and the parameters measured revealed that the relationship between BMR and GSH-Px activity at baseline nearly reached significance $(r=-0.219 ; P=0.057)$, but the mean value of the intervention period correlated significantly with calculated $B M R$ at the end of the study $(r=-0.294$; $P=0.011)$. BMR correlated also with plasma $\beta$-carotene concentration both at baseline $(r=-0.334 ; P=0.003)$, as well as during the intervention period $(r=-0.284$; $P=0.014)$. Interpretation of these associations is difficult, but one could hypothesize that, according to the 'rate of living theory', those with a higher BMR might be more susceptible to oxidative damage, due to lower GSH-Px activity and lower $\beta$-carotene concentrations. 
From this study it can be concluded that in the given context, the consumption of reduced-fat products lead to lower energy intake as compared to consumption of their full-fat equivalents. Furthermore, consumption of reduced-fat products decreased vitamin E intake and altered dietary fatty acid composition. However, neither the difference in energy intake, nor the change in dietary fat composition seemed to affect the integrity of the antioxidant scavenging capacity, assessed by measuring plasma MDA and antioxidative vitamins (lycopene, $\beta$-carotene and $\alpha$-tocopherol) and erythrocyte free radical scavenging enzymes (SOD, GSH-Px and catalase).

\section{AKNOWLEDGEMENT}

The authors would like to thank Ms. A. Engelgeer-Bekius for her skilful research assistance.

\section{REFERENCES}

1. Weindruch $\mathrm{R}$, Walford RL. The retardation of aging and disease by dietary restriction. Charles $\mathrm{C}$. Thomas Publisher, Springfield Illinois, USA, 1988.

2. Masoro EJ. Nutrition and aging, a current assessment. J Nutr 1985;115:842-848.

3. Walford RL, Harris SB, Weindruch R. Dictary restriction and aging: historical phases, mechanisms and current directions. J Nutr 1987;117:1650-1654.

4. Velthuis-te Wierik EJM, van den Berg $\mathrm{H}$. Energy restriction, the basis for successful aging in man? Nutr Res 1994;14:1113-1134.

5. van het Hof $\mathrm{KH}$, Weststrate JA, van den Berg $\mathrm{H}$, Velthuis-te Wicrik EJM, de Graaf $\mathrm{C}$, Zimmermanns $N$, Westerterp KR, Westerterp-Plantenga $M$, Verbocket-van de Venne WPHG. MSFAT-study: long-term health effects of realistic consumption of low-fat products in healthy non-obese volunteers. Study design and preliminary results. Submitted for publication.

6. Westerterp KR, Wouters L, van Marken Lichtenbelt WD. The Maastricht protocol for the measurement of body composition and energy expenditure with labeled water. Obesity Res (in press).

7. Young IS, Trimble ER. Measurement of malondialdehyde in plasma by high performance liquid chromatography with fluorimetric detection. Ann Clin Biochem 1991;28:504-508.

8. Aebi H. Catalase in vitro. in: Packer L. ed. Methods in enzymology. Orlando, Academic Press Inc. 1984;105:121-126.

9. Belsten JL, Wright AJA. European Community FLAIR reference assay or whole-blood glutathione peroxidase (GSH-Px); results of an inter-laboratory trial. Submitted for publication.

10. Paglia DE, Valentine WN. Studics on the quantitative and qualitative characterization of erythrocyte glutathione peroxidase. J Lab Clin Med 1967;70:158-169.

11. Velthuis-te Wierik EJM, van den Berg H, Schaafsma G, Hendriks HFJ, Brouwer A. Encrgy restriction, a useful intervention to retard human aging? Results of a feasibility study. Eur J Clin Nutr 1994;48:138-148.

12. Bellisle F, Perez C. Low-cnergy substitutes for sugars and fats in the human dict: impact on nutritional regulation. Neuroscience and Behavioral Reviews 1994;18:197-205.

13. Prewitt TE, Schmeisser D, Bowen PE, Aye P, Dolecek TA, Langenberg P, Cole T, Brace L. Changes in body weight, body composition, and energy intake in women fed high- and low-fat diets. Am J Clin Nutr 1991;54:304-310. 
14. Feucrs RJ, Weindruch R, Hart RW. Caloric restriction, aging and antioxidant enzymes. Mut Res 1993;295:191-200.

15. Yu BP. Antioxidant action of dietary restriction in the aging process. J Nutr Sci Vitaminol 1993;39:S75-S83.

16. Fallat RW, Glueck CJ, Lutmer R, Mattson FH. Short-term study of sucrose polyester a nonabsorbable fat-like material as a dietary agent for lowering plasma cholesterol. Am J Clin Nutr 1976;29:1204-1215.

17. Mellies MJ, Vitale RD, Jandacek RJ, Lamkin GE, Glueck CJ. The substitution of sucrosepolyester for dietary fat in obese, hypercholcsterolemic outpatients. Am J Clin Nutr 1985;41:1-12.

18. Scott KJ, Thurnham, Hart DJ, Bingham S. The correlation between intake of lutein, lycopene and $\beta$-carotene from vegetables and fruit and concentrations in blood plasma. In: Newer apects of micronutrients. Nutrition Socicty, Irish scction and micronutrient group, University College, Cork, 1994.

19. Järvinen R, Knekı P, Seppänen R, Heinonen M, Aaran RK. Dietary determinants of serum $\beta$-carotene and serum retinol. Eur J Clin Nutr 1993;47:31-41.

20. Voedingsraad. Nederlands Voedingsnormen. Voorlichtingsbureau voor de Voeding. 's-Gravenhage 1989, herdruk 1992.

21. Chen LC, Boissenneault G, Hayek MG, Chow CK. Dietary fat effects on hepatic lipid peroxidation and enzymes of $\mathrm{H}_{2} \mathrm{O}_{2}$ metabolism and NADPH generation. Lipids 1993;28:657-662.

22. Bellisola G, Galassini S, Moschini G, Poli G, Pcrona G, Guidi G. Selenium and glutathione peroxidase variations induced by polyunsaturated fatty acids oral supplementation in humans. Clin Chim Acta 1992;205:75-85.

23. Godin DV, Garnctt ME. Species-related variations in tissue antioxidant status - I. differences in antioxidant enzyme profiles. Comp Biochem Physiol 1992;103:737-742.

24. Gucmouri L, Artur Y, Herbeth B, Jeandel C, Cuny G, Siest G. Biological variability of superoxide dismutase, glutathione peroxidase, and catalase in blood. Clin Cem 1991;37:1932-1937.

25. Harman D. Frec radical theory of aging: history. In: Emerit I, chance B. eds. Free radicals and aging. Bascl, Switzerland, Birkhäuser Verlag, 1992: pp 1-10.

26. Sohal RS, Allen RG. Relationship between oxygen metabolism, aging and development. Free Radical Biol Med 1986;2:117-160.

27. Cutler RG. Antioxidants and aging. Am J Clin Nutr 1991;53:373S-379S.

28. Westerterp KR, Donkers JHHLM, Fredrix EWHM, Boekhoudt P. Energy intake, physical activity and body weight: a simulation model. $\mathrm{Br} \mathrm{J}$ Nutr (in press). 


\section{General Discussion}

There seems ample evidence to conclude that ER extends both mean and maximum lifespan of species, representing different types of animals such as a nematode (Caenorhabditis elegans), the fruit fly (Drosophila melanogaster) and rodents (Mus and Rattus). ${ }^{1-3}$ Moreover, ER decreases susceptibility to several diseases in rodents. ${ }^{1}$ However, the finding that ER beneficially affects the ageing process has been criticized by saying that the relationship between ER and ageing supports an opposite interpretation as well, namely that dietary excess, as often seems to be the case in caged animals, reduces life span. ${ }^{4}$ This argument can be countered by a study of Weindruch et al. ${ }^{5}$ who reported that up to the point where ER approaches an actual starvation level, still a relationship between the level of ER and life span extension could be demonstrated. However, one can still argue that improvement in rodent life-span is a result of being spared a pathological environment. With respect to the potential application of ER in humans the question is whether we have lost the type of response exhibited by rodents due to control of our evolutionary environment or that we have optimized our environment during evolution and have reached maximum life span already.

So, we do not know whether humans have the capacity to respond to ER with postponed ageing. Therefore, the intriguing, phylogenetically independent anti-ageing effect of ER raises several questions with regard to human ageing: 1) could some (or all) of these effects be realized in man on an appropriate ER regimen, or is the life prolonging effect of ER just a phenomenon unique to short-lived species?; 2) can ER extend human life span beyond its present limit of 110-115 years?; 3) does ER also extend health span (i.e. time until the onset of age related diseases) and if so, what is the underlying mechanism?; 4) at what age should an energy restricted diet be introduced?; etc. As, to our knowledge, no previous reports have been published into the relevance of findings from animal studies to man, the studies described in this thesis are a first attempt. Although it is hard, if not impossible, to assess whether humans have the capacity to respond to ER with postponed ageing, several approaches can be considered as an effort to answer these questions such as studying in-vitro cultures of mammalian cells or studying gene expression. ${ }^{6}$ However, in our opinion a prerequisite before studying potential age-retardation effects in humans is to study the potential of implementation of 
an ER-diet tenable for the longer term, as well as to investigate potential health risks or benefits of ER. Next, short term effects of ER in humans on physiological systems, related to the ageing process could be compared with short- and long term effects of ER in animals. In this Chapter these items will be discussed after a brief remark about the social aspects of ER.

\section{SOCIAL ASPECTS OF LIFE EXTENSION BY ENERGY RESTRICTION}

Several people will object against attempts to postpone human ageing by energy restriction as they feel that extending life span is socially unacceptable and could lead to high costs of health care for the elderly. The ethical aspects and the social desirability of postponing ageing are beyond the scope of this thesis. However, ER will presumably not be adopted by an entire population, even if it was proven to be successful. If a subgroup of subjects chooses to follow an energy restricted diet, adequate in essential nutrients, this will most probably not lead to drastic social changes. Besides, as society will probably benefit more from extension of health span in stead of extension of life span, it is also interesting to study whether ER could extend health span.

Since energy restriction is most probably the most suitable model to study the ageing process, it might at least provide insight in the human ageing process.

\section{POTENTIAL OF IMPLEMENTATION OF ENERGY RESTRICTION}

\section{What level of ER will be appropriate in man}

The level of ER that will be appropriate in man for the longer term is uncertain. In their semistarvation study Keys and colleagues ${ }^{7}$ showed that $50 \%$ ER is not acceptable for the longer term as it appeared to introduce several negative health effects (symptoms of apathy and listlessness, ultimately leading to severe energy malnutrition). Therefore, in the first study the level of ER was aimed at $20 \%$. However, due to underreporting of habitual energy intake the actual level of ER appeared to be approximately $30 \%$. From the results on energy expenditure and body composition, described in Chapter 5, it can be concluded that the imposed level of $30 \%$ ER was actually too high to be regarded as acceptable for the longer-term. From this finding, in conjunction with the slightly, but significantly decreased physical performance (Chapter 4), it can be concluded that if ER is to be implemented for the longer term it should be at least at a milder level than $30 \%$. Even when a level of $20 \%$ ER had been imposed in these subjects, then, according to a computer simulation model, ${ }^{8}$ subjects' body fat would decrease to ca. $5.6 \%$ and they 
would still be in negative energy balance after a period of one year. A level of 4-6\% (or ca. $2.5 \mathrm{~kg}$ ) body fat has been suggested to be the lower limit in healthy men, and represents the point at which individuals enter a phase of increased muscle catabolism. ${ }^{9}$ Thus, $4-6 \%$ body fat should be considered as an absolute minimum. Therefore, even this $20 \%$ ER level would be too high for the longer term. According to Weindruch and Walford, a daily intake of $6.3-8.4 \mathrm{MJ} /$ day $(1,500-2,000 \mathrm{kcal})$ will induce a gradual weight loss in men, and if it includes RDA's of all essential nutrients, can hardly be regarded as a dangerous program. As energy intake was $9.2 \mathrm{MJ} /$ day on average during the intervention period in the subjects in the ER group, Weindruch and Walford's recommendation should be regarded as too low.

As a consequence of the underreporting, subjects in the control group were restricted in their intake too, but at a very mild level. In contrast to the ER group, subjects in the control group seemed to stabilize at the end of the 10-week study, after which they had lost $2.1 \mathrm{~kg}$ on average. This mild level of ER, most probably $10 \%$, seemed to be acceptable for the longer term, but did not result in beneficial effects on blood pressure, lipid profile or fibrinolytic factors after 10 weeks.

From studies on genetically obese mice it seems unlikely that, within certain limits, the amount of body fat plays a crucial role in the ageing process. When energy intake is restricted in these mice their life span is extended past that of normal mice fed ad libitum, even though their body weight and percentage of body fat remain significantly higher than those of non-obese mice. ${ }^{10}$ Therefore, another approach of imposing ER is related to the concept of an equilibrium 'set point', which argues that the body defends a particular weight by shifting the energy efficiency of the metabolic machine." According this set-point theory each individual has a particular set-point determined by genetic endowment plus his/her early feeding history. The response to decreased energy intake is to increase efficiency in order to maintain body weight. Weindruch and Walford assume that any degree of sustained weight loss below the genetic set-point of the individual might yield survival benefits in terms of maximum as well as average life span. ${ }^{1}$ They elaborate on this by suggesting that for individuals whose body weight has been stable since ages 20-30 that body weight is precisely their set-point. For those who have gradually gained body weight, the appropriate set point is uncertain, but would be their weight at 20-30 years. Although the existence of such a set-point has been questioned ${ }^{12}$ this approach of stabilizing at a body weight below one's body weight at 20-30 years will most probably be more feasible than imposing a longerterm fixed level of ER. As the subjects in the ER group in our first study lost approximately $10 \%$ body weight, without any obvious injurious effects, it would have been interesting to study the long-term effects after they were stabilized at their body weight achieved at the end of 10 weeks ER. 
To summarize, for the longer term, the imposed level of ER in man should in any case be lower than $30 \%$. A level of $10 \%$ seemed to be more feasible for the longer term, but did not affect health parameters after 10 weeks. In addition, in stead of imposing a fixed level of ER, stabilization at a body weight below one's body weight at 20-30 years will most probably more feasible.

\section{How can ER be achieved in man?:}

Besides the uncertainty about the appropriate level that could be imposed in humans, which in any case should thus be lower than 30\%, another question is how this restriction of energy intake could be achieved. Most designs of energy restriction studies in rodents involve limiting the intake of all or at least most food components at a certain moment in life. Therefore, decreasing 'overall' energy intake (i.e. eating less of everything while maintaining the relative contributions of the macronutrients), using the habitual intake as the reference point, is an obvious way to reduce the energy intake in man and has been imposed in the first study.

Initially, it was unclear whether retardation of the ageing process is due to the decreased energy intake or to a particular dietary component. Yet, animal studies have convincingly demonstrated that the dietary factor in energy restriction studies responsible for the increase in life span and the retardation of the ageing process is the decrease in energy intake per sé, irrespective of how ER was attained. ${ }^{13}$ Reduction of the protein intake to the level of the dietary restricted rats did also increase longevity but less markedly than did dietary restriction. ${ }^{14}$ However, the increase of longevity was related to retarding nephropathy rather than influencing ageing processes as is the case with dietary restriction. Furthermore, decreasing the intake of fat or mineral components without decreasing the intake of energy did not influence mortality characteristics of the rats. ${ }^{15}$

Energy percentage derived from fat is higher than recommended in most western countries. Several studies have indicated that a high-fat diet is accompanied by a high energy intake. ${ }^{16,17}$ The body has limited ability to oxidize fat compared with its ability to oxidize carbohydrate and protein. It has been suggested that the RQ (respiratory quotient; $\mathrm{CO}_{2}$ produced $/ \mathrm{O}_{2}$ consumed) is higher than the $\mathrm{FQ}$ (food quotient) while using high carbohydrate/low fat diets, which indicates that the subject is mobilizing body fat. ${ }^{18}$ Thus, as the energy intake itself is responsible for the anti-ageing effect and fat intake should be reduced, another option is to reduce the energy intake by decreasing dietary fat intake. The availability of reduced fat products has increased during the last decennium and consumption of these products might be a convenient way to reduce the energy intake in 'free living' situation. Therefore, in the second study, the MSFATstudy, the potential of reduced fat products to reduce the energy intake, and its effects on general health was studied. As described in Chapter 9 and 10, consumption of 
reduced fat products did not reduce the energy intake as compared to baseline values. However, as compared to the control group a significant difference in energy intake as well as in percentage energy intake derived from fat has been found. At least, considering the entire study population $(n=120)$, ad libitum consumption of these products prevented the overconsumption of energy and dietary fat since subjects in the control group gained $1 \mathrm{~kg}$ on average, while subjects in the reduced fat group remained weight stable. The difference in the change in body fat $(0.61 \mathrm{~kg})$ nearly reached significance. Nevertheless, since a difference in energy intake has been achieved between the control group, receiving full-fat products, and the reduced-fat group it might be concluded that macronutrient composition plays a role in energy intake.

This thesis was based on the concept that any level of energy intake below the habitual energy intake of a subject with a stable weight is a certain form of ER. However, ER can be induced in different ways. Energy intake is one side of the energy balance, the other side is energy expenditure. A topic not addressed to in this thesis, but not less interesting, is the role of exercise in increasing health and longevity. Hollozy ${ }^{19,20}$ found that voluntary exercise on activity wheels in rats increased the mean but, in contrast to energy restricted controls of the same weight, did not result in an extension of the maximum length of life. When energy intake in wheel running rats was increased such that runners and sedentary control rats attained similar peak body weights, runners showed a significant prolongation of average longevity. ${ }^{21}$ In humans there seems to be no indication that there is a relation between a history of athletic status and longevity. ${ }^{22.23}$ However, mean life expectancy has reported to be higher in Finnish team members in intercountry games than in a reference group. This increase in life expectancy was mainly explained by decreased cardiovascular mortality. In addition, no difference in maximum life span between groups was observed. ${ }^{24}$ Similar results are obtained in a Dutch study which showed that the mortality ratio in a group of recreational participants in the Dutch eleven cities ice skating tour $(200 \mathrm{~km})$ was significantly lower than that in the general population in the Netherlands, which lead to the conclusion that the capacity for prolonged and vigorous physical exercise, particularly if it is recreational, is a indicator of longevity. ${ }^{25}$ Although it can not be excluded that these studies are biased by the fact that only 'stronger' subjects are capable in exercising regularly, these studies in man suggest that exercise might at least prolong mean life span, comparable to the findings in rodents mentioned above. Exercise as such has beneficial effects on cardiovascular function, lipoprotein risk factors for $\mathrm{CHD}$, and has a preventive effect on diabetes and bone mineral loss, ${ }^{26}$ and thus increases health-span. 


\section{HEALTH RISKS/BENEFITS OF ENERGY RESTRICTION}

Introduction of an energy restricted diet in healthy non-obese subjects may result in health benefits but also in health risks. For example, too much weight loss resulting in decreased capacity for physical and mental performance should be avoided. Also, extreme hunger feelings and immune dysfunction might be undesirable side effects of imposed ER. On the other hand, high quality food intake resulting in gradual weight loss, may be expected to yield a number of health benefits even if life span is not extended. Rowe and $\mathrm{Kahn}^{27}$ have made a differentiated 'usual' and 'successful' ageing: age-related changes such as increases in blood pressure, serum cholesterol levels and bone loss are considered as physiologic. However, those who demonstrate little or no loss in a constellation of physiologic functions have aged successfully.

The results of our first study, described in this thesis in Chapter 3-6 revealed that at 10 weeks of energy restriction under dietary controlled conditions no significant changes in hunger and satiety or in obvious health risks were observed. On the contrary, the imposed level of ER, approximately $30 \%$, seemed to act beneficially on blood pressure and lipid profile (Chapter 3), as well as on fibrinolytic factors in those subjects with initially high PAI-1 activity levels (Chapter 6). In Chapter 4 it has been concluded that 10 weeks of 'moderate' ER lead to a slight but significant decrease in maximal power output when compared to the change in the control group, measured with a bicycle ergometer. The decrease of 6.3 Watt in maximal output in the ER group represented a decrease of only $2.5 \%$, and was not significantly different from zero. In addition, this decrease in maximal power output was not related to the amount of weight loss. This observation is in agreement with the finding that aerobic power was not changed, ${ }^{28}$ or even improved, ${ }^{29}$ after a period of VLCD resulting in considerable amounts of weight loss.

Results from the MSFAT-study showed that the difference in energy intake and the difference in percentage energy derived from fat, induced by long-term consumption of reduced fat products, did not beneficially nor adversely affect lipid profile, immune status parameters, ${ }^{30}$ fibrinolytic factors or outcomes of the oral glucose tolerance test (Chapter 9).

Thus, apart from a potential life extending effect of ER, the results of the first study studies show that short-term energy restriction, resulting in $10 \%$ body weight loss and a final BMI of $22.6 \mathrm{~kg} / \mathrm{m}^{2}$, beneficially affects general health parameters blood pressure, lipid profile and fibrinolytic factors, even in non-obese men. Whether these effects could be maintained after the subjects had stabilized at their new body weight requires further investigation. The results of the MSFAT study showed that consumption of reduced fat intake lowers percentage energy derived from fat to the recommended 
level of 30-35 en\%. As a high fat intake is related to the high prevalence of cardiovascular diseases, obesity and cancer, consumption of reduced fat products might have a potential to maintain health.

\section{THE UNDERLYING MECHANISM OF THE BENEFICIAL EFFECTS OF ENERGY RESTRICTION}

Several possible mechanisms through which ER modulates the ageing process have been suggested. As described in Chapter 1, free radical reactions are considered to play an important role in the ageing process and have been related to the progressive accumulation of age-related degenerative changes. $\mathrm{Harman}^{31}$ formulated his 'free radical theory of ageing' as early as in 1954, in which he postulated that ageing might be attributed at least in part to accumulative damage caused by radical generation associated with cellular metabolic activity. In line with this suggestion a negative correlation between age and SOD activity was found in the MSFAT study (Chapter 10). However, the relevance of this finding is not clear, since on the basis of Harman's theory more correlations between age and free radical damage or free radical scavenging capacity could be expected.

\section{ER and oxidative stress:}

Energy restriction seems to improve, or at least maintain, the balance between prooxidants and antioxidants, leading to reduced free radical damage during ageing in rodents by lowering the free radical production rate and/or by enhancing the free radical scavenging capacity (Chapter 1 ). As this observation has received much attention lately, we investigated whether short-term ER and consumption of reduced fat product affects free radical scavenging capacity and damage in humans. However, no effect of 10 weeks ER or 6 months consumption of reduced fat products on selected parameters of plasma antioxidative vitamins, erythrocyte free radical scavenging enzyme activities nor the plasma lipid peroxidation product malondialdehyde could be demonstrated (Chapter 7 and Chapter 10 respectively). Ten weeks of ER did not affect urinary or lymphocyte $80 H d G$ concentration and selected parameters of genotoxicity either (Chapter 7). Possible reasons for not finding an effect are discussed in these chapters. Briefly, the reasons mentioned are: 1) free radical damage may be less in humans because of a relatively lower metabolic rate. As a consequence, they might benefit less from ER than species with a high metabolic rate; 2) the differences achieved might have been too small to detect changes or correlations between (changes in) parameters, 3) the period studied might have been too short, 4) the antioxidant/prooxidant balance might be rather 
stable in the age category used in this study and 5) an important reason for not finding changes in the parameters of oxidative stress and antioxidative capacity might be the type of biomarker used. It can be argued that finding no effects on a peripheral level does not exclude that changes have occurred on a cellular level. Nevertheless, due to one (or a combination) of these factors average levels of the parameters related to the prooxidant/antioxidant balance were not affected by 10 weeks of ER nor by 6 months consumption of reduced fat products.

Metabolic rate and oxidative stress:

According to Harman's theory, free-radical damage can by reduced by lowering metabolic rate. This suggestion has been supported by studies from $\mathrm{Cutler}^{32}$ who showed an inverse relationship between species-specific life span and metabolic rate. However, in contrast to Cutler, we studied relationships within one species. Our results do not indicate that the parameters measured would change with decreased metabolic rate. Such a change could be expected on the basis of Sacher's ${ }^{33}$ suggestion that ER reduces metabolic rate and thereby retards the ageing process. In line with Cutler' ${ }^{32}$ 'rate of living theory' calculated BMR (based on $\mathrm{kg}$ fat-free mass and $\mathrm{kg}$ fat mass) and GSH-Px activity were inversely related (Chapter 10). However, this relationship was only found in the MSFAT-study, but not in the first study, probably due to the small number of subjects. To which extent this apparent relationship between BMR and GSH-Px activity is observed by chance, remains uncertain. If a relationship between metabolic rate and free radical damage within a species exists, one would expect to find correlations between BMR and at least some of the other parameters such as plasma malondialdehyde (MDA) concentration, erythrocyte superoxide dismutase (SOD) activity, etc. as well. Further (epidemiological) studies are needed in order to confirm this relationship.

Free radical damage and free radical scavenging capacity in humans can only be measured using 'indirect' measurements. By measuring free radical scavenging enzymes, antioxidative enzymes as well as radical damage such as lipid peroxidation products (MDA) and DNA-adducts it was tried to evaluate both aspects and to complete the picture as much as possible. However, a good marker for oxidative stress is still lacking. 


\section{CONCLUSION}

From the studies described in this thesis it appears that 30\% ER is not an acceptable strategy for the longer term. However, this level of ER resulted after 10 weeks in $10 \%$ weight loss, a final BMI of $22.6 \mathrm{~kg} / \mathrm{m}^{2}$ on average and beneficially affected several health status parameters. A mild level of ER, i.e approximately $10 \%$, seems to be more feasible but did not result in positive changes in health parameters after 10 weeks. Consumption of reduced fat products under 'free living conditions' did reduce the percentage derived from fat to the recommended level but did not reduce the energy intake when compared to baseline values. However, energy intake was significantly lower during consumption of reduced fat products as compared to consumption of the full-fat equivalents. From these results it can be concluded that at present a feasible level of ER may be hard to implement as a long-term intervention under free living conditions. Moreover, short-term effects of ER in our study did not confirm the finding in animals that ER beneficially affects the prooxidant/antioxidant balance. Thus, if one succeeds in maintaining a energy restricted diet the beneficial effects, i.e. postponed ageing, remains to be established.

\section{RECOMMENDATIONS FOR FUTURE RESEARCH}

It would be too ambitious to expect this thesis to provide a final answer to the question whether ER will be applicable in man. However, on the basis of the results presented in this thesis some recommendations can be made for future research.

The Level of ER:

- Since 10 weeks of ER, resulting in $10 \%$ weight loss on average, seems to affect several 'health-parameters' beneficially. It would be interesting to investigate whether such a positive effect can be maintained over a longer period after stabilization on this new body weight.

- This $10 \%$ weight reduction seemed to be an acceptable level for the short term. However, what level of weight reduction will be optimal in terms of acceptability and health for the long term remains to be studied.

- At the population level it will most probably be more convenient to strive after an optimal body mass index in stead of an optimal body composition. An intriguing questions remains whether an 'optimal' BMI can be defined in terms of maximal life and health span. Data available up to now show a J- or U-shaped curve between BMI and mortality. ${ }^{34}$ However, this relationship seems to be confounded by lean smokers 
and pre-existing illness or to represent only a subpopulation (7th-day adventists, vegetarians). Studies in which these confounders are controlled for are recommended.

- Recently, is has been reported that weight changes (i.e. both weight loss and weight gain) of $1-5 \mathrm{~kg}$, independent of BMI, are associated with significantly increased mortality. ${ }^{35}$ In addition, weight cycling appears to correlate positively with waist-hip ratio, ${ }^{36}$ which in turn has been associated with increased mortality. ${ }^{37}$ These data do not imply that obese persons should remain obese, but this might imply that ER should be applied at least in order to prevent the usual weight gain during ageing. Again, the relationship between weight loss and mortality might be confounded by pre-existing illness. Therefore, more research into the relationship between weight change and mortality is needed.

\section{Achievement:}

- Since consumption of reduced fat products resulted in significantly lower energy intake as compared to consumption of full-fat equivalents, it would still be interesting to investigate whether longer term consumption of reduced fat products reduces the energy intake.

- Another approach which remains to be studied is whether long term consumption of artificially sweetened products, whether or not in combination with reduced fat products, reduces the habitual energy intake.

- Since the use of dietary fibre has been suggested to have an impact on satiety, ${ }^{38}$ it seems also worthwhile to investigate its potential for reducing the energy intake.

\section{Biomarkers of ageing:}

- Ageing research is complicated by the lack of a suitable 'biomarker of ageing'. The development of such a biomarkers is urgently needed. Such biomarkers should 1) be measurable without health risks for the subject, 2) be highly reproducible and reflect physiological age, i.e. status of physiological functions with respect to subjects' chronological age (years), 3) show significant age changes within a relatively brief time period and 4) the clinical functions should be crucial to the health of species. ${ }^{39}$ As discussed in Chapter 7 the fact that most of the evidence of the anti-ageing effect of ER on free radical reactions and oxidative stress in animal studies is based upon findings obtained from organ tissues, especially liver, complicates a comparison between human and animal data. Studies in man are limited to the substrates readily available for analysis such as blood and urine samples. 


\section{REFERENCES}

1. Weindruch R, Walford RL. The retardation of aging and disease by dietary restriction. Charles C. Thomas Publisher, Springfield Illinois, USA, 1988.

2. Barrows $\mathrm{CH}$, Kokkonen GC. Dictary restriction and life extension - biological mechanisms. In: Moment GB, ed. Nutritional approaches to aging research. Boca Raton, Florida, CRC Press Inc., 1982.

3. Masoro AJ. Nutrition and aging - a current assessment. J Nutr 1985;115:842-848.

4. Cherkin A. Letter to the editor. Age 1979;2:51.

5. Weindruch RL, Naylor PH, Goldstein AL, Walford RL. Influences of aging by dietary restriction: longevity, cancer, immunity and lifetime encrgy intake. J Nutr 1986;116:641.

6. Rose MR, Nusbaum TJ. Prospects for postponing human aging. FASEB J 1994;8:925-928.

7. Keys A, Brozek J, Henschel A, Michelsen O,Taylor HL. The biology of human starvation, Vols 1 and 2. Minneapolis: University of Minnesota Press, 1950.

8. Westerterp KR, Donkers, JHHLM, Fredrix, EWHM, Bockhoudt P. Energy intake, physical activity and body weight: a simulation model. $\mathrm{Br} \mathrm{J}$ Nutr (in press).

9. Friedl KE, Moore RJ, Martinez-Lopez LE, Vogel JA, Askew EW, Marchitelli LJ, Hoyt RW, Gordon CC. Lower limit of body fat in healthy active men. J Appl Physiol 1994;77:933-940.

10. Harrison DE, Archer JR, Astlc CM. Effects of food restriction on aging: scparation of food intake and adiposity. Proc Natl Acad Sci USA 1984;81:1835-1838.

11. Harris RBS. Role of set-point theory in regulation of body weight. FASEB I 1990;4:3310-3318.

12. Cabanac M. Role of set-point theory - reply. FASEB J 1991;5:2105-2106.

13. Masoro EJ. Potential role of the modulation of fucl use in the antiaging action of dietary restriction. In: Franceschi $\mathrm{C}$ cd. Aging and cellular defence mechanisms. New York, Ann NY Acad Sci 1992;663:403-411.

14. Yu BP. Masoro EJ, McMahan CA. Nutritional influences on aging of Fischer 344 rats. I. Physical, metabolic and longevity characteristics. J Gerontol 1985;40:657-670.

15. Iwasaki K, Gleiser CA, Masoro EJ, McMahan CA, Sco E, Yu BP. Influence of the restriction of individual dietary components on longevity and age-rclated desease of Fischer rats: The fat component and mineral component. J Gerontol Biol Sci 1988;43:B13-B21.

16. Danforth E. Diet and obcsity. Am J Clin Nutr 1985;41:1132-1145.

17. Lissner L, Levitsky DA, Strupp BJ, Kalkwalf HJ, Roc DA. Dietary fat and the regulation of energy intake in human subjects. Am J Clin Nutr 1987;46:886-892.

18. Westerterp KR. Food quotient, respiratory quotient, and encrgy balance. Am J Clin Nutr 1993;57 suppl:759S-765S.

19. Hollozy JO, Smith EK, Vining M, Adams S. Effect of voluntary exercise on longevity of rats. J Appl Physiol 1985;59:826-831.

20. Holloszy JO, Schechtman KB. Interaction between excrcise and food restriction: effects on longevity of male rats. J Appl Physiol 1991;70:1529-1539.

21. Holloszy JO. Exercise increases average longevity of female rats despite increased food intake and no growth retardation. J Gerontol 1993;48:B97-100.

22. Schnohr P. Longevity and causc of death in male athletic champions. Lancet 1971;2:1364-1366.

23. Polednak AP, Damon A. College athletics, longevity and cause of death. Hum Biol 1970;42:2846.

24. Sarna S, Sahi T, Koskenvuo M, Kaprio J. Increased life expectancy of world class male athletes. Mcd Sci Sports Excrc 1993;25:237-244.

25. van Saase JL, Noteboom WM, Vandenbroucke JP. Longevity of men capable of prolonged vigorous physical exercise: a 32 year follow up of 2259 participants in the Dutch eleven citics ice skating tour. Br Med J 1990;301:1409-1411.

26. Smith EL, Smith PE, Gilligan C. Diet, exercise, and chronic discase patterns in older adults. Nutr Rev 1988;46:52-61.

27. Rowe JW, Kahn RL. Human aging: usual and successful. Science 1987;237:143-149.

28. van Dale D, Schoffelen PFM, ten Hoor F, Saris WHM. Effects of addition of exercise to energy 
restriction on 24-hour cnergy expenditure, sleeping metabolic rate and daily physical activity. Eur J Clin Nutr 1989;43:441-451.

29. Saris WHM, van Dale D. Effects of exercise during VLCD diet on metabolic rate, body composition and acrobic power, pooled data of four studies. Int J Obesity 1989;13 suppl 2:169170.

30. van het Hof $\mathrm{KH}$, Weststrate JA, van den Berg $\mathrm{H}$, Velthuis-te Wierik EJM, de Graaf C, Zimmermanns NJH, Westerterp KR, Westerterp-Plantenga $M$, Verbocket-van de Venne WPHG. Long-term effects on health of spontancous consumption of reduced fat versus full fat products in healthy subjects. Submitted.

31. Harman D. Frec radical theory of aging: History. In: Emerit I, Chance B. eds. Free Radicals and Aging. Basel, Birkhäuser Verlag, Switzerland, 1992, pp 1-10.

32. Cutler RG. Antioxidants, aging and longevity. In: Pryor WA ed. Free radicals in biology, vol 6 . Acadamic Press, New York, 1984:371-428.

33. Sacher GA. Life table modifications and life prolongation. In: Finch CE, Hayflick L, eds. Handbook of the biology of aging. New York, van Nostrand Reinold. 1977:582-638.

34. Berg FM. Health risks of obesity. Obesity and Health, Graphic Designs and Printing, Hettinger, N.D. 1993.

35. Lee IM, Paffenbarger RS. Change in body weight and longevity. JAMA 1992;268:2045-2049.

36. Rodin J, Radke-Sharpe N, Rebuffé-Scrive M, Greenwood MRC. Weight cycling and fat distribution. Int J Obesity 1990;14:303-310.

37. Larsson B, Svärdsudd K, Welin L, Wilhelmsen L, Björntop P, Tibblin G. Abdominal adipose tissue distribution, obesity, and risk of cardiovascular disease and death: 13-year follow up of participants in the study of men born in 1913. Br Med J 1984;288:1401-1404.

38. Burley VJ, Paul AW, Blundell JE. Influence of a high-fibre food (myco-protein) on appetite: effects on satiation (within meals) and satiety (following meals). Eur J Clin Nutr 1993;47:409-418.

39. Reff ME, Schneider EL. Biomarkers of aging. Washington DC, US. Dept of Health and Human Scrvices (NIH Pub \#82-2221), 1982. 
Energy restriction (ER), while maintaining the intake of adequate amounts of essential nutrients, retards the ageing process and extends life span in various animal species. Although several potential mechanisms have been put forward, the mechanism behind this phenomenon remains unknown. The literature on the effects of ER on three physiological processes related to ageing, i.e. adaptation of energy metabolism, free radical reactions and antioxidative capacity, and the endocrine system have been reviewed in Chapter 1. From this review it has been concluded that:

1) in both animals and man severe energy restriction lowers the resting metabolic rate (RMR), expressed in absolute terms. Long-term energy restriction, for example in undernourished labourers and anorexia nervosa patients, decreases the activity of metabolic tissue and probably increases metabolic efficiency, since in these studies RMR expressed per $\mathrm{kg}$ fat-free mass was found to be reduced;

2) in animals, a decrease in the activity of free radical scavenging enzymes with increasing age has been found. ER, however, seems to maintain and/or improve protection against free radical damage in these animals, which may play a role in the life-prolonging effect. However, data on the effects of ageing and ER on damage due to free radicals or free radical scavenging capacity in man are absent; and

3) ageing affects the hormonal system in both animals and man which is manifested in dysfunction of the sympathetic nervous system, decreased $\mathrm{T} 4$ concentrations, decreased secretion of gonadotropic hormones, and decreased glucose tolerance. This can be a result of 'wear and tear' with advancing age. ER prevents the decrease in T4, testosterone and LH which provides evidence for the hypothesis that ER maintains the functional integrity of the neuroendocrine system.

There certainly are quantitative differences in metabolism between animals and men. However, with regard to these three physiological processes, neither the effects of ER nor the age related changes seemed to differ between animals and man. From this point of view, ER might have a beneficial effect on the ageing process in man as well. However, little is known regarding the applicability of ER as an intervention to retard human ageing. Moreover, the life-long animal studies are hard, of not impossible, to mimic in interventions in humans.

A prerequisite before studying potential age-retardation effects in humans is to study the potential of implementation of an ER-diet tenable for the longer term, as well as to investigate potential health risks or benefits of ER. Therefore, this project was started with a 10-week intervention study in order to investigate the applicability as well as potential health benefits or risks of a moderate energy restricted diet, aimed to contain $80 \%$ of the energy of reported intake ( $20 \% \mathrm{ER}$ ), assessed by means of a 7-day dietary record. The 
results of this study, performed in 24 healthy middle-age men (range 35-50 yr) are described in Chapter 3-7. Weight loss was considerable in the ER group $(-7.4 \pm 2.6 \mathrm{~kg}$; $\mathrm{n}=16$ ), and there was no tendency for stabilization on a new energy balance. Subjects in the control group, lost some weight too $(-2.7 \pm 2.1 \mathrm{~kg} ; \mathrm{n}=8)$. This study showed that this ten weeks of ER had beneficial effects on blood pressure and HDL-cholesterol concentration, without having adverse effects on physical and mental performance, and feelings of hunger, satiety and mood (Chapter 3 ). The effects on physical performance are further elaborated in Chapter 4. Maximal power output showed a slight decrease $(-6.3 \pm 13.6$ Watt $)$, which appeared to be significant $(P=0.049)$ when compared to the change in the control group ( $4.3 \pm 5.9$ Watt). However, this decrease was not related to the decrease in body weight. In addition, no effects of ER on substrate utilization during submaximal exercise were observed. Chapter 5 describes the effects of ER on energy metabolism and body composition in these 24 subjects. By making use of the doubly labelled water technique in 8 subjects of the ER group it appeared that reported energy intake was $82.5 \%$ of total energy expenditure (ADMR = average daily metabolic rate), resulting in an actual level of ER of 33\%, rather than $20 \%$. Furthermore, in the ER group $83 \%$ of the weight loss was fat mass, $17 \%$ was fat-free mass. ADMR decreased significantly. Resting metabolic rate decreased in the ER group, even when taking into account the decrease of fat-free mass.In addition, the plasma concentration of the thyroid hormone T3 decreased, while reverse T3 concentration showed an increase. Another health aspect that can be affected by ER is the haemostatic system. From the results presented in Chapter 6, is can be concluded that ER lead to decreased plasminogen activator inhibitor type 1 (PAI-1) antigen concentration, as well as to decreased tissue-type plasminogen activator (tPA) antigen concentration. These changes were more clear in those subjects with a high baseline PAI activity (> $9 \mathrm{IU} / \mathrm{ml}$ ). As a high concentration of PAI-1 antigen has been associated with an increased risk for coronary thrombosis, these findings suggest that ER beneficially affects fibrinolytic factors, at least in subjects with higher baseline PAI activity.

The beneficial effects of ER on the ageing process has been hypothesized to proceed by lowering the production rate of free radicals (probably secondary to a lower metabolic rate) and/or by the maintenance of (or enhancing) effective scavenging capacity of free radicals. Therefore, the effects of 10 weeks ER on the primary antioxidant defence system measured by the antioxidant enzymes superoxide dismutase (SOD), glutathione peroxidase (GSH-Px) and catalase, as well as on the antioxidant vitamins $C, E, A$ and $\beta$-carotene was assessed. In addition, oxidative damage, measured by the lipid peroxidation product malondialdehyde (MDA), and the DNA-adduct 8-hydroxydeoxyguanosine (8OHdG), low-density lipoprotein resistance of in-vitro copper mediated oxidation, and markers of genotoxicity were also investigated. (Chapter 7). None of these parameters were found to be affected by 10 weeks 
of ER. However, this result does not exclude that ER affects the antioxidant/prooxidant balance on the cellular level, nor that these parameters would not be affected by ER on the longer-term.

This first study was performed under strictly dietary controlled conditions and does not provide information about the feasibility to reduce the energy intake under 'free living' conditions. Therefore, a second study was executed under 'free living conditions' in which the potential of reduced-fat products to reduce the energy intake was investigated. This study was part of a multi-centre study, the MSFAT-study (i.e. Multicentre Study on FAT reduction), on the health effects of consumption of reduced fat products. The control and reduced-fat products were provided through a realistic shop in order to mimic a 'free living' situation. The design of this 6 month parallel comparison trial has been described extensively in Chapter 8. In the MSFAT-study the same parameters as in the first study were measured. Realistic consumption of reduced-fat products lead to a significantly lower energy intake as well as to lower percentage of energy derived from dietary fat as compared to consumption of full-fat equivalents. However, this did not result in a change in the coronary heart disease risk markers PAI-1 antigen, tPA activity, fibrinogen concentration, factor VII concentration and insulin sensitivity (Chapter 9). Since both energy restriction as well as dietary fat intake might affect the antioxidative capacity, again, parameters that reflect the antioxidant/prooxidant balance (plasma MDA, antioxidative vitamins lycopene, $\beta$-carotene and $\alpha$-tocopherol, and erythrocyte free radical scavenging enzymes SOD, GSH-Px and catalase) were measured (Chapter 10). The results indicate that neither the difference in energy intake, nor the decrease in vitamin $\mathrm{E}$ intake and a change in dietary acid composition seemed to affect the prooxidant/antioxidant balance.

The results of these two studies are discussed in Chapter 11 in view of the following questions:

- What is the potential of implementation of an ER-diet tenable for the longer term?

- what level of ER will be appropriate for the long term?

- how can an ER-diet, acceptable for the long term, be achieved in man?

- Does ER result in health benefits and/or health risks?

- Does short-term ER affect the antioxidant/prooxidant balance, a potential underlying mechanism of the beneficial effects of ER, in man?

It has been concluded that from the studies described in this thesis it appears that $30 \%$ ER is not an acceptable longer-term strategy. This level of ER resulted in $10 \%$ weight loss, a final BMI of $22.6 \mathrm{~kg} / \mathrm{m}^{2}$ on average and beneficially affected several health status parameters. A mild level of ER, i.e. approximately $10 \%$, seems to be more feasible but this did not result in changes in health parameters after 10 weeks, as can be assessed on the 
basis of the control group who were mildly restricted in their energy intake due to underreporting. Consumption of reduced fat products under 'free living conditions' did reduce the percentage energy derived from fat to the recommended level but did not reduce the energy intake when compared to baseline levels. However, energy intake was significantly lower during consumption of reduced fat products as compared to consumption of the full-fat equivalents. From these results it can be concluded that a feasible level of ER seems hard to implement as a long-term intervention under free living conditions. However, short-term effects of ER beneficially affected several health-status parameters which might at least affect the 'health'-span if these changes can be maintained for the longer term. Our study did not support the finding in animals that ER beneficially affects the prooxidant/antioxidant balance. However, whether the prooxidant/antioxidant balance would be affected by longer term ER, or in older subjects, needs further investigation. 
Beperking van de energie inneming (energie restrictie; ER), bij een adequate voorziening van essentiële nutriënten, vertraagt het verouderingsproces en verlengt de maximale levensduur bij verschillende soorten proefdieren. Ondanks dat er verschillende suggesties zijn gedaan is het onderliggende mechanisme nog steeds niet opgehelderd. De literatuur met betrekking tot de effecten van ER op drie fysiologische systemen die mogelijk gerelateerd zijn aan het verouderingsproces (verandering van het energie metabolisme, reacties door vrije radicalen en antioxidatieve capaciteit, en het neuro-endocriene systeem) zijn samengevat in Hoofdstuk 1. Uit de in dit hoofdstuk besproken literatuur kan het volgende worden geconcludeerd:

1) bij zowel proefdieren als de mens leidt strenge energie restrictie tot een verlaging van de ruststofwisseling, uitgedrukt als $\mathrm{kJ}$ per dag. Lange termijn ER, zoals bijvoorbeeld beschreven bij een groep ondervoede arbeiders of bij anorexia nervosa patiënten, resulteert eveneens in een afname van de metabole snelheid, en waarschijnlijk ook tot een verhoogde metabole efficiëntie omdat bij deze mensen ook de ruststofwisseling uitgedrukt als $\mathrm{kJ}$ per $\mathrm{kg}$ vet-vrije massa (= metabool actieve massa) verlaagd is.

2) bij proefdieren lijkt de activiteit van enzymen die vrij-radicalen neutraliseren gedurende het verouderingsproces af te nemen. Bij beperking van de energie inneming lijkt echter de vrij-radicaal opvangcapaciteit langer gehandhaafd of zelfs verbeterd waardoor minder schadeprodukten ontstaan, hetgeen een rol zou kunnen spelen bij het vertragen van het verouderingsproces. Helaas zijn er nauwelijks gegevens bekend over de effecten van ER en veroudering bij de mens enerzijds en vrij-radicaal schade en opvangcapaciteit anderzijds.

3) de verandering van het neuro-endocriene systeem gedurende het verouderingsproces uit zich in een verminderde functie van het sympatisch zenuwstelsel, afname van het schildklier hormoon thyroxine (T4), afname van de geslachtshormonen, en een verminderde glucose tolerantie. ER voorkomt de afname van $T 4$, het mannelijke geslachtshormoon testosteron en het vrouwelijke geslachtshormoon luteïniseringshormoon (LH). Dit fenomeen bevestigt de hypothese dat ER de functionele integriteit van het hormonale systeem handhaaft.

Hoewel er weliswaar kwantitatieve verschillen zijn in het metabolisme tussen dier en mens, lijkt het niet aannemelijk dat, ten opzichte van de bovengenoemde fysiologische systemen, het effect van veroudering of ER verschilt tussen mens en dier. Om deze reden zou ER ook het verouderingsproces bij de mens kunnen vertragen. Er is echter tot nu toe weinig onderzoek gedaan naar de toepasbaarheid van ER als een interventie bij de mens om het verouderingsproces te vertragen. Daarnaast zijn er helaas nauwelijks gegevens over de effecten van ER op het verouderingsproces bij de mens, noch over de accumulatie van schadeprodukten, noch over de vrij-radicaal opvangcapaciteit. 
Een noodzakelijke voorwaarde om de mogelijke verouderingseffecten bij de mens te onderzoeken, is het bestuderen van de mogelijkheden om bij de mens een aanvaardbare energiebeperkte voeding te introduceren, en om hierbij te kijken naar eventuele gezondheidsrisico's of -winst. Het in dit proefschrift beschreven onderzoek werd daarom gestart met een 12 weken durende studie ( 2 weken inloopperiode; 10 weken interventie) om zowel de toepasbaarheid als eventuele gezondheidseffecten van een matige energiebeperking te bestuderen. Het niveau van energie inneming was gericht op $80 \%$ van de gebruikelijke energie inneming (20\% ER), welke geschat was op basis van de 7-daagse opschrijfmethode. De resultaten van deze studie, uitgevoerd bij 24 gezonde mannen (35-50 jaar) zijn beschreven in de Hoofdstukken $3 \mathrm{t} / \mathrm{m} 7$. Het gewichtsverlies in de ER groep gedurende de 10 weken was aanzienlijk $(-7.4 \pm 2.6 \mathrm{~kg} ; \mathrm{n}=16)$, en er was geen tendens tot gewichtsstabilisatie. De proefpersonen in de controle groep verloren ook wat gewicht $(-2.7 \pm 2.1 \mathrm{~kg} ; \mathrm{n}=8)$. Tien weken ER had een gunstig effect op de bloeddruk en de HDL-cholesterol concentratie, terwijl er geen negatieve effecten te zien waren op fysiek en mentaal prestatievermogen, en gevoelens van honger en verzadiging en stemming (Hoofdstuk 3). Het effect op het fysiek prestatievermogen is uitgebreid beschreven in Hoofdstuk 4. Het maximale prestatievermogen nam in de ER groep af $(-6.3 \pm 13.6 \mathrm{Watt})$, deze verandering was significant verschillend van die in de controle groep ( $4.3 \pm 5.9$ Watt). Echter, de daling in maximaal prestatievermogen was niet gerelateerd aan het gewichtsverlies. Het substraatgebruik tijdens submaximale inspanning veranderde niet door ER. Hoofdstuk 5 beschrijft het effect van ER op energiemetabolisme en lichaamssamenstelling in deze 24 mensen. Door gebruik te maken van tweevoudig gemerkt water is bij 8 proefpersonen in de ER groep het totale energiegebruik gemeten. Uit deze meting bleek dat de gerapporteerde energie inneming slechts $82.5 \%$ van het totale energiegebruik gedurende de inloopperiode bedroeg. Als gevolg van deze onderrapportage was de opgelegde ER geen 20\% maar 33\%. Het gewichtsverlies in de ER groep bleek voor ca. $83 \%$ uit verlies aan vet-massa en voor ca. $17 \%$ uit vet-vrije massa. Het totale energiegebruik daalde significant evenals de ruststofwisseling, ook wanneer de laatste gecorrigeerd werd voor de verandering in vet-vrije massa. De plasmaconcentratie van het schildklierhormoon T3 vertoonde een significante daling, terwijl de concentratie van het reverse-T3 een stijging vertoonde. Een ander gezondheidsaspect dat werd bestudeerd is de haemostase. Uit de resultaten weergegeven in Hoofdstuk 6 kan worden geconcludeerd dat ER leidde tot een afname in de plasminogeen activator inhibitor type 1 (PAI-1) antigen concentratie en in de weefseltype plasminogeen activator (tPA) antigen concentratie. Deze verandering was het meest uitgesproken in personen die bij aanvang van de studie een hoge PAI activiteit (>9 IU/ml) hadden. Omdat een hoge PAI-1 antigen concentratie als een risicofactor voor coronaire hartziekten wordt beschouwd, suggereren deze resultaten dat ER een gunstig effect heeft op fibrinolysefactoren bij personen met een hoge PAI activiteit. 
Een hypothese om het gunstige effect van ER op het verouderingsproces te verklaren is dat dit effect gemedieerd wordt door verlaging van de produktie van vrije radicalen, secundair aan een verlaagd metabolisme, en/of door handhaving (of verbetering) van de opvangcapaciteit van vrije radicalen. Daarom werd het effect van 10 weken ER op het primaire antioxidant systeem onderzocht, i.e. zowel de activiteit van de antioxidant enzymen in erythrocyten (superoxide dismutase, SOD; glutathion peroxidase, GSH-Px; en catalase) als de concentraties van antioxidant vitaminen in plasma (C, A, E en $\beta$-caroteen). Daarnaast werden oxidative schadeprodukten zoals het lipid peroxidatie produkt malondialdehyde (MDA) en het DNA-adduct 8-hydroxydeoxyguanosine (8OHdG) gemeten, en werden genotoxiciteits-markers en de oxideerbaarheid van het low density lipoproteïne bepaald. Geen van deze parameters veranderden onder invloed van 10 weken ER (Hoofdstuk 7). Deze resultaten sluiten echter niet uit dat er geen verandering in de prooxidant/antioxidant balans heeft plaatsgevonden op cellulair niveau, of dat de gemeten parameters niet beïnvloedt worden na lange termijn ER.

Deze eerste studie werd uitgevoerd onder streng gecontroleerde omstandigheden en geeft daarom geen informatie over de toepasbaarheid van ER in een 'vrij-levende' situatie. Daarom werd een tweede studie uitgevoerd als onderdeel van de MSFAT-studie (Multi-center S Studie naar vet (ㅁat) reductie), een studie naar de gezondheidseffecten van laag-vet produkten. De controle (vol-vet) produkten en de laag-vet produkten werden verstrekt via een speciaal hiervoor ingerichte winkel. De opzet van deze 6 maanden durende studie is beschreven in Hoofdstuk 8. In de MSFAT-studie werden dezelfde parameters gemeten als in de eerste studie dat beschreven is in dit proefschrift. Consumptie van laag-vet produkten leidde tot een significant lagere energie inneming en een lagere bijdrage van vet aan energie in vergelijking met consumptie van de vol-vet controle produkten. Echter, dit resulteerde niet in een verandering in gemeten risicofactoren voor hart- en vaatziekten, PAI-1 antigen, tPA activiteit, fibrinogeen concentratie, Factor VII concentratie en insuline gevoeligheid (Hoofdstuk 9). Omdat zowel energiebeperking als vetzuursamenstelling in de voeding de antioxidant status kunnen beïnvloeden werd ook in deze studie een aantal parameters bepaald die betrekking hebben op de antioxidant/prooxidant balans (plasma MDA, de antioxidanten lycopeen, $\beta$-caroteen en $\alpha$-tocopherol, en antioxidant enzymen SOD, GSH-Px en catalase in erythrocyten) gemeten. Op basis van de resultaten werd geconcludeerd dat noch het verschil in energie inneming, noch de afname in vitamine $E$ inneming noch de verandering in vetzuursamenstelling in de voeding de prooxidant/antioxidant balans beïnvloeden (Hoofdstuk 10).

De resultaten van deze twee studies worden bediscussieerd in Hoofdstuk 11 aan de hand van de volgende onderzoeksvragen: 
- Wat is de mogelijkheid om een energiebeperkt dieet bij de mens te introduceren zodanig dat het aanvaardbaar is voor de lange termijn?

- welk niveau van ER kan gedurende lange tijd volgehouden worden?

- hoe kan een aanvaardbaar niveau van ER bereikt worden bij de mens?

- Resulteert ER in gezondheidsrisico's of gezondheidswinst?

- Beïnvloedt ER de antioxidant/prooxidant balans, en worden de gunstige effecten van

ER op het verouderingsproces via dit systeem gemedieerd?

Uit de studies beschreven in dit proefschrift kan worden geconcludeerd dat $30 \%$ ER in ieder geval geen acceptabele en na te streven optie is voor de lange termijn omdat stabilisatie op een nieuw energiebalans onrealistisch lijkt. Dit niveau van ER resulteerde na 10 weken in gemiddeld $10 \%$ gewichtsverlies en een Body Mass Index (BMI) van $22.6 \mathrm{~kg} / \mathrm{m}^{2}$. Wel werden op korte termijn verschillende gezondheidsparameters gunstig beïnvloedt. Korte termijn ER zou daarom de 'gezondheidsduur' kunnen verlengen indien deze veranderingen gehandhaafd blijven voor de lange termijn nadat de proefpersonen gestabiliseerd zouden worden op de aan het eind van de 10 weken bereikte BMI. De controle groep onderging als gevolg van onderrapportage een milde vorm van energie beperking. Deze milde energie beperking, ca. $10 \% \mathrm{ER}$, lijkt voor de langere termijn meer acceptabel, maar leidde op korte termijn niet tot veranderingen in gezondheidsparameters.

Door consumptie van laag-vet produkten onder 'vrij-levende' omstandigheden werd het percentage energie uit vet verlaagd tot een aanbevolen hoeveelheid, maar de energie inneming werd niet lager in vergelijking met de uitgangswaarden. Echter, de energie inneming was wel lager in de groep die laag-vet produkten consumeerden dan in de groep die de overeenkomstige produkten met een hoog-vet gehalte consumeerden.

Uit deze twee studies kan worden geconcludeerd dat een aanvaardbaar niveau van ER moeilijk is vast te stellen en als een lange termijn interventie te implementeren onder vrij-levende condities met als doel het verouderingsproces te vertragen. Onze studies bevestigden niet de bevinding bij dieren dat ER de prooxidant/antioxidant balans gunstig beïnvloedt. Of deze balans wel te beïnvloeden is door lange termijn ER of in oudere proefpersonen vereist nader onderzoek. 


\section{Dankwoord}

Het schrijven van dit hoofdstuk betekent eveneens terugkijken op een periode bij TNO-Voeding waar ik met veel plezier heb gewerkt. Het maakt me ook bewust van het feit dat veel mensen hebben meegewerkt aan de tot stand koming van dit boekje. Een aantal van hen wil ik hier met name noemen.

Veel dank ben ik verschuldigd aan mijn co-promotor Henk van den Berg. Henk, wij konden het samen meestal goed vinden, wat er mede voor zorgde dat de afgelopen vier jaar zijn omgevlogen. Jouw vertrouwen in mijn werk en de adviezen en kritische kanttekeningen op de manuscripten heb ik erg gewaardeerd.

Dank ook aan mijn tweede co-promotor Klaas Westerterp. Klaas, jouw snelle en efficiënte wijze waarop je reageerde op mijn brieven en telefoontjes werkte stimulerend en heb ik erg op prijs gesteld.

Mijn promotoren Wim Saris en Ruud Hermus wil ik bedanken voor de zinvolle suggesties op met name de inleiding en de discussie van dit procfschrift. Wim Saris wil ik tevens bedanken voor zijn rol als eerste promotor.

Gertjan Schaafsma, jij hebt je altijd ingezet voor mijn belangen, en aan jou heb ik mede te danken dat ik na mijn stage-periode deze promotieplaats heb mogen vervullen.

Anneke Engelgeer-Bekius was onmisbaar bij het uitvoeren van de MSFAT-studie. Anneke, jij hebt ten behoeve van de MSFAT-study heel wat vrieskou $\left(-20^{\circ} \mathrm{C}\right)$ doorstaan, in ca. 600 huidplooien geknepen en ca. 300 eetdagboekjes doorgenomen. De hoeveelheid pizza's en kant-en-klaar maaltijden die je met een karretje door regen en sneeuw moest vervoeren is echter ontelbaar. Anneke, hartelijk dank voor de fijne samenwerking en voor het feit dat je nu de taak van paranimf op je wilt nemen.

Petra van Aken-Schneijder en Ann Colen, bij jullie kon ik terecht voor de diëtetistische en huishoudkundige ondersteuning en voor praktische tips bij het uitvoeren van de studies. Bedankt hiervoor.

Twee stagiaires bewegingswetenschappen van de Vrije Universiteit Amsterdam hebben een belangrijk aandeel geleverd in het afnemen van de fysieke inspanningstesten bij de vrijwilligers. Wieke Hoogzaad en Marleen van der Horst, dank jullie wel!

Helga Peeters wil ik bedanken voor haar aandeel als stagiaire Gezondheidswetenschappen in de analyse van malondialdehyde. 
Van de divisie Pharma wil ik Wilfred Sieling, Theo Hoofwijk en Jaap Odink graag bedanken voor hun hulp bij praktische uitvoer van de studies. Jan Catburg en zijn medewerkers dank ik voor het uitvoeren van alle klinisch-chemische analyses. Verder dank ik alle analisten die betrokken zijn geweest bij de vitamine analyses, radioimmunologische bepalingen, genotoxiciteits bepalingen en de immunologische analyses.

Naast de analyses die gedaan zijn bij TNO-Voeding in Zeist is er buiten de deur ook het één en ander bepaald. De medewerkers van het Gaubius Instituut Leiden en van TNO-PG Leiden wil ik danken voor de bepaling van de heamostase parameters en voor de bepaling van de oxideerbaarheid van $\mathrm{LDL}$, en van $80 \mathrm{HdG}$ in lymfocyten. I would like to thank Steffen Loft and Henrik Poulsen from the University of Copenhagen for their cooperation and their analysis of $8 \mathrm{OHdG}$ excretion.

Dirk van der Heij, 'ome Dirk', belangstellend heb je de verschillende hoofdstukken in dit proefschrift gelezen en voor engels-taligen leesbaarder gemaakt. Hartelijk dank hiervoor. Niek van Breederode, bedankt voor het oplossen van mijn problemen die betrekking hadden op vax-terminals, computers en printers. Jan Blom, bedankt voor het kopieerwerk dat altijd 'even tussendoor' kon.

Hanny Leezer-de Hoog, jij heb meermalen in je avonduren dit proefschrift nagekeken om de puntjes op de $\mathrm{i}$ te zetten. Het is ongelooflijk hoe je de tekst hebt doorgenomen om alle oneffenheden eruit te halen. Bedankt!

Alle (ex)collega's van TNO-Voeding die hier niet met naam zijn genoemd. Hartelijk dank voor de gezellige tijd! Ik zal jullie missen.

Zonder medewerking van proefpersonen had dit onderzoek nooit kunnen worden uitgevoerd. Alle vrijwilligers die hebben meegedaan wil ik daarom bedanken voor hun doorzettingsvermogen.

Mijn dank gaat ook uit naar de leden van de beoordelingscommissie: Prof. dr. H. Kuipers, Prof. dr. A. van Es, Dr. G. Hornstra, Prof. dr. D.L. Knook en Prof. dr. E.F.M. Wouters, voor het beoordeling van dit proefschrift.

Mijn ouders ben ik dankbaar voor de mogelijkheid en voor de stimulans die zij mij gaven om te studeren. Mijn zus Sylvia te Wierik wil ik bedanken voor de betrokkenheid bij mijn werk en dat zij de taak van paranimf op zich wil nemen.

Tenslotte wil ik natuurlijk Paul bedanken voor al zijn steun. 


\section{Curriculum vitae}

Erica J.M. Velthuis-te Wierik werd geboren op 21 april 1967 te Raalte. In 1984 haalde zij haar HAVO diploma aan het Florens Radewijns College te Raalte. Aansluitend ging zij naar het VWO aan dezelfde school waarvoor zij in 1986 haar diploma kreeg. In datzelfde jaar begon zij haar studie Gezondheidswetenschappen, met als afstudeerrichting Biologische Gezondheidkunde aan de Rijksuniversiteit Limburg te Maastricht. Haar afstudeerstage met als onderwerp 'de invloed van matig alcoholgebruik op risicofactoren voor hart- en vaatziekten' deed zij van december 1989 tot en met augustus 1990 bij TNO-Voeding te Zeist, om in november 1990 haar doctoraal te behalen. Van oktober 1990 tot en met mei 1991 was zij in dienst van TNO om haar medewerking te verlenen voor het schrijven van een literatuuroverzicht wat resulteerde in het boek 'biomedical and social aspects of alcohol use, a review of the literature'. Per 1 juni 1991 trad zij in dienst als assistent in opleiding (A.I.O.) bij de Vakgroep Humane Biologie (Dr. K.R. Westerterp en Prof. dr. W.H.M. Saris) van de Rijksuniversiteit Limburg te Maastricht. Het onderzoek dat zij gedurende vier jaar verrichtte is echter uitgevoerd bij TNO-Voeding te Zeist (Dr. H. van den Berg en Prof. dr. ir. R.J.J. Hermus) en is beschreven in dit proefschrift. Sinds 1 mei 1995 is zij werkzaam als Scientific Editor bij N.V. Organon, een business unit van Akzo-Nobel. 


\section{Papers:}

Deurenberg P, Westerterp KR, Velthuis-te Wierik EJM. Between-laboratory comparison of densitometry and bio-electrical impedance measurements. Brit J Nutr 1994;71:309-316. de Graaf C, Drijvers JJMM, Zimmermanns NJH, van het Hof KH, Weststrate JA, van den Berg H, Velthuis-te Wierik EJM, Westerterp KR, Westerterp-Plantenga MS, Verboeket-van der Venne WPHG. Energy and fat compensation during long term consumption on reduced fat products. (submitted for publication).

Hendriks HFJ, Veenstra J, Kluft C, Velthuis-te Wierik EJM, Schaafsma G. A moderate dose of beer, wine or spirits has large postprandial effects on fibrinolytic factors derived from the endothelium. BMJ 1994;308:1003-1006.

van het Hof $\mathrm{KH}$, Weststrate JA, van den Berg $\mathrm{H}$, Velthuis-te Wierik EJM, de Graaf C, Zimmermans NJH, Westerterp KR, Westerterp-Plantenga MS, Verboeket-van de Venne WPHG. Magnitude of experimental manipulation in a long-term study on health effects of spontaneous consumption of reduced fat versus full fat products in healthy non-obese volunteers. (submitted for publication).

van het Hof $\mathrm{KH}$, Weststrate JA, van den Berg $\mathrm{H}$, Velthuis-te Wierik EJM, de Graaf $\mathrm{C}$, Zimmermans NJH, Westerterp KR, Westerterp-Plantenga MS, Verboeket-van de Venne WPHG. Long term effects on health of spontaneous consumption of reduced fat versus full fat products in healthy subjects. (submitted for publication).

Loft S, Velthuis-te Wierik EJM, van den Berg H, Poulsen HE. Energy restriction and oxidative DNA-damage in humans. Cancer Epidemiol Biomarkers Prevention (accepted for publication)

Snelten H, te Wierik E, Veenstra J, Schaafsma G. De invloed van bier en wijn op de gastrinespiegel. Voeding 1991;52:86-9.

Veenstra J, te Wierik E and Kluft C. Alcohol and fibrinolysis: a review. Fibrinolysis 1990;4 Supp2:64-8.

Velthuis-te Wierik EJM, van den Berg H. Energy restriction, the basis for successful aging in man? Nutr Res 1994;14:1113-1134.

Velthuis-te Wierik EJM, van den Berg H, Schaafsma G, Hendriks HFJ, Brouwer A. Energy restriction, a useful intervention to retard human ageing? Results of a feasibility study. Eur J Clin Nutr 1994;48:138-148.

Velthuis-te Wierik EJM, van den Berg H, Weststrate JA, van het Hof KA, de Graaf C. Consumption of reduced fat products: effects on parameters of antioxidative capacity. (submitted for publication).

Velthuis-te Wierik EJM, Hoogzaad LV, van den Berg H, Schaafsma G. Effects of moderate energy restriction on physical performance and substrate utilization in non-obese men. 
Int J Sports Med 1994;15:478-484.

Velthuis-te Wierik EJM, Kluft C, van den Berg H, Weststrate JA. Consumption of reduced fat products, haemostatic parameters and oral glucose tolerance test. (submitted for publication).

Velthuis-te Wierik EJM, van Leeuwen REW, Hendriks HFJ, Verhagen H, Loft S, Poulsen $\mathrm{HE}$, van den Berg $\mathrm{H}$. Moderate energy restriction does not affect indicators of oxidative stress and genotoxicity in humans. (accepted in J Nutr).

Velthuis-te Wierik EJM, Meijer P, Kluft C, van den Berg H. Beneficial effect of a moderately energy-restricted diet on fibrinolytic factors in non-obese men. (accepted in Metabolism).

Velthuis-te Wierik EJM, Westerterp KR, van den Berg H. Effect of a moderately energyrestricted diet on energy metabolism and body composition in non-obese men. Int $\mathrm{J}$ Obesity (in press).

te Wierik E, Veenstra J, Schaafsma G. Do alcoholic beverages have an additional effect on the postprandial gastrin response in humans? Alcohol Alcoholism 1991;26:121-4.

Abstracts:

Velthuis-te Wierik EJM. The effects of moderate energy restriction on physical performance Int J Sports Med 1993;14:294.

Velthuis-te Wierik EJM, van den Berg H. Gematigde energierestrictie en preventie van ouderdomsziekten: toepasbaarheid bij de mens. Voeding 1993;54 nr 4:16.

Velthuis-te Wierik EJM, van den Berg H. Effect van matige energierestrictie op energiemetabolisme en oxidatieve stress. Voeding 1994;55 $\mathrm{nr}$ 4:14.

Velthuis-te Wierik EJM, Westerterp KR, van den Berg H. Effect of moderate energy restriction on energy metabolism and body composition. Int J Obesity 1994;18 suppl 2: 52 , abstr 200.

Verhagen H, Velthuis-te Wierik EJM, Leeman WR, de Vogel N, Bruijntjes-Rozier TCDM, van den Berg $\mathrm{H}$. Cytogenetic biomonitoring in a controlled energy restriction study with human volunteers. Hum Exp Toxicol 1994;13:732.

te Wierik E, Veenstra J. Beer and release of gastrin in humans. Gastroenterology 1992;102;1824-5.

\section{Book Chapters:}

van den Berg H, Velthuis-te Wierik EJM. 'Succesvol' verouderen door een energiebeperkte voeding? In: Blom MM, Kuin Y, Hendriks HFJ eds. Ouder worden '93. Utrecht, Nederlands Instituut voor Zorg en Welzijn (NIZW), 1993, pp 33-38. 
te Wierik E. Moderate and excessive drinking, problem drinking and alcoholism. Definitions. In: van der Heij DG, Schaafsma G. eds. Biomedical and social aspects of alcohol use: a review of the literature. Wageningen, Pudoc, 1991:5-13.

te Wierik E. Alcohol and pregnancy. In: van der Heij DG, Schaafsma G. eds. Biomedical and social aspects of alcohol use: a review of the literature. Wageningen, Pudoc, 1991:180-9.

te Wierik E. Factors influencing behaviour in relation to alcohol. In: van der Heij DG, Schaafsma G. eds. Biomedical and social aspects of alcohol use: a review of the literature. Wageningen, Pudoc, 1991:204-27.

te Wierik E. Alcohol and traffic. In: van der Heij DG, Schaafsma G. eds. Biomedical and social aspects of alcohol use: a review of the literature. Wageningen, Pudoc, 1991:228-37.

te Wierik E. Prevention of alchol abuse: models of control. In: van der Heij DG,

Schaafsma G. eds. Biomedical and social aspects of alcohol use: a review of the literature. Wageningen, Pudoc, 1991:238-51.

te Wierik E. Measures to control alcohol abuse. In: van der Heij DG, Schaafsma G. eds. Biomedical and social aspects of alcohol use: a review of the literature. Wageningen, Pudoc, 1991:252-62.

te Wierik E, Vrij-Standard WG. Effects of alcohol on vitamin metabolism. In:

van der Heij DG, Schaafsma G. eds. Biomedical and social aspects of alcohol use: a review of the literature. Wageningen, Pudoc, 1991:72-82.

te Wierik E, Vrij-Standard WG. Effects of alcohol on water and mineral balance. In:

van der Heij DG, Schaafsma G. eds. Biomedical and social aspects of alcohol use: a review of the literature. Wageningen, Pudoc, 1991:83-89.

te Wierik E, Vrij-Standard WG. Effects of alcohol on various organs and tissues. In: van der Heij DG, Schaafsma G. eds. Biomedical and social aspects of alcohol use: a review of the literature. Wageningen, Pudoc, 1991:157-68.

te Wierik E, Vrij-Standard WG. Alcohol and cancer. In: van der Heij DG, Schaafsma G. eds. Biomedical and social aspects of alcohol use: a review of the literature. Wageningen, Pudoc, 1991:169-79. 
